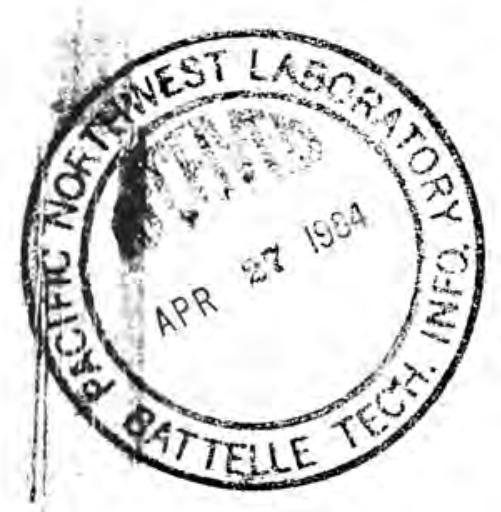

\title{
Effects of Tuff Waste Package Components on Release From 76-68 Simulated Waste Glass
}

Final Report

G. L. McVay

G. R. Robinson

April 1984

Prepared for

Lawrence Livermore National Laboratory

under a Related Services Agreement

with the U.S. Department of Energy

under Contract DE-AC06-76RLO 1830

Pacific Northwest Laboratory

Operated for the U.S. Department of Energy

by Battelle Memorial Institute

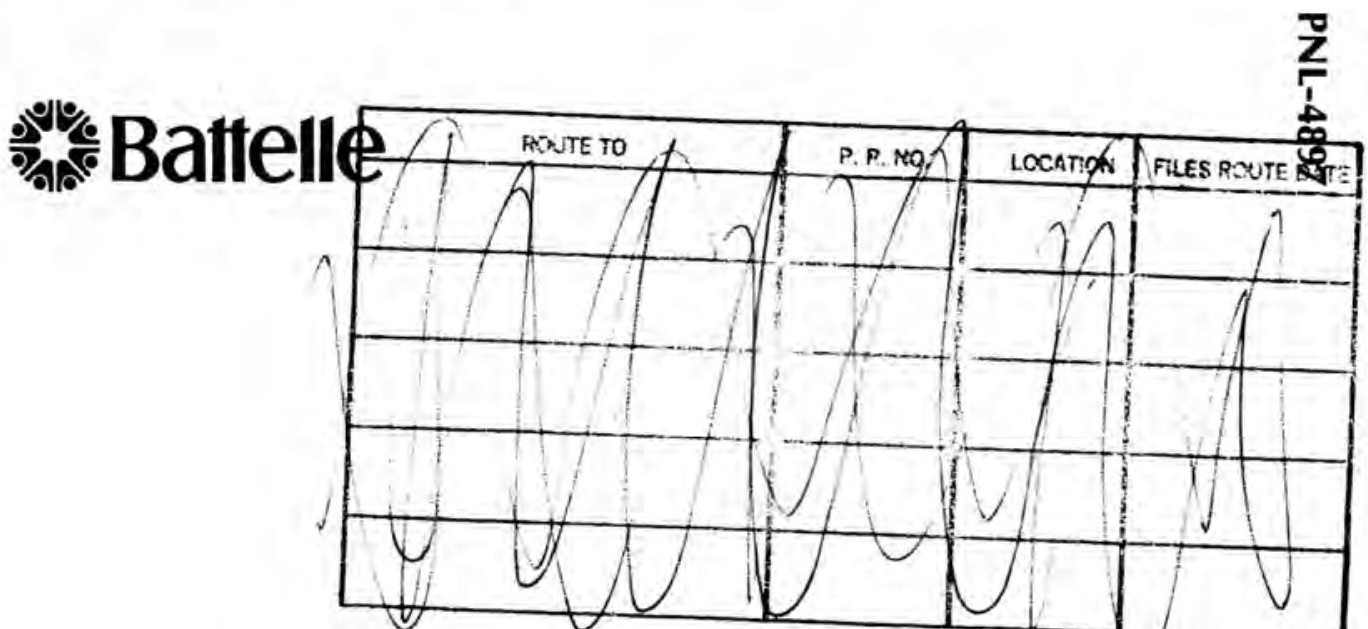




\section{DISCLAIMER}

This report was prepared as an account of work sponsored by an agency of the United States Government. Neither the United States Government nor any agency thereof, nor any of their employees, makes any warranty, express or implied, or assumes any legal liability or responsibility for the accuracy, com' pleteness, or usefulness of any information, apparatus, product, or process disclosed, or represents that its use would not infringe privately owned rights. Reference herein to any specific commercial product, process, or service by trade name, trademark, manufacturer, or otherwise, does not necessarily constitute or imply its endorsement, recommendation, or favoring by the United States Government or any agency thereof. The views and opinions of authors expressed herein do not necessarily state or reflect those of the United States Government or any agency thereof.

PACIFIC NORTHWEST LABORATORY

operated by

BATTELLE

for the

UNITED STATES DEPARTMENT OF ENERGY

under Contract DE-AC06-76RLO 1830 
PNL -4897

UC-70

EFFECTS OF TUFF WASTE PACKAGE COMPONENTS ON RELEASE FROM 76-68 SIMULATED WASTE GLASS

\section{Final Report}

G. L. McVay

G. R. Robinson

Apri1 1984

Prepared for

Lawrence Livermore National Laboratory under a Related Services Agreement with the U. S. Department of Energy under Contract DE-ACO6-76RLO 1830

Pacific Northwest Laboratory

Richland, Washington 99352 



\section{SUMMARY}

An experimental matrix has been conducted that will allow evaluation of the effects of waste package constituents on the waste form release behavior in a tuff repository environment. Tuff rock and groundwater were used along with $304 \mathrm{~L}, 316$, and $1020 \mathrm{M}$ ferrous metals to evaluate release from uranium-doped MCC 76-68 simulated waste glass. One of the major findings was that in the absence of $1020 \mathrm{M}$ mild steel, tuff rock powder dominates the system. However, when $1020 \mathrm{M} \mathrm{mild} \mathrm{steel} \mathrm{is} \mathrm{present,} \mathrm{it}$ appears to dominate the system. The rock-dominated system results in suppressed glass-water reaction and leaching while the 1020M-dominated system results in enhanced leaching--but the metal effectively scavenges uranium from solution. The 300 -series stainless steels play no significant role in affecting glass leaching characteristics. 



\section{CONTENTS}

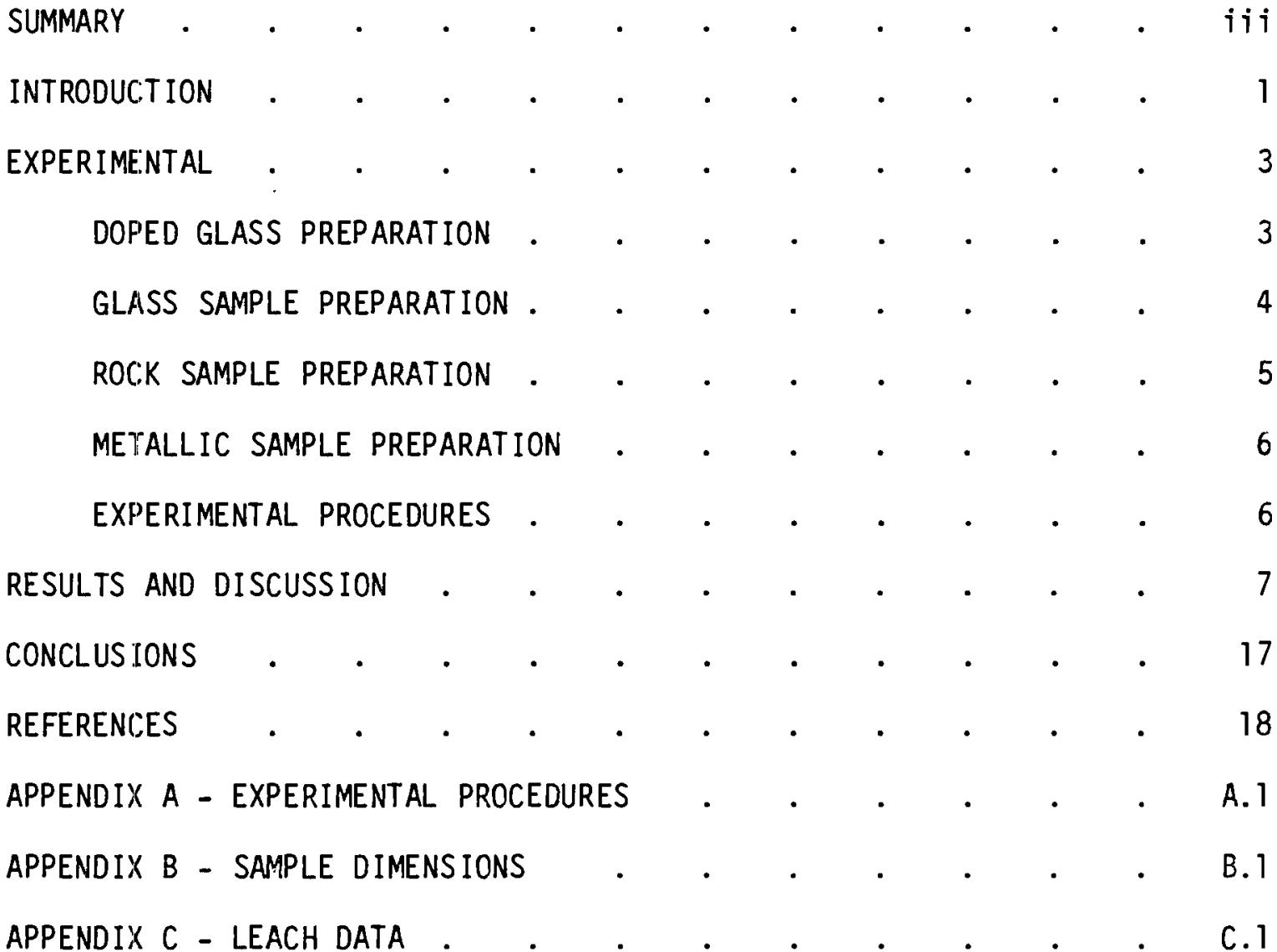





\section{TABLES}

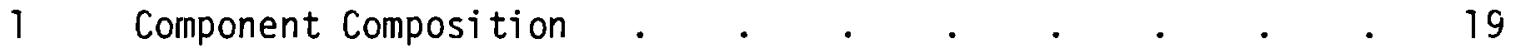

2 Composition of Metal1ic Samples (in wt\%) . . . . $\quad 20$

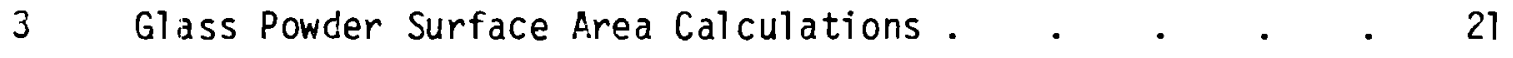

4 Test Matrix . . . . . . . . . . . . 22

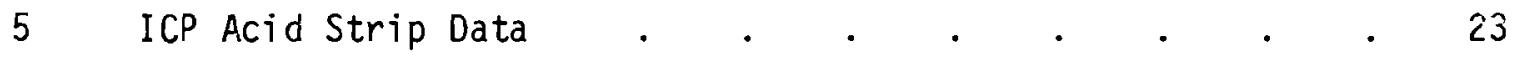




\section{FIGURES}

1 Boron release from 76-68 simulated waste glass in tuff groundwater at $40,70,90$, and $150^{\circ} \mathrm{C}$ for 3 to 182 days at an SA.N of $10 \mathrm{~m}^{-1}$. . . . . . . .

2 Silicon release from 76-68 simulated waste glass in tuff groundwater at $40,70,90$, and $150^{\circ} \mathrm{C}$ for 3 to 182 days at an SA/N of $10 \mathrm{~m}^{-1}$. . . . . 25

3 Time-dependent uranium concentrations in tuff groundwater contacting 76-68 simulated waste glass at 40, 70, 90, and $150^{\circ} \mathrm{C}$ for times from 3 to 182 days at an $S A / V$ of

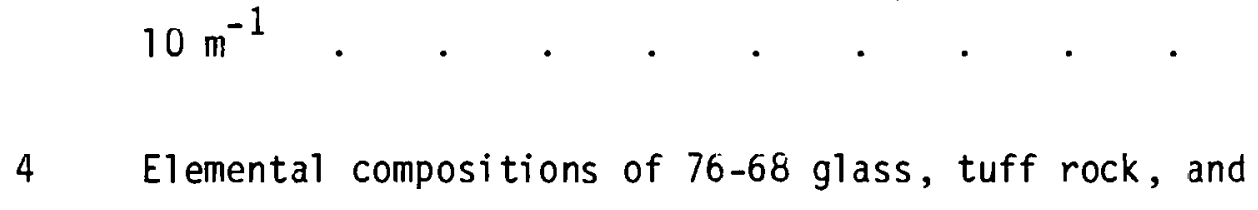
tuff groundwater . . . . . . . . . .

5 Effect of preleaching tuff rock monoliths at $90^{\circ} \mathrm{C}$ for one day on elemental removal in $90^{\circ} \mathrm{C}$ tuff groundwater. . . . . . . . . . . 28

6 Effect of preleaching tuff rock powder at $90^{\circ} \mathrm{C}$ for one day on elemental removal in $90^{\circ} \mathrm{C}$ tuff groundwater . $. \quad . \quad . \quad . \quad . \quad$. . . .

7 The change in time-dependent Si solution concentration in $90^{\circ} \mathrm{C}$ tuff groundwater as glass and rock monolithic samples are adcied. Glass sample surface area/tuff groundwater volume $(S A / V)=10 \mathrm{~m}^{-1}$. Rock monolithic samples had same geometric surface area as glass. 
8 The change in time-dependent $B$ solution concentration in $90^{\circ} \mathrm{C}$ tuff groundwater as glass and rock monolithic samples are added. Glass sample surface area/tuff groundwater volume $(S A / V)=10 \mathrm{~m}^{-1}$. Rock monolithic sample had same gecmetric surface area as glass . . . . . . .

9 Time-dependent silicon solution concentrations in $90^{\circ} \mathrm{C}$ tuff groundwater comparing the effects of tuff rock monolithic and powdered samples . . . . . . . 32

10 Tine-dependent $B$ solution concentrations in $90^{\circ} \mathrm{C}$ tuff groundwater comparing the effects of tuff rock monolithic and powdered samples . . . . . . . . . 33

11 Time-dependent $\mathrm{Si}$ concentrations in $90^{\circ} \mathrm{C}$ tuff groundwater comparing the effects of increasing the relative glass surface area . . . . . . . . . . . . 34

12 Time-dependent $B$ concentrations in $90^{\circ} \mathrm{C}$ tuff groundwater comparing the effects of increasing the relative glass surface area . . . . . . . . . . 35

13 Time-dependent $B$ concentrations in $90^{\circ} \mathrm{C}$ tuff groundwater with various tuff rock quantities and SA/V ratios . . 36

14 Time-dependent $\mathrm{Si}$ concentrations in $50^{\circ} \mathrm{C}$ tuff groundwater comparing rock surface areas . . . . . . . . . 37

15 Time-dependent $B$ concentrations in $90^{\circ} \mathrm{C}$ tuff groundwater comparing the ratio of rock to glass . . . . . . 38

16 Time-dependent uranium concentrations in $90^{\circ} \mathrm{C}$ tuff groundwater as a function of tuff rock surface area . . 39 
17. Comparison of component contribution to $\mathrm{pH}$ in $90^{\circ} \mathrm{C}$ tuff groundwater. All samples were monolithic with an $S A / N=10 \mathrm{~m}^{-1}$

18 Effects of metals on $\mathrm{pH}$ in $90^{\circ} \mathrm{C}$ tuff groundwater. All samples were monolithic with an $S A / V=10 \mathrm{~m}^{-1}$. . 41

19 Effect of metals on $B$ solution concentration in $90^{\circ} \mathrm{C}$ tuff groundwater. All samples were monolithic and of the same surface area . . . . . . . . . .

20 Effect of metals on the time-dependent $B$ solution concentration in $90^{\circ} \mathrm{C}$ tuff groundwater comparing SA/V and rock surface area effects

21 Effect of metal type on uranium solution concentration in $90^{\circ} \mathrm{C}$ tuff groundwater. All samples were monolithic and the $S A / N=10 \mathrm{~m}^{-1}$. . . . . . . . 44

22 The effects of various conditions on reaction layer thickness for a 91 -day exposure to $50^{\circ} \mathrm{C}$ tuff groundwater. All samples were monoliths and $S A / N=10 \mathrm{~m}^{-1}$

23 SEM cross-sections of reaction layer thicknesses under

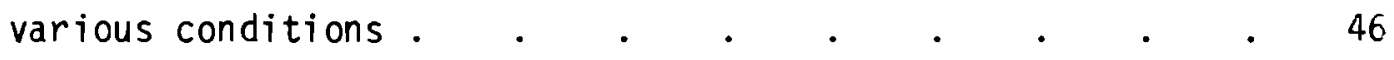

24 SEM cross-section of 76-68 glass exposed for 91 days to $150^{\circ} \mathrm{C}$ tuff groundwater . . . . . . .

25 Effect of filtering on a monolithic glass and rock interactive experiment in $90^{\circ} \mathrm{C}$ tuff groundwater with an $S A / V=10 \mathrm{~m}^{-1}$. . . . . . . 48 
26 The same as for Figure 25 except for the presence of a 304 L sample . . . . . . . . . . . . 49

27 Illustration of replication of experiments containing glass and rock powder at an $S A / V=100 \mathrm{~m}^{-1}$ in $90^{\circ} \mathrm{C}$ tuff groundwater . . . . . . . . . 50

28 Illustration of replication of experiments containing glass, rock powder, and $304 \mathrm{~L}$ SS at an SA $/ \mathrm{N}=100 \mathrm{~m}^{-1}$ in $90^{\circ} \mathrm{C}$ tuff groundwater . . . . . . . 5 

EFFECTS OF TUFF WASTE PACKAGE COMPONENTS ON

RELEASE FROM 76-68 SIMULATED WASTE GLASS

\section{INTRODUCTION}

Deep geologic disposal of radioactive nuclear waste has received international attention in recent years. It has become the method of choice for nuclear waste disposal and, because of this, a very significant research activity is being funded by the Department of Energy to evaluate various geologies for potential repository sites. The geomedia currently being considered in the United States are salt, basalt, tuff, and very recently, granite.

The most generally accepted concept for disposal of high-level radioactive waste is to incorporate it into a solid waste form that is placed into a deep geologic repository. The waste form is normally considered to be part of a multiple barrier system (called a waste package) which gives redundant safeguards against the removal of radioactive elements from the repository. This waste package can consist of a waste form, hard barriers, and backfill materials.

In every repository design, the radioactive waste is contained within a waste form. The waste form that is currently favored and the one that has received the largest amount of research is borosilicate glass for reprocessed waste and possibly spent fuel if reprocessing does not become a reality for commercial waste. Hard barriers include both canister and overpack materials. The canister is commonly a 300-series stainless steel, such as $304 \mathrm{~L}$, whereas the overpack material depends on the waste-package design and repository selection. In some designs the overpack is a relatively thin layer of highly corrosion-resistant material, such as a titanium alloy, placed over the canister. In other designs the overpack is 
a thick layer of less corrosion-resistant metal such as cast iron or ductile iron. The backfill materials can be clays (which act as a water barrier), other materials which have special water-restrictive or sorptive characteristics, or crushed rock of the same type as the repository media. In general, the waste-package designs have not been finalized and could vary with changing Nuclear Regulatory Commission regulations and repository media type.

Waste forms have typically been investigated in aqueous solutions with none of the other waste-package component materials present. This approach leads to an understanding of waste-form behavior in "normal" water environments only. However, except for rather severe accident scenarios, the waste form will not be exposed directly to the unaltered groundwater. Under expected repository conditions, the groundwater will progressively move through the barriers of the waste package by diffusion, corrosion, or other barrier-failure modes. Therefore, the waste form will be exposed to altered groundwater as well as the remains of the other waste-package constituents. Since reliable long-time prediction of elemental release characteristics from the waste package and the repository is required for licensing, it is necessary to understand the effects of other waste-package constituents on elemental release from the waste form.

The current concept for a waste package to be used in a tuff repository is to incorporate the waste form in $304 \mathrm{~L}$ stainless steel with no additional hard barriers or backfill material other than the tuff rock. Additionally, it is possible that the borehole will be lined with a soft iron such as $1020 \mathrm{M}$ and, therefore, this material should be considered as available for interactive effects.

In an effort to understand release from a waste package system in a tuff repository, a series of interactive experiments were conducted in tuff groundwater using 76-68 glass, tuff rock, and ferrous metals. The 76-68 glass was chosen because of the large existing data base and because it represents, in a generic sense, a commercial waste glass. The metals used were both $304 \mathrm{~L}$ and 316 stainless steels as well as 1020M mild steel. Interactive effects between metals and 76-68 glass have been reported 
previously, $(1-3)$ but not for the metals used in the se experiments and not in a realistic tuff repository environment.

Al1 tests conducted were static in nature and designed to evaluate the effects of rock and of candidate metals on release of constituents from the glass. The glass was doped with uranium but did not contain other actinides or Tc. Therefore, release of many relevant radionuclides can only be inferred. Additionally, the effects of radiation, radiolysis, and the determination of solubility limits along with appropriate alteration products were not addressed in this reported research.

\section{EXPERIMENTAL}

The purpose of the experimental program was to evaluate interactive effects of candidate waste package constituents on release characteristics from the waste form in a tuffaceous environment. Materials used in this investigation were:

- Tuff groundwater obtained from wel1 J-13 near the Yucca Mountain site

- Topopah Spring tuff rock

- 76-68 simulated waste glass $\left(\mathrm{UO}_{2}\right.$ doped) as prepared by PNL

- Candidate metals: 304L SS, 316 SS, and 1020M

The compositions of the waste glass, tuff rock, and tuff groundwater used are given in Table 1 . The metallic sample compositions are given in Table 2.

DOPED GLASS PREPARATION

The $\mathrm{UO}_{2}$ doped glass was prepared as follows:

Bars of previously mel ted and cast 76-68 glass (MCC No. 's 309, 307, 281,276 , and 265) were prepared for doping by crushing and sieving to -100 mesh size fraction. The dopant solution was prepared by 
dissolving $\mathrm{UO}_{2}$ powder in nitric acid solution and diluting this with D.I. water to the desired concentration level. The dopant solution was added to the powdered glass, mechanically mixed, and then heated on a hot plate until dry. The doped glass powder was then melted in a platinum crucible at $1100^{\circ} \mathrm{C}$ for 30 minutes prior to casting. The glass bars were cast into a steel bar mold assembly preheated on a hot plate. When the bars were sufficiently solidified, they were transferred to the auxiliary furnace where they were held at $500^{\circ} \mathrm{C}$ for 2 hours and furnace-cooled to room temperature. The resultant material had the composition as shown in Table 1 . This analysis was obtained from center cuts of two different bars from which specimens were selected.

\section{GLASS SAMPLE PREPARATION}

Glass samples were used in both monolithic and powdered forms depending upon the surface area desired.

Monoliths: Specimens were cut from cast bars with a low-speed diamond saw using deionized water as the cutting medium. The outside surfaces of the cast bars were completely removed by sawing, and samples were cut from the inner core. After cutting, the samples were ultrasonically cleaned in deionized water and absolute ethanol to remove adherent fines.

Powders: Cast glass bars, after surface removal by sawing, were crushed in a steel mortar and pestle. The powders were then sieved across magnets and separated into size fractions of $-40+80$ mesh and $-100+200$ mesh. Reduction by more conventional methods resulted in powders that were too fine in particle size. Surface areas were calculated from average particle sizes as illustrated in Table 3 . It was necessary to calculate surface areas rather than measure them because BET techniques are not useful for powders with surface areas this small. Compositional analysis of the two size fractions were both the same as that obtained from monolithic samples, Table 1. Therefore, the glass is homogeneous on the scale evaluated. Prior to utilization, the glass powders were ultrasonically cleaned in deionized water and absolute ethanol to remove adherent ultrafines. 
ROCK SAMPLE PREPARATION

Rock samples used were supplied by Lawrence Livermore National Laboratory. Analysis of the rock composition is given in Table 1. As can be seen, the total of elements only sum to $92.2 \mathrm{wt} \%$ and, therefore, the analysis is not adequate and can only be used as a rough guide. The rock was highly porous in nature and $\mathrm{N}_{2}$ BET analysis of the monolithic rock yielded a measured surface area of $0.823 \mathrm{~m}^{2} / \mathrm{g}$. This is much higher than the glass powders used in this study, Table 3 . Therefore, if the porosity is accessible to water, then the tests containing both rock and water should be rock dominated. Crushing of the rock to -60 mesh powder resulted in an increase in the $\mathrm{N}_{2}$ BET measured surface area to $1.40 \mathrm{~m}^{2} / \mathrm{g}$. It was considered necessary to include all of the rock powder, rather than separate out a size fraction, due to apparent inhomogeneities and the unknown effect of trace elements.

Monoliths: Rock monolithic samples were cut from the as-received Topopah Spring tuff rock with a low-speed diamond saw using deionized water as the cutting medium. The cut rock specimens were ultrasonically cleaned in deionized water and absolute ethanol to remove adherent fines. In interactive experiments involving both monolithic rock and glass samples, the rock specimen was cut to achieve the same geometric surface area as the glass.

Powders: As-received tuff rock was covered with plastic bags and broken with a hammer until all the pieces were small enough to fit into a steel mortar and pestle. These pieces were crushed until all passed through a 10-mesh screen. Some metal contamination from the steel of the mortar was noticed and removed from the rock by sieving it across magnets. The -10 mesh powder was then transferred to a ball mill and processed until all material passed through a -60 mesh screen. The -60 mesh powder was used unwashed for interactive testing. It was felt that the fines might be enriched in certain elements (due to the heterogeneous appearance of the rock), which could be preferentially removed by washing. 


\section{METALLIC SAMPLE PREPARATION}

Metallic samples were only used in monolithic form and were prepared in a similar manner regardless of whether $304 \mathrm{~L}$, 316SS or $1020 \mathrm{M}$ metal was used. The metallic specimens were cut to the same geometric surface area as the monolithic glass samples. The compositions of metals used are given in Table 2.

300 Series Stainless Steel Monoliths: The samples were sawed to the appropriate size and ultrasonically cleaned in acetone, absolute ethanol, and deionized water prior to use.

1020M Mild Steel Monoliths: The procedure used for 1020M samples was identical to that used for stainless steels except that the samples were acid etched in 1:1 $\mathrm{HCl}$ and rinsed in deionized water prior to ultrasonic cleaning. The purpose for the acid etch was to remove corrosion layers that existed on the unsawed surfaces of the samples.

\section{EXPERIMENTAL PROCEDURES}

The detailed experimental procedure is given in Appendix $A$ and, therefore, will only be summarized here. All of the tests were static, conducted in Teflon containers, and included tuff groundwater. The tests were divided into four categories as can be seen from the test matrix shown in Table 4. These four categories are as follows:

- Test I - Glass + tuff groundwater

- Test II - Glass + tuff rock + tuff groundwater

- Test III - Glass + tuff rock + metal + tuff groundwater

- Test IV - Tuff water blanks, tuff groundwater blanks, replicates, and rock preleach effects

Experimental variables were temperature $\left(40\right.$ to $150^{\circ} \mathrm{C}$ ), time (3 to 182 days), and surface area ratios of components as listed in Table 4.

The procedures used closely follow the Materials Characterization Center MCC-1 and MCC-3 procedures. (4) For Test I, the glass samples were 
leached on teflon supports. In Test II, glass powders and rock samples were placed on the floor of the teflon container. Glass monoliths were placed on tefl on supports. In Test III, both the rock and metal were placed on the container floor, while the monolithic glass samples resided on a teflon support. Glass powders were placed on the container floor. In many of the experiments containing glass powder, a small glass coupon was added for solid state analysis.

After the designated time period, the solutions were cooled and the $\mathrm{pH}$ measured. All solutions containing powders or precipitates were filtered using a $0.45 \mu \mathrm{m}$ filter. If the solution was clear, an unfiltered aliquote was also taken. Additionally, as the solution volume permitted, aliquotes were taken and filtered through 50 and 18 Angstrom filters. Solutions were analyzed initially for elemental concentrations by use of the induction coupled plasma spectrometer (ICP), and more recently analyses were also made for anions. All solutions submitted for ICP analyses were acidified to $1 \% \mathrm{~V} / \mathrm{V}$ with ultrex nitric acid. The leach containers were acid stripped with a $1 \% \mathrm{~V} / \mathrm{V}$ nitric acid solution which was also submitted for ICP analysis. The acid strip analysis is meaningless for experiments that contained powders due to the inability to reliably rinse all of the powder from the container prior to acid stripping.

Solid state analyses of selected leached glass samples were performed by secondary ion mass spectrometry (SIMS) and scanning electron microscopy (SEM) with dispersive $X$-ray analysis (EDAX). X-ray fluorescence (XRF) analyses were also conducted on selected filter papers.

\section{RESULTS AND DISCUSSION}

The experimental matrix, Table 4, was designed to evaluate the interactive effects of potential waste package constituents on release characteristics of the waste form. The tests were divided into four major categories to progressively increase the complexity of the system being evaluated and, thereby, to hopefully better understand the processes occurring. 
In Tests 1 and 4 , baselines were established. Test 1 was designed to evaluate waste form release characteristics in tuff groundwater without interactive effects from other waste package constituents. These results should be the basis from which interactive effects are measured. Test 2 was designed to evaluate the effects of tuff rock on waste form release characteristics. The rock and glass samples were either in monolithic or in powdered form depending upon component surface area ratios desired. The test marked "II-90D" was duplicated, i.e., the same experiment was rerun with fresh samples at a different time to evaluate the reproducibility of experimental and analytical techniques.

Test 3 was intended to simultaneously evaluate the effects of both tuff rock and ferrous metal on waste form release characteristics. The metals evaluated were the relatively inert 300 series stainless steels, $304 \mathrm{~L}$ and 316, and the more reactive $1020 \mathrm{M}$ mild steel. As in Test 2, both powdered and monolithic glass and rock samples were used to vary the component surface area ratios and the glass surface-area-to-groundwater volume ratios. Test III-90B was run in duplicate and contained ten times the normal metallic surface area to be consistent with the ten-fold increase in glass surface area, i.e., the metal and glass surface area ratios remained the same.

In all other tests the metallic surface area was equivalent to monolithic glass sample surface areas. Therefore, if the glass surface areas were increased by using powders, the metallic surface area remained constant (except for Test III-90B), resulting in a surface area ratio change.

The experiments conducted in Test 4 were for the purpose of establishing baseline data for the tuff rock/tuff groundwater system, the time dependence of tuff groundwater composition alone, and various effects of washing and/or preleaching the rock constituents of interactive tests. Tests IV-90A and IV-90B were to evaluate the time dependent release from tuff rock monolithic and powdered samples, respectively, in tuff groundwater.

The series of tests IV-CM and IV-CP illustrate temperature-dependent release from one-day preleaching of tuff rock monoliths and powders, 
respectively, in tuff groundwater. Tests IV-90D and IV-90E are repeats of tests IV-90A and IV-90B with the exception that the rock samples were preleached prior to initiation of the experiment. The tests labeled IV-23-PO and IV-MO give solution analyses for the elements removed from the rock samples during the cleaning procedure. Tests IV-90F and IV-90G are repeats of II-90A and II-90B with the rock samples being preleached in tuff groundwater. If preleaching makes no difference, then the two series of tests should yield the same results.

Finally, Test IV-90 is an evaluation of the time-dependent stability of the tuff groundwater at $90^{\circ} \mathrm{C}$. The majority of experiments were conducted at $90^{\circ} \mathrm{C}$; comparisons were made and effects evaluated from the $90^{\circ} \mathrm{C}$ results.

There is a large amount of data that has been generated by the experiments outlined in Table 4 and described above. This data is all included in tabular form in Appendix C. Only certain facets and aspects of the data, which appeared most relevant to the authors, have been plotted and will be discussed. Along this line, only $\mathrm{B}$, $\mathrm{Si}$, and uranium release results will be considered in the text. Other elemental release values can be obtained from Appendix $C$. The release values for $B$ are particularly important from an understanding point of view since $B$ does not readily sorb on the waste package constituents or on the container walls, nor is it normally associated with precipitates. Therefore, $B$ represents the amount of glass reaction that has occurred.

The concentration of $\mathrm{Si}$ in solution is important because the release characteristics of the waste glass have been shown to be directly related to $S i$ solution concentrations. (5) Since $S i$ is a major constituent in both the glass and the tuff rock, only general effects information can be obtained. The release values for uranium are important as an indicator of actinide behavior.

Release characteristics of 76-68 glass in tuff groundwater alone, Test 1 , are illustrated in Figures 1,2 , and 3 for $B$, Si, and uranium, respectively. Other elements of interest can be gleaned from Appendix $C$. The data shown in Figures 1 and 2 are illustrated in three-dimensional 
plots. This allows the most information to be illustrated in the least amount of space and gives a better overall picture of the elemental release characteristics. Figure 1 for B and Figure 2 for Si show identical trends, i.e., that elemental release is enhanced with both temperature and time and that the temperature increase from 90 to $150^{\circ} \mathrm{C}$ results in the largest increase in elemental release. The activation energy for $B$ release from 76-68 glass into tuff groundwater was determined to be $16 \mathrm{Kcal} / \mathrm{mole}$, which agrees reasonably well with the previously determined ${ }^{(6)} 18 \mathrm{Kcal} / \mathrm{mole}$ for 76-68 glass in D.I. water. This indicates that glass-water interactions are similar in tuff groundwater and in deionized water.

Uranium release results from 76-68 glass into tuff groundwater are shown in Figure 3 . This figure illustrates that there is somewhat more scatter in the uranium data than for other elements evaluated. This is due in part to the relatively lower concentrations in solution. However, it can be seen from Figure 3 that relatively little uranium was released at $40^{\circ} \mathrm{C}$. At higher temperatures, the uranium release data appear to be independent of temperature within the data scatter. In fact, there appears to be very little time dependence within the data scatter at any temperature evaluated. Initial $\mathrm{pH}$ values for the tuff groundwater averaged 7.3 and, after 91 days of leaching, the $\mathrm{pH}$ value rose to 8.5 at $40^{\circ} \mathrm{C}, 9.0$ at $70^{\circ} \mathrm{C}, 9.3$ at 90 and $150^{\circ} \mathrm{C}$. The $\mathrm{pH}$ value is an indicator of glass reaction which has occurred and has a large effect on the solubility limit of uranium. In general, over a pH range of 7 to 9.5 (which spans the leaching results), the solubility of uranium decreases with increasing $\mathrm{pH}$. Therefore, the lower solution concentrations of uranium observed at $40^{\circ} \mathrm{C}$ is not the result of solubility limits but rather of lower glass reaction rates. It cannot be inferred from the data shown in Figure 3 whether solubility limits control the solution concentrations at higher temperatures. However, from the $B$ release data of Figure 1 , it can be seen that the glass reaction increases with both temperature and time, and thus, the fact that uranium concentrations do not increase indicates that al teration products and corresponding solubility limits may be controlling the solution concentration of uranium. Assuming the average solution concentration of uranium is about one ppm, then this converts to 
$4 \times 10^{-6} \underline{M}$, which is not an unreasonable solubility limit for anhydrous uranium oxide at $\mathrm{pH}$ values of $g$ in air saturated solutions.

When constituents of the waste package (other than the glass) are added to the test, interactive effects can become important. In addition, analyses become more complicated due to the same elements being present in more than one component of the test. This is illustrated in Figure 4 where the elemental compositions of the glass, tuff rock, and tuff groundwater are simultaneously displayed. As can be seen, there are many common elements such as $\mathrm{Na}$, $\mathrm{Si}$, and $\mathrm{Ca}$.

No matter what waste package design is finally selected, tuff rock will be present. Therefore, it is important to evaluate the effects of tuff rock on waste form release characteristics. This is done in test series 2 (see Table 4). Both tuff rock monoliths (of the same geometric surface area as the glass monolithic samples) and tuff rock powders were used to conduct the interactive tests. The rock monoliths were ultrasonically cleaned after cutting. The rock powder was not normally cleaned due to the apparent inhomogeneity of the rock which, it was feared, would result in heterogeneous compositional variations between powder particle sizes. Since the fine powder particles preferentially dissolve due to their relatively large surface areas, exposure to water in cleaning or preleaching procedures could result in undesirably altered rock powder samples. The entire rock sample preparation is described under the previous experimental section. Since it is the author's understanding that rock samples are preleached at LLNL, a comparison of elemental release into $90^{\circ} \mathrm{C}$ tuff groundwater from rock samples prepared in the manner used in this test matrix to preleached rock samples are given in Figures 5 and 6 for monoliths and powders, respectively. As can be seen from the figures, there is essentially no difference in release characteristics between cleaned and preleached monolithic rock samples. However, there is a larger difference observed (Figure 6) in the case of powders. Uncleaned powders result in more elemental release when exposed to water than preleached powders. The effect of preleaching rock samples prior to interactive testing, however, is small when waste form release characteristics are being evaluated, see Appendix $C$. 
An evaluation of the effect of tuff rock on $\mathrm{Si}, \mathrm{B}$, and uranium elemental release from $76-68$ glass has been conducted as a function of the surface area ratios of rock/glass samples and as a function of glass sample surface area to tuff groundwater ratios (see Table 4). These results are illustrated in Figures 7 through 16.

The time-dependent effect on Si solution concentration of adding tuff rock monoliths and waste glass monoliths to tuff groundwater are illustrated in Figure 7 . The glass sample surface area to tuff groundwater volume ratio $(S A / V)$ is $10 \mathrm{~m}^{-1}$ with rock and glass monolithic samples being equal in surface area. It can be seen from Figure 7 that the tuff groundwater alone changes insignificantly while addition of either rock or glass or both causes enhanced silicon solution concentrations. The presence of $\mathrm{Si}$ in solution has a strong retardation on glass leaching (5) due to reduction of the silicate matrix dissolution as silicon saturation is approached. That this is happening can be seen in Figure 8 , which illustrates the time-dependent $B$ solution concentration as glass and rock are added to tuff groundwater.

Again, glass and rock monoliths were added which were of the same surface area and the $S A / V=10 \mathrm{~m}^{-1}$. Boron is an indicator of glass reaction which has occurred because it does not normally form precipitates nor sorb on the container wall to any extent. As can be seen from Figure 8 , there is a small amount of B released from the rock monoliths which should not affect interpretation of the results. Glass alone in tuff groundwater releases the most amount of $B$. When a monolithic rock sample is added, the $B$ in solution decreases somewhat, indicating that less glass reaction has occurred. This seems reasonable since silicon has been added to the solution from the tuff rock which will somewhat retard glass-water interaction.

When rock powder is added to the system, the concentration of $\mathrm{Si}$ in solution increases significantly above that achieved with either rock or glass monoliths alone, particularly at longer times (Figure 9). This increased $\mathrm{Si}$ in solution should result in reduced glass reaction with the tuff groundwater. That this is the case is illustrated in Figure 10 where 
time-dependent $B$ solution concentrations are shown as a function of rock sample type. It is obvious that tuff rock powder is much more effective at reducing glass-water reactions (and thus release) than the rock monolith.

This is a particularly interesting point because the surface areas as determined by $\mathrm{N}_{2} \mathrm{BET}$ are not consistent with this result. The average $\mathrm{N}_{2}$-BET surface area of the rock monoliths is $0.28 \mathrm{~m}^{2}$. This is because of the high degree of porosity of the rock samples evaluated. The $\mathrm{N}_{2}-\mathrm{BET}$ surface area of the $0.1 \mathrm{gm}$ rock powder sample was $0.13 \mathrm{~m}^{2}$. This is approximately half of the monolithic rock sample surface area. Obviously, the $\mathrm{N}_{2}$-BET surface area measured on the monolithic rock sample is not as effective as the rock powder surface area. It could be that not all of the porosity contributing to the monolithic rock surface area is accessible by the liquid or that there is a large difference in reactivity of the powdered surface area compared to the monolithic porosity surfaces or that both effects are operative. Whether rock monoliths or powder are used, the system should be rock dominated (based on $\mathrm{N}_{2}$-BET surface areas) because the glass surface area, in a $S A / V=10$ experiment, is approximately $10^{-4}$ $\mathrm{m}^{2}$, which is 3 orders of magnitude less glass surface area than rock.

Even in cases where one order of magnitude more glass surface area is used, i.e., SA $/ V=100$ instead of 10 , the effects of tuff rock powder on release from the glass are the same, Figures 11 and 12 . The addition of ten times more glass surface area has little effect on silicon solution concentrations, indicating that the system is al ready rock-dominated with only $0.1 \mathrm{gm}$ rock powder, Figure 11. This is substantiated by Figure 12, which illustrates that $B$ release, i.e., glass-water interaction, is significantly reduced by 0.1 gm rock powder and does not increase to any extent with time. Increasing the glass surface area present by one order of magnitude does not significantly increase boron release, i.e., glass-water reaction.

The results illustrated in Figure 13 summarizes the findings discussed so far, i.e., glass-tuff groundwater reactions are drastically reduced by the addition of rock powder but not nearly as much by the addition of rock monolithic samples. Additionally, Figure 13 also illustrates that 
increasing the glass and rock powder surface area by one order of magnitude has no significant effect on $B$ release. Increases in the quantity of rock powder above 0.1 gram cause increased $S i$ solution concentrations but have small additional effects on $B$ release from the glass as is illustrated in Figures 14 and 15. The small increase in boron observed when $S A / V=400 \mathrm{~m}^{-1}$ with $4 \mathrm{gm}$ rock powder could come either from the glass or from impurities in the rock. Glass reaction layer thicknesses were undetectably small with rock powder present, indicating that the boron probably came from the additional rock powder.

Al though increases in rock powder above $0.1 \mathrm{gm}$ made little difference in $B$ solution concentrations, it makes a large difference in uranium solution concentrations, Figure 16 . With $0.1 \mathrm{gm}$ rock powder present, the amount of uranium in solution is about one order of magnitude less than with no rock present, figure 3 . Increasing the amount of rock present lowers the uranium solution concentration even though the amount of glass increases, Figure 16. These results can probably be explained by uranium sorption on the rock surfaces.

The last waste package constituent to be considered in regard to interactive effects is ferrous metal. The metals considered in this investigation are $304 \mathrm{~L}$ and 316 stainless steel as we 11 as $1020 \mathrm{M} \mathrm{mild}$ stee1. The 300-series stainless steels form a protective chrome oxide layer and are not expected to be reactive. However, the 1020M mild steel is more reactive and is expected to have a larger interactive effect.

The effect of waste package constituents on $\mathrm{pH}$ is shown in Figure 17 for glass and tuff rock monolithic samples in tuff groundwater at an SA/V of $10 \mathrm{~m}^{-1}$. Additionally, 304L stainless steel samples of the same geometric surface area as the glass are included with the rock and glass in Figure 17. There is no effect on pH of the rock or 304L SS over what is observed for glass alone. This is consistent with the fact that rock monoliths caused relatively little effect on glass-water interactions. The 304L SS also seems to be inert as far as pH alteration is concerned.

This is not the case, however, for 1020M steel as can be seen from Figure 18. This figure shows $\mathrm{pH}$ changes for glass and tuff rock monolithic 
samples with metal present in $90^{\circ} \mathrm{C}$ tuff groundwater. The rock and metal samples are of the same surface area as the glass sample and the $S A / V=10 \mathrm{~m}^{-1}$. As can be seen, the 300 -series stainless steels are similar and have essentially no effect, while lo20M mild steel increases the $\mathrm{pH}$ level significantly higher than the glass alone does. This indicates a large amount of reaction occurring between metal and water. Therefore, the 1020M metal should have an effect on glass reaction and release characteristics.

That this occurs is illustrated in Figure 19, which it can be seen that $304 \mathrm{~L}$ and 316 stainless steel have little effect on $B$ release, while $1020 \mathrm{M}$ has a large effect. These experiments were conducted with monolithic rock samples and, therefore, may not be expected to be rock dominated from previous discussions. Nevertheless, the 1020M steel has a large effect under the se experimental conditions.

The inclusion of rock powder in the test matrix shows interesting results as can be seen in Figure 20. In this series of tests, when the $S A / V$ was increased from 10 to 100 , the metal sample surface area was increased by ten to keep the surface area ratio constant. Additionally, rock powder was used instead of a rock monolith. This system should still be rock dominated since the rock surface area is still two orders of magnitude greater than either the glass or metal. However, as can be seen from Figure 20 , the $1020 \mathrm{M}$ metal is dominating the system and causing very large glass reactions (as determined by B release) to occur. The $304 \mathrm{~L} \mathrm{SS}$ has essentially no effect even when its surface area has been increased by a factor of 10. More research needs to be conducted to determine how much rock is needed to overcome the $1020 \mathrm{M}$ steel.

The effect of metal on uranium solution concentrations is shown in Figure 21. These tests were conducted with glass and rock monolithic samples and show less uranium in solution than was observed for glass alone, Figure 3, but much more than was observed for rock powder, Figure 16. Rock powder reduces glass reaction with water and offers possible sorption sites for the uranium. Acid stripping of the metal samples, Table 5 , shows that $1020 \mathrm{M}$ is much more effective at removing 
uranium from solution than the stainless steels. This could be due to the fact that 1020M samples cause more glass reaction and thus have more uranium in solution to sorb or al so because iron hydroxide is forming, which is a very good scavenger for actinides.

The fact that $B$ has been used as an indicator or glass reaction throughout requires some verification. With this intention, reaction layer thicknesses were measured with an SEM on cross-sections of reacted samples. The results are shown in Figure 22 for comparison to B results. As can be seen from the figure, tuff rock monoliths and 300-series stainless steels cause little effect on reaction layer thicknesses. However, 1020M steel causes a large increase in reaction layer thickness. Additional1y, $150^{\circ} \mathrm{C}$ temperatures cause large reaction layers. Figures 23 and 24 show the SEM photographs of sample cross-sections. In addition to observations made from Figure 22 , the effect of $0.1 \mathrm{gm}$ rock powder should be noted on Figure 23. The rock powder results in no detectable reaction layer on the glass and on adherent layer of rock powder fines.

Almost all of the experiments were filtered. Figures 25 and 26 show some of these results. In these figures, it can be seen that filtration has removed only a small amount of Si from solution. Since $S i$ is tied up in most colloids and/or precipitates, then it appears that these were not present in large quantities in the experiments plotted. The experiments shown in Figure 25 are with monolithic glass and rock samples and in Figure 26 with monolithic glass, rock, and 304L SS samples. Other experiments, which were conducted with glass and/or rock powder, as well as those incorporating $1020 \mathrm{M}$ stee 1 show more effect of filtration due to the formation of precipitates and/or colloids. These data can be gleaned from Appendix $C$.

The reproducibility of the data is illustrated in Figures 27 and 28 . Duplicate experiments were conducted at separate times to evaluate the experimental and analytical aspects of the program. The replicate experiments are marked on the test matrix in Table 4 . One experiment (Figure 27) was Test 2 with rock and glass powder, and the other experiment (Figure 28) was Test 3 which was identical with the exception of the 
inclusion of a piece of 304L SS. The Si release data from both experiments are essentially the same because of the relative inertness of $304 \mathrm{~L}$ SS. Replication of the data is good.

\section{CONCLUSIONS}

The major conclusions that can be drawn from the completion of this test matrix are as follows:

- In the absence of $1020 \mathrm{M}$ mild steel, tuff rock powder dominates the system.

- Tuff rock monolithic samples do no have a large effect on 76-68 glass release characteristics even though the rock monolith has a large $\mathrm{N}_{2}$-BET surface area.

- Increasing amounts of rock powder do not detectably decrease $B$ release (it is already very low) but has a significant effect on reducing uranium solution concentrations.

- When 1020M mild steel is present, it appears to dominate the system, significantly increasing glass reaction. However, the 1020M steel also scavenges uranium from solution, probably as a result of iron hydroxide formation, increased $\mathrm{pH}$, and reduced Eh. 


\section{REFERENCES}

1. Buckwalter, C. Q. and L. R. Pederson. 1982. "Inhibition of Nuclear Waste Glass Leaching by Chemisorption." J. Am. Ceram. Soc. $65(9): 431-436$.

2. McVay, G. L. and C. Q. Buckwalter. 1983. "Effect of Iron on Waste-Glass Leaching." J. Am. Ceram. Soc. 66(3):170-174.

3. Shade, J. W., L. R. Pederson and G. L. McVay. 1983. Waste Glass/Metal Interactions in Brines. PNL-SA-10913, Pacific Northwest Laboratory, Richland, Washington.

4. The Nuclear Waste Materials Handbook, Test Methods. DOE/TIC-11400. Prepared by Materials Characterization Center, J. E. Mendel, ed.

5. Pederson, L. R., C. Q. Buckwalter, G. L. McVay and B. L. Riddle. 1982. "Glass Surface Area to Solution Volume Ratio and Its Implications to Accelerated Leach Testing." Scientific Basis for Nuclear Waste Management, Vol. 6, pp. 47-54.

6. Bradley, D. J., D. G. Coles, F. N. Hodges, G. L. McVay and R. E. Westerman. 1983. Nuclear Waste Package Materials Testing Report: Basaltic and Tuffaceous Environments. PNL-4452, Pacific Northwest Laboratory, Richland, Washington. 
TABLE 1. Component Composition

\begin{tabular}{|c|c|c|c|c|}
\hline OXIDES & $\mathrm{UO}_{2} \underset{\text { Wt } \%}{\text { SPIKED }}(76-68)$ & $\begin{array}{l}\text { TUFF ROCK } \\
\text { wt\% }\end{array}$ & ELEMENTS & $\begin{array}{l}\text { TUFF WATER } \\
\text { ppm }\end{array}$ \\
\hline $\mathrm{SiO}_{2}$ & 42.00 & 70.000 & Si & 30.100 \\
\hline $\mathrm{Na}_{2} \mathrm{O}$ & 12.70 & 3.720 & $\mathrm{Na}$ & 47.500 \\
\hline $\mathrm{Fe}_{2} \mathrm{O}_{3}$ & 9.56 & 0.860 & $\mathrm{Fe}$ & \\
\hline $\mathrm{B}_{2} \mathrm{O}_{3}$ & 9.00 & & B & \\
\hline ZnO & 5.10 & & $\mathrm{Zr}$ & \\
\hline $\mathrm{UO}_{2}$ & 3.98 & & U & \\
\hline $\mathrm{TiO}_{2}$ & 3.08 & 0.100 & $\mathrm{Ti}$ & \\
\hline $\mathrm{CaO}$ & 2.37 & 0.610 & $\mathrm{Ca}$ & 12.400 \\
\hline $\mathrm{La}_{2} \mathrm{O}_{3}$ & 4.10 & & La & \\
\hline $\mathrm{MoO}_{3}$ & 1.97 & & Mo & \\
\hline $\mathrm{Nd}_{2} \mathrm{O}_{3}$ & 1.40 & & Nd & \\
\hline $\mathrm{Ce}_{2} \mathrm{O}_{3}$ & 0.90 & & $\mathrm{Ce}$ & \\
\hline $\mathrm{Cs}_{2} \mathrm{O}$ & 1.10 & & Cs & \\
\hline $\mathrm{P}_{2} \mathrm{O}_{5}$ & 0.80 & & $P$ & \\
\hline $\mathrm{BaO}$ & 0.55 & 0.007 & $\mathrm{Ba}$ & \\
\hline $\mathrm{Al}_{2} \mathrm{O}_{3}$ & 0.59 & 12.000 & Al & \\
\hline $\mathrm{K}_{2} \mathrm{O}$ & & 4.510 & $k$ & 4.600 \\
\hline Sro & 0.40 & 0.005 & $\mathrm{Sr}$ & 0.042 \\
\hline $\mathrm{Cr}_{2} \mathrm{O}_{3}$ & 0.47 & & $\mathrm{Cr}$ & \\
\hline $\mathrm{NiO}$ & 0.23 & & $\mathrm{Ni}$ & \\
\hline $\mathrm{MnO}_{2}$ & & 0.060 & Sm & \\
\hline CuO & & 0.010 & $\mathrm{Mn}$ & \\
\hline $\mathrm{Li}_{2} \mathrm{O}$ & & & $\mathrm{Cu}$ & \\
\hline $\mathrm{MgO}$ & & 0.070 & Li & 0.047 \\
\hline \multirow[t]{2}{*}{$\mathrm{ZrO}_{2}$} & 1.89 & 0.030 & $\mathrm{Mg}$ & 1.900 \\
\hline & & & $Z r$ & \\
\hline
\end{tabular}


TABLE 2. Composition of Metallic Samples

(in wt\%)

\begin{tabular}{llllllll}
$\begin{array}{l}\text { TYPE } \\
\text { NO. }\end{array}$ & C & $\begin{array}{l}\text { Mn } \\
\text { MAX }\end{array}$ & $\begin{array}{l}\text { Si } \\
\text { MAX }\end{array}$ & $\begin{array}{l}\text { MAX } \\
\text { MAX }\end{array}$ & Cr & Ni \\
\hline $304 L^{\star}$ & 0.03 & 2.00 & 1.00 & 0.045 & 0.03 & $18-20$ & $8-12$ \\
$316 S S^{\star}$ & 0.08 & 2.00 & 1.00 & 0.045 & 0.03 & $16-18$ & $10-14$ \\
$1020 M^{\star *}$ & 0.19 & 0.36 & 0.29 & 0.430 & & &
\end{tabular}

Remainder $\mathrm{Fe}$

*American Iron and Steel Institute, standard type numbers

**Lusk Metals Test Report, Speci. AISI, Source Pitt Stee1 heat No. B27625 
TABLE 3. Glass Powder Surface Area Calculations

$\begin{array}{ll}S A / V=100 & S A / V=400 \\ -40+80 & -100+200 \\ .0299 & .0112 \\ .005364 & .000753 \\ 2.673 \mathrm{E}-5 & 1.405 \mathrm{E}-6 \\ 66.890 & 178.635\end{array}$


TABLE 4. TEST MATRIX

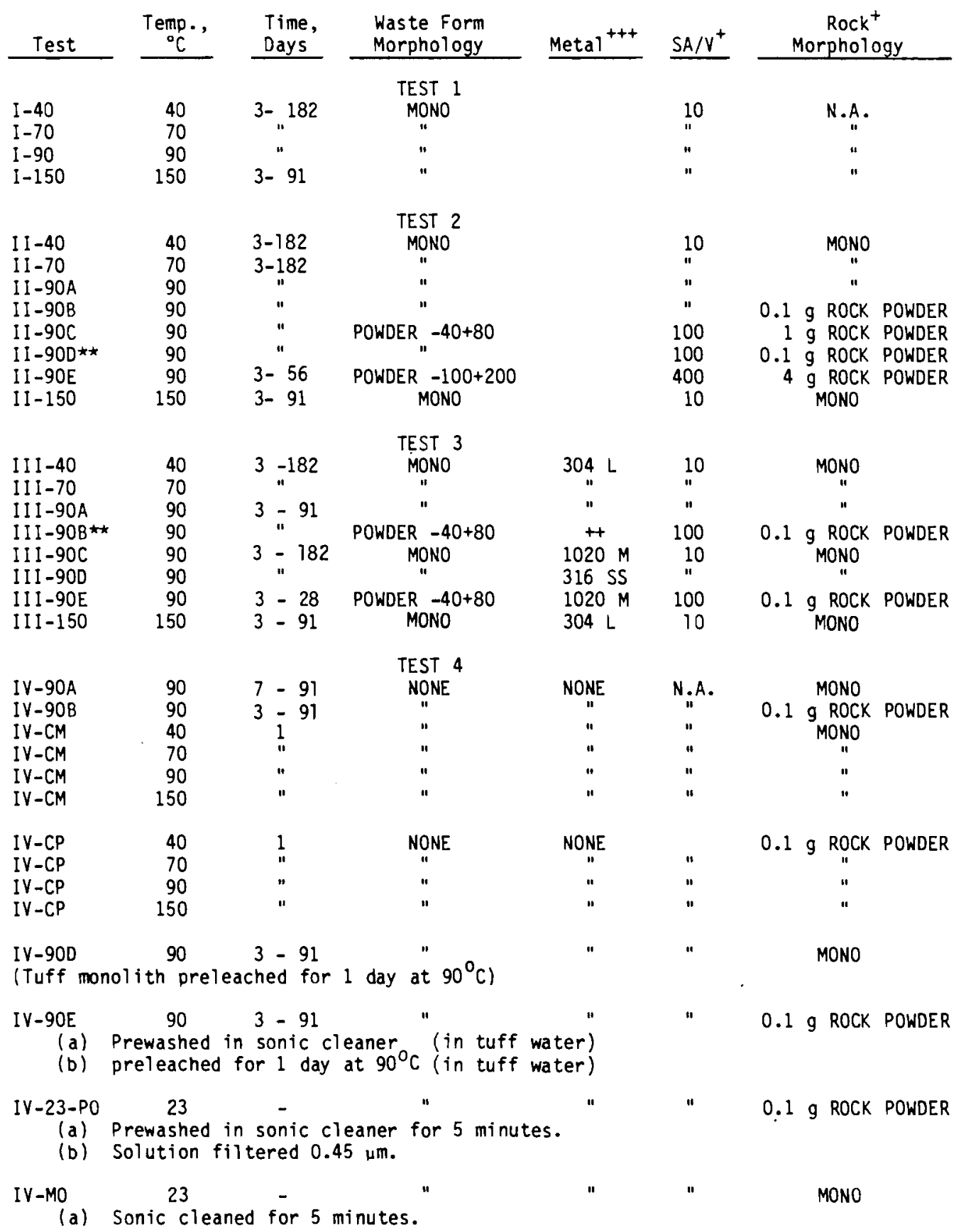

IV-90F $90 \quad 3-91 \quad$ MONO $\quad 10 \quad$ MONO

(a) Tuff rock monoliths preleached for 1 day at $90^{\circ} \mathrm{C}$ in tuff water.

$\begin{array}{llllllll}\text { IV-90G } & 90 & 3 & -91 & 91 & \text { MONO } & 10 & 0.1 \mathrm{~g} \text { ROCK POWDER }\end{array}$

(a) Tuff rock powder sonic-cleaned.

(b) Tuff rock powder preleached for 1 day at $90^{\circ} \mathrm{C}$ in tuff water.

$\begin{array}{lllll}\text { IV-90 } 90 & 3-91 & \end{array}$

(a) Tuff water on $1 y$.

* Glass sample surface area/leachate volume.

* Duplicate experiments made.to 28 days.

+ Rock monoliths had the same geometric surface area as the glass sample. Rock powder was -60 mesh.

++ Metallic surface area is ten times glass monolith surface area to be consistent with higher $S A / V$.

+++ Metallic surface area was equal to glass surface area. 
TABLE 5. ICP ACID STRIP DATA

METALS IN $3 \mathrm{~N} \mathrm{HNO}+.5 \mathrm{~N} \mathrm{HF}$

\begin{tabular}{|c|c|c|c|c|c|c|c|c|c|c|}
\hline $\begin{array}{l}\text { ELEMENTS } \\
\text { DET. LIM }\end{array}$ & Blank & $\begin{array}{l}\text { l020M } \\
\text { Blank }\end{array}$ & $\begin{array}{l}90 \mathrm{C}-56 \\
1020 \mathrm{M}\end{array}$ & $\begin{array}{l}90 \mathrm{C}-91 \\
1020 \mathrm{M}\end{array}$ & $\begin{array}{l}316 S S \\
\text { Blank }\end{array}$ & $\begin{array}{l}90 D-56 \\
316 \mathrm{SS}\end{array}$ & $\begin{array}{l}900-91 \\
316 \text { SS }\end{array}$ & $\begin{array}{l}304 \mathrm{~L} \\
\text { b lank }\end{array}$ & $\begin{array}{l}90 A-56 \\
304 L\end{array}$ & $\begin{array}{l}90 A-91 \\
304 \mathrm{~L}\end{array}$ \\
\hline $\operatorname{AL}(.03)^{\star}$ & 100 & & & & & & & & & 100 \\
\hline $\mathrm{B}(.01)$ & & & & & & & & & & 130 \\
\hline $\mathrm{Ca}(.0 \hat{z})$ & & & & & & & & & & \\
\hline $\operatorname{cr}(.02)$ & & & & & 130 & 240 & 160 & 100 & 240 & 088 \\
\hline $\mathrm{Fe}(.005)$ & 67 & 6000 & 78,600 & 29,800 & 520 & 970 & 590 & 400 & 940 & 310 \\
\hline $\mathrm{Na}(.16)$ & & & & & & & & & & \\
\hline $\mathrm{Ni}(.02)$ & 20 & & & & 089 & 180 & 120 & 057 & 140 & 067 \\
\hline $\mathrm{Si}(.02)$ & 350 & 450 & 440 & 730 & 640 & 470 & 320 & 1,100 & 500 & 1,500 \\
\hline$U(.0005)$ & & & & 1.063 & & & 0.083 & & & 0.077 \\
\hline
\end{tabular}

${ }^{\star} \mathrm{mg} / \ell \quad(\mathrm{ppm})$ 




\section{URANIUM ANALYSIS}
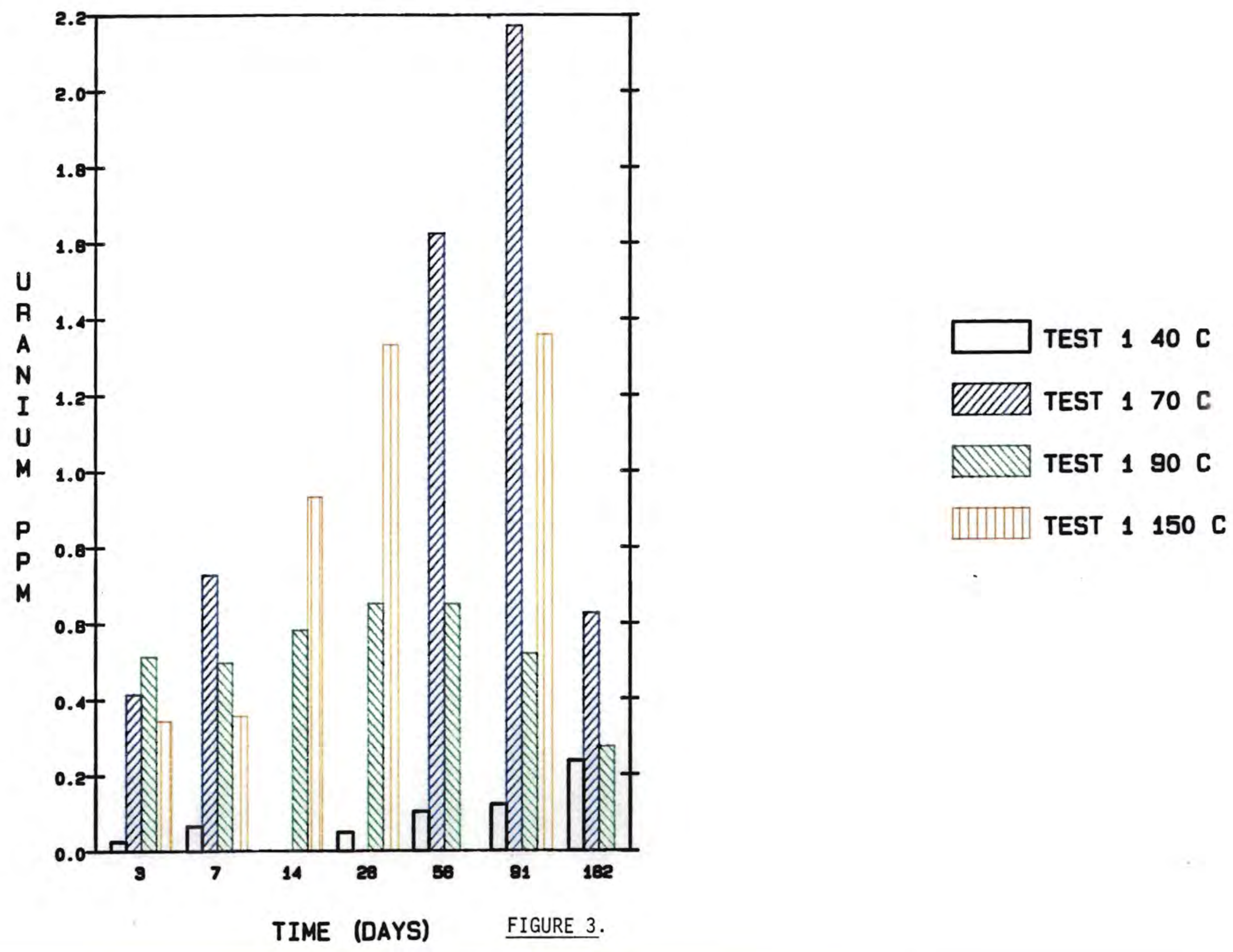


$$
L
$$




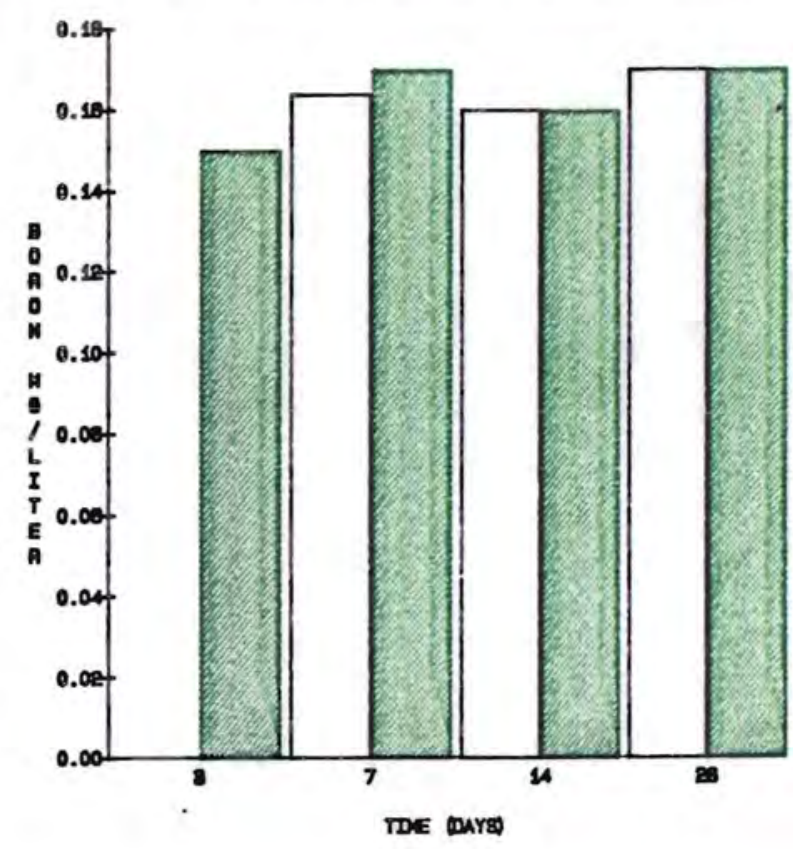

\section{$\square$ DENED MOTH}

menas vam

$\stackrel{\infty}{\infty}$
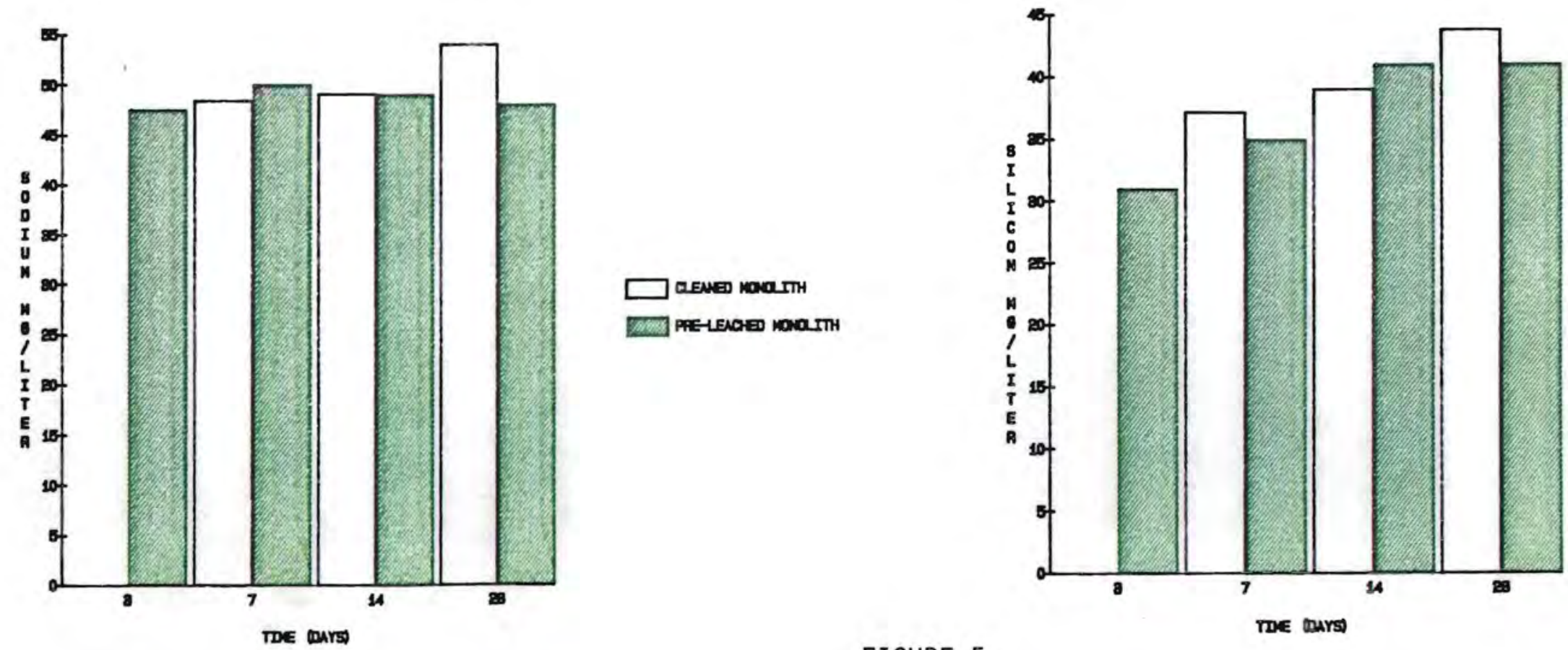


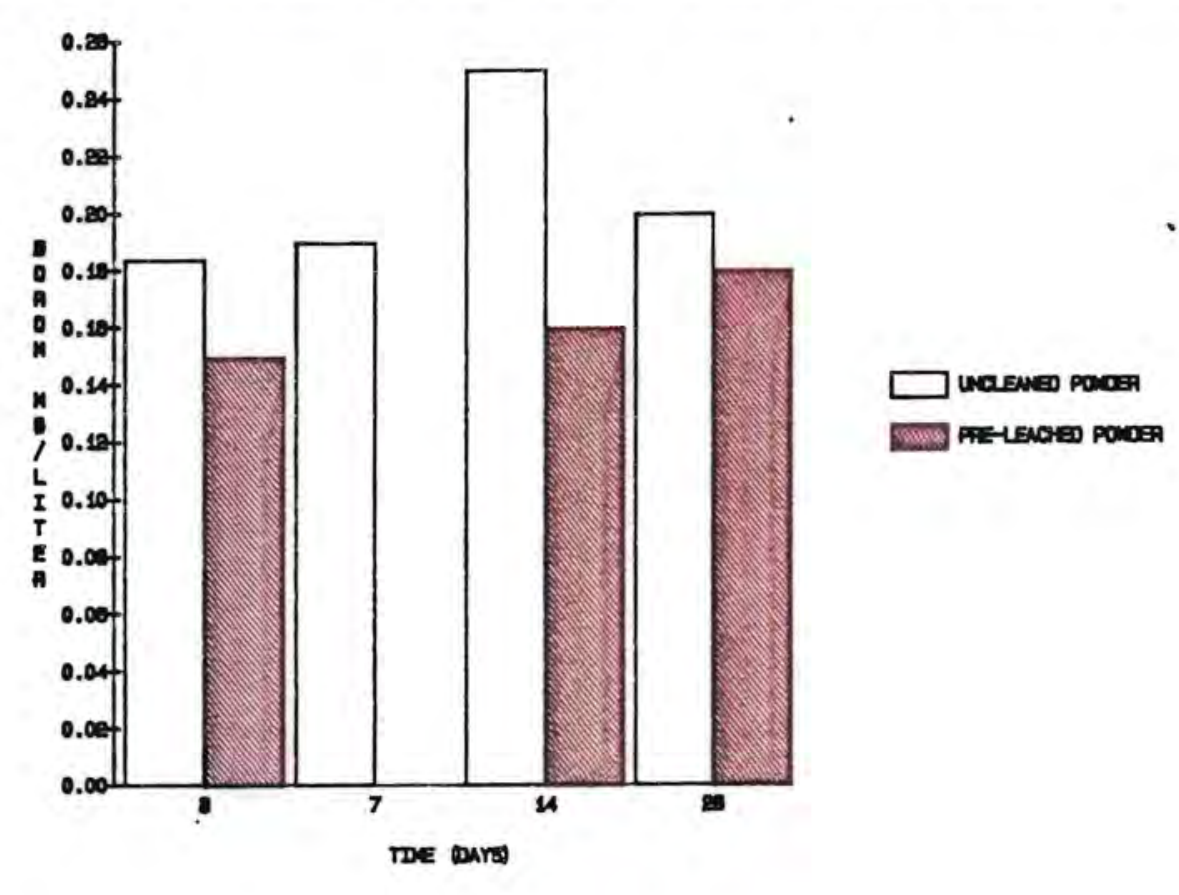

$\tilde{\sigma}$
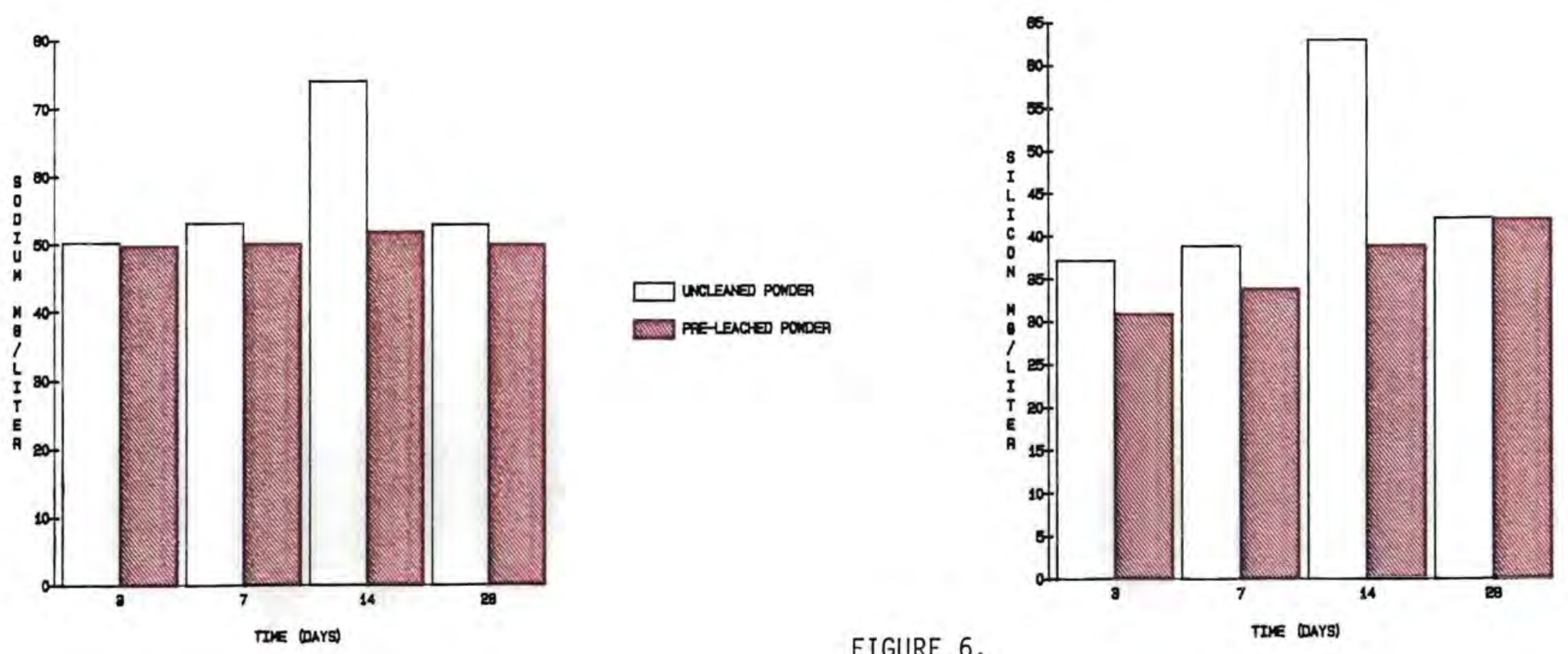

UNCLENED PONDEA

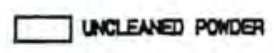

DPE-LACEED PONDER 


\section{COMPARISON OF COMPONENT CONTRIBUTION \\ SILICON , 90C}

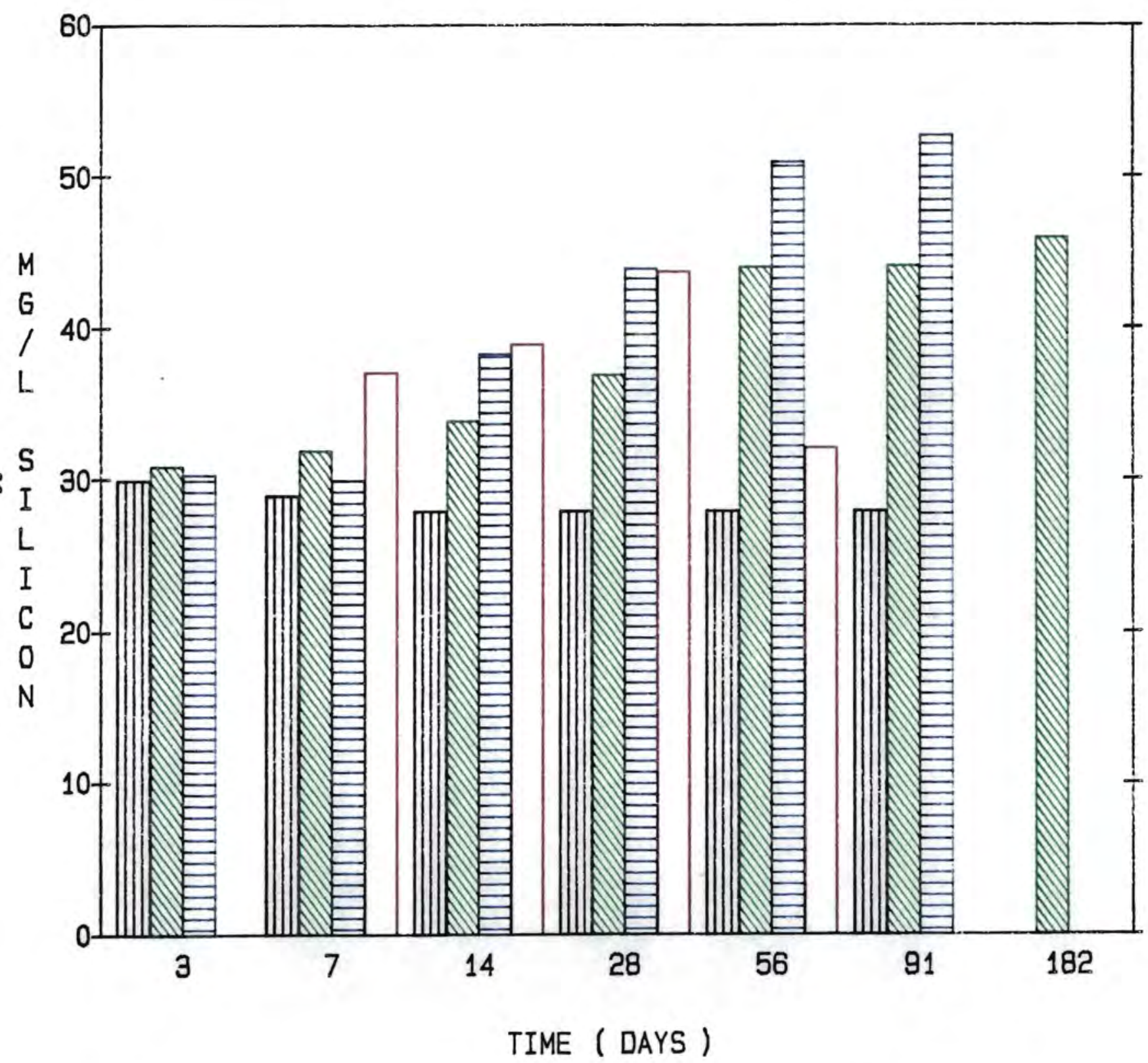

FIGURE 7.
[I! III TUFF WATER

MMU (76-68) WASTE GLASS

E (76-68) GLASS + ROCK

TUFF ROCK 
COMPARISON OF COMPONENT CONTAIBUTION

BORON , 90 C

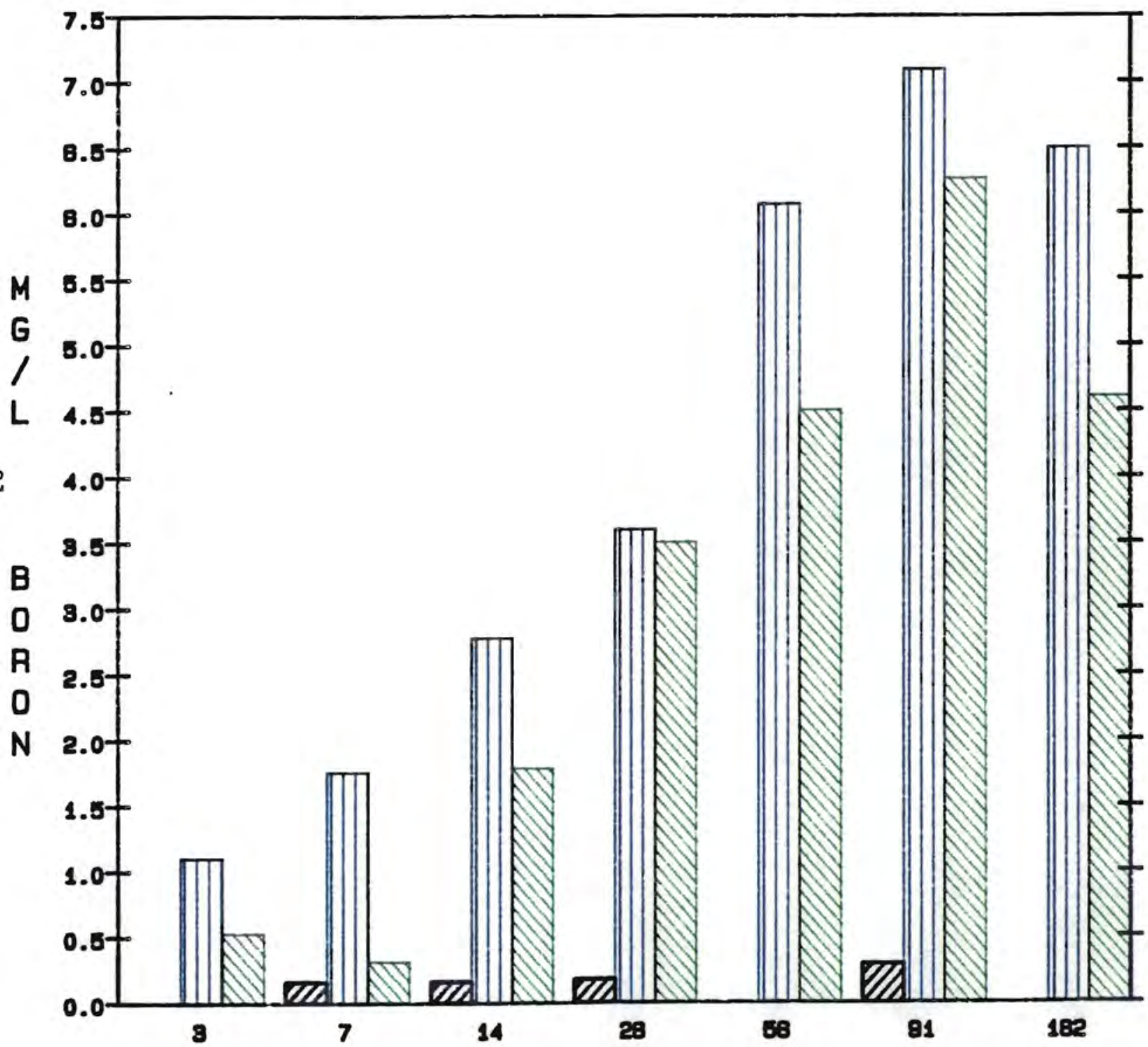

TIME ( DAYS )
ROCK IN WATER

WIII GLASS IN WATER

GLASS + ROCK IN WATER

\section{FIGURE 8.}


EFFECTS OF GLASS/ROCK

SILICON $90 \mathrm{C}$

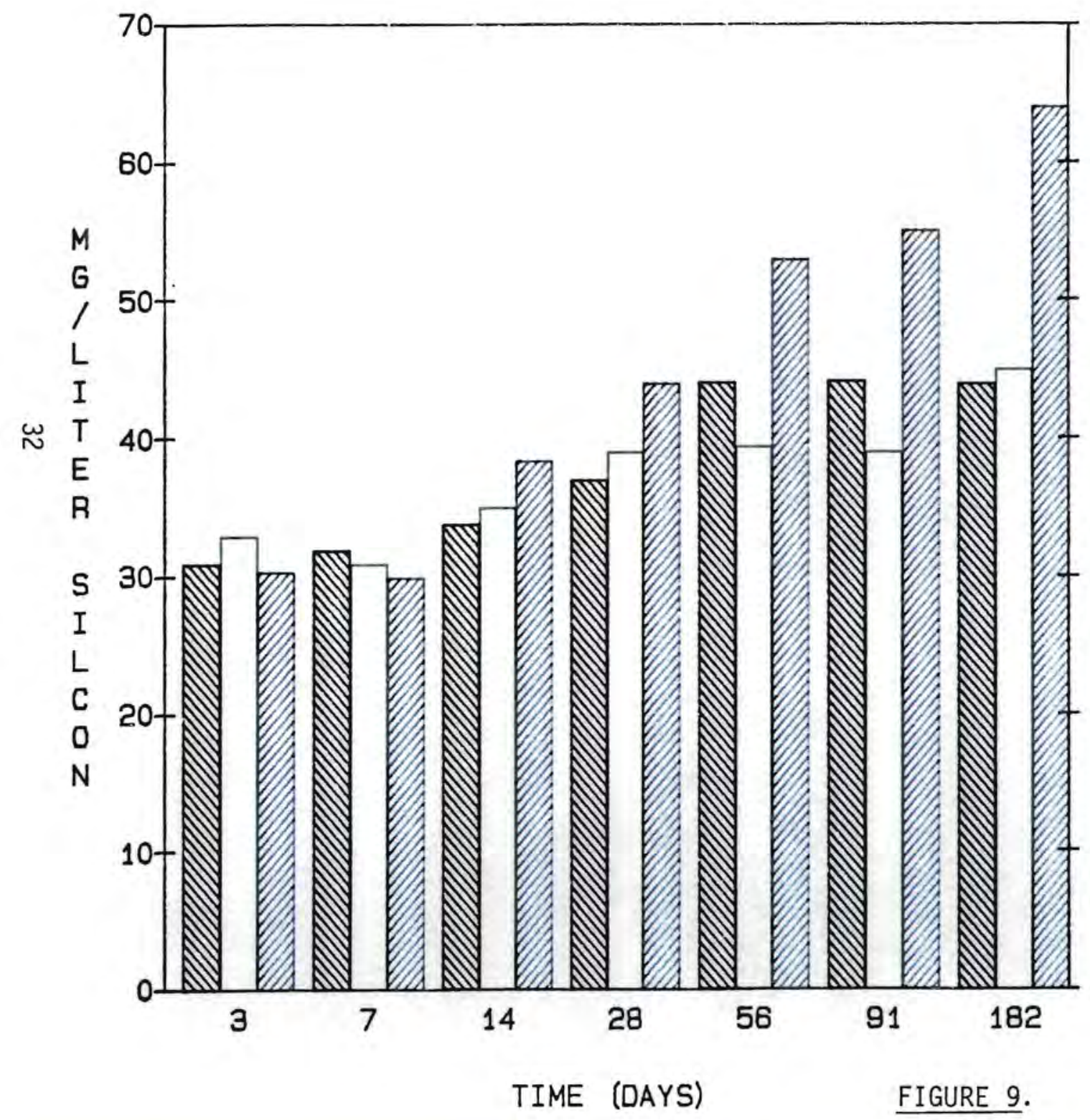

SA $/ V=10$ GLASS ONLY

$S A / V=10$ R. $M$.

VIIIII

$S A / V=10.16$ ROCK POWDER 
BORON, 9OC
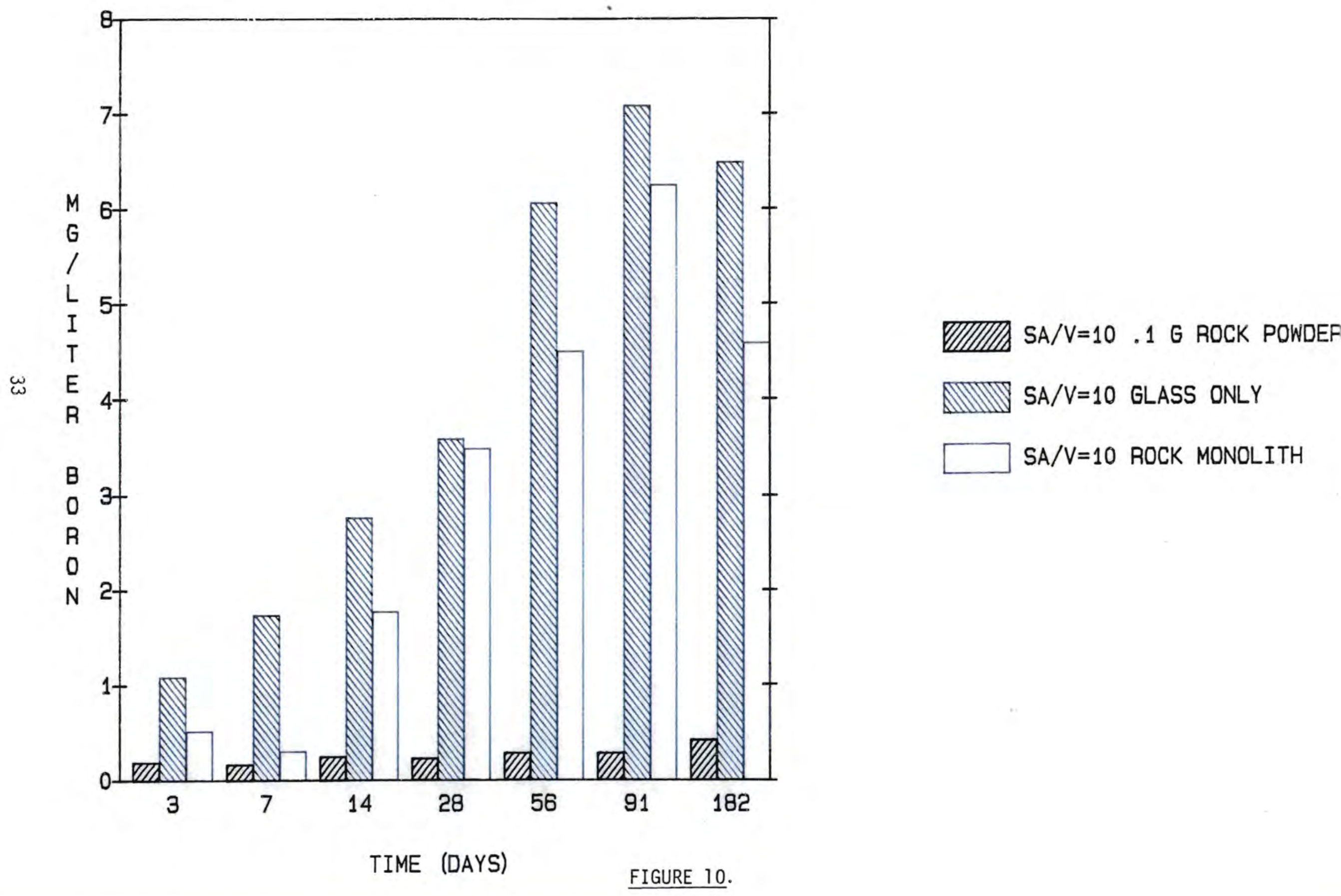


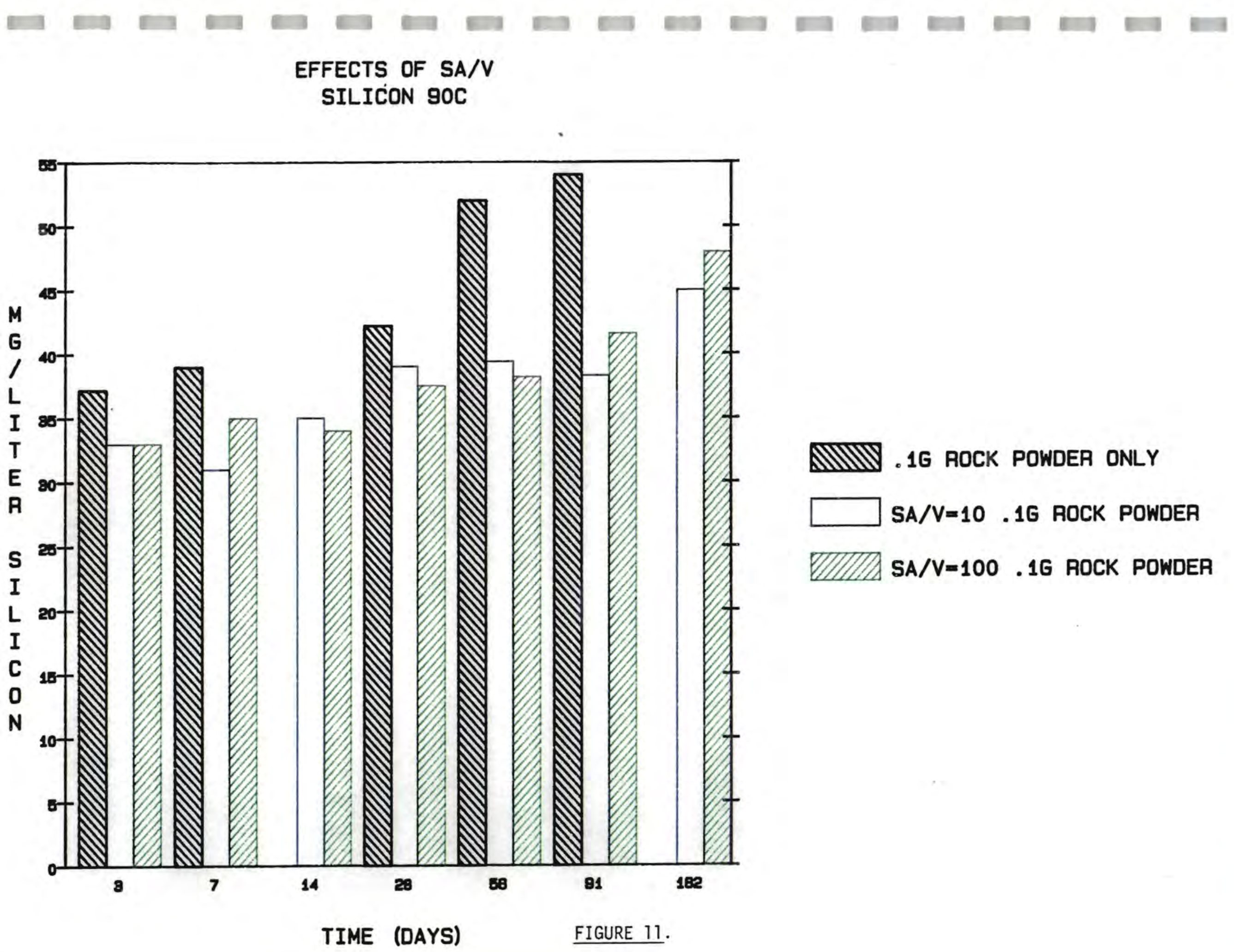


EFFECTS OF SA/V

BORON $90 \mathrm{C}$

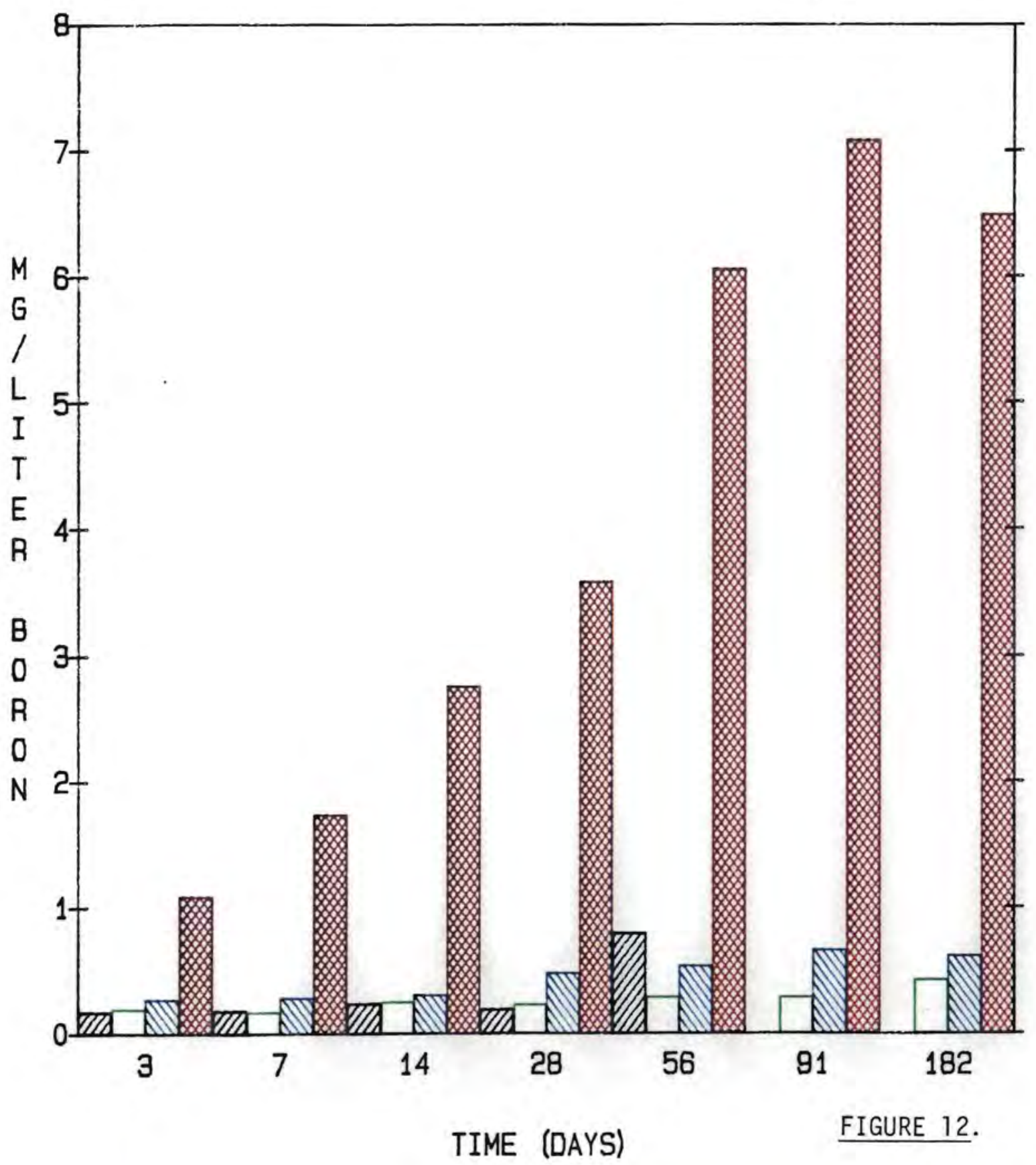

VIIIIIA . 1G ROCK POWDER

$\square$ SA/V=10 .16 ROCK POWDER

MUV SA $/ V=100.16$ ROCK POWDER

SA/V=10 GLASS ONLY

TIME (DAYS) 
EFFECTS OF GLASS/ROCK

BORON, $90 \mathrm{C}$

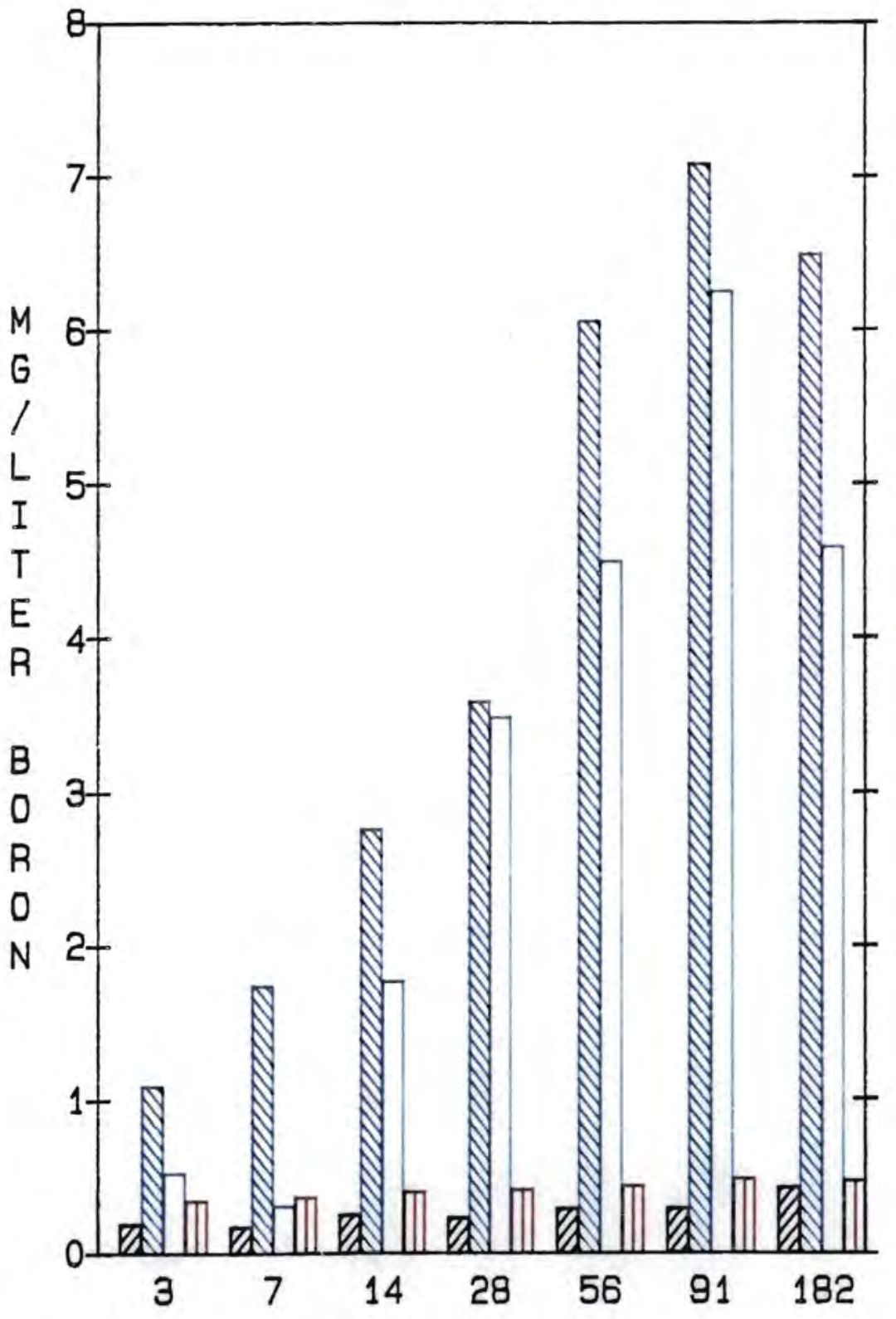

VIIIIA $S A / V=10.1$ G ROCK POWDER

MUV $S A / V=10$ GLASS ONLY

SA/V=10 ROCK MONOLITH

|l||| || SA/V=100 1 G ROCK POWDER

TIME (DAYS)

FIGURE 13. 
EFFECTS OF GLASS/ROCK

SILICON $90 \mathrm{C}$

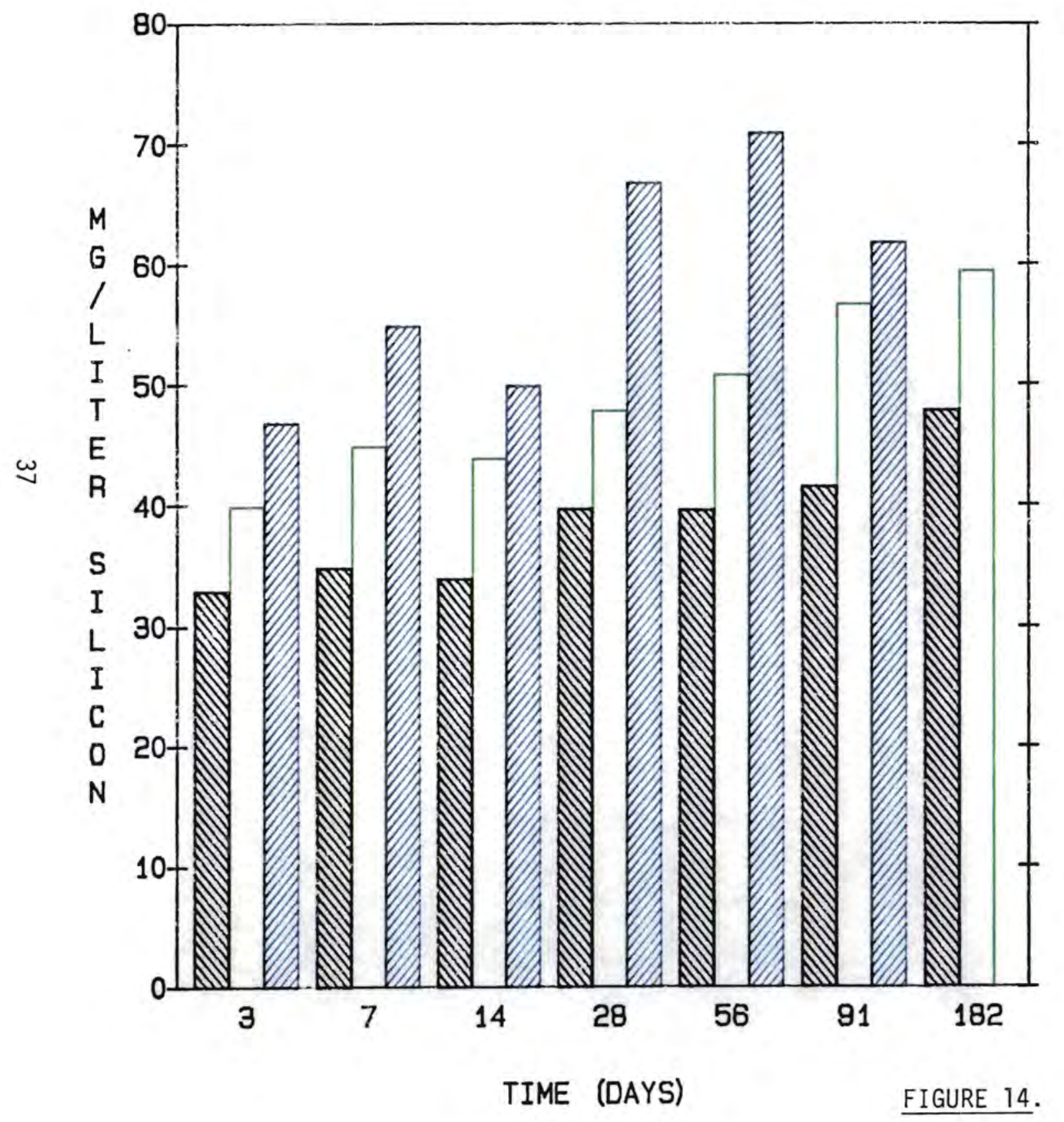

MIII $S A / V=100$. 1G ROCK $S A / V=100 \quad 1 G$ ROCK $S A / V=400 \quad 4 G$ ROCK 
EFFECTS OF. GLASS/ROCK

BORON, GOC

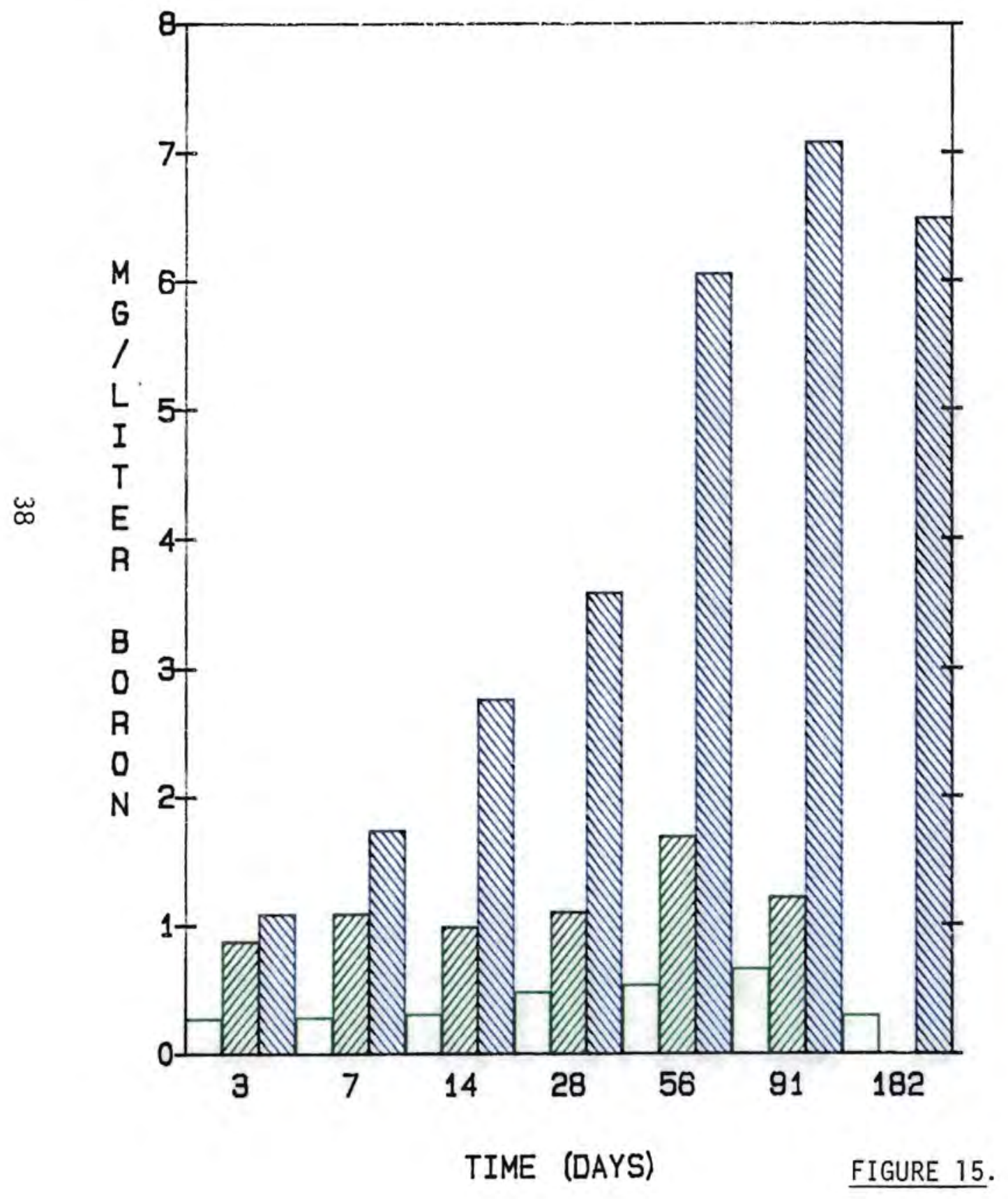

$\square$ SA $/ \mathrm{V}=100$.1G ROCK POWDER

VIIII SA/V=400 4G ROCK

$\mathbb{M}=\mathrm{SA} / \mathrm{V}=10$ GLASS ONLY 
URANIUM ANALYSIS

GLASS+ROCK

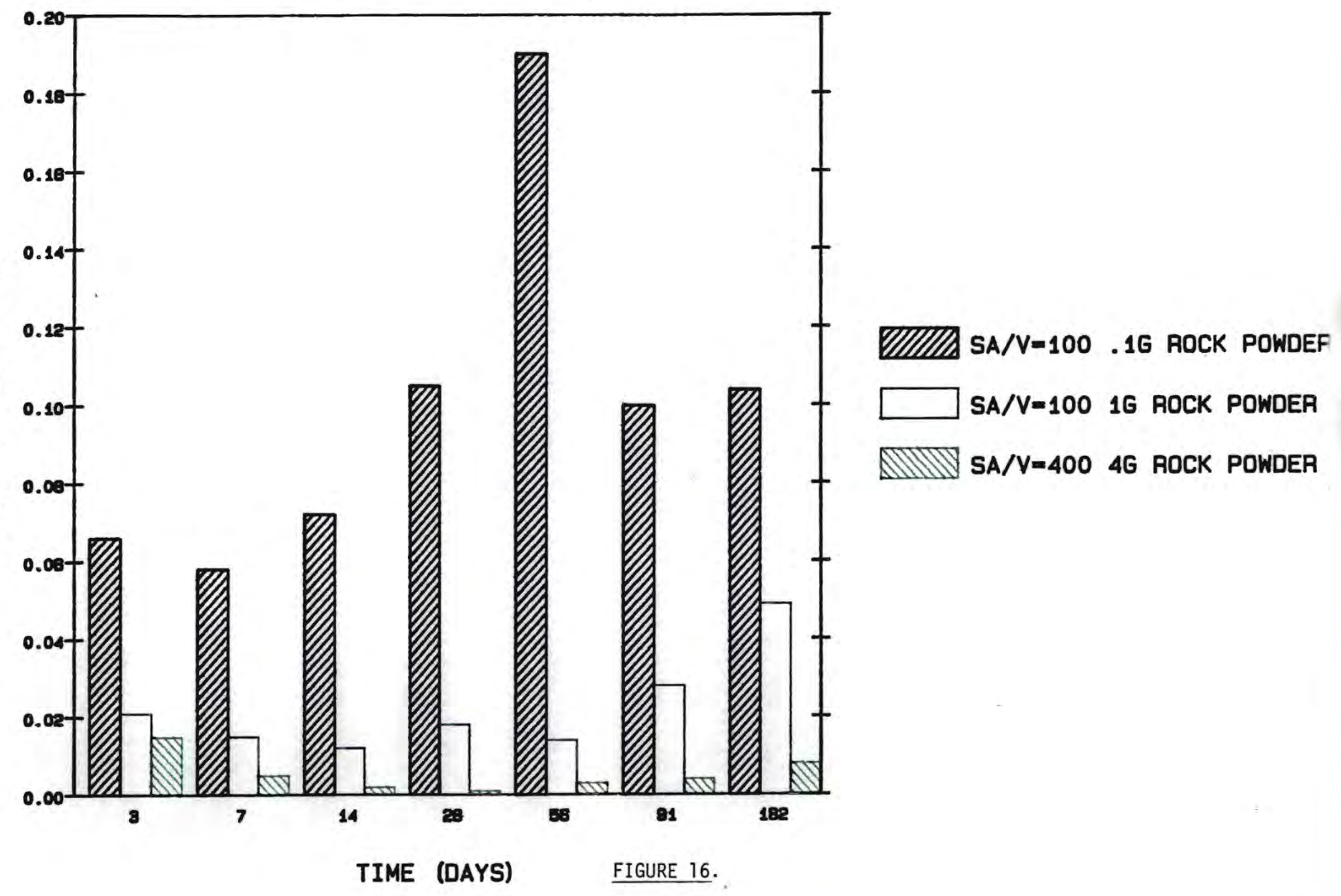




\section{INTERACTIVE EFFECTS}

BORON 9OC
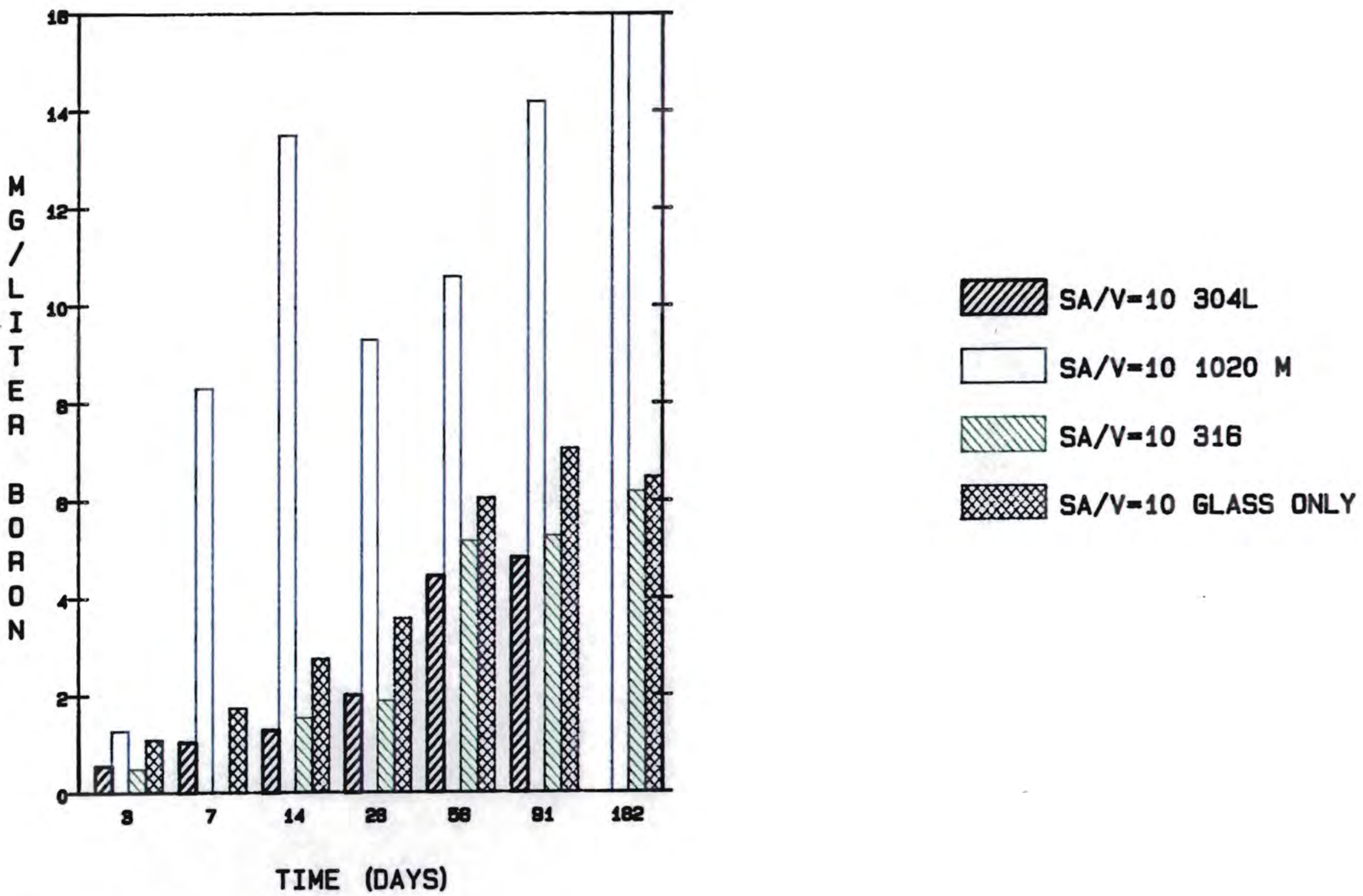


\section{METALS AND URANIUM}

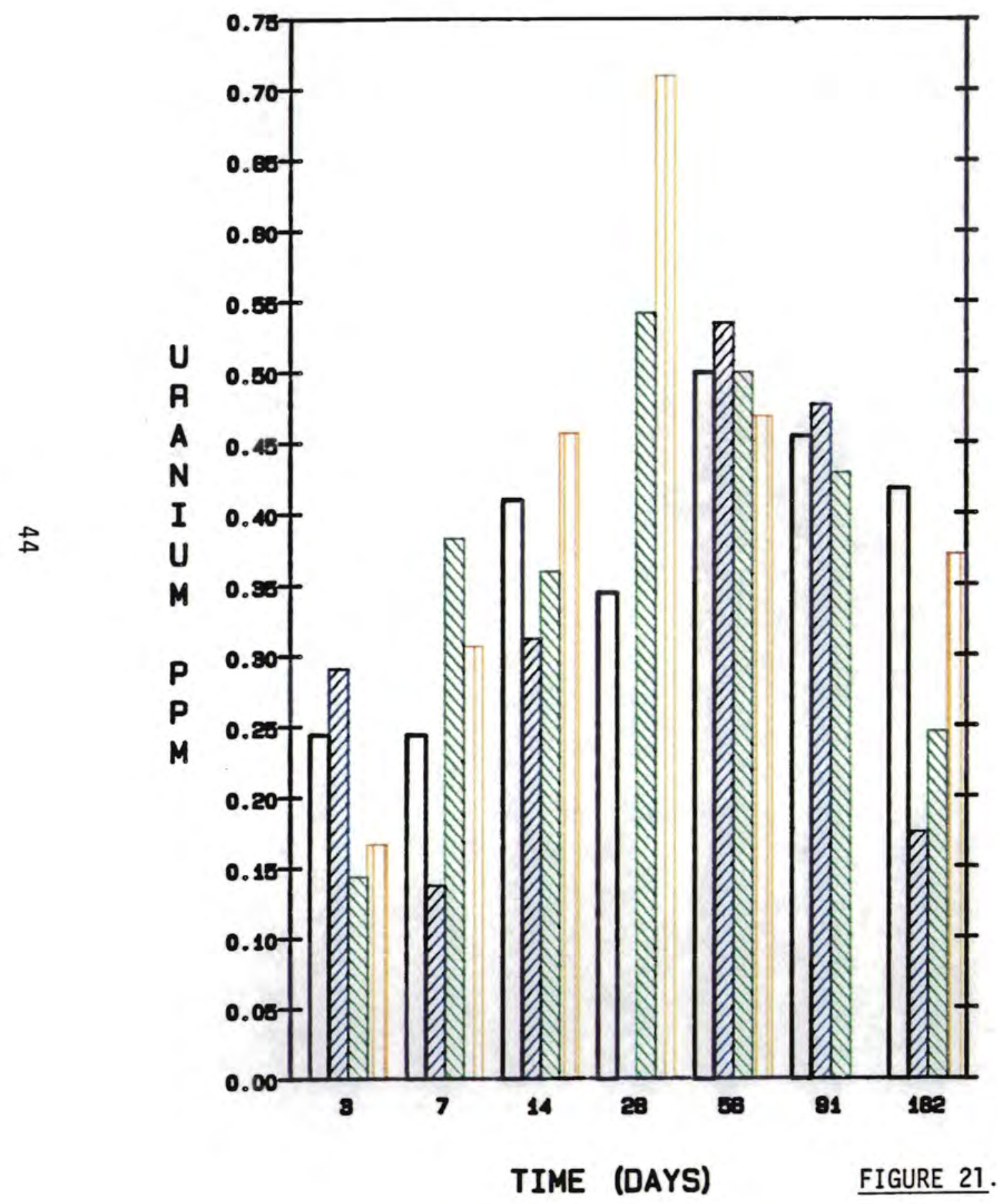

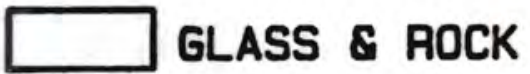

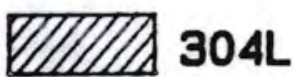
316 SS $1020 M$ 
GEL LAYER THICKNESS

80 C . 81 DAYS

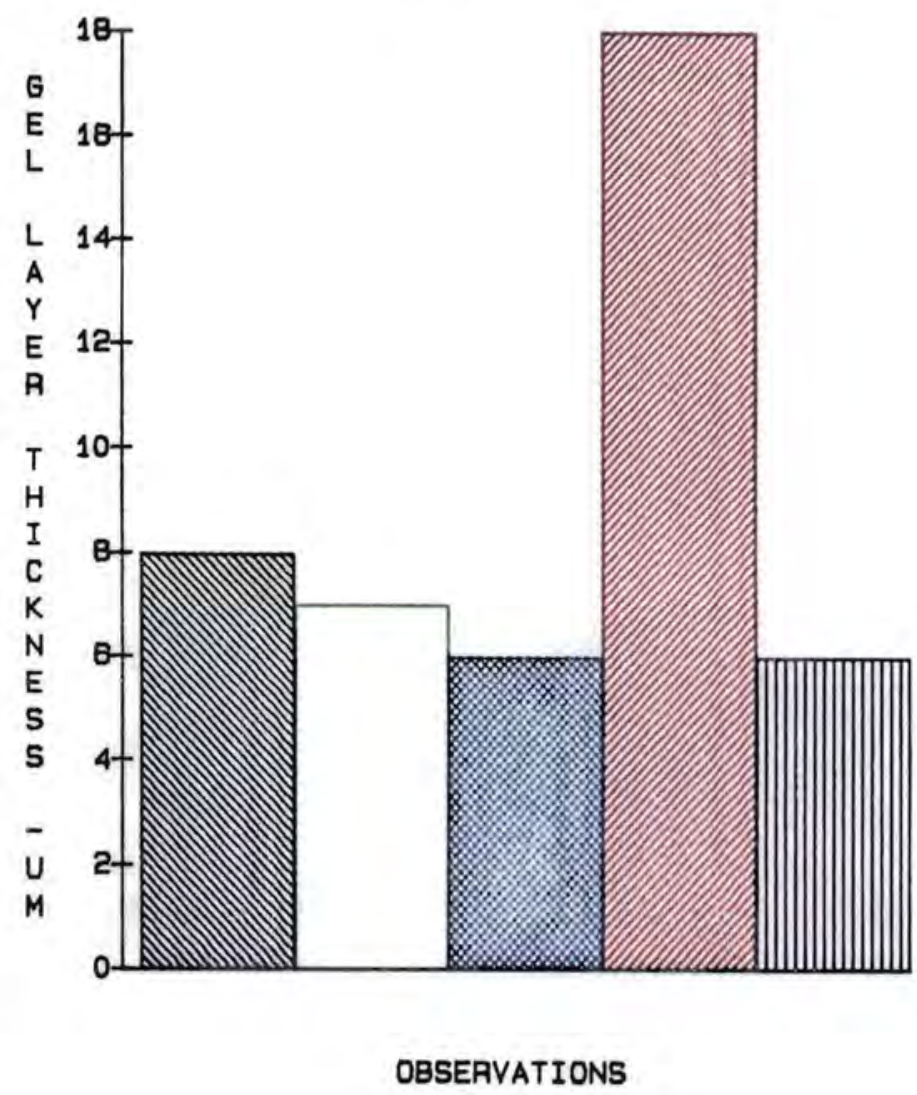

GLASS ONLY

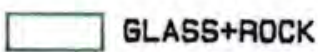

304L

VIIIIIA 1020 M STEEL

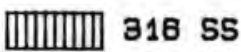

GEL LAYER THICKNESS FOR TESTS 1, 2, 83

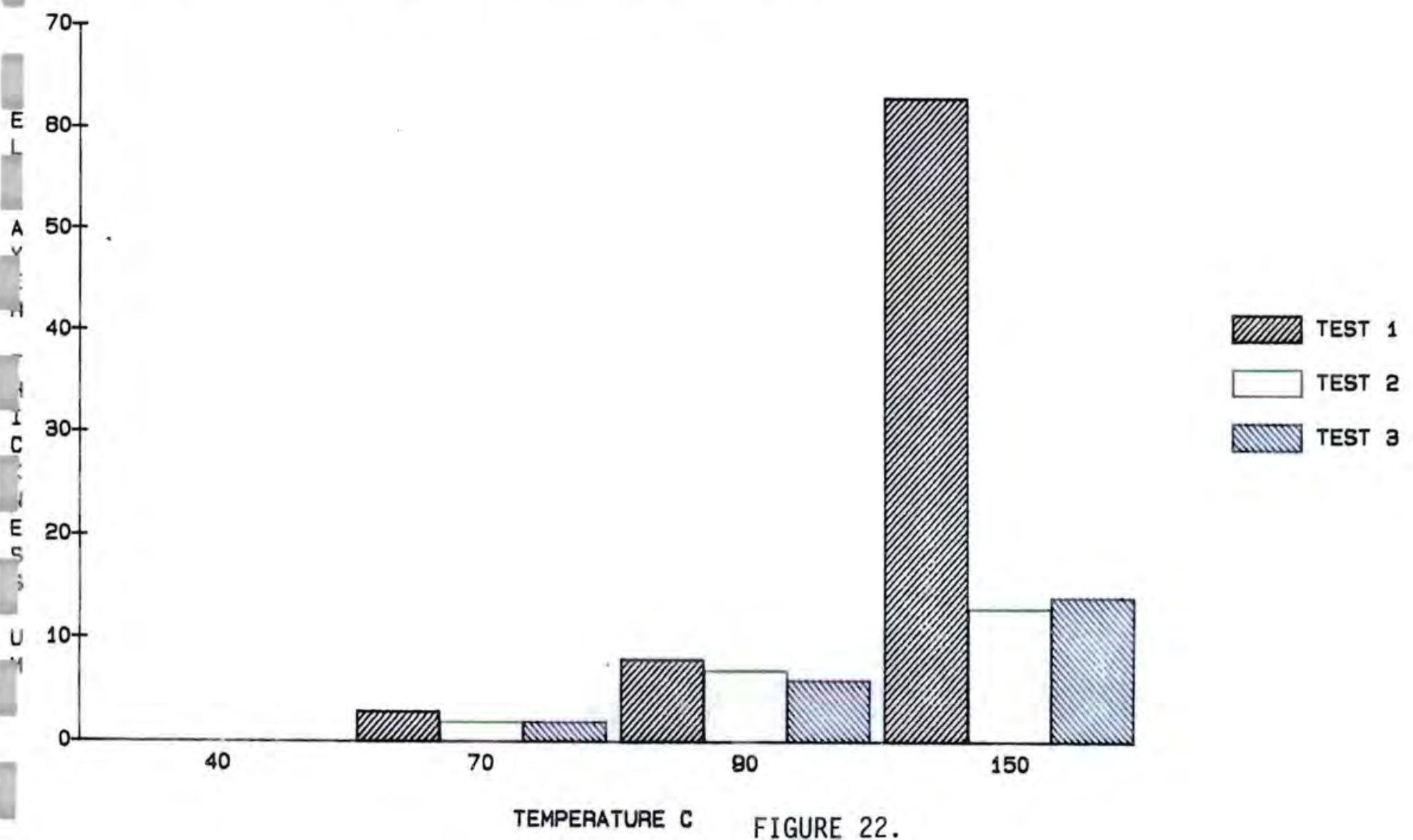





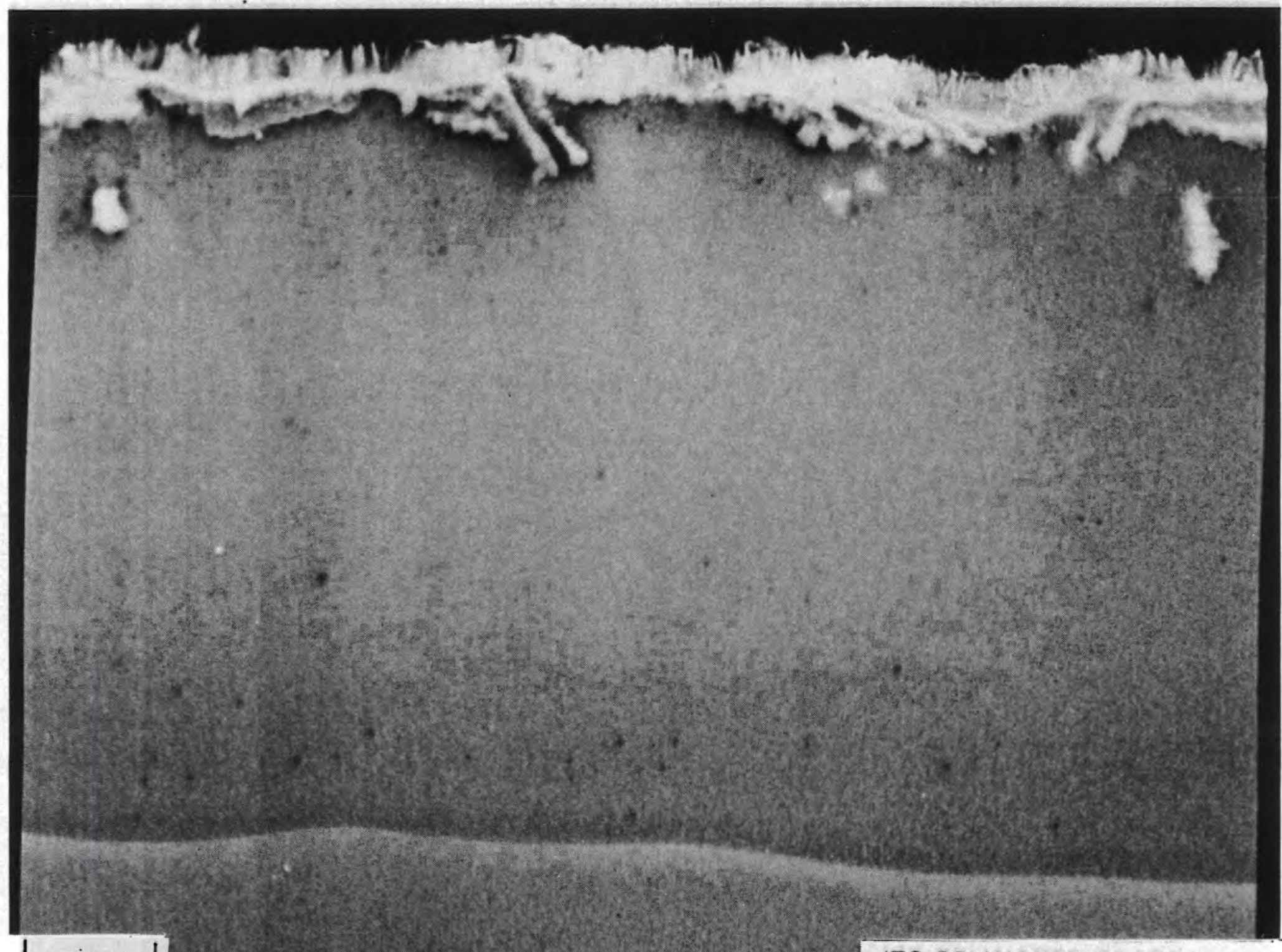




\section{EFFECT OF FILTERING \\ SILICON $90 \mathrm{C}$}

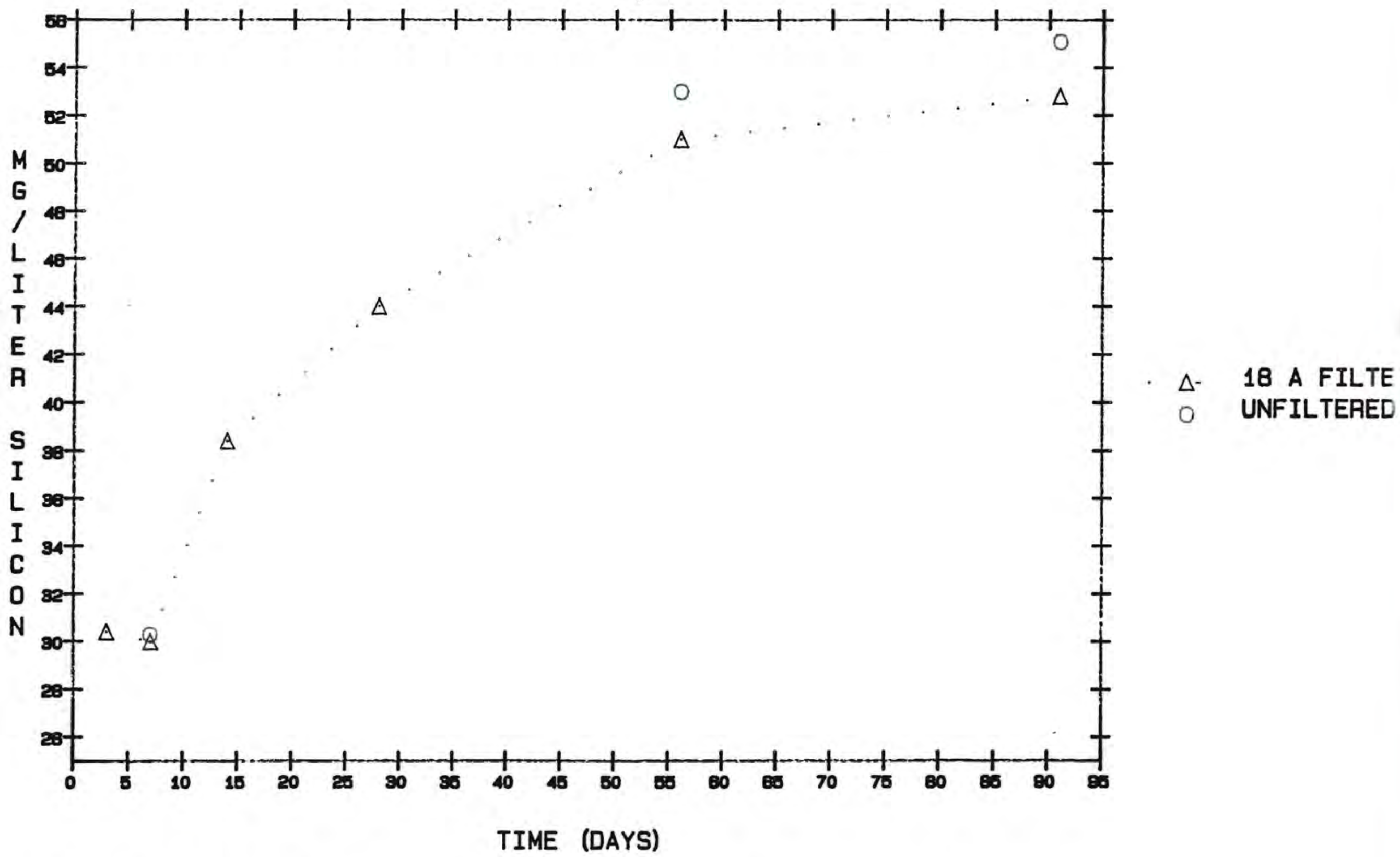


EFFECTS OF FILTERING

SILICON TEST3 9OC

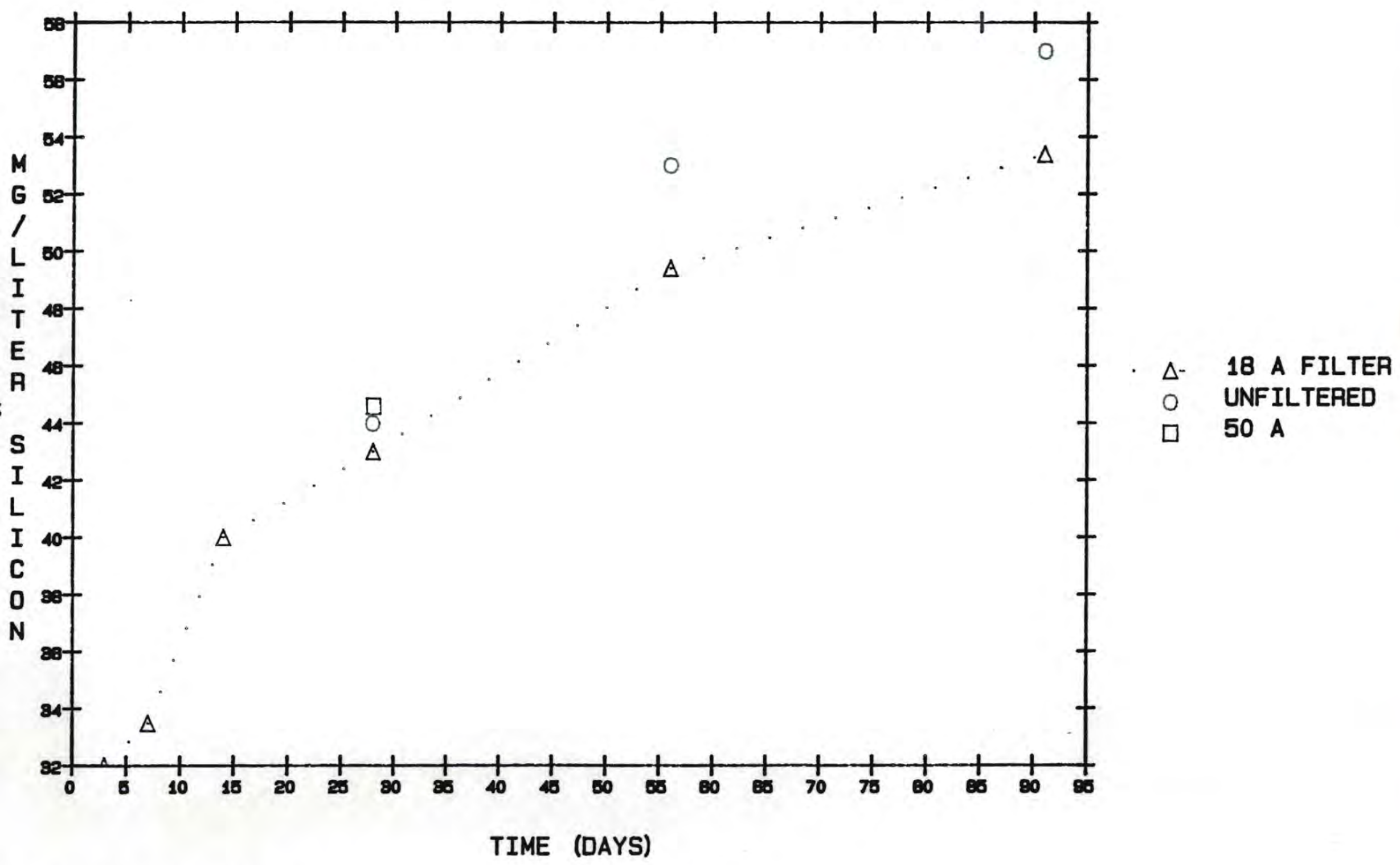


REPLICATE DATA SETS

TEST 2 - D, 90 C

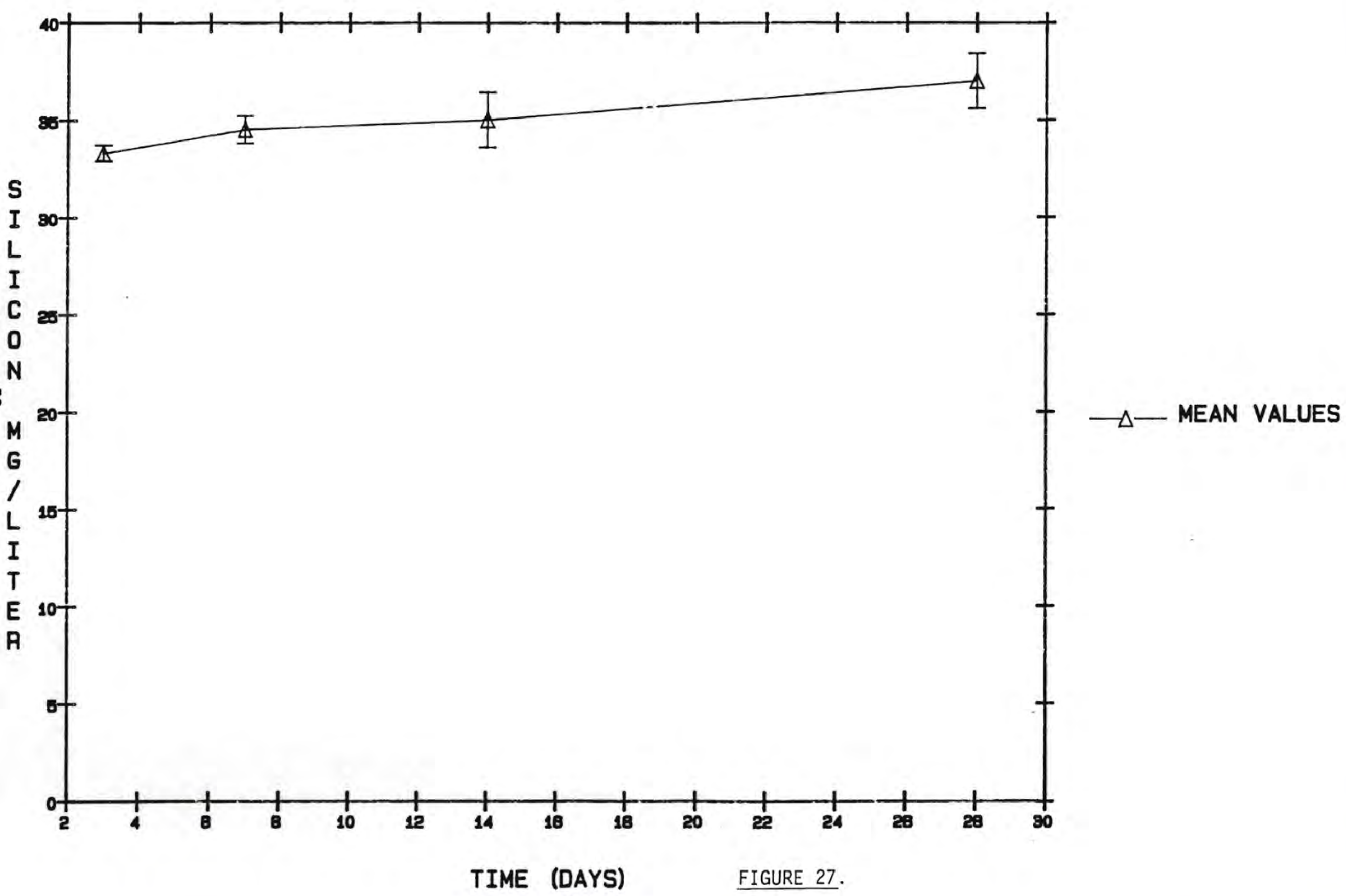




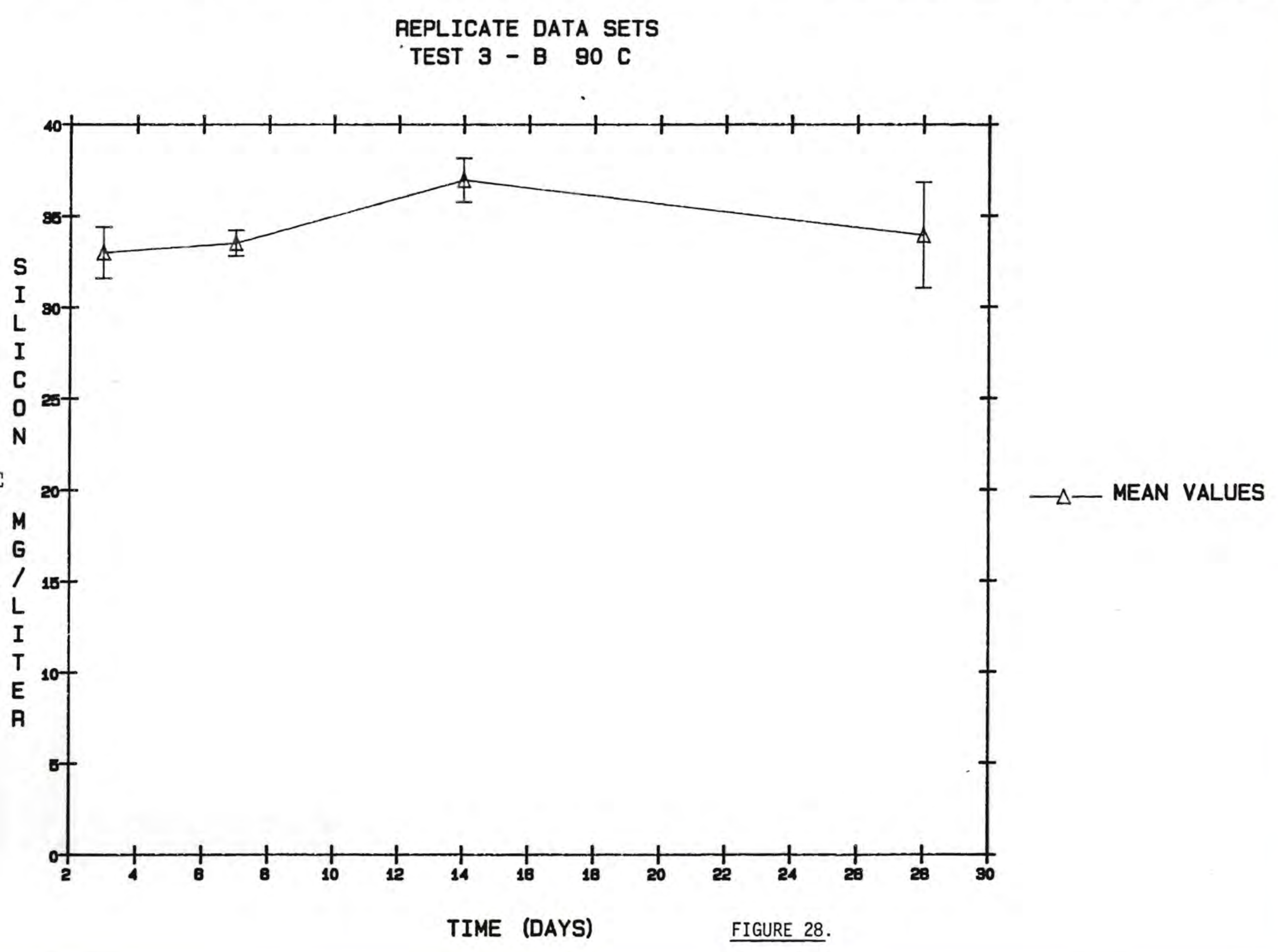


APPENDIX A

EXPERIMENTAL PROCEDURES 

INDEX FOR EXPERIMENTAL PROCEDURES

\author{
for \\ INVESTIGATION OF THE BEHAVIOR AND INTERACTIONS \\ OF TUFF WASTE PACKAGE COMPONENTS
}

Title

- Procedures for Determination of the Leach Rate and Interactive Reaction of LLNL Waste Package Materials
Identification

Date Author

$10-83$

G.R. Robinson LLNL-TP-1 


\section{PROCEDURES FOR DETERMINATION OF \\ THE LEACH RATE AND INTERACTIVE \\ REACTION OF LLNL WASTE \\ PACKAGE MATERIALS}

GR Robinson

October, 1983

I. Material Preparation

II. Specimen Preparation
A. Tuff Rock Monoliths
B. Tuff Rock Powders
C. $\mathrm{UO}_{2}$ Spiked (76-68) Glass Monoliths
D. UO- Spiked MCC (76-68) Glass Powders
E. 1020 Mild Steel
F. $316 \mathrm{SS}$
G. 304 L Steel

III. Experimental Procedure
A. Leaching Procedure
B. Specimen Handling
C. Sampling Procedure for Monolith Leachates
D. Sampling Procedure for Powdered Specimen Leachates

For Approval of

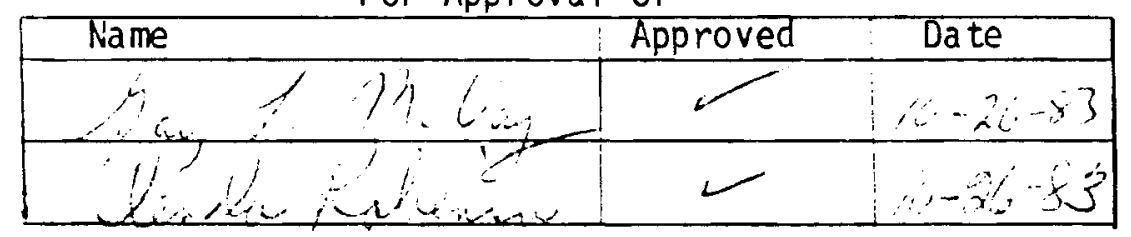




\section{TEST CONDITIONS, SAMPLE PREPARATION AND DESCRIPTION}

\section{MATERIAL PREPARATION}

The material tested was MCC $(76-68)$ borosilicate glass spiked with 3.7 vit\% $\mathrm{UO}_{2}$. This material was prepared by John Wald, Pacific Northwest Laboratory, 308 Building, on December 22, 1982, as follows:

Bars of previously melted and cast $76-68$ glass were prepared for doping by crushing and sieving to -100 mesh size fraction. The dopant solution was prepared by dissolving $\mathrm{UO}_{2}$ powder in nitric acid solution and diluting this with D.I. water to the desired concentration level. The dopant solution was added to the powdered glass, mechanicaliy mixed, and then heated on a hot plate until dry. The doped glass powder was then melted in a platinum crucible at $1100^{\circ} \mathrm{C}$ for 30 minutes prior to casting. The glass bars were cast into a steel bar mold assembly preheated on a hot plate. When the bars were sufficiently solidified, they were transferred to the auxiliary furnace where they were held at $500^{\circ} \mathrm{C}$ for 2 hours and furnace cooled to room temperature. The resultant material had the composition as shown in Table 1.1 found in the final report. This analysis was obtained from center cuts of two different bars from which specimens were selected.

\section{SPECIMEN PREPARATION}

\section{II.A. Tuff Rock Monoliths}

Sections of as-received Topopah Spring Tuff rock were cut to give surface areas of 150,200 , and $250 \mathrm{~mm}^{2}$. Specimen dimensions and calculated surface areas were recorded. These specimens were cut on a low-speed Buehler Isomet saw using a 200-grit (10w density) diamond saw blade using D.I. water as a collant. Geometric surface areas of glass and rock were kept the same for tests in which sample/rock ratio equals one. 


\section{II.B. Tuff Rock Powders}

One complete section of as-received tuff rock was covered with plastic bags and broken with a hammer until all the pieces were small enough to fit into a steel mortar and pestle. These pieces were crushed until all passed through a 10-mesh screen. Some metal contamination from the steel of the mortar was noticed and removed from the rock by sieving it across magnets. The -10 mesh powder was then transferred to a ball mill, and the entire section was processed until al1 material passed through a -60 mesh screen. The -60 mesh powder was used unwashed for Tests 1, 2 , and 3 and as described in Table 1 on Test 4 . Samples were prepared by weighing and the weights recorded. II.C. $\underline{U O}_{2}$ Spiked NCC $(76-68)$ Glass Monoliths

Six $1 / 2$ by $1 / 2$ by 3 -inch bars were used as received from John wald of Battelle, Pacific Northwest Laboratories, Richland, Wa shington. Specimens were cut with a Buehler low-speed saw using a low-density (200-grit) diamond saw blade. D.I. water vias used as the cutting medium and crystal bond as the adhesive. The outside surface of the as-formed bars was completely removed; and then from the remaining sections, specimens of 150,200 and $250 \mathrm{~mm}^{2}$ surface area were cut as needed and used at random. Only specimens within \pm 10 percent of the needed surface area were used.

\section{II.D. $\mathrm{UO}_{2}$ Spiked MCC (76-68) Glass Powders}

Defective (chipped), or specimens that failed to meet the $\pm 10 \%$ surface area requirements were used for the powdered specimens. These were placed in a steel mortar and pestle and crushed. The crushed glass was then sifted through $-40+80$ mesh sieves, a second set -100 +200 , and still a third, -200 . Surface areas vere calculated, summarized and recorded.

II.E. 1020 Mild Steel

Steel sheets were used as received from Stan Pittman of Battelle, Pacific Northwest Laboratory, Richland, Washington. Specimens were cut by staming from a .06" thick sheet. These were sonic cleaned in 
acetone, an absolute alcohol. These specimens were then acid etched in $1: 1 \mathrm{HCl}$ very quickly and then sonic cleaned in D.I. water to clean off an initial corroded layer on the surface of the metal. Bulk analysis is given in Table 2 and specimen dimensions, surface areas, and weights were recorded.

II.F. 316 SS

316 SS was used as received from E. S. Churman of the Battelle, Pacific Northwest Laboratory machine shop. The specimens were machined to the proper size from a 3-inch diameter cylinder labeled: CPTF, 316SST, HT No. 10536. Bulk analysis is presented by X-ray diffraction diagrams in Figure 1. Specimens were sonic cleaned in acetone, absolute alcoriol, and D.I. water.

II.F. 304 L Steel

$304 \mathrm{~L}$ specimens were used as received from E. S. Churman of the PNL machine shop. These were machined to the proper size from a bar labeled CF 304L ANN 008763 COND "01" SO H.T. AL1855 Mill Crucible 12-8. Bulk analysis is presented by $X$-ray profiles in Figure 1 and nominal compositions as listed in Table 2.

\section{EXPERIMENTAL PROCECURE}

Samples were prepared according to MCC - 1 and 3 as needed, SA/V values were calculated using Table 3 for glass powders.

\section{III.A. Leaching Procedure}

The leaching procedure used was as given in MCC-1 for LLNL Test 1 and $\mathrm{MCC}-1$ and MCC-3 where applicable in the other LLNL tests with the following exceptions:

1. Glass powders were used in all tests with $S A / V=100 \mathrm{~m}^{-1}$ and $400 \mathrm{~m}^{-1}$. These specimens were static leached and not agitated.

2. Powdered rock and rock monoliths were used in Tests 3 and 4 , along with the glass specimens being tested.

3. Metals were also added in Test III along with giass and rock specimens. 


\section{III.B. Specimen Handling}

All handling of specimens was done with tweezers and dust-free plastic gloves.

\section{III.C Sampling Procedure for Monolith Leachates}

1. An aliquot of tuff water was taken, the pH determined, and the aliquot discarded.

2. The volume of leachant was determined based on the geometric surface area of the specimen.

3. The calculated volume of leachant was placed in clean leach containers. The specimens were added and completely submersed. The leach container with contents was weighed and placed in a preheated environmental chamber at the test temperature. The da te and time were recorded.

4. After 24 hours, the leach containers were retightened. The testing period was controlled to within $2 \%$. At the appropriate time, the containers were removed, and the date and time recorded. The containers were allowed to cool, then we ighed, and the final weight recorded.

5. The specimens were removed from the leach containers and rinsed with high-purity water, $\mathrm{H}_{2} \mathrm{O}$ and ETOH $1: 1$, and ETOH. They were dried to constant weight, then weighed and stored in sealed, labeled containers.

$\epsilon$. An aliquot of the cooled leachate was taken and the $\mathrm{pH}$ mea sured.

7. An aliquot was removed for anion analysis.

8. If no material was observed as precipitated or sloughed from the specimen, another aliquot was taken and labeled unfiltered.

9. The solution was acidified to $1 \%, \mathrm{~V} / \mathrm{V}$, with conc. $\mathrm{HNO}_{3}$, allowed to stand at room temperature overnight, and submitted for ICP and CS analysis. (If solids were observed in the leachate, the solution was filtered using a $.45 \mu \mathrm{m}$ filter and then acidified.) 
10. Another aliquot was taken and filtered through an $18 \mathrm{~A}$ filter. This aliquot was acidified to $1 \%, V / V$, with conc. $\mathrm{HNO}_{3}$. The solution was allowed to stand at room temperature overnight anci submitted for ICP and CS analysis.

11. Another aliquot was taken and filtered through an $50 \mathrm{~A}$ filter. This aliquot was acidified to $1 \%, V / V$, with conc. $\mathrm{HNO}_{3}$. The solution was allowed to stand at room temperature overnight and submitted for ICP and Cs analysis.

12. All filters were dried, labeled, and saved. A few' were submitted for $x$-ray fluorescent analysis.

13. A very small aliquot was taken from the $18 \mathrm{~A}$ filtered solution for uranium analysis.

14. A $1 \% \mathrm{HNO}_{3}$ solution was added to the empty jars, to the level of the original leachant. These were placed in the test oven overnight. This acid strip solution was then submitted for ICP and CS analysis.

III.C Sampling Procedure for Powdered Specimen Leachates

1. The required glass powder weight was calculated by using the needed $S A / V$ ratio and the surface area per unit weight of the powder. Nominal rock power weights of $.1 \mathrm{~g}, 1 \mathrm{~g}$ and 4 grams were used.

2. Very small glass coupons were added (and included in SA/V calculations) for surface analysis.

3. The powdered specimen procedure was identical to the monolith procedure except that the leachate solution was always filtered using a $.45 \mu$ millipore filter after $\mathrm{pH}$ determination. The powder was collected, dried, and stored in sealed containers; then steps 7 to 14 of monolith procedure followed.

Samples for surface analysis were selected at the end of the test. Gel layer thickness determinations were made; ESCA scans and Sims depth profiles were made. 


\section{Calibrations and Standards}

- Moore and Wright (Sheffield) Ltd. Micro 2000 standard foil supplied by the manufacturer. HEDL 364-47-01-004

- Calibrated with a micrometer calibration device at the 3717-B Building Standard Laboratory, Hanford Engineering Development Laboratory, Richland, Wa. (a)

- 6-m. frequency.

Thermocouples:

- Type K (chromel-alumel).

- Calibrated against a platinum resistance thermometer over the temperature range of $25^{\circ}$ to $200^{\circ} \mathrm{C}$. HEDL 364-47-01-002

- as requested

Thermocouple Probe:

- John M. Fluke, co. Model 2190A-600

- Certified by the manufacturer against NBS standards.

- Calibrated against a platinum resistance thermometer over the range of $25^{\circ}$ to $200^{\circ} \mathrm{C}$. HEDL 364-7906-002.

- 6-mo. frequency

Balance:

Mettler P1 1200 HEDL 364-06-01-002

Mettler A3 HEDL 364-06-01-003

Mettler PC 4400 HEDL 364-06-01-001

Mettler PC H20t HEDL 364-06-01-001

- Calibrated against standard weights

- 1-mo. frequency

Volume:

- High precision pipettes calibrated, using the weight of distilled water contained HEDL 364-28-04-001

HEDL 364-28-04- 
TABLE A.1. STANDARD WATER LEACH ANALYSES

\begin{tabular}{lrrrrrrr} 
ELEMENTS & $8-3-83$ & $12-16-82$ & OBSERVATIONS \\
\hline NA & 86.100 & 88.700 & 86.800 & 91.500 & 88.300 & 88.2800 & 2.090933 \\
B & 48.800 & 50.700 & 50.400 & 50.200 & 49.800 & 49.9800 & 0.736206 \\
SI & 19.900 & 20.600 & 20.400 & 20.800 & 20.100 & 20.3600 & 0.364692 \\
SR & 5.070 & 5.100 & 5.200 & 5.280 & 5.190 & 5.1680 & 0.084083 \\
CS & 5.200 & 5.200 & 5.100 & 5.490 & 4.800 & 5.1580 & 0.247629 \\
ND & 2.070 & 2.110 & 2.140 & 2.160 & 2.160 & 2.1280 & 0.038341 \\
MO & 2.000 & 2.020 & 2.020 & 2.080 & 2.000 & 2.0240 & 0.032863 \\
CE & 1.860 & 1.910 & 1.920 & 1.970 & 2.000 & 1.9320 & 0.054498 \\
SH & 0.016 & 0.066 & 0.034 & 0.050 & 0.022 & 0.0376 & 0.020513 \\
AL & 0.014 & 0.053 & 0.029 & 0.034 & 0.026 & 0.0312 & 0.014237 \\
CA & 0.024 & 0.041 & 0.020 & 0.026 & 0.021 & 0.0264 & 0.008503 \\
FE & 0.011 & 0.022 & 0.002 & 0.003 & 0.044 & 0.0164 & 0.017387 \\
CR & 0.008 & 0.041 & 0.004 & 0.006 & 0.019 & 0.0156 & 0.015339 \\
AS & 0.006 & 0.030 & 0.007 & 0.010 & 0.017 & 0.0140 & 0.009925 \\
BA & 0.008 & 0.009 & 0.008 & 0.009 & 0.008 & 0.0084 & 0.000548 \\
LI & 0.002 & 0.011 & 0.000 & 0.002 & 0.007 & 0.0044 & 0.004506 \\
ZN & 0.004 & 0.005 & 0.005 & 0.003 & 0.005 & 0.0044 & 0.000894 \\
CU & 0.004 & 0.005 & 0.002 & 0.003 & 0.005 & 0.0038 & 0.001304 \\
MN & 0.000 & 0.007 & 0.000 & 0.001 & 0.004 & 0.0024 & 0.003050
\end{tabular}

Note: Blind standard samples from a stable and homogeneous solution are submitted for analysis twice a week. Table 6 is a random sampling of analyses over a nine-month period and is presented as a demonstration of accuracy to be expected from PNL ICP analysis. 


\section{LEACH CONTAINERS}

Three different styles of leach containers were used in the LLNL waste package tests.

1. No. 0102 Jar, 2 fl. oz/ $60 \mathrm{ml}$ PFA labware from Savillex. $\left(40,70,90^{\circ} \mathrm{C}\right.$ short-term 3 to 28 -day tests)

2. No. 561 PFA labware jar from Savillex.

$\left(40,70,90^{\circ} \mathrm{C}\right.$ long-term 56 to 182 -day tests)

3. No. 4745 Teflon-lined acid digestion bombs from Parr Instrument Company for $150^{\circ} \mathrm{C}$ tests.

Glass specimens were held near the centroid of the leach volume by a PFA Teflon support screen in all previously listed leach vessels. Metal and rock samples were placed on the floor of the containers--always separated from the glass specimens. A11 powders were placed on the floor of the containers.

Leach containers and sample bottles were cleaned according to MCC-1 procedures. 
APPENDIX B

SAMPLE DIMENSIONS 

LLNL WASTE PACKAGE TESTS

LABEL ING FORNIAT

\author{
[Test] [Year] [Set] [Temp] [Subset] [Time] [Solution]/[or Material] \\ Test - TU (tuff) LLNL Waste Package Tests \\ Year $\quad-1983$ \\ Set - I (glass only), II (glass + rock), III (glass + rock + meta1), \\ IV (rock only) \\ Temp. $\quad-40,70,90$ or $150^{\circ} \mathrm{C}$ \\ Subset - Subset with SA/V or sample/rock varied (See Table 4) \\ Time - Test matrix $3,7,14,28,56,91,182$ days \\ Solution: UN - unfiltered \\ AS - acid strip \\ $18 \mathrm{~A}-18 \mathrm{~A}$ filter \\ $50 A-50 A$ filter \\ $10 \mathrm{X}$ - 10X dilution \\ DUP - duplicate \\ $.45 \mu \mathrm{m}-.45 \mu \mathrm{m}$ filter \\ N.D. - not detected \\ Material - G(glass), R (rock), M (metal)
}

Example: TU83-II90-C14AS represents a tuff waste package interactive test conducted in 1983 containing glass + tuff rock at $90^{\circ} \mathrm{C}$. Sample conditions and ratios are described in Table 4 under II-90C. The tests were conducted for 14 days, and these particular results are for the container acid strip solutions. 
SPECIMEN DEMINSIONS FOR LLNL MATRIX

\begin{tabular}{|c|c|c|c|c|c|}
\hline $\begin{array}{l}\text { TEST NO. I } \\
\text { GLASS SPECIMENS }\end{array}$ & $\begin{array}{l}\text { X AVE. } \\
(\mathrm{mm})\end{array}$ & $\begin{array}{l}\text { Y AVE. } \\
(\mathrm{mm})\end{array}$ & $\begin{array}{l}\text { Z AVE. } \\
(\mathrm{mm})\end{array}$ & $\begin{array}{l}\text { SIRFACE AREA } \\
\text { (mn }) 2\end{array}$ & $\begin{array}{l}\text { SPECIMEN WT. } \\
(\mathrm{gm})\end{array}$ \\
\hline TU83-I40-3G & 4.1715 & 10.4030 & 3.6930 & 194.440 & 0.4828 \\
\hline $\begin{array}{l}\text { TU83-I40-7G } \\
\text { TU83-I40-14G }\end{array}$ & 5.5785 & 9.9755 & 2.4585 & 187.800 & 0.3969 \\
\hline TU83-I 40-28G & 4.9080 & 9.9775 & 3.5145 & 202.600 & 0.4615 \\
\hline TU83-I40-56G & 7.2585 & 6.4020 & 5.5600 & 244.840 & 0.6982 \\
\hline TU83-I40-91G & 4.8640 & 5.0530 & 10.0110 & 247.710 & 0.6907 \\
\hline TU83-I 40-182G & 1.8255 & 9.5280 & 9.1435 & 242.408 & 0.4261 \\
\hline TU83-I70-3G & 4.1975 & 3.6845 & 10.5185 & 196.740 & 0.4603 \\
\hline TU83-I70-7G & 4.9240 & 9.8800 & 3.2645 & 194.000 & 0.4729 \\
\hline TU83-I 70-14G & & & & & \\
\hline TU83-I 70-28G & 5.3785 & 9.7655 & 3.3725 & 207.200 & 0.5287 \\
\hline TU83-I 70-56G & 6.8830 & 4.3270 & 8.9360 & 259.910 & 0.7635 \\
\hline TU83-I70-91G & 4.2120 & 5.1830 & 9.9980 & 231.520 & 0.6225 \\
\hline TU83-I 70-182G & 9.5030 & 9.1100 & 1.7720 & 239.100 & 0.4478 \\
\hline TU83-I90-3G & & & & & 0.4609 \\
\hline TU83-I90-7G & 4.9000 & 9.9540 & 3.2755 & 194.900 & 0.4677 \\
\hline TU83-I90-14G & 5.2340 & 9.7800 & 3.4175 & 205.200 & 0.5024 \\
\hline TU83-I90-28G & 6.0700 & 9.4040 & 2.2925 & 185.100 & 0.3797 \\
\hline TU83-I90-56G & 9.1285 & 9.4961 & 1.7850 & 239.870 & 0.4445 \\
\hline TU83-I90-91G & 4.9650 & 5.2040 & 10.0540 & 256.160 & 0.6798 \\
\hline TU83-I90-182G & 6.8820 & 4.3650 & 8.4670 & 250.530 & 0.7050 \\
\hline TU83-I150-3G & 9.1050 & 3.9610 & 2.5960 & 139.980 & 0.2803 \\
\hline TU83-I150-7G & 9.0980 & 2.6390 & 3.9600 & 140.976 & 0.2843 \\
\hline TU83-I150-14G & 9.0910 & 3.9640 & 2.7360 & 143.520 & 0.2919 \\
\hline TU83-I 150-28G & 9.4980 & 3.9500 & 2.5630 & 143.940 & 0.2731 \\
\hline TU83-I 150-56G & 8.8730 & 4.6045 & 2.7110 & 154.786 & 0.2948 \\
\hline TL83-I150-91G & 8.7795 & 4.6210 & 2.5370 & 149.119 & 0.2764 \\
\hline TU83-I 150-182G & 8.8295 & 4.5800 & 2.4995 & 147.912 & 0.2927 \\
\hline
\end{tabular}


SPECIMEN DEMINSIONS FOR LLNL MATRIX

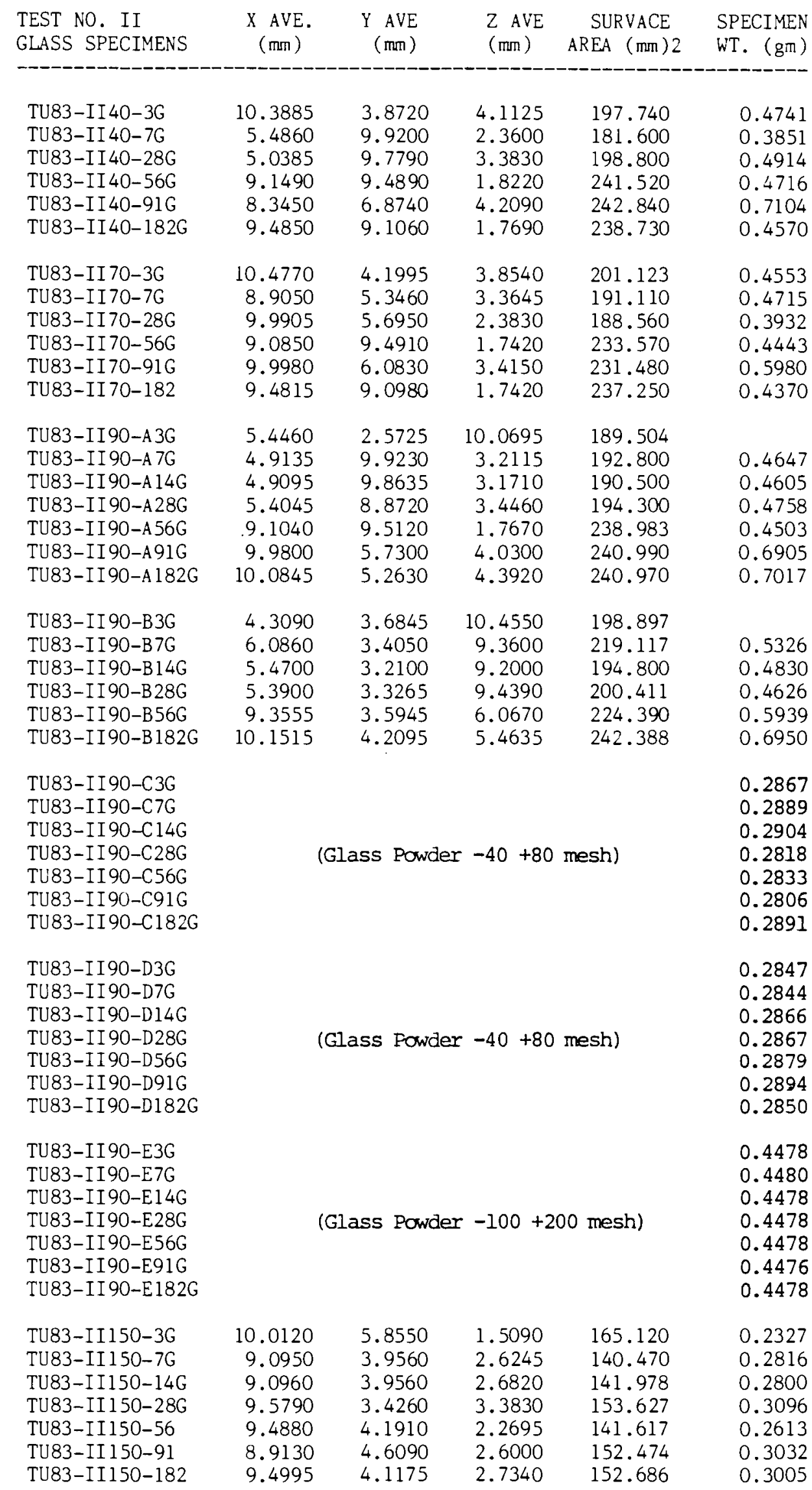


SPECIMEN DIMENSIONS USED IN LLNL, STUDY

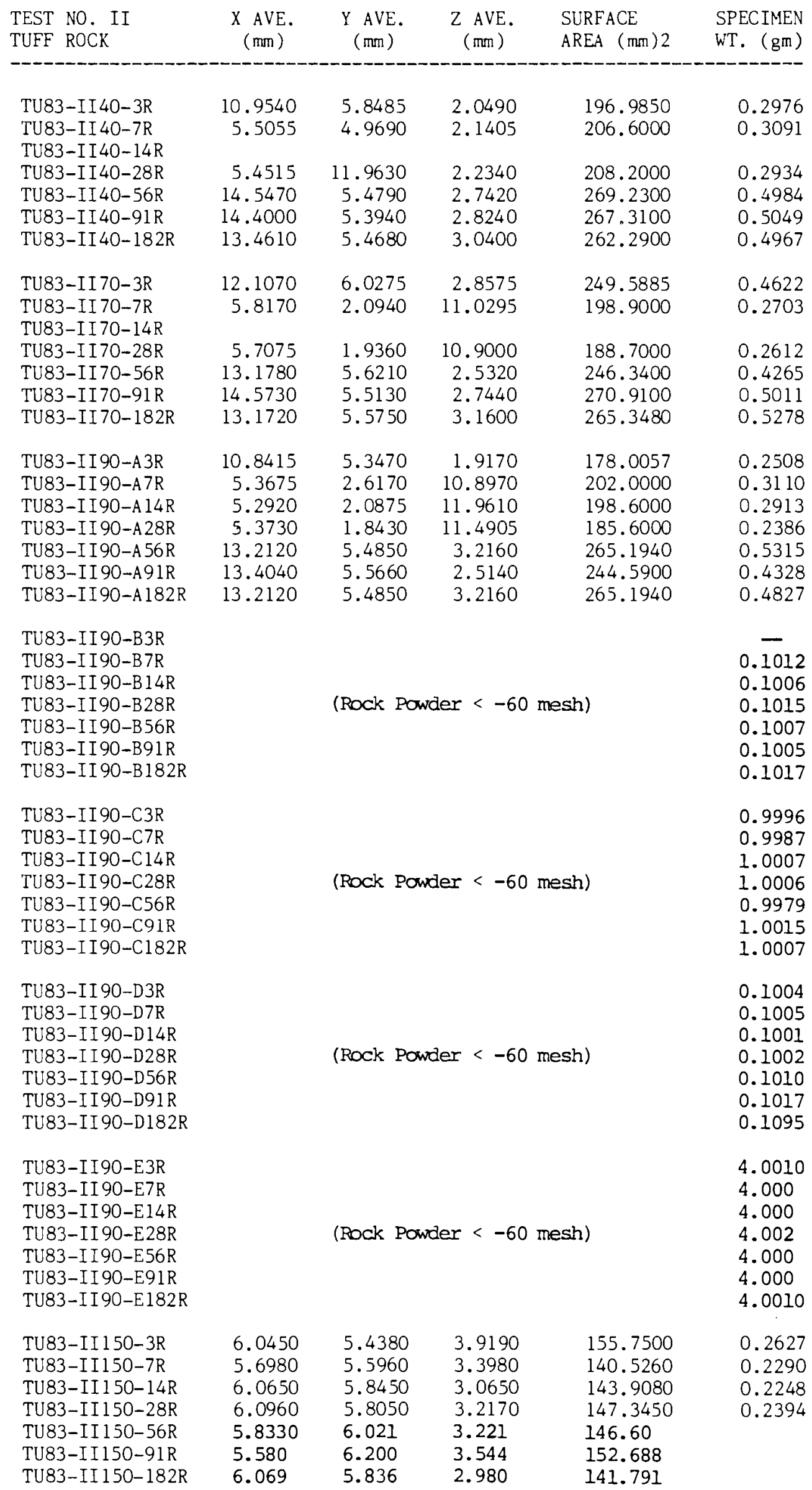


DIMENSIONS OF SPECIMENS USED FOR LLNL STUDY

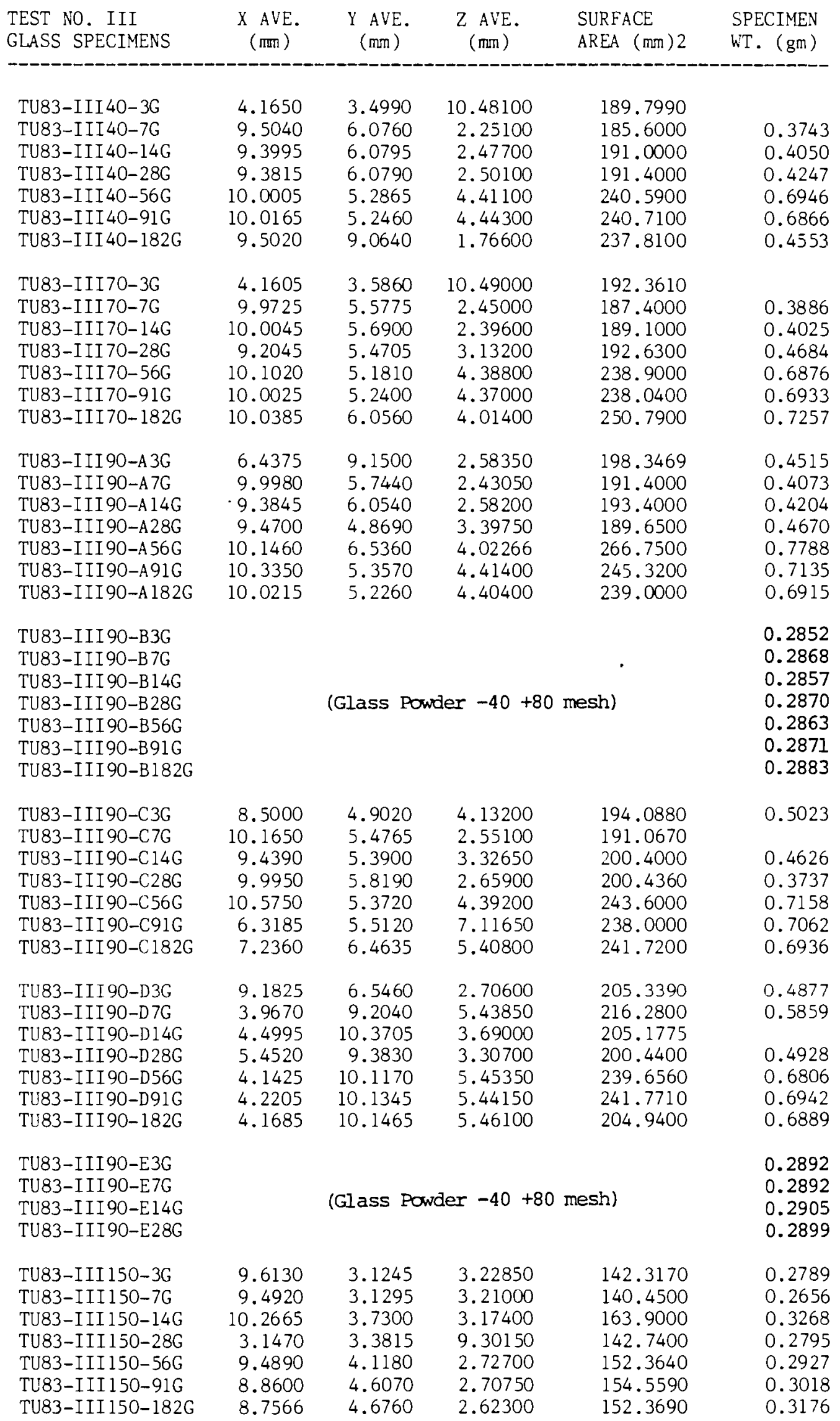


DIMENSIONS OF SPECIMENS USED IN LLNL MATRIX

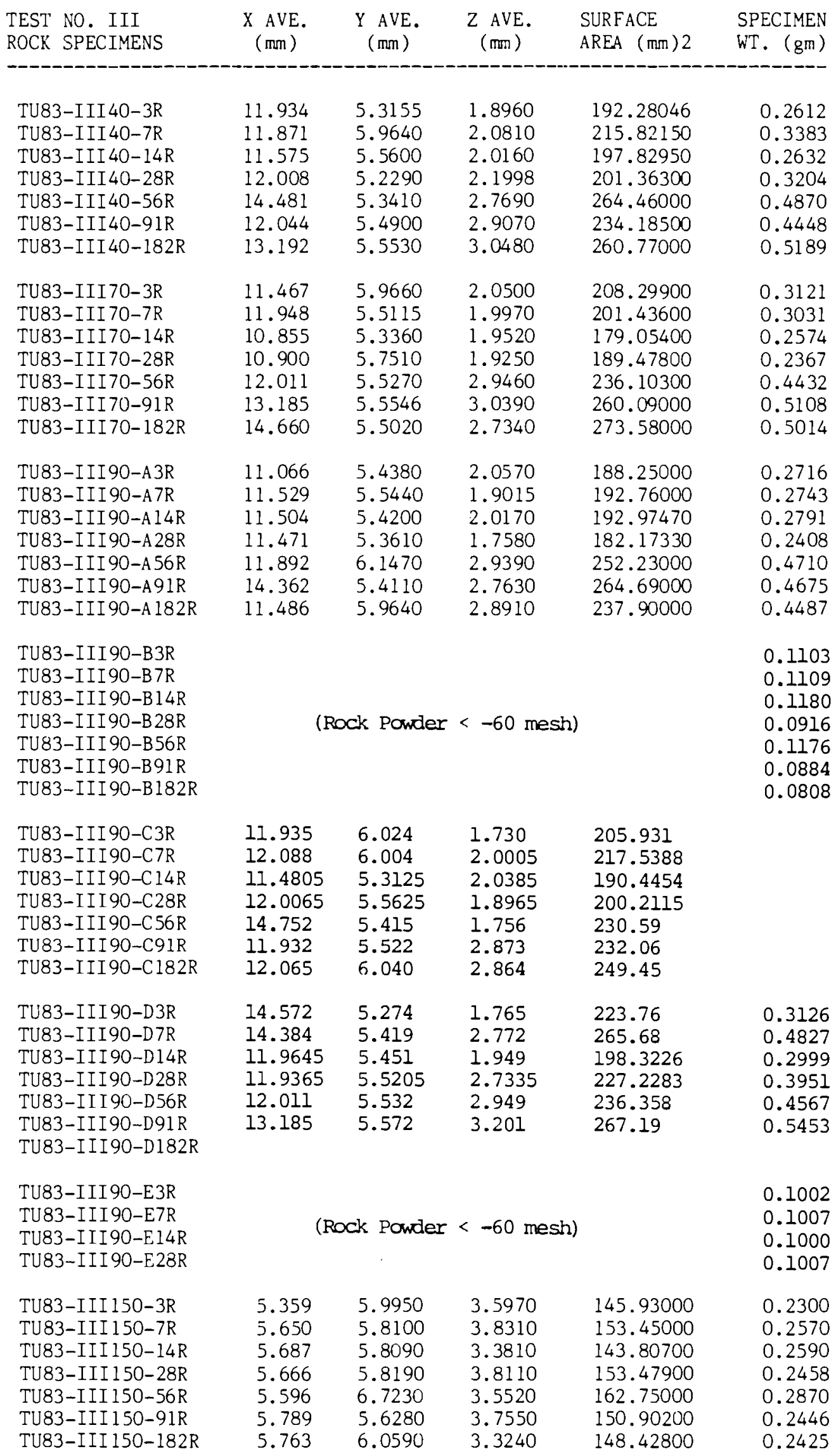


DIMERSIJUS DF SOEOHE:US FOR LLUL MATEY

\begin{tabular}{|c|c|c|c|c|c|c|}
\hline $\begin{array}{l}\text { TEST W. III } \\
\text { METAL SPECIMENS }\end{array}$ & $\underset{\substack{x \\
(\mathrm{~m} m)}}{(\mathrm{m})}$ & $\begin{array}{l}\text { V }+ \text { VIE. } \\
(\mathrm{mm})\end{array}$ & 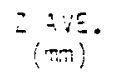 & $\begin{array}{l}\text { SURFACE } \\
\text { AREA }(m) 2\end{array}$ & $\begin{array}{l}\text { YETAL } \\
\text { TYPE }\end{array}$ & $\begin{array}{l}\text { SFECIME: } \\
\text { VT: (gm) }\end{array}$ \\
\hline 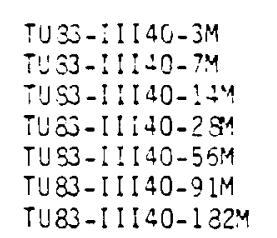 & $\begin{array}{r}7.243 \\
7.221 \\
7.275 \\
7.202 \\
10.159 \\
10.138 \\
10.173\end{array}$ & $\begin{array}{l}5.107 \\
4.701 \\
5.132 \\
5.017 \\
4.400 \\
5.123 \\
5.105\end{array}$ & $\begin{array}{l}5.059 \\
5.119 \\
4.509 \\
1.303 \\
5.115 \\
4.775 \\
5.096\end{array}$ & $\begin{array}{l}199.1840 \\
190.4070 \\
194.0010 \\
191.5950 \\
238.3370 \\
249.6160 \\
259.6200\end{array}$ & $\begin{array}{l}304 L \\
304 L \\
304 L \\
304 L \\
304 L \\
304 L \\
304 L\end{array}$ & $\begin{array}{l}1.4530 \\
1.3335 \\
1.3898 \\
1.3730 \\
1.7833 \\
1.0285 \\
2.0827\end{array}$ \\
\hline 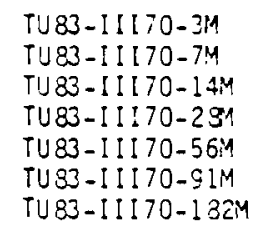 & $\begin{array}{r}7.228 \\
7.248 \\
7.270 \\
7.267 \\
10.277 \\
10.290 \\
10.257\end{array}$ & $\begin{array}{l}5.090 \\
4.943 \\
5.104 \\
5.099 \\
5.017 \\
5.045 \\
5.037\end{array}$ & $\begin{array}{l}4.379 \\
5.109 \\
4.846 \\
4.999 \\
5.082 \\
5.048 \\
5.115\end{array}$ & $\begin{array}{l}193.7800 \\
196.2213 \\
194.1400 \\
197.7440 \\
258.5500 \\
258.6480 \\
257.7500\end{array}$ & $\begin{array}{l}304 L \\
304 L \\
304 L \\
304 L \\
304 L \\
304 L \\
304 L\end{array}$ & $\begin{array}{l}1.3924 \\
1.3893 \\
1.3883 \\
1.3820 \\
2.0516 \\
2.0399 \\
2.0487\end{array}$ \\
\hline 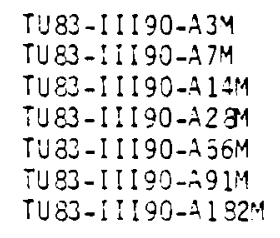 & $\begin{array}{r}7.279 \\
7.161 \\
7.286 \\
7.338 \\
10.258 \\
4.605 \\
4.808\end{array}$ & $\begin{array}{l}4.879 \\
5.085 \\
5.124 \\
5.082 \\
4.947 \\
5.105 \\
5.126\end{array}$ & $\begin{array}{r}5.107 \\
5.034 \\
4.520 \\
4.729 \\
4.908 \\
10.203 \\
10.202\end{array}$ & $\begin{array}{l}195.2100 \\
196.1200 \\
138.3425 \\
192.0520 \\
250.7400 \\
245.1790 \\
251.9800\end{array}$ & $\begin{array}{l}304 \mathrm{~L} \\
304 \mathrm{~L} \\
304 \mathrm{~L} \\
304 \mathrm{~L} \\
304 \mathrm{~L} \\
304 \mathrm{~L} \\
304 \mathrm{~L}\end{array}$ & $\begin{array}{l}1.4070 \\
1.4234 \\
1.3299 \\
1.3976 \\
1.9379 \\
1.3884 \\
1.9548\end{array}$ \\
\hline $\begin{array}{l}\text { TU } 83-11190-33 i 4 \\
\text { TU } 83-i:: 90-37: 4 \\
\text { TU } 33-\text { II } 190-814 \text { M }\end{array}$ & $\begin{array}{l}25.374 \\
25.352 \\
25.380 \\
25.360 \\
25.494 \\
25.517 \\
25.406 \\
25.365 \\
25.472 \\
25.381 \\
25.342 \\
25.396 \\
25.363 \\
25.381 \\
25.502 \\
25.386 \\
25.391 \\
25.401 \\
25.399 \\
25.368 \\
25.366 \\
25.375 \\
25.466 \\
25.362 \\
25.386 \\
25.370 \\
25.404 \\
25.378\end{array}$ & $\begin{array}{l}5.166 \\
5.128 \\
5.142 \\
5.158 \\
5.363 \\
5.165 \\
5.157 \\
5.162 \\
5.247 \\
5.158 \\
5.149 \\
5.120 \\
5.161 \\
5.143 \\
5.334 \\
5.145 \\
5.258 \\
5.164 \\
5.201 \\
5.160 \\
5.108 \\
5.150 \\
5.159 \\
5.170 \\
5.157 \\
5.154 \\
5.153 \\
5.152\end{array}$ & $\begin{array}{l}4.058 \\
4.016 \\
3.988 \\
4.374 \\
4.746 \\
4.294 \\
4.147 \\
4.073 \\
4.117 \\
4.110 \\
4.000 \\
4.040 \\
4.142 \\
4.396 \\
3.686 \\
3.953 \\
3.952 \\
4.169 \\
4.670 \\
4.089 \\
2.931 \\
4.262 \\
4.011 \\
4.669 \\
4.163 \\
4.114 \\
4.001 \\
4.339\end{array}$ & $\begin{array}{l}509.9570 \\
504.7560 \\
504.4500 \\
528.6157 \\
506.4130 \\
527.1190 \\
515.5270 \\
510.5890 \\
520.2430 \\
512.8900 \\
504.9300 \\
506.6230 \\
514.6577 \\
529.4450 \\
502.3263 \\
502.9140 \\
509.2921 \\
517.2220 \\
550.0440 \\
511.4860 \\
498.7560 \\
521.9440 \\
508.4610 \\
547.2600 \\
516.1617 \\
512.6740 \\
507.1410 \\
526.4340\end{array}$ & $\begin{array}{l}304 \mathrm{~L} \\
304 \mathrm{~L} \\
304 \mathrm{~L} \\
304 \mathrm{~L} \\
304 \mathrm{~L} \\
304 \mathrm{~L} \\
304 \mathrm{~L} \\
394 \mathrm{~L} \\
304 \mathrm{~L} \\
304 \mathrm{~L} \\
304 \mathrm{~L} \\
304 \mathrm{~L} \\
304 \mathrm{~L} \\
304 \mathrm{~L} \\
304 \mathrm{~L} \\
304 \mathrm{~L} \\
304 \mathrm{~L} \\
304 \mathrm{~L} \\
304 \mathrm{~L} \\
304 \mathrm{~L} \\
304 \mathrm{~L} \\
304 \mathrm{~L} \\
304 \mathrm{~L} \\
304 \mathrm{~L} \\
304 \mathrm{~L} \\
304 \mathrm{~L} \\
304 \mathrm{~L} \\
304 \mathrm{~L}\end{array}$ & $\begin{array}{l}4.1406 \\
4.0812 \\
4.0727 \\
4.4527 \\
4.5726 \\
4.3750 \\
4.2082 \\
4.1556 \\
4.1092 \\
4.2151 \\
4.0718 \\
4.0775 \\
4.2327 \\
4.4734 \\
3.7725 \\
4.0255 \\
4.0195 \\
4.2598 \\
1.6535 \\
4.1716 \\
3.9251 \\
4.3238 \\
4.0668 \\
4.7879 \\
4.2409 \\
4.1933 \\
4.0926 \\
4.4215\end{array}$ \\
\hline 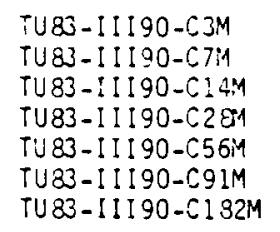 & $\begin{array}{r}8.500 \\
10.056 \\
10.077 \\
9.381 \\
9.859 \\
9.841 \\
10.439\end{array}$ & $\begin{array}{r}4.902 \\
7.578 \\
7.515 \\
7.415 \\
10.151 \\
9.823 \\
10.164\end{array}$ & $\begin{array}{l}4.132 \\
1.482 \\
1.476 \\
1.463 \\
1.483 \\
1.471 \\
1.464\end{array}$ & $\begin{array}{l}194.0880 \\
204.6700 \\
204.4600 \\
197.1430 \\
259.5000 \\
251.1870 \\
272.5200\end{array}$ & 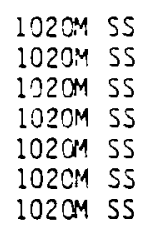 & $\begin{array}{l}0.7948 \\
0.8368 \\
0.8271 \\
0.7975 \\
1.0913 \\
1.0606 \\
1.1473\end{array}$ \\
\hline $\begin{array}{l}\text { TU } 83-[1190-03 M \\
\text { TU } 83-[1190-074 \\
\text { TU } 83-[1190-014 M \\
\text { TU } 83-[1190-0234 \\
\text { TU } 83-[1190-050 M \\
\text { TU } 33-11190-091 M \\
\text { TU } 83-11190-0132 M\end{array}$ & $\begin{array}{l}7.545 \\
5.098 \\
5.112 \\
5.101 \\
5.029 \\
5.048 \\
5.036\end{array}$ & $\begin{array}{l}5.003 \\
5.157 \\
5.102 \\
5.146 \\
5.157 \\
5.102 \\
5.072\end{array}$ & $\begin{array}{r}5.110 \\
7.580 \\
7.572 \\
7.607 \\
10.235 \\
10.143 \\
10.119\end{array}$ & $\begin{array}{l}205.7584 \\
208.0466 \\
208.3974 \\
208.3974 \\
250.3765 \\
257.4127 \\
255.6509\end{array}$ & $\begin{array}{ll}316 & 5 S \\
316 & S S \\
315 & S S \\
316 & S S \\
315 & S S \\
316 & S S \\
316 & S S\end{array}$ & $\begin{array}{l}1.5550 \\
1.5520 \\
1.5540 \\
2.0594 \\
2.0214 \\
2.0089\end{array}$ \\
\hline TU $83-11190-\varepsilon 3 M$ & $\begin{array}{r}10.010 \\
9.851 \\
7.579 \\
10.258 \\
10.576 \\
10.035 \\
10.017 \\
10.072\end{array}$ & $\begin{array}{r}10.263 \\
10.409 \\
9.906 \\
10.074 \\
9.951 \\
10.116 \\
10.282 \\
7.477\end{array}$ & $\begin{array}{l}1.471 \\
1.479 \\
1.471 \\
1.454 \\
1.468 \\
1.438 \\
1.461 \\
1.468\end{array}$ & $\begin{array}{l}265.1030 \\
254.8000 \\
201.5960 \\
265.8040 \\
270.7500 \\
260.9820 \\
255.3030 \\
202.1405\end{array}$ & $\begin{array}{l}1020 \text { SS } \\
1020 \text { SS } \\
1020 \text { S5 } \\
1020 \text { SS } \\
1020 \text { SS } \\
1020 \text { SS } \\
1020 \text { SS } \\
1020 \text { SS }\end{array}$ & \\
\hline
\end{tabular}


JIMENSE: IS OF SPESIMENS FJR LLUL WTFIX

\begin{tabular}{|c|c|c|c|c|c|c|}
\hline $\begin{array}{l}\text { TEST NO. } 1 \text { II } \\
\text { METAL SPECIMENS }\end{array}$ & $\underset{(\pi, \pi)}{x \rightarrow 1 E .}$ & $\begin{array}{l}\text { y ive. } \\
\text { (mm) }\end{array}$ & Z AVE. & $\begin{array}{l}\text { SURFACE } \\
\text { AREA (TM)? }\end{array}$ & $\begin{array}{l}\text { METHL } \\
\text { TYPS }\end{array}$ & $\begin{array}{l}\text { SPEC?ME: } \\
\text { NT. (gm) }\end{array}$ \\
\hline \multirow{10}{*}{ TU83-111 Э0-E7M } & 10.239 & $10.02 \vdots$ & 1.433 & $26 j .16 \equiv 0$ & $10205 j$ & \\
\hline & 9.946 & 7.425 & 1.453 & 198.3360 & $: 020 \mathrm{S5}$ & \\
\hline & 10.078 & 10.029 & 1.483 & 251.7800 & $1020 \mathrm{S3}$ & \\
\hline & 10.213 & 10.141 & 1.468 & 266.8990 & 1020 SS & \\
\hline & 10.122 & 10.135 & 1.454 & 254.0800 & 102053 & \\
\hline & 10.000 & 10.325 & 1.436 & 264.8700 & $1020 \mathrm{SS}$ & \\
\hline & 10.017 & 5.023 & 1.425 & 143.4940 & 1020 SS & \\
\hline & 10.079 & 5.082 & 1.448 & 146.5790 & 1020 SS & \\
\hline & 9.872 & 7.298 & 1.459 & 194.1937 & $1020 \leqq 5$ & \\
\hline & & & & & & 8.2618 \\
\hline \multirow[t]{8}{*}{ TUß3-IIIGO-EIHM } & 10.197 & 10.081 & 1.464 & 264.9660 & 1020 SS & \\
\hline & 10.149 & 10.361 & 1.456 & 270.0320 & 1023 SS & \\
\hline & 10.217 & 10.056 & 1.466 & 264.9250 & 1020 SS & \\
\hline & 10.058 & 10.293 & 1.432 & 265.3390 & 1020 SS & \\
\hline & 10.216 & 10.009 & 1.464 & 263.7230 & 1020 SS & \\
\hline & 10.070 & 7.508 & 1.560 & 206.0500 & 1020 SS & \\
\hline & 7.542 & 9.935 & 1.485 & 201.7600 & 1020 SS & \\
\hline & 9.995 & 10.229 & 1.441 & 252.7630 & 102055 & \\
\hline \multirow[t]{11}{*}{ 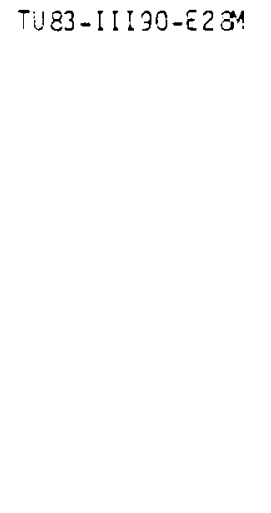 } & 10.040 & 5.056 & 1.460 & 145.6040 & $1020 \mathrm{SS}$ & \\
\hline & 10.157 & 10.351 & 1.469 & 270.5227 & 1020 SS & \\
\hline & 9.842 & 7.553 & 1.468 & 199.7450 & 1020 SS & \\
\hline & 10.019 & 10.205 & 1.475 & 264.1480 & 102055 & \\
\hline & 9.996 & 7.360 & 1.444 & 197.2650 & 1020 SS & \\
\hline & 10.044 & 7.328 & 1.470 & 198.2780 & 1020 SS & \\
\hline & 9.954 & 7.440 & 1.466 & 199.1150 & 1020 SS & \\
\hline & 9.899 & 7.543 & 1.469 & 200.5809 & 1020 SS & \\
\hline & 9.387 & 7.354 & 1.448 & 195.3480 & $1020 \mathrm{SS}$ & \\
\hline & 10.042 & 4.964 & 1.465 & 143.6040 & 102055 & \\
\hline & & & & & & 8.1580 \\
\hline TU $83-[! I 150-3 M$ & 5.080 & 5.063 & 5.080 & 154.4930 & $304 L$ & 0.9348 \\
\hline TU83-IIII50-7M & 5.027 & 5.090 & 5.004 & 152.4460 & $304 \mathrm{~L}$ & 0.9934 \\
\hline TU $83-$ I I I $150-144$ & 5.023 & 4.813 & 5.024 & 147.1840 & $304 L$ & 0.9609 \\
\hline$T \cup 83-[111150-284$ & 5.151 & 5.029 & 5.007 & 155.0000 & $304 L$ & 0.9695 \\
\hline TU83-III150-56i1 & 5.018 & 5.026 & 5.103 & 152.9500 & $304 L$ & 0.9898 \\
\hline TU83-III150-91:4 & 4.854 & 4.951 & 5.127 & 148.6050 & $304 L$ & 0.9508 \\
\hline TiJ $82-111150-182 M$ & 4.319 & 5.101 & 5.142 & 151.1820 & $304 \mathrm{~L}$ & 0.9750 \\
\hline
\end{tabular}


TABLE B.1. DIMENSIONS OF SPECIMENS FOR LLNL TEST MATRIX

TEST NO. IVAla) TUFF ROCK MONOLITHS

$$
\begin{array}{lll}
X \text { AVE. } & \text { Y AVE. } & \text { Z AVE. } \\
(\mathrm{mm}) & (\mathrm{mm}) & (\mathrm{mm})
\end{array}
$$

$\begin{array}{lll}S A & \text { KAT. } & \text { VOL. } \\ (m m)^{2} & (g m) & m l\end{array}$

\begin{tabular}{lrrrrr}
\hline & & & & \\
TU83-IVS0-A3 & 5.971 & 5.478 & 3.554 & 146.798 & 14.67 \\
TU83-IV90-A7 & 5.822 & 6.028 & 3.360 & 149.822 & 14.98 \\
TU83-IV90-A14 & 10.893 & 5.659 & 3.033 & 223.691 & 22.40 \\
TU83-IV90-A28 & 11.480 & 6.025 & 2.804 & 236.650 & 23.61 \\
TU83-IV90-A56 & 6.006 & 5.823 & 2.769 & 135.455 & 13.47 \\
TU83-IV90-A91 & 10.953 & 5.768 & 2.813 & 220.426 & 22.01 \\
TU83-IV90-A.182 & 11.037 & 5.794 & 2.927 & 226.425 & 22.64
\end{tabular}

(a) Tuff rock monoliths, leached in tuff water at $90^{\circ} \mathrm{C}$

TABLE B.2. SPECIMENS FOR LLNL TEST MATRIX

\begin{tabular}{lll}
$\begin{array}{lll}\text { TEST NO. IVB (a) } \\
\text { TUFF ROCK POWDERS }\end{array}$ & $\begin{array}{c}\text { WT. } \\
\text { (gm) }\end{array}$ & $\begin{array}{l}\text { VOL. } \\
\mathrm{ml}\end{array}$ \\
\hline TU83-IV90-B3 & .10043 & 20.00 \\
TU83-IV90-E7 & .10063 & 20.02 \\
TU83-IV90-B14 & .10027 & 20.01 \\
TU83-IV90-B28 & .10069 & 20.00 \\
TU83-IV90-B56 & .10062 & 20.00 \\
TU83-IV90-B91 & .10020 & 20.02 \\
TU83-IV90-B182 & .10015 & 20.01
\end{tabular}

(a) Tuff Rock powder, $<60$ mesh, leached at $90^{\circ} \mathrm{C}$ in tuff water.

\begin{tabular}{|c|c|c|c|c|c|c|}
\hline $\begin{array}{l}\text { TEST NO. IVCM(a) } \\
\text { TUFF ROCK MONOLITHS }\end{array}$ & $\begin{array}{l}X \text { AVE. } \\
(\mathrm{mm})\end{array}$ & $\begin{array}{l}\text { Y AVE. } \\
(\mathrm{mm})\end{array}$ & $\begin{array}{l}\text { Z AVE. } \\
(\mathrm{mm})\end{array}$ & $\stackrel{S A}{(m m)^{2}}$ & $\underset{\langle g m\}}{W T}$ & $\begin{array}{l}\text { VOL. } \\
m l\end{array}$ \\
\hline TU83-IV40-CM & 6.053 & 5.624 & 3.640 & 153.092 & & 15.20 \\
\hline TU83-IV90-CM & 5.674 & 5.803 & 3.842 & 154.042 & & 15.40 \\
\hline TU83-IV90-CM & 6.074 & 6.104 & 3.617 & 162.247 & & 16.23 \\
\hline TU83-IV150-CM & 5.978 & 7.644 & 2.302 & 154.597 & & 15.23 \\
\hline
\end{tabular}

TABLE B.3. SPECIMEN DIMENSIONS FOR LLNL TEST MATRIX

(a) Tuff rock monoliths leached in tuff water for one day at $40,70,90$, and $150^{\circ} \mathrm{C}$. 
TABLE B.4. SPECIMENS FOR LLNL TEST MATRIX

TEST NO. I $V-C P(a)$
TUFF ROCK POWDERS

\begin{tabular}{lcr} 
TEST NO. IV-CP(a) & $\begin{array}{c}\text { WT. } \\
\text { TUFF ROCK POWDERS }\end{array}$ & \multicolumn{1}{c}{ VOL. } \\
& $\mathrm{ml}$ & \\
\hline TU83-IV40-CP & .1000 & 20.05 \\
TU83-IV70-CP & .1005 & 20.02 \\
TU83-IV90-CP & .1001 & 2.05 \\
TU83-IV150-CP & .1002 & 15.00
\end{tabular}

(a) Tuff Rock powders, $<60$ mesh, leached in tuff water at $40,70,90$, and $150^{\circ} \mathrm{C}$ for one day.

TABLE B.5. SPECIMEN DIMENSIONS FOR LLNL. TEST MATRIX

TEST NO. IVSO-D(a) $X$ AVE. Y AVE. $Z$ AVE. (mim) (mm)

SA $2 \quad$ WT. VOL TUFF ROCK MONOLITHS $(m n)$

(n)

TU83-IV90-D3 (b)

TU83-I $Y 90-D 7$

TU83- IV90-D14

TU83-I V90-D28

TU83-IV90-D56

TU83- I $V 90-D 91$

TU83- IV90-D182

$\begin{array}{ll}196.548 & 19.61 \\ 212.643 & 20.74 \\ 194.033 & 19.65 \\ 200.010 & 19.64 \\ 183.425 & 19.61 \\ 191.683 & 19.62 \\ 195.119 & 19.62\end{array}$

(a) Tuff rock monoliths preleached for one day in $137.34 \mathrm{ml}$ tuff water.

(b) Then leached at $90^{\circ} \mathrm{C}$ for the specified time period.

TABLE B.6. SPECIMENS FOR LLNL TEST MATRIX

TEST NO. IV $90-E(a)$

TUFF ROCK POWDERS

\begin{tabular}{cc}
$\begin{array}{c}\text { WT. } \\
(\mathrm{gm})\end{array}$ & $\begin{array}{c}\text { VOL. } \\
\mathrm{ml}\end{array}$ \\
\hline .10004 & 20.04 \\
.10040 & 20.00 \\
.10010 & 20.02 \\
.10061 & 20.01 \\
.10019 & 20.01 \\
.10030 & 20.00 \\
.10040 & 20.04
\end{tabular}

(a) Tuff rock powders, $<60$ mesh, preleached for one day in tuff water at $90^{\circ} \mathrm{C}$.

(b) Then leached at $90^{\circ} \mathrm{C}$ for the specified time period. 
TABLE B.7. SPECIMENS FOR LLNL TEST MATRIX

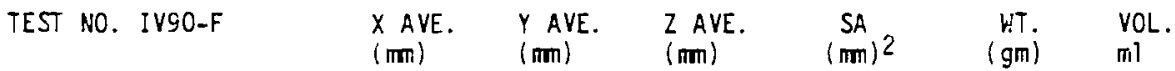

MCC $(76-68)$ GLASS MONOLITHS ${ }^{(a)}$

\begin{tabular}{lllllll}
\hline TU83-IV90-F3 & 9.370 & 6.672 & 2.283 & 198.265 & .2224 & 19.80 \\
TU83-IV90-F7 & 9.333 & 6.797 & 2.349 & 202.658 & .3080 & 20.29 \\
TU83-IV90-F14 & 5.70 & 6.996 & 4.429 & 192.422 & .4192 & 19.22 \\
TU83-IV90-F28 & 9.342 & 6.733 & 2.368 & 201.909 & .3053 & 20.18 \\
TU83-IV90-F56 & 9.349 & 6.699 & 2.067 & 151.611 & .4880 & 19.17 \\
TU83-IV90-F91 & 9.382 & 6.667 & 6.707 & 211.742 & .2985 & 21.16 \\
TU83-IV90-F182 & 9.375 & 6.695 & 2.248 & 197.77 & .3760 & 19.77
\end{tabular}

TUFF ROCK MONOLITHS (b)

\begin{tabular}{lllll}
\hline TU83-IV90-F3 $(c)$ & 5.504 & 1.576 & 12.011 & 187.424 \\
TU83-IV90-F7 & 5.479 & 2.291 & 11.509 & 203.814 \\
TU83-IV90-F14 & 5.423 & 3.204 & 11.502 & 233.172 \\
TU83-IV90-F28 & 5.441 & 2.295 & 10.886 & 153.402 \\
TU83-IV90-F56 & 6.112 & 2.878 & 12.169 & 253.979 \\
TU83-IV90-F91 & 5.489 & 2.044 & 11.972 & 202.869 \\
TU83-IV90-F782 & 5.491 & 2.550 & 11.998 & 220.956
\end{tabular}

(a) MCC (76-68) GLASS MONOLITHS: Leached with the following tuff rock specimens.

(b) Tuff rock monoliths preleached for one day in tuff water at $90^{\circ} \mathrm{C}$.

(c) Then leached for the specified periods with MCC (76-68) waste glass in tuff water at $90^{\circ} \mathrm{C}$.

TABLE B.8. SPECIMENS FOR LLNL TEST MATRIX

TEST NO. IV-G X AVE. Y AVE. Z AVE. SA

MCC (76-68) GLASS MONOLITHS(a)

\begin{tabular}{lllllll}
\hline TU83-IVSO-G3 & 9.170 & 6.480 & 2.642 & 201.526 & .4660 & 20.15 \\
TU83-IV90-G7 & 8.254 & 5.357 & 3.590 & 180.16 & .4631 & 18.61 \\
TU83-IV90-G14 & 9.366 & 6.978 & 2.311 & 206.26 & .3984 & 20.62 \\
TU83-IV90-628 & 8.195 & 5.345 & 3.715 & 188.20 & .4536 & 18.83 \\
TU83-IV90-G56 & 8.358 & 5.435 & 2.331 & 155.15 & .2964 & 15.51 \\
TU83-IV90-691 & 8.251 & 5.337 & 3.148 & 173.62 & .3790 & 17.35 \\
TU83-IV90-6182 & 8.043 & 5.363 & 2.990 & 166.43 & .3615 & 16.64
\end{tabular}

TUFF ROCK MONOLITHS(b)

$\begin{array}{lc}\text { TU83-IV90-G3(C) } & .10063 \\ \text { TU83-IV90-G7 } & .10053 \\ \text { TU83-IV90-G14 } & .10013 \\ \text { TU83-IVG0-G28 } & .10003 \\ \text { TUE3-IV90-G56 } & .10042 \\ \text { TU83-IV90-G91 } & .10055 \\ \text { TU83-IV90-G182 } & .10051\end{array}$

(a) MCC (76-68) glass monoliths leached with tuff rock powder.

(b) Tuff rock powder, $<60$ mesh, preleached for one day in tuff water at $90^{\circ} \mathrm{C}$.

(c) Then leached for the specified periods with MCC $(76-68)$ waste glass in tuff water at $90^{\circ} \mathrm{C}$. 

APPENDIX C

LEACH DATA 

LLNL WASTE PACKAGE TESTS

LEACH TEST 1 DATA (GLASS ONLY), TUFF WATER

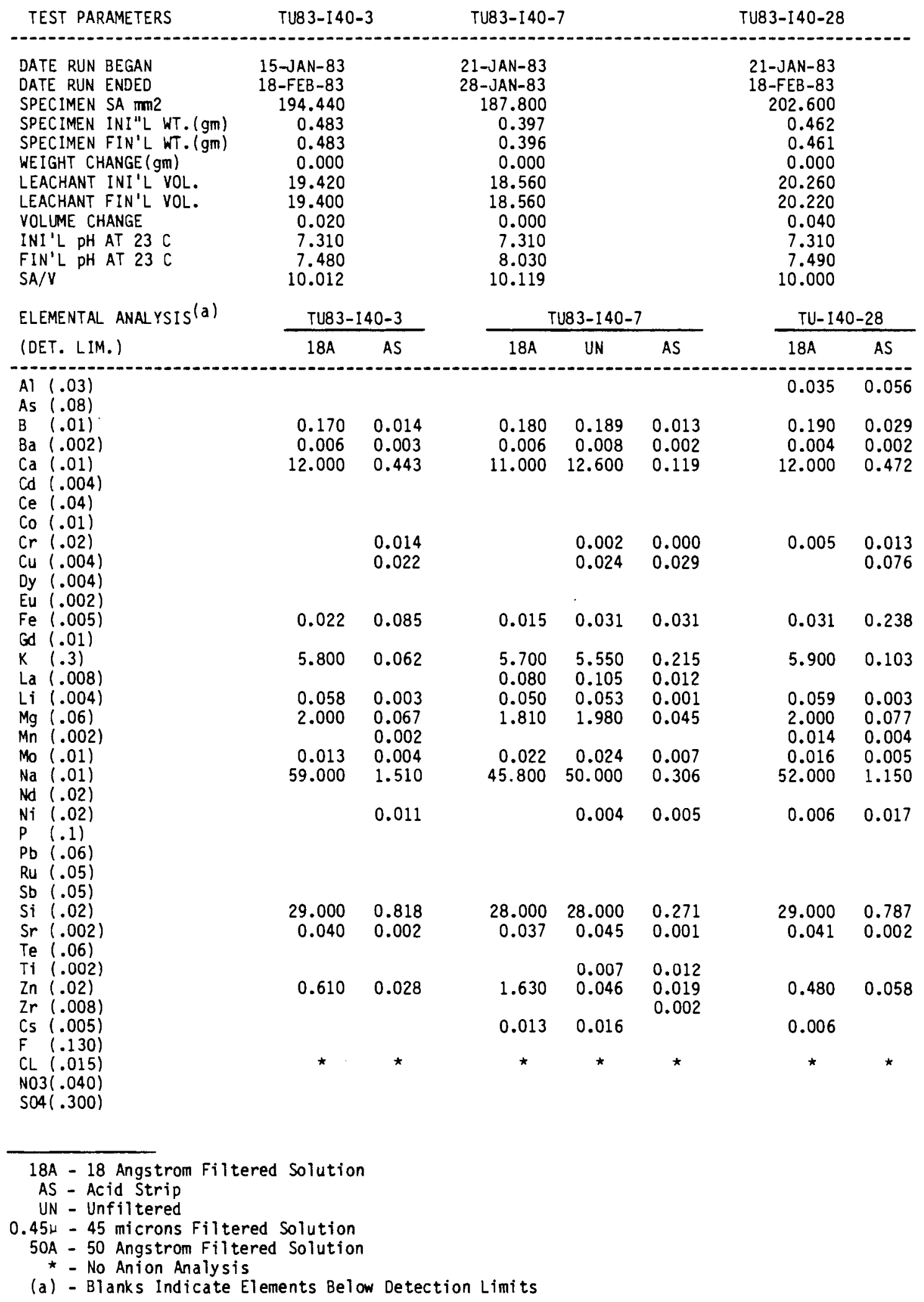


LLNL WASTE PACKAGE TESTS LEACH TEST I DATA (GLASS ONLY), TUFF WATER

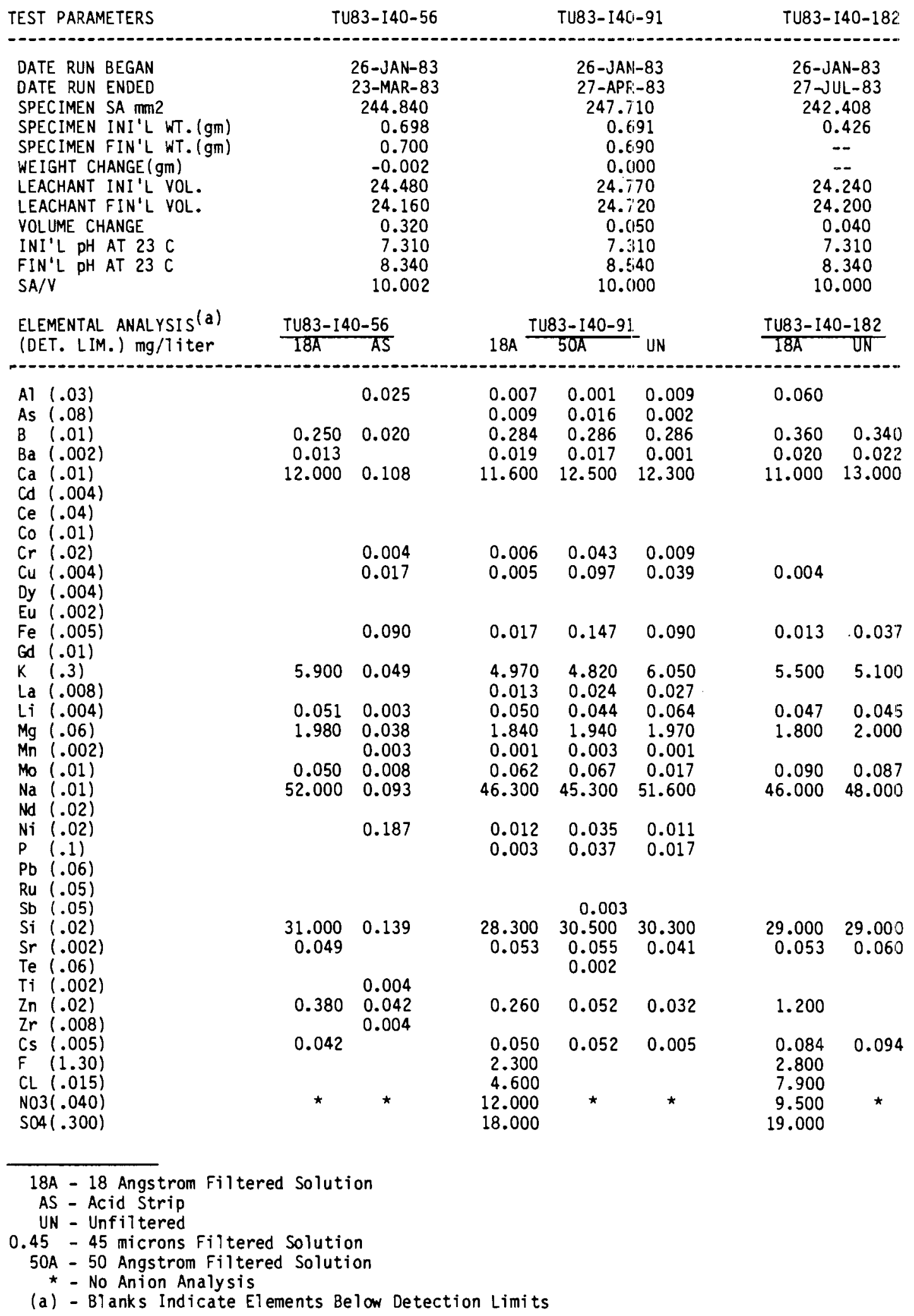


LLNL WASTE PACKAGE TESTS LEACH TEST I DATA (GLASS ONLY), TUFF WATER

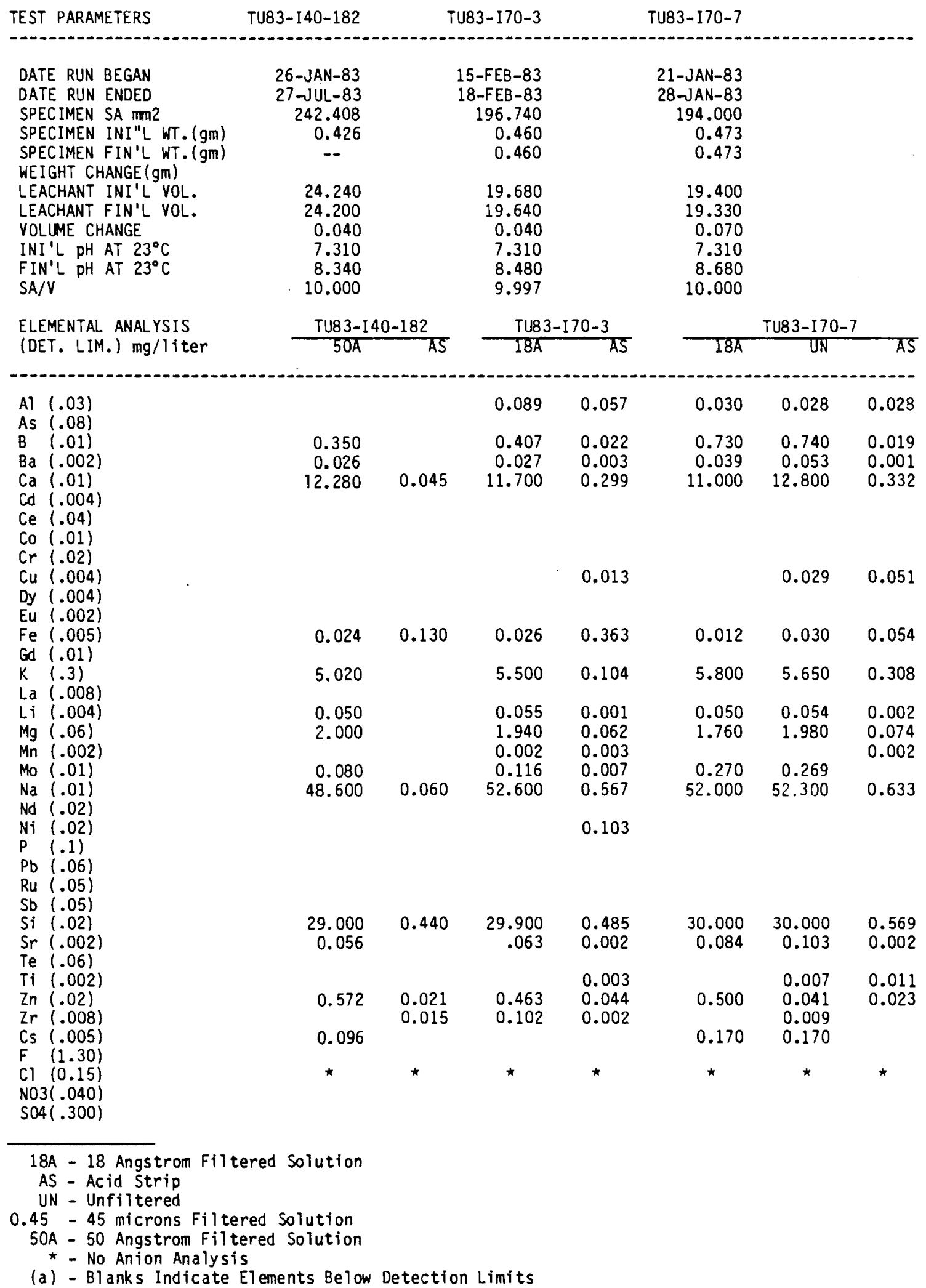


LLNL WASTE PACKAGE TESTS

LEACH TEST 1 DATA (GLASS ONLY), TUFF WATER

\begin{tabular}{|c|c|c|c|}
\hline TEST PARAMETERS & TU83-I 70-28 & TU 83- I 70-56 & TU83-I 70-91 \\
\hline $\begin{array}{l}\text { DATE RUN BEGAN } \\
\text { DATE RUN ENDED } \\
\text { SPECIMEN SA mm2 } \\
\text { SPECIMEN INI"L WT. (gm) } \\
\text { SPECIMEN FIN'L WT.(gm) } \\
\text { WEIGHT CHANGE (gm) } \\
\text { LEACHANT INI'L VOL. } \\
\text { LEACHANT FIN'L VOL. } \\
\text { VOLUME CHANGE } \\
\text { INI'L PH AT } 23 \mathrm{C} \\
\text { FIN'L PH AT } 23 \mathrm{C} \\
\text { SA } / V\end{array}$ & $\begin{array}{r}21-J A N-83 \\
18-F E B-83 \\
207.200 \\
0.529 \\
0.528 \\
0.000 \\
20.720 \\
20.540 \\
0.180 \\
7.310 \\
8.660 \\
10.000\end{array}$ & $\begin{array}{r}26-J A N-83 \\
23-M A R-83 \\
259.910 \\
0.764 \\
0.763 \\
0.000 \\
25.990 \\
25.830 \\
0.160 \\
7.310 \\
8.860 \\
10.000\end{array}$ & $\begin{array}{r}26-J A N-83 \\
\text { O2-APR- } 83 \\
231.520 \\
0.623 \\
0.622 \\
0.000 \\
23.150 \\
22.900 \\
0.250 \\
7.310 \\
8.970 \\
10.001\end{array}$ \\
\hline
\end{tabular}

$S A / V$

10.000

10.001

\begin{tabular}{|c|c|c|c|}
\hline & TU83-I70-28 & TI183-170-5 & TU 83-I 70-91 \\
\hline
\end{tabular}

184 AS

$\begin{array}{rlllll}0.050 & 0.050 & 0.044 & 0.060 & 0.045 & \\ & & & & 0.002 & \\ 1.550 & 0.071 & 2.450 & 0.014 & 3.260 & 3.220 \\ 0.058 & 0.006 & 0.064 & 0.005 & 0.048 & 0.054 \\ 10.000 & 1.370 & 8.800 & 1.600 & 5.970 & 6.590 \\ & & & & 0.007 & \end{array}$

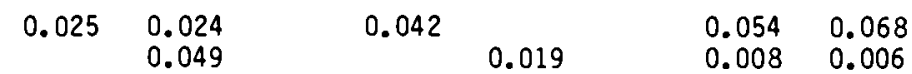

$\mathrm{Cu}(.004)$

Dy $(.004)$

Eu $(.002)$

$\mathrm{Fe}(.005)$

$\mathrm{Gd}(.01)$

$\mathrm{K}(.3)$

La $(.008)$

Li $(.004)$

$\mathrm{Mg}(.06)$

$\mathrm{Mn}(.002)$

Mo $(.01)$

$\mathrm{Na}(.01)$

Nd $(.02)$

$\mathrm{Ni}(.02)$

$\mathrm{P}(.1)$

$\mathrm{Pb}(.06)$

Ru $(.05)$

$\mathrm{Sb}(.05)$

Si $(.02)$

Sr $(.002)$

$\mathrm{Te}(.06)$

$\mathrm{Ti}(.002)$

$\operatorname{Zn}(.02)$

$\operatorname{Zr}(.008)$

Cs $(.005)$

F $(.130)$

$\mathrm{CL}(.015)$

$\mathrm{N} 03(.040)$

S04 (.300)

$18 A$ - 18 ANSTROM FILTERED SOLUTION

$0.026 \quad 0.176$

$0.014 \quad 0.140$

$0.058 \quad 0.047$

$5.300 \quad 0.136$

5.600

4.670

5.170

\subsection{4}

$0.550 \quad 1.110$

0.047

0.360

1.100

0.050

0.012

$0.620 \quad 0.005$

1.000

0.125

0.110

$55.000 \quad 2.090$

57.000

0.017

$1.350 \quad 1.370$

0.039

0.040

$52.100 \quad 56.700$

0.128

AS - ACID STRIP SOLUTION

UN - UNFILTERED

* - NO ANION ANAL YSIS

\begin{tabular}{|c|c|c|c|c|c|}
\hline $\begin{array}{r}31.000 \\
0.150\end{array}$ & $\begin{array}{l}2.690 \\
0.010\end{array}$ & $\begin{array}{r}34.000 \\
0.200\end{array}$ & $\begin{array}{l}1.300 \\
0.009\end{array}$ & $\begin{array}{r}32.900 \\
0.197\end{array}$ & $\begin{array}{r}33.300 \\
0.220\end{array}$ \\
\hline 0.140 & $\begin{array}{l}0.003 \\
0.180\end{array}$ & 0.140 & $\begin{array}{c}0.006 \\
0.320 \\
0.025\end{array}$ & 0.108 & \\
\hline 0.550 & 0.024 & 0.920 & * & $\begin{array}{c}0.800 \\
3.900 \\
7.700 \\
9.100 \\
18.000\end{array}$ & 0.920 \\
\hline
\end{tabular}

(a) - BLANKS INDICATE ELEMENTS BELOW DETECTION LIMITS 
LLNL WASTE PACKAGE TESTS

LEACH TEST 1 DATA (GLASS ONLY), TUFF WATER

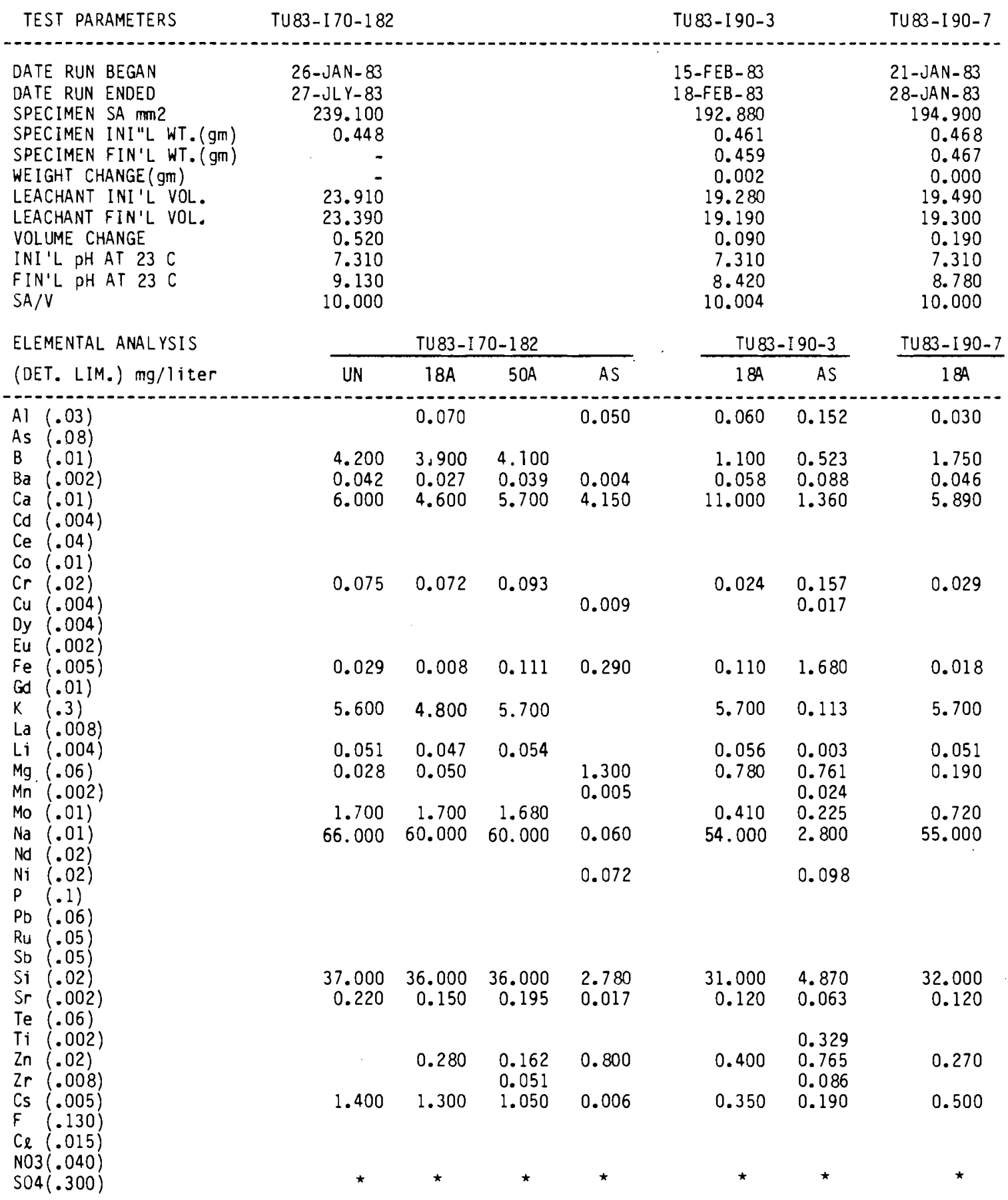

\footnotetext{
184 - 18 Angstrom Filtered Solution 
LLNL WASTE PACKAGE TESTS LEACH TEST I DATA (GLASS), TUFF WATER

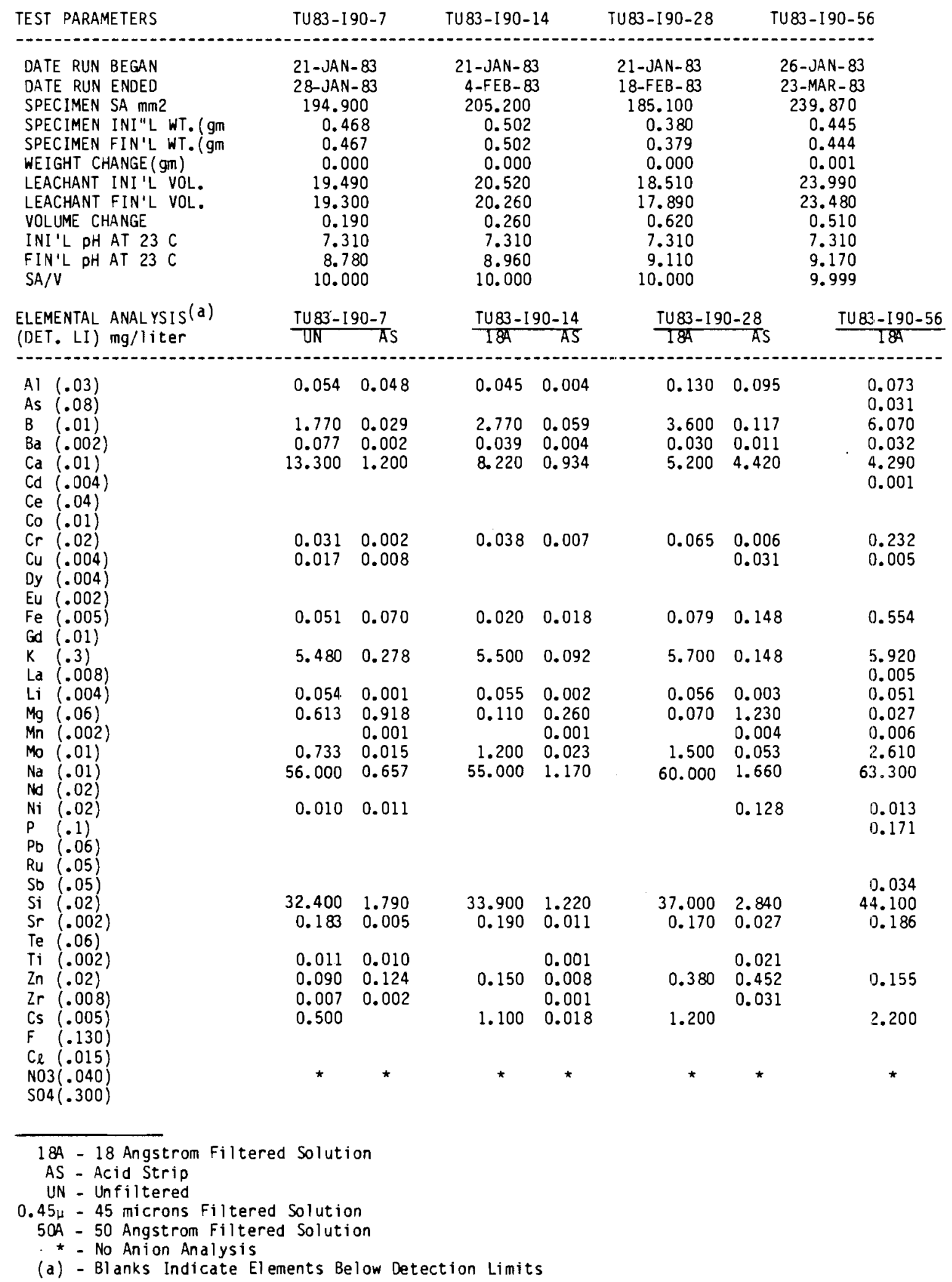


LLNL WASTE PACKAGE TESTS LEACH TEST I DATA (GLASS ONLY), TUFF WATER

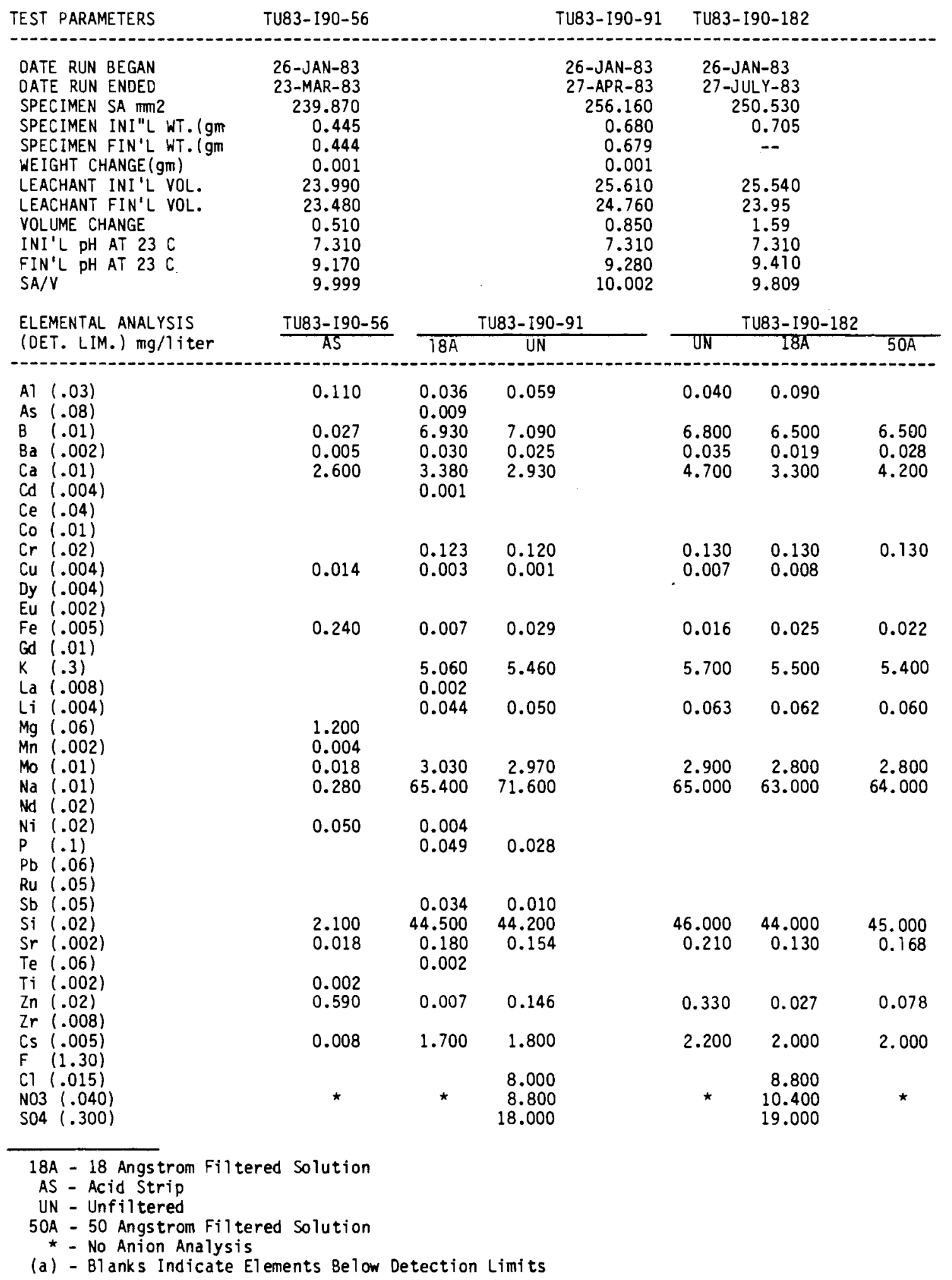


LLNL WASTE PACKAGE TESTS LEACH TEST I DATA (GLASS OVLY), TUFF WATER

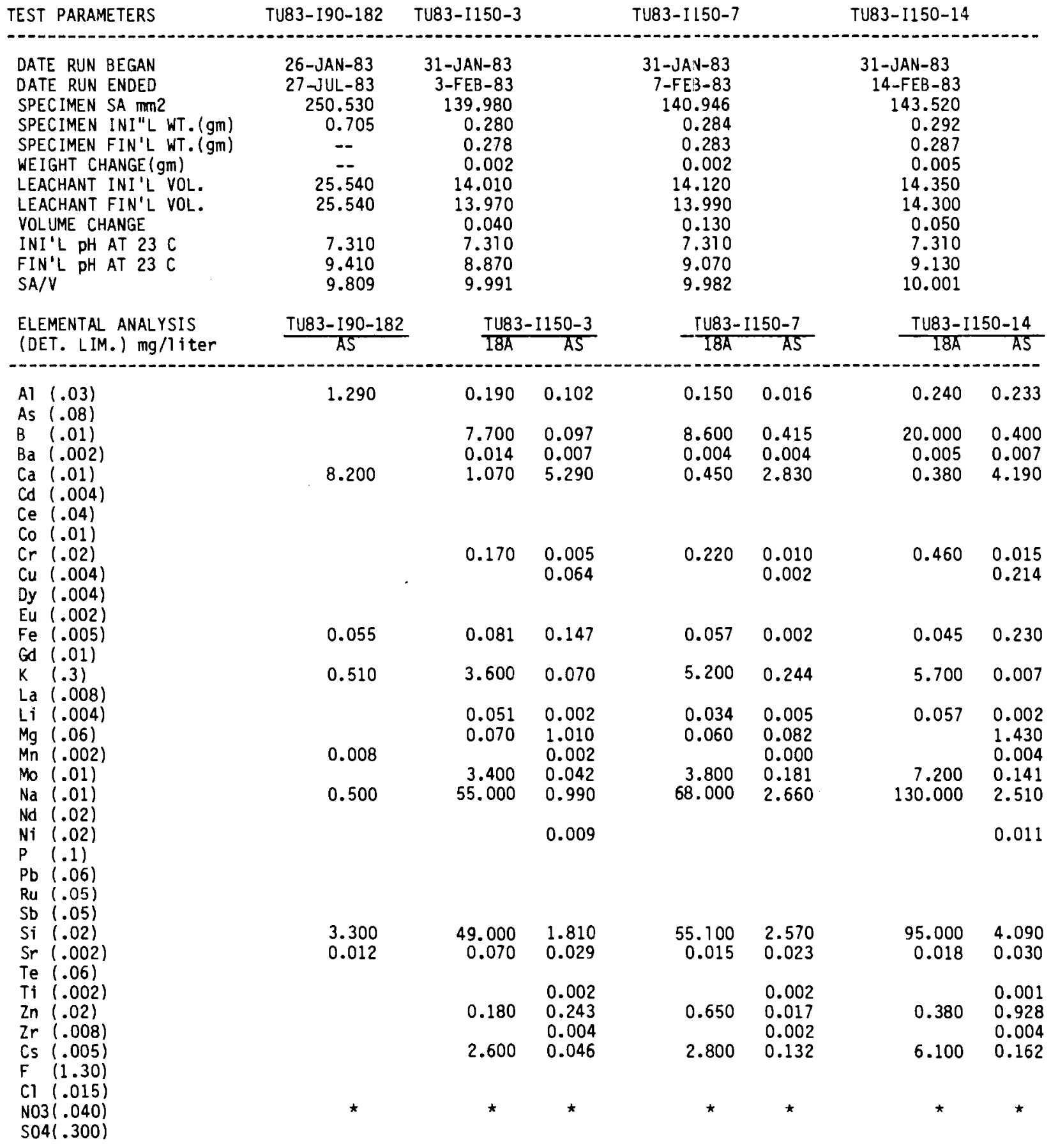

\footnotetext{
18A - 18 Angstrom Filtered Solution

AS - Acid Strip

UN - Unfiltered

$0.45 \mu-45$ microns Filtered Solution

50A - 50 Angstrom Filtered Solution

* - No Anion Analysis

(a) - Blanks Indicate Elements Below Detection Limits
} 
LLNL WASTE PACKAGE TESTS

LEACH TEST 1 DATA (GLASS ONLY), TUFF WATER

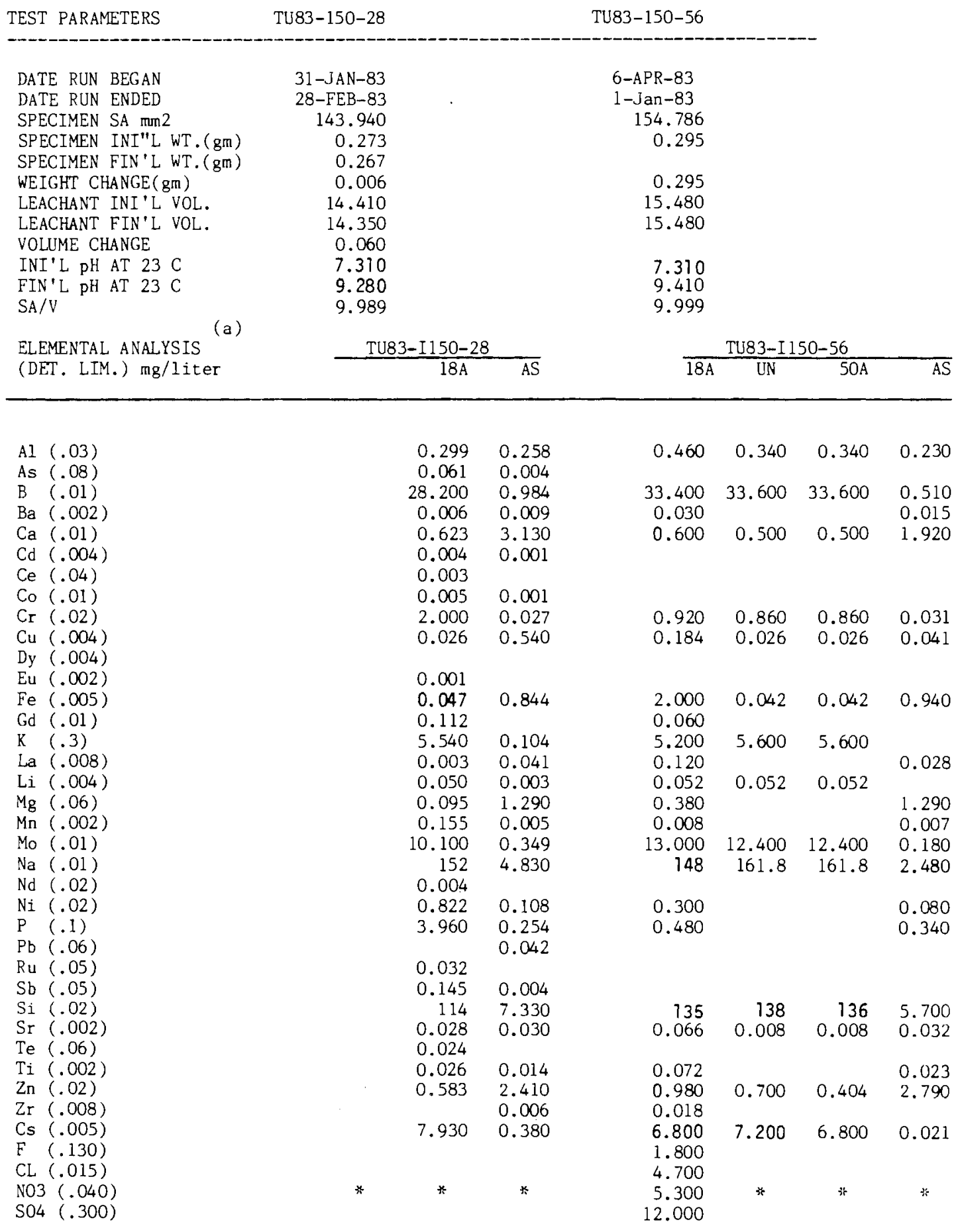

\footnotetext{
18A - 18 Angtrom Filtered Solution

AS - Acid Strip

UN - Unfiltered

50A - 50 Angstrom Filtered Solution

* - No anion Analysis
} 
LLNL WASTE PACKAGF TFSTS LEACH TEST I DATA

IGLASS . ,TUFF WATER

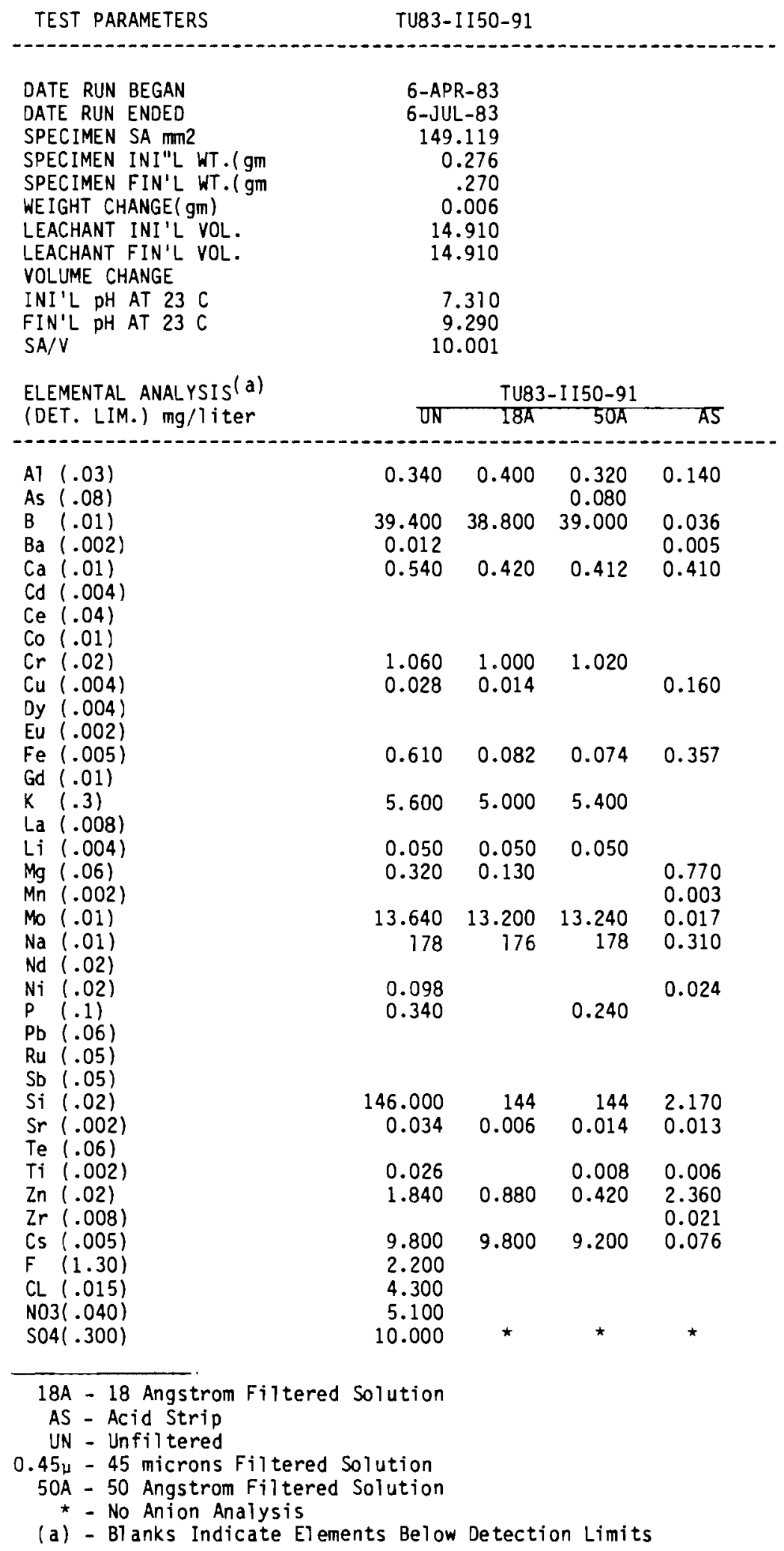


LLNL WASTE PACKAGE TESTS LEACH TEST I I DATA (GLASS AND ROCK), TUFF WATER

\begin{tabular}{|c|c|c|c|c|c|c|c|}
\hline TEST PARAMETERS & \multicolumn{2}{|c|}{ TU83-I 140-3 } & \multicolumn{3}{|c|}{ TU83-I I40-7 } & \multicolumn{2}{|c|}{ TU83-I I 40-28 } \\
\hline $\begin{array}{l}\text { DATE RUN BEGAN } \\
\text { DATE RUN ENDED } \\
\text { SPECIMEN SA mm2 } \\
\text { PARTICLE SIZE } \\
\text { SPECIMEN INI"L WT.(gm) } \\
\text { SPECIMEN FIN'L WT.(gm) } \\
\text { WEIGHT CHANGE (gm) } \\
\text { LEACHANT INI'L VOL. } \\
\text { LEACHANT FIN'L VOL. } \\
\text { VOLUME CHANGE } \\
\text { INI'L PH AT } 23 \mathrm{C} \\
\text { FIN'L PH AT } 23 \mathrm{C} \\
\text { SA/V }\end{array}$ & $\begin{array}{r}22-F E B- \\
25-F E B \\
197.7 \\
\text { MONOL } \\
0.4 \\
0.5 \\
19.7 \\
19.7 \\
7.3 \\
7.5 \\
10.0\end{array}$ & & \multicolumn{3}{|c|}{$\begin{array}{r}21-J A N-83 \\
28-J A N-83 \\
181.600 \\
\text { MONOLITH } \\
0.385 \\
0.3845 \\
--- \\
18.160 \\
18.140 \\
0.020 \\
7.310 \\
8.140 \\
10.000\end{array}$} & $\begin{array}{r}21-J A N \\
18-\mathrm{FEB} \\
198 . \\
\text { MONOL } \\
0 . \\
\\
19 . \\
\\
7 . \\
8 . \\
10 .\end{array}$ & $\begin{array}{l}83 \\
83 \\
00 \\
\text { TH } \\
91 \\
-- \\
- \\
80 \\
-- \\
- \\
10 \\
30 \\
00\end{array}$ \\
\hline $\begin{array}{l}\text { ELEMENTAL ANALYSIS(a) } \\
\text { (DET.LIM)MG/LITER }\end{array}$ & \multicolumn{2}{|c|}{$\frac{\text { TU83-I I } 40-3}{18 \mathrm{~A}} \mathrm{AS}$} & \multicolumn{3}{|c|}{ TU83-I I 40-7 } & \multicolumn{2}{|c|}{ TU83-I I 40-28 } \\
\hline $\begin{array}{ll}\text { Al } & (.03) \\
\mathrm{As} & (.08) \\
\mathrm{B} & (.01) \\
\mathrm{Ba} & (.002) \\
\mathrm{Ca} & (.01) \\
\mathrm{Cd} & (.004) \\
\mathrm{Ce} & (.04) \\
\mathrm{Co} & (.01) \\
\mathrm{Cr} & (.02) \\
\mathrm{Cu} & (.004) \\
\mathrm{Dy} & (.004) \\
\mathrm{Eu} & (.002) \\
\mathrm{Fe} & (.005) \\
\mathrm{Gd} & (.01) \\
\mathrm{K} & (.3) \\
\mathrm{La} & (.008) \\
\mathrm{Li} & (.004) \\
\mathrm{Mg} & (.06) \\
\mathrm{Mn} & (.002) \\
\mathrm{Mo} & (.01) \\
\mathrm{Na} & (.01) \\
\mathrm{Nd} & (.02) \\
\mathrm{Ni} & (.02) \\
\mathrm{P} & (.1) \\
\mathrm{Pb} & (.06) \\
\mathrm{Ru} & (.05) \\
\mathrm{Sb} & (.05) \\
\mathrm{Si} & (.02) \\
\mathrm{Sr} & (.002) \\
\mathrm{Te} & (.06) \\
\mathrm{Ti} & (.002) \\
\mathrm{Zn} & (.02) \\
\mathrm{Zr} & (.008) \\
\mathrm{Cs} & (.005) \\
\mathrm{F} & (.130) \\
\mathrm{Cl} & (.015) \\
\mathrm{NO} & \\
\mathrm{NO} & \end{array}$ & $\begin{array}{r}6.200 \\
0.014 \\
0.047 \\
1.800 \\
0.005 \\
0.011 \\
46.000\end{array}$ & $\begin{array}{l}0.041 \\
0.010 \\
0.410\end{array}$ & $\begin{array}{r}0.020 \\
7.400 \\
0.090 \\
0.050 \\
1.800 \\
0.005 \\
0.020 \\
47.500\end{array}$ & $\begin{array}{r}0.028 \\
0.032 \\
0.175 \\
0.005 \\
12.700 \\
0.001 \\
0.002 \\
0.002 \\
0.002 \\
0.056 \\
\\
0.001 \\
0.032 \\
\\
7.270 \\
0.110 \\
0.054 \\
1.930 \\
0.005 \\
0.020 \\
49.000 \\
0.010 \\
0.018 \\
0.121 \\
\\
0.004 \\
0.012 \\
28.200 \\
0.046 \\
\\
0.009 \\
0.044 \\
0.004 \\
0.006\end{array}$ & $\begin{array}{l}0.166 \\
0.022 \\
0.016 \\
0.002 \\
0.323 \\
0.001 \\
0.017 \\
0.003 \\
0.003 \\
0.057 \\
0.001 \\
0.001 \\
0.036 \\
0.040 \\
0.325 \\
0.012 \\
0.001 \\
0.076 \\
0.001 \\
0.008 \\
0.934 \\
0.014 \\
0.009 \\
0.022 \\
0.013 \\
0.013 \\
0.019 \\
0.712 \\
0.002 \\
0.009 \\
0.013 \\
0.021\end{array}$ & $\begin{array}{r}0.032 \\
\\
7.970 \\
0.003 \\
0.057 \\
1.840 \\
0.005 \\
0.028 \\
50.300 \\
\\
0.011 \\
0.022\end{array}$ & $\begin{array}{l}0.078 \\
0.012 \\
0.173 \\
0.006 \\
0.002 \\
0.077 \\
0.002 \\
0.006 \\
1.510 \\
0.012 \\
0.009 \\
0.003 \\
\\
0.008 \\
0.992 \\
0.003 \\
0.006\end{array}$ \\
\hline
\end{tabular}

\footnotetext{
18A - 18 Angstrom Filtered Solution

AS - Acid Strip

UN - Unfiltered

* - No Anion Analysis

(a) - Blanks Indicate Elements Below Detection Limits
} 
LLNL WASTE PACKAGE TESTS LEACH TEST II DATA (GLASS AND ROCK), TUFF WATER

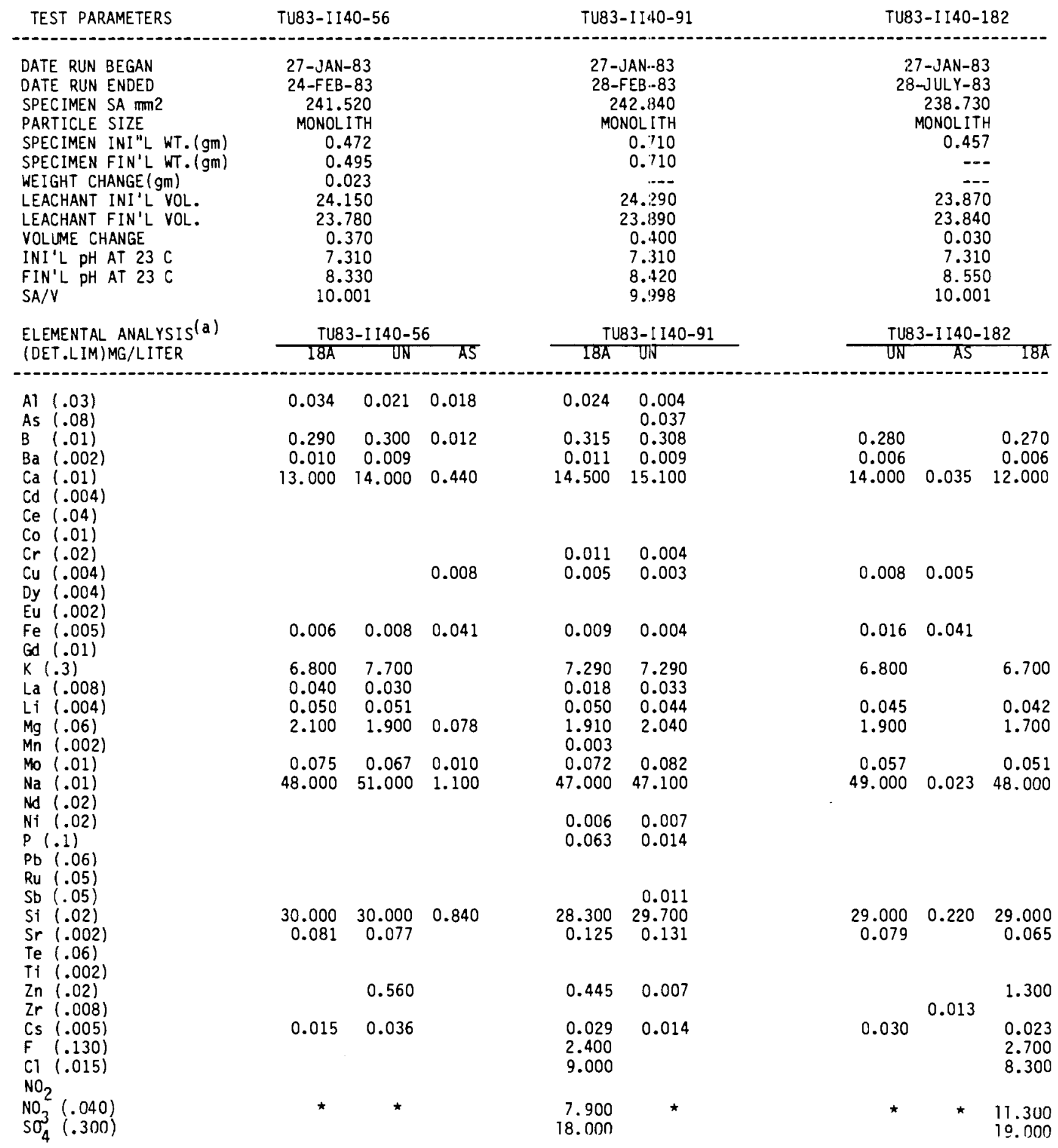

\footnotetext{
18A - 18 Angstrom Filtered Solution

AS - Acid Strip

UN - Unfiltered

* - No Anion Analysis

(a) - Blanks Indicate Elements Below Detection Limits
} 
LLNL WASTE PACKAGE TESTS LEACH TEST II DATA (GLASS AND ROCK), TUFF WATER

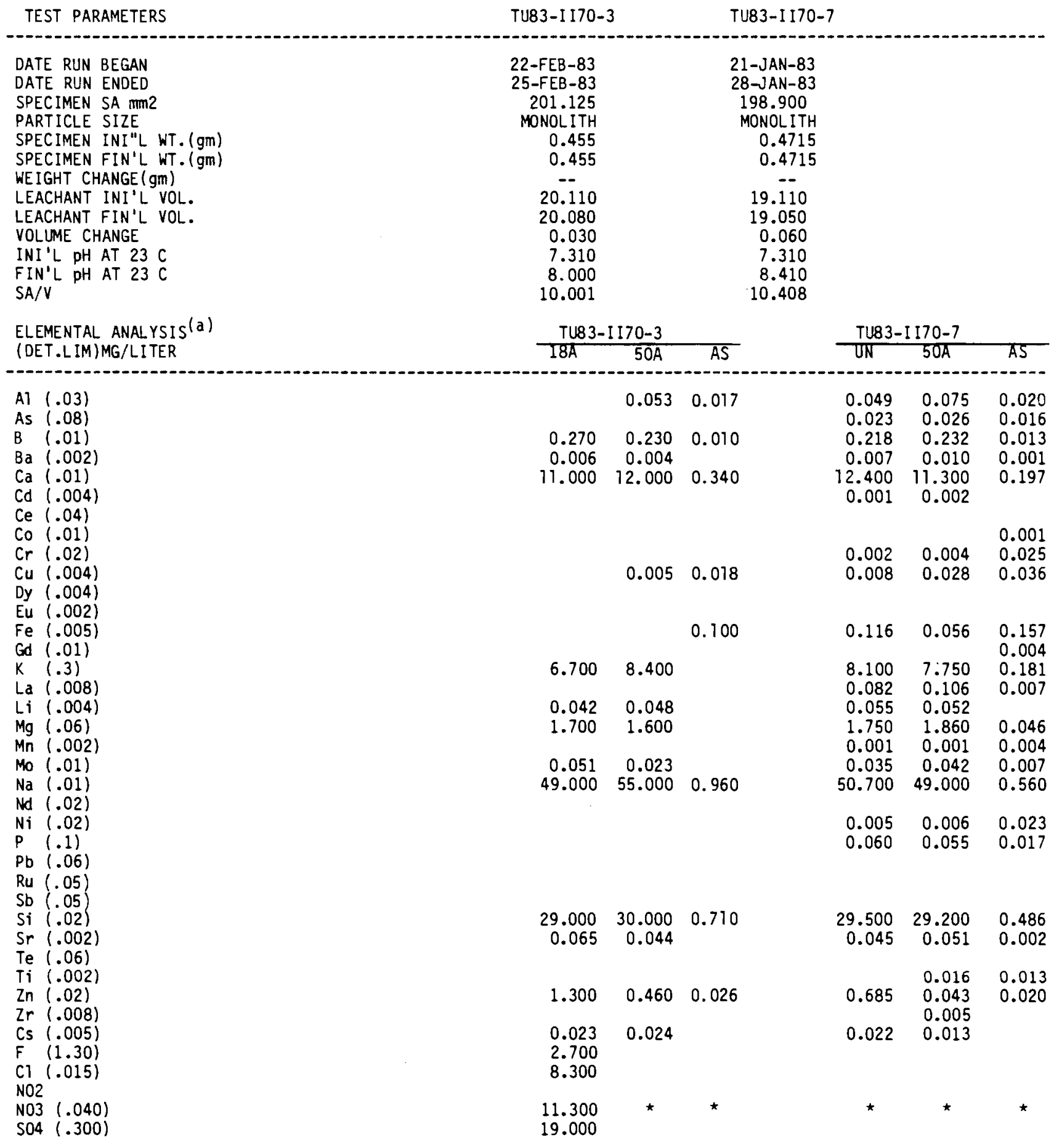

\footnotetext{
18A - 18 Angstrom Filtered Solution

AS - Acid Strip

UN - Unfiltered

$0.45 \mu-45$ microns Filtered Solution

50 - 50 Angstrom Filtered Solution

* - No Anion Analysis
}

(a) - Blanks Indicate Elements Below Detection Limits 
LLNL WASTE PACKAGE TESTS LEACH TEST I I DATA (GLASS AND ROCK), TUFF WATER

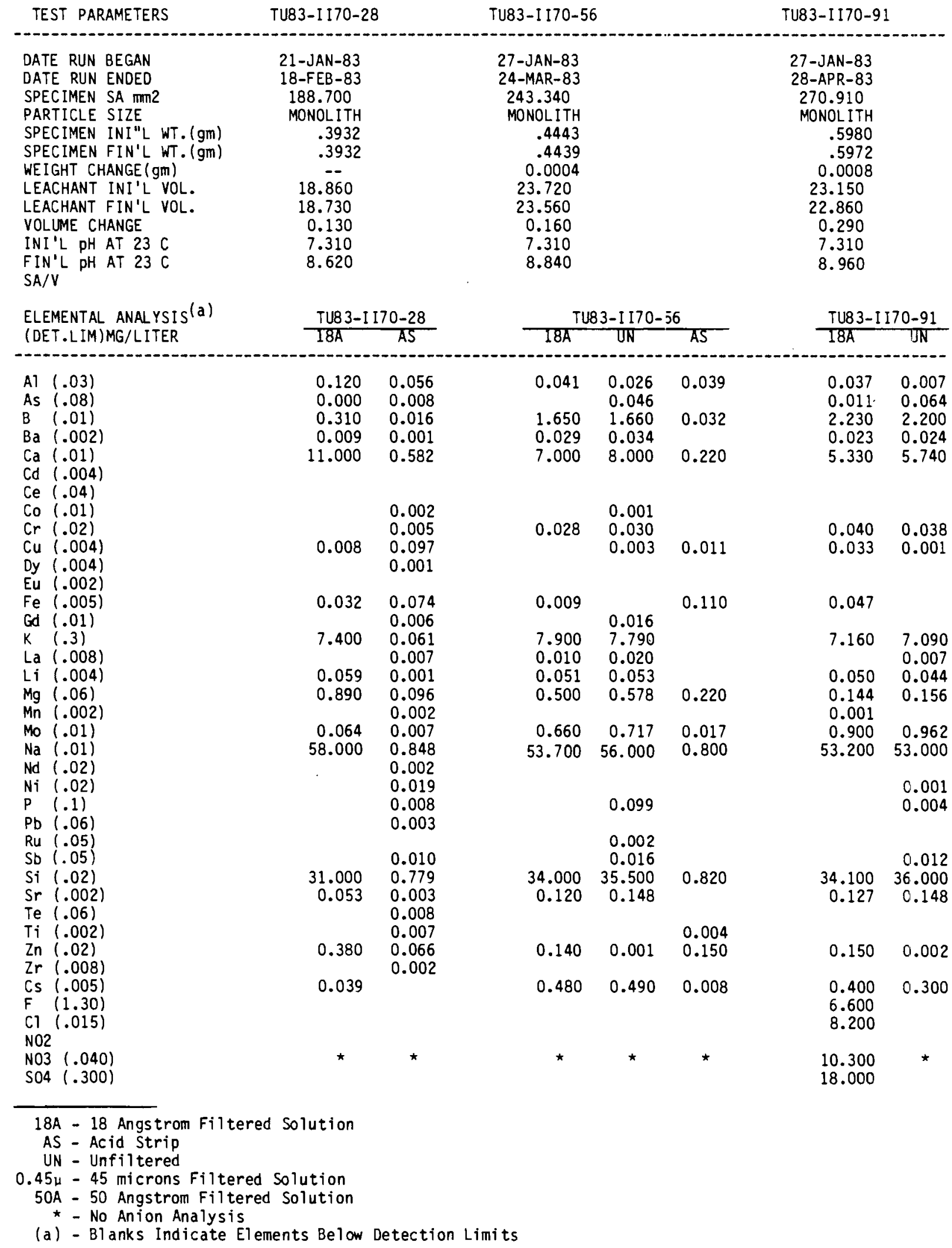


LLNL WASTE PACKAGE TESTS LEACH TEST II DATA (GLASS AND ROCK), TUFF WATER

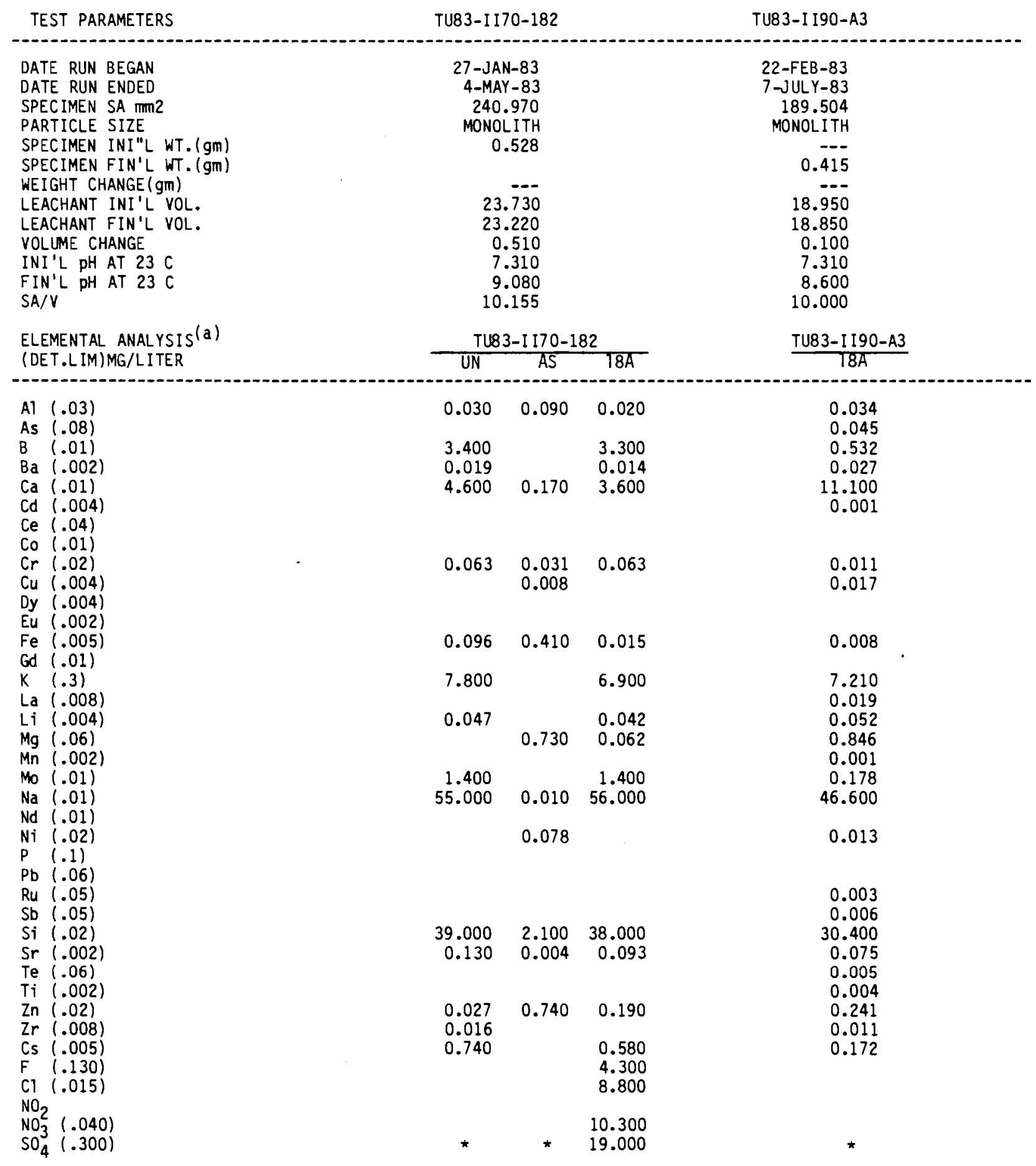

\footnotetext{
18A - 18 Angstrom Filtered Solution

AS - Acid Strip

UN - Unfiltered

(a) - Blanks Indicate Elements Below Detection Limits
} 
LLNL WASTE PACKAGE TESTS LEACH TEST II DATA (GLASS AND ROCK), TUFF WATER

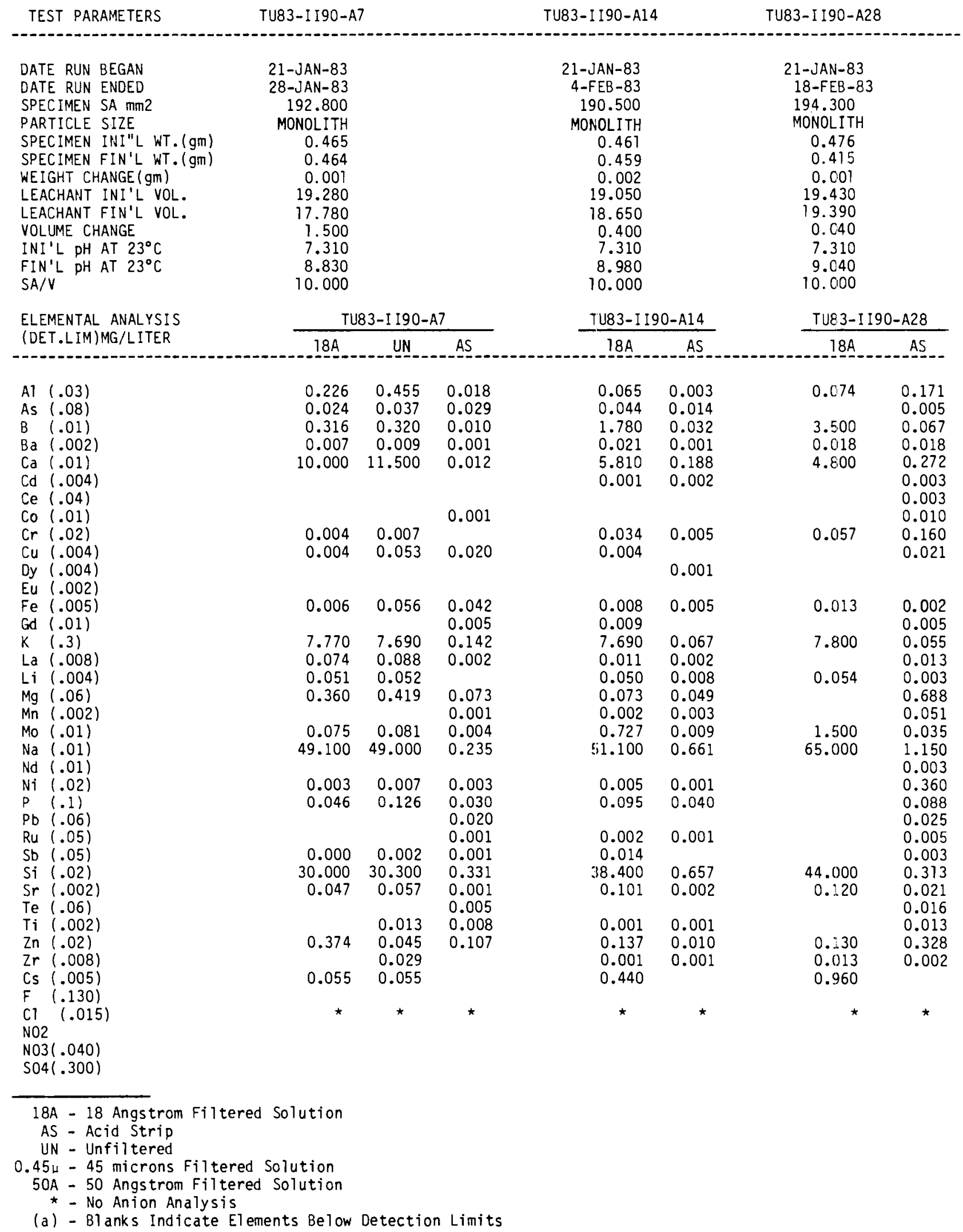


LLNL WASTE PACKAGE TESTS LEACH TEST II DATA (GLASS AND ROCK), TUFF WATER

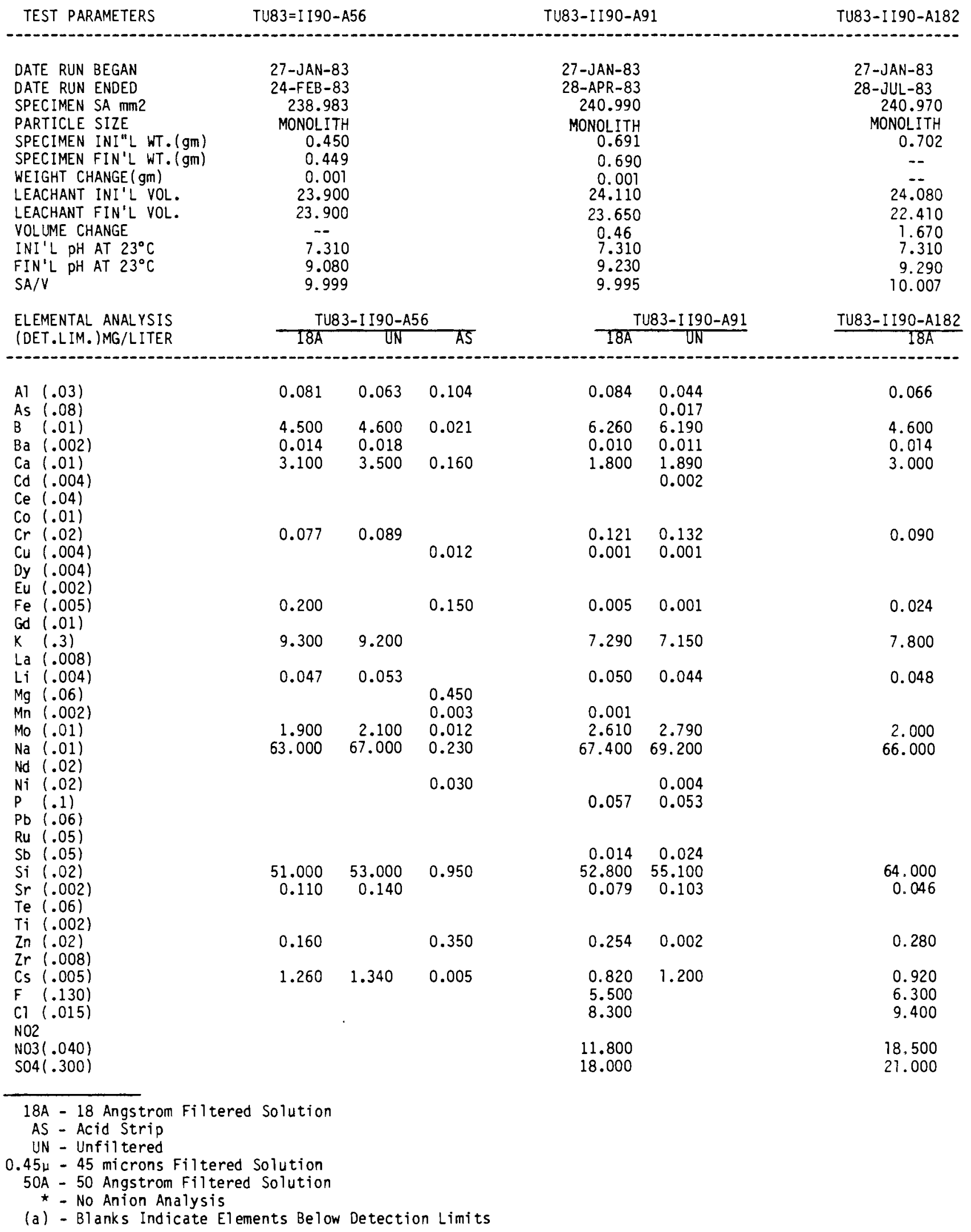


LLNL WASTE PACKAGE TESTS LEACH TEST II DATA (GLASS AND ROCK), TUFF WATER

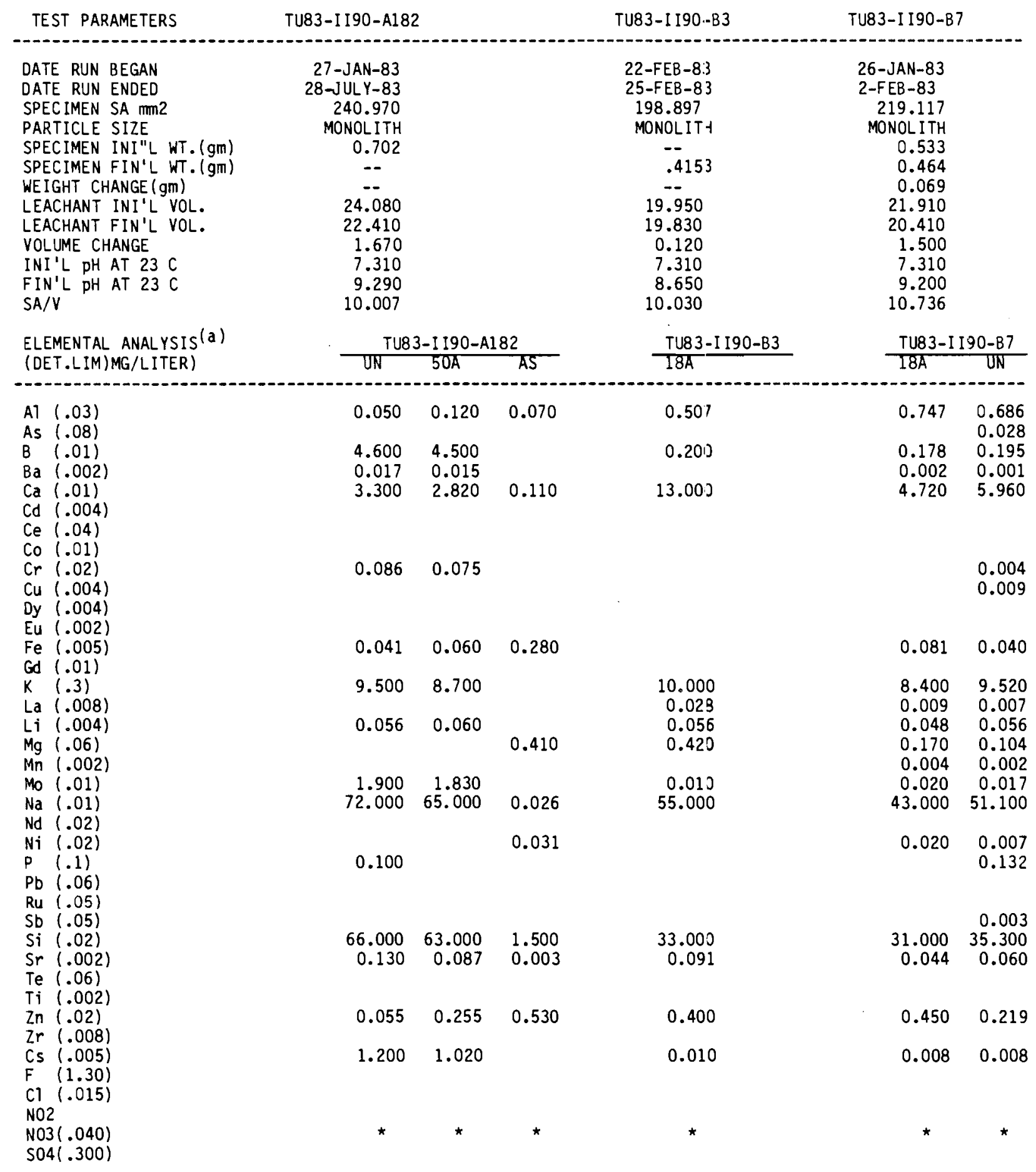

\footnotetext{
18A - 18 Angstrom Filtered Solution

AS - Acid Strip

UN - Unfiltered

$0.45 \mu-45$ microns Filtered Solution

$50 \mathrm{~A}$ - 50 Angstrom Filtered Solution

* - No Anion Analysis

(a) - Blanks Indicate Elements Below Detection Limits
} 
LLNL WASTE PACKAGE TESTS LEACH TEST II DATA (GLASS AND ROCK), TUFF WATER

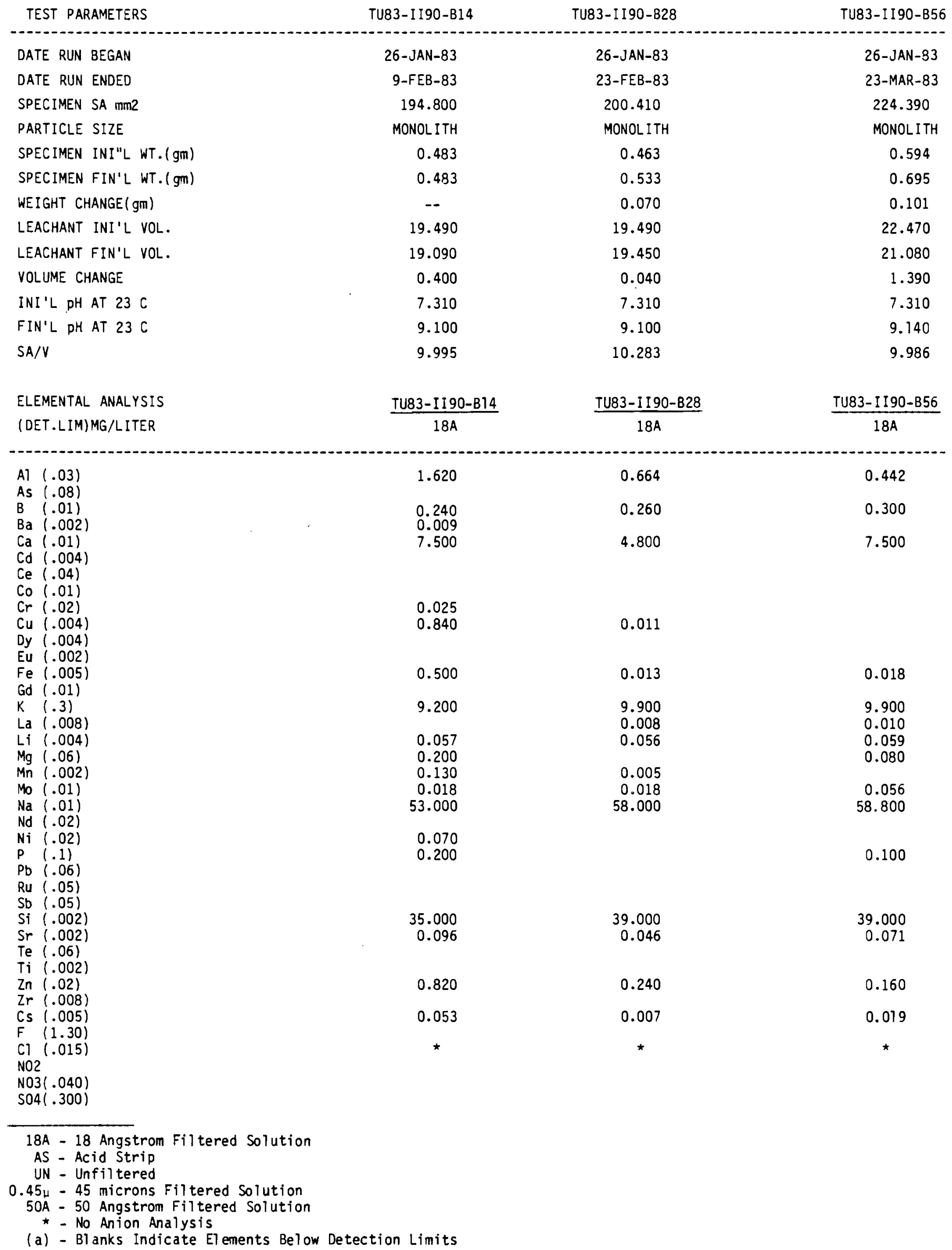


LLNL WASTE PACKAGE TESTS LEACH TEST II DATA (GLASS AND ROCK), TUFF WATER

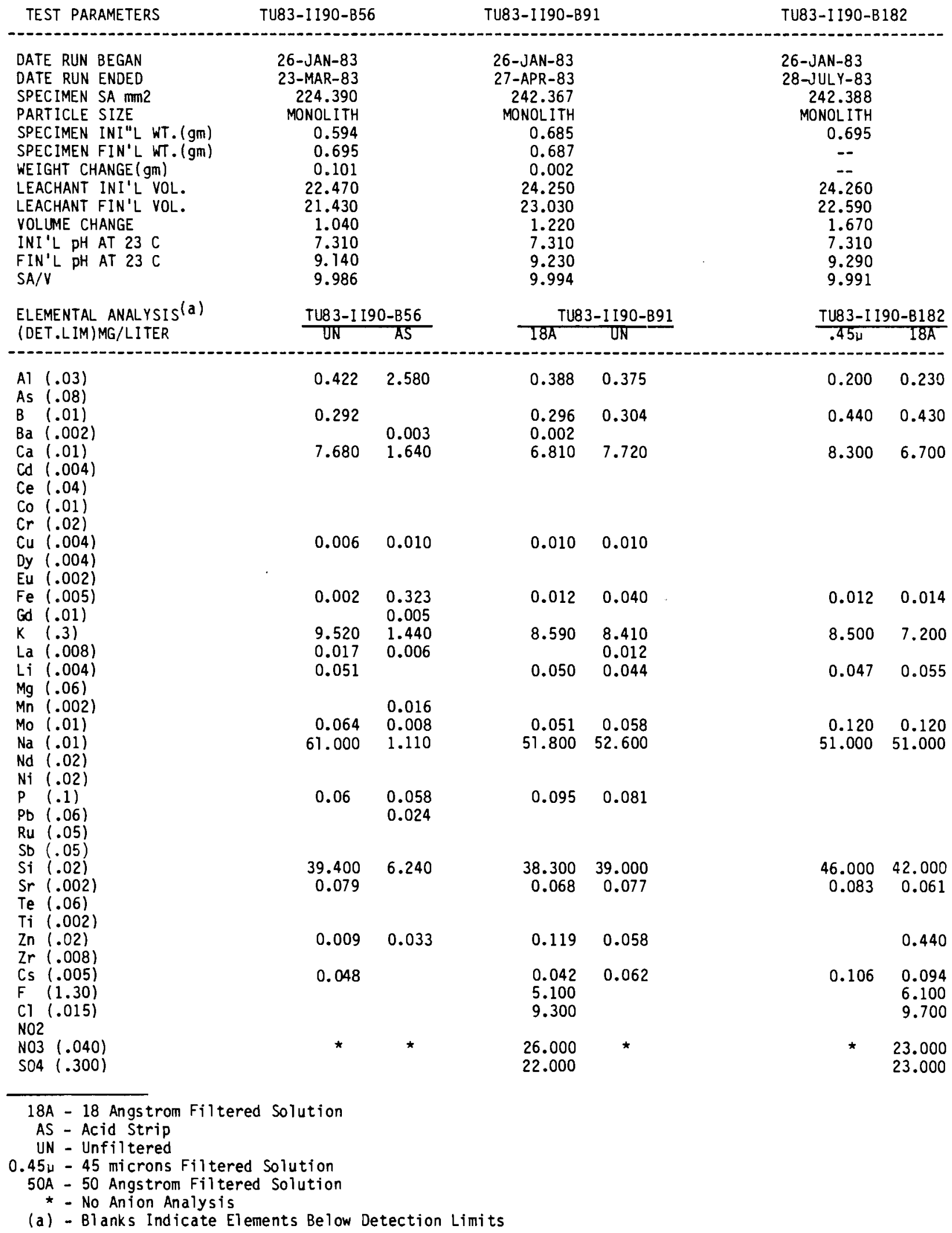


LLNL WASTE PACKAGE TESTS LEACH TEST II DATA (GLASS AND ROCK), TUFF WATER

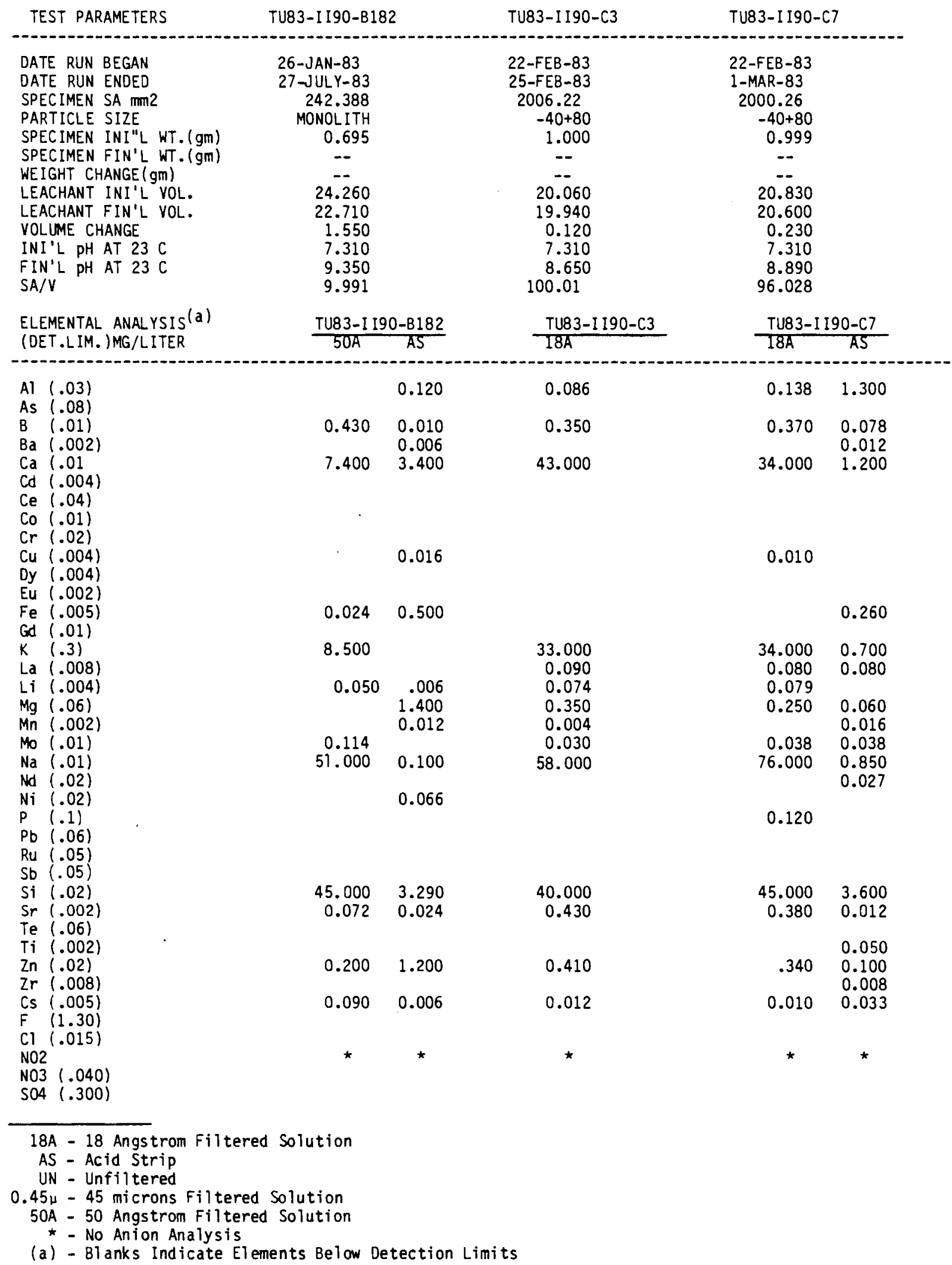


LLNL WASTE PACKAGE TESTS LEACH TEST II DATA (GLASS AND ROCK), TUFF WATER

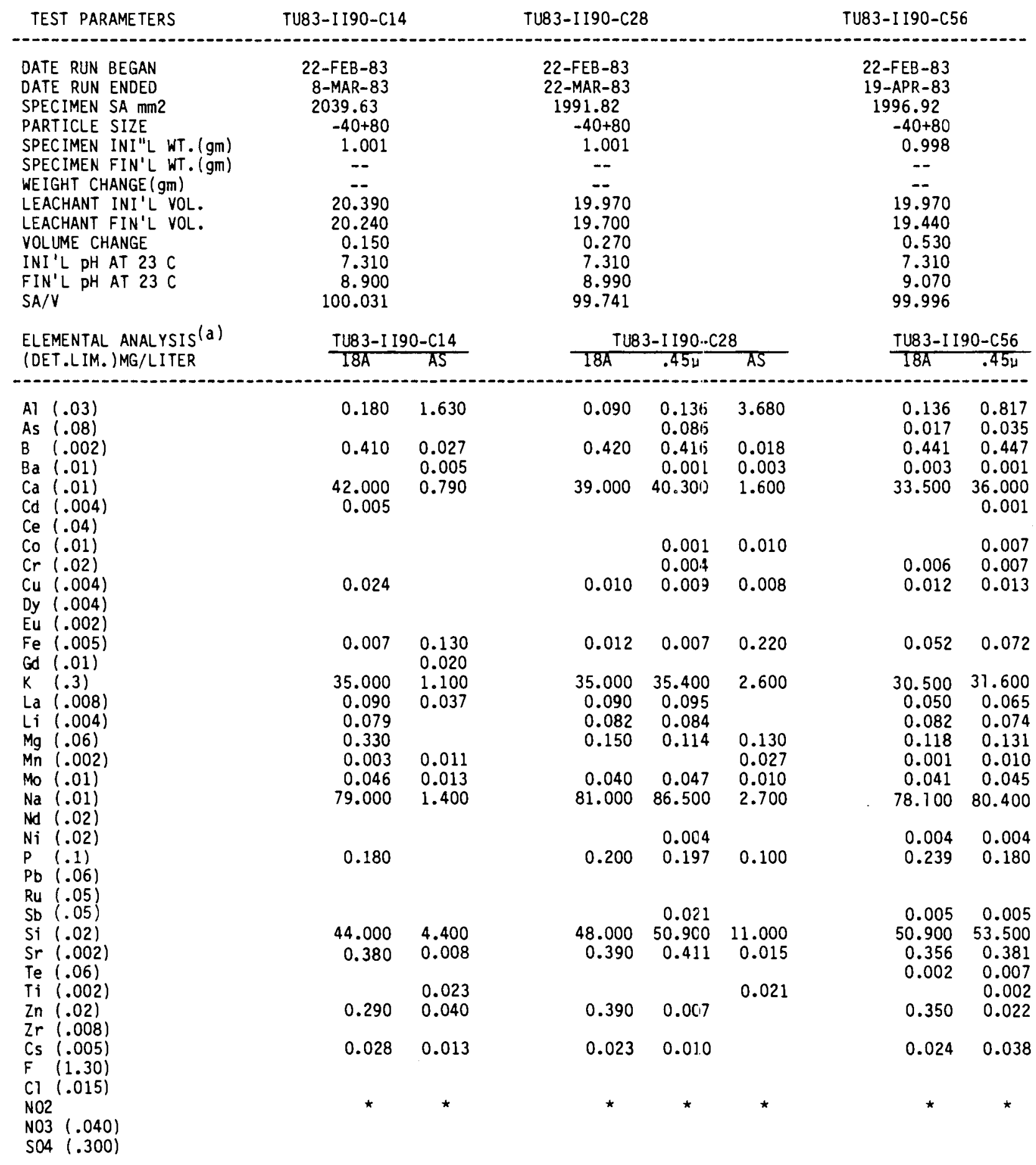

\footnotetext{
18A - 18 Angstrom Filtered Solution

AS - Acid Strip

UN - Unfiltered

$0.45 \mu-45$ microns Filtered Solution

50A - 50 Angstrom Filtered Solution

* - No Anion Analysis

(a) - Blanks Indicate Elements Below Detection Limits
} 
LLNL WASTE PACKAGE TESTS LEACH TEST I I DATA (GLASS AND ROCK), TUFF WATER

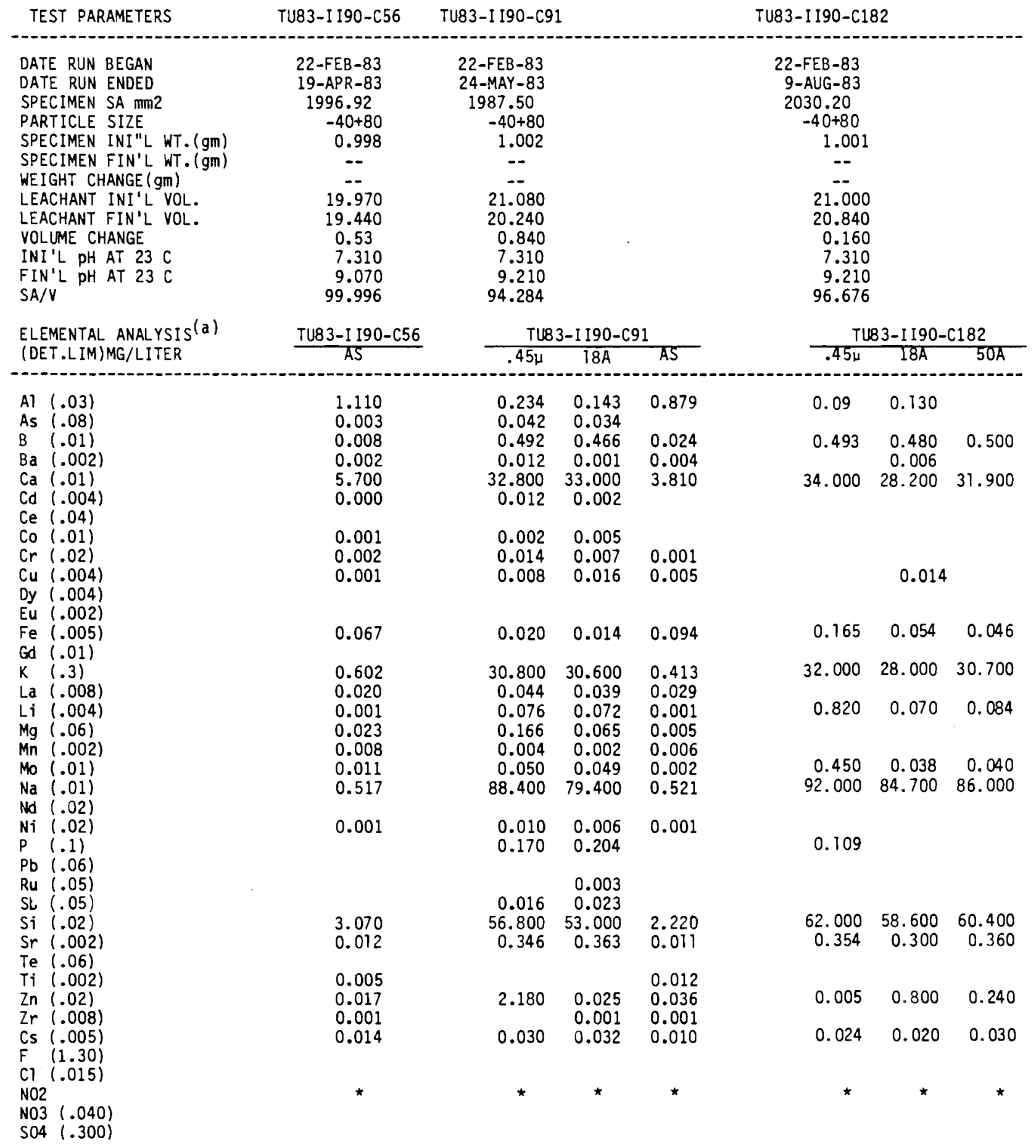

18A - 18 Angstrom Filtered Solution

AS - Acid Strip

UN - Unfiltered

$0.45 \mu$ - 45 microns Filtered Solution

50A - 50 Angstrom Filtered Solution

* - No Anion Analysis

(a) - Blanks Indicate Elements Below Detection Limits 
LLNL WASTE PACKAGE TESTS

LEACH TEST I I DATA (GLASS AND ROCK), TUFF WATER

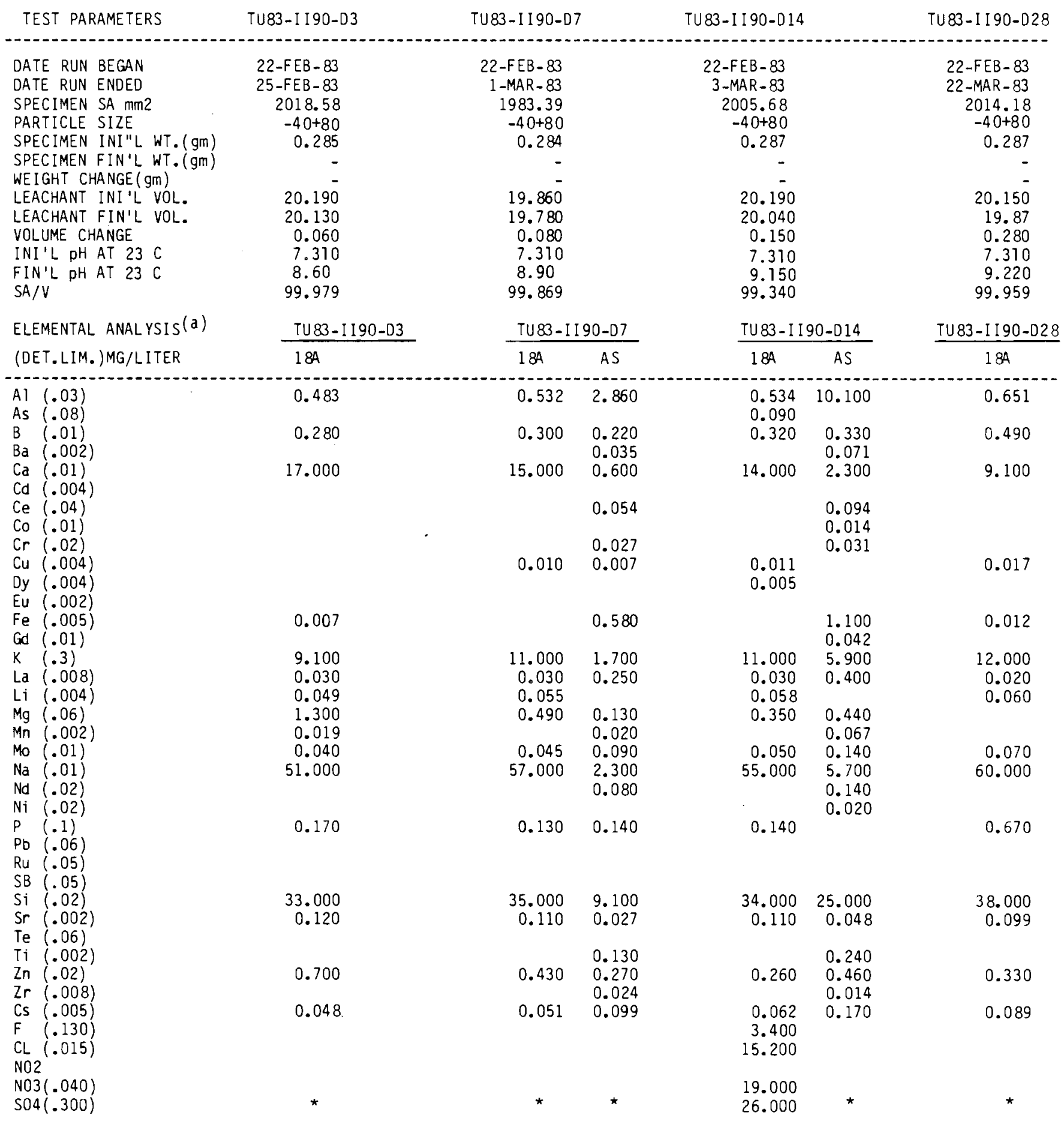

\footnotetext{
184 - 18 Angstrom Filtered Solution

AS - Acid Strip

UN - Unfiltered

$0.45 \mu-45$ microns Filtered Solution

$50 A$ - 50 Angstrom Filtered Solution

* - No Anion Analysis

(a) - Blanks Indicate El ements Below Detection Limits
} 
LLNL WASTE PACKAGE TESTS

LEACH TEST I I DATA (GLASS AND ROCK), TUFF WATER

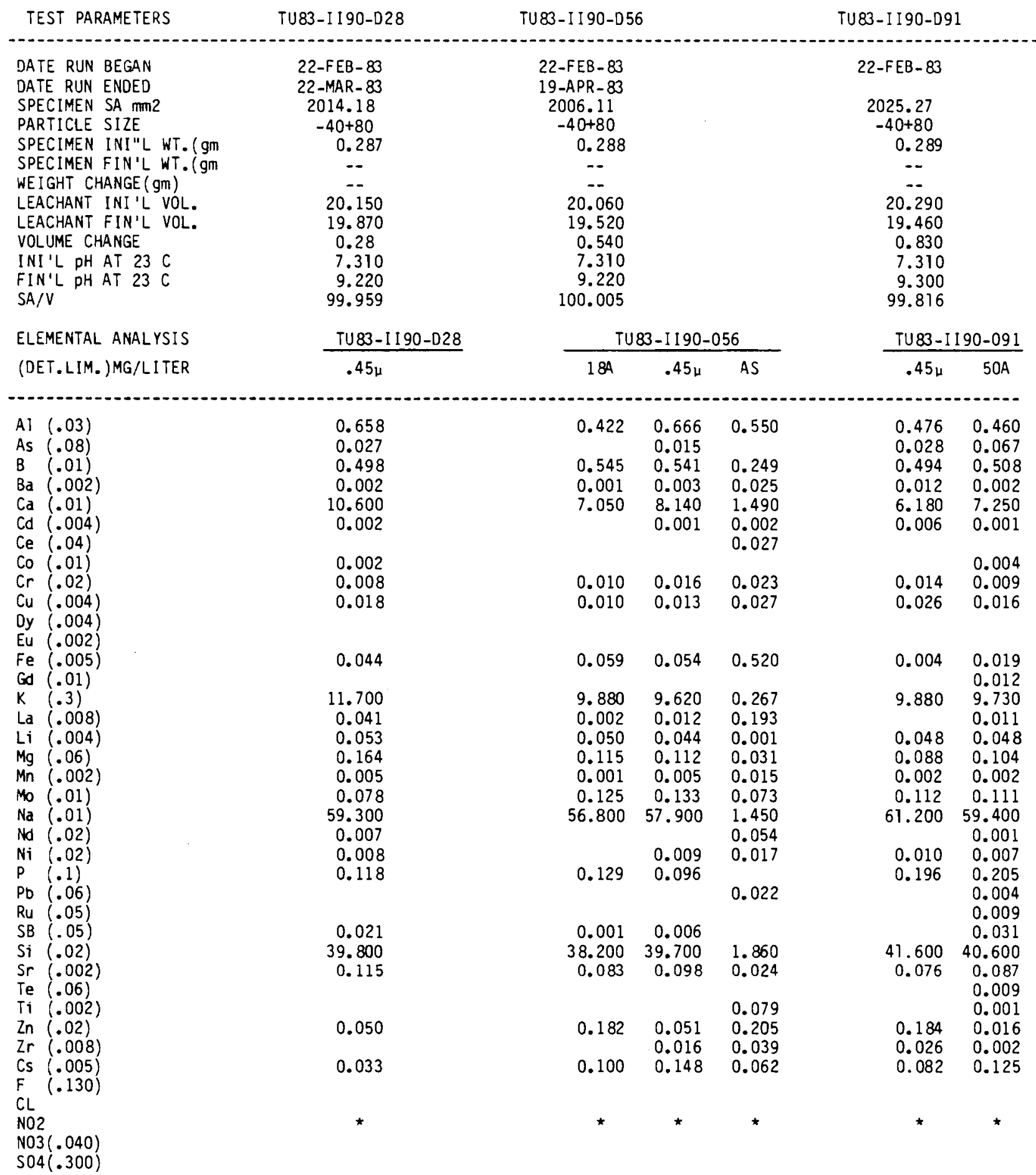

184 - 18 Angstrom Filtered Solution

AS - Acid Strip

UN - Unfiltered

$0.45_{\Perp}$ - 45 microns Filtered Solution

$50 \mathrm{~A}$ - 50 Angstrom Filtered Solution

* - No Anion Analysis

(a) - Blanks Indicate Elements Below Detection Limits 
LLNL WASTE PACKAGE TESTS LEACH TEST II DATA (GLASS + ROCK), TUFF WATER

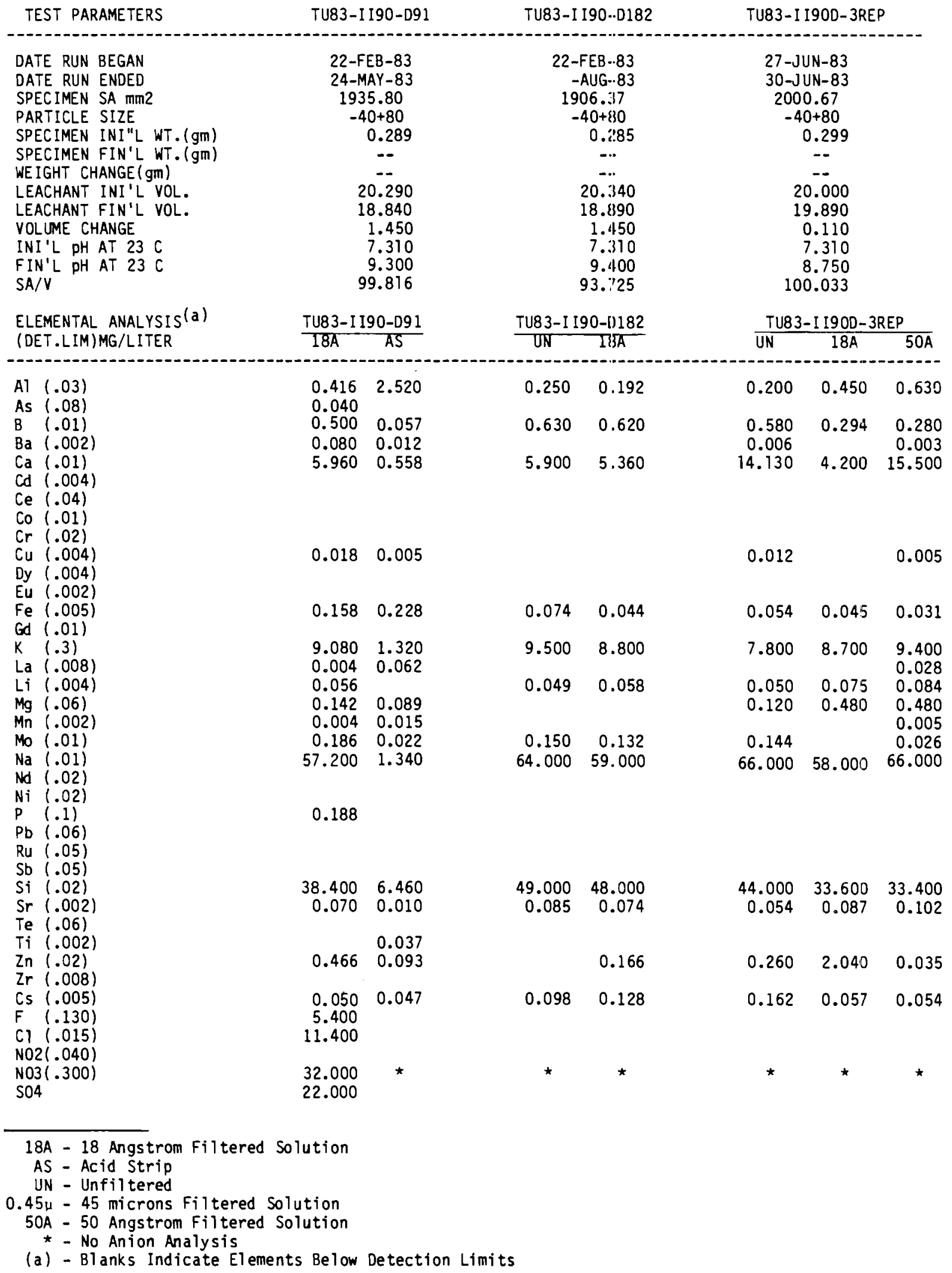


LLNL WASTE PACKATE TESTS LEACH TEST II DATA (GLASS + ROCK), TUFF WATER

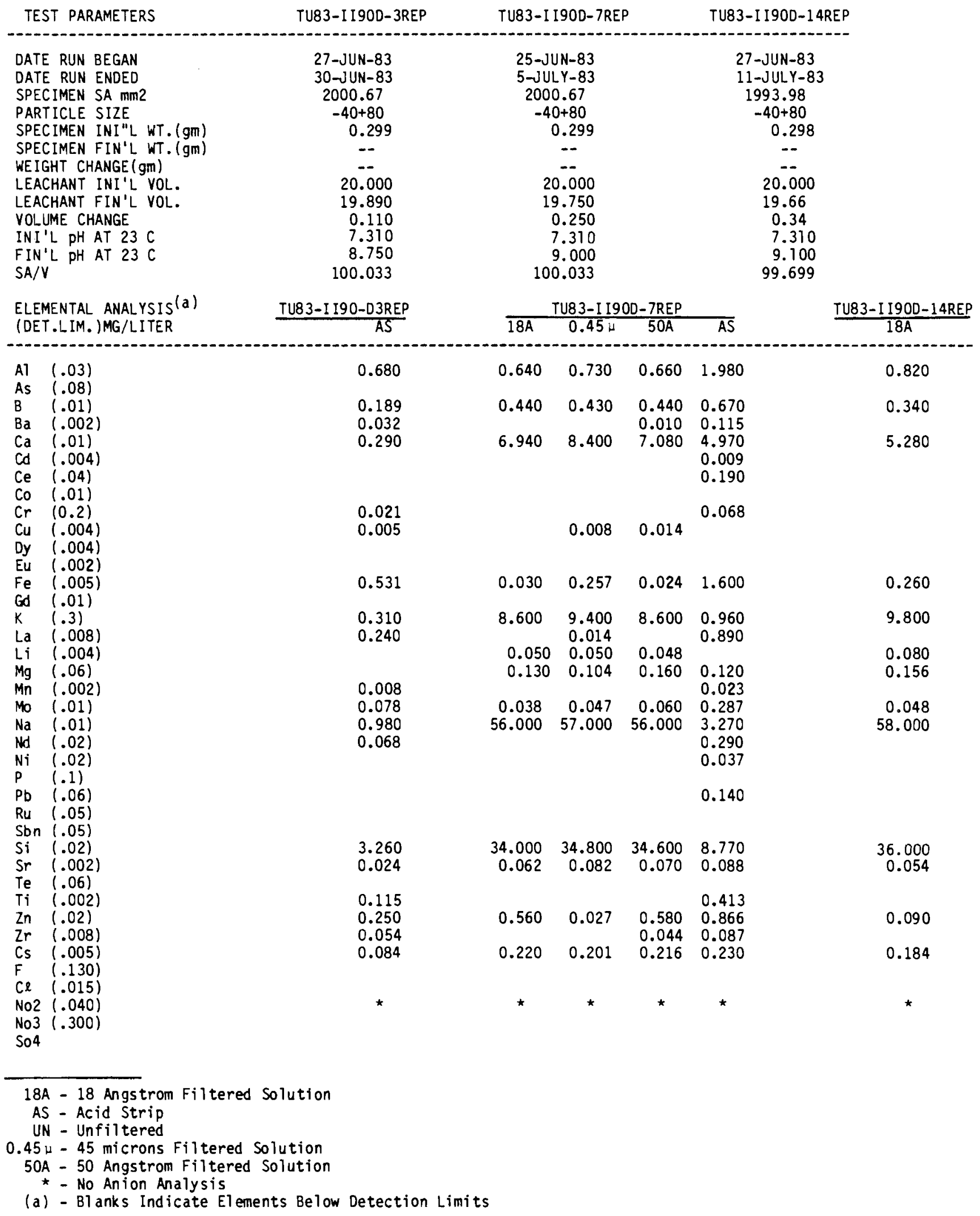


LLNL WASTE PACKAGE TESTS LEACH TEST II DATA (GLASS + ROCK), TUFF WATER

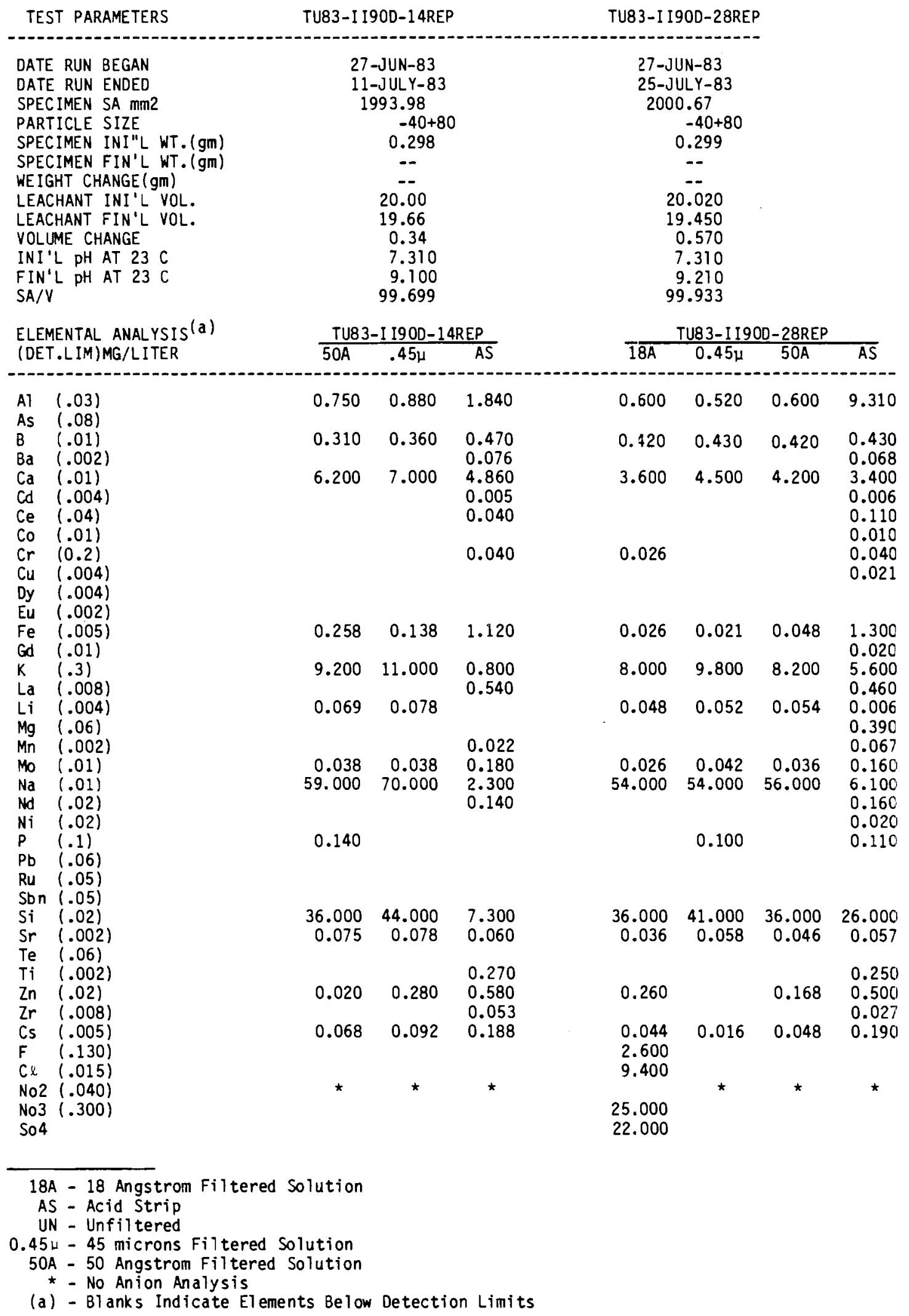


LLNL WASTE PACKAGE TESTS LEACH TEST II DATA (GLASS AND ROCK), TUFF WATER

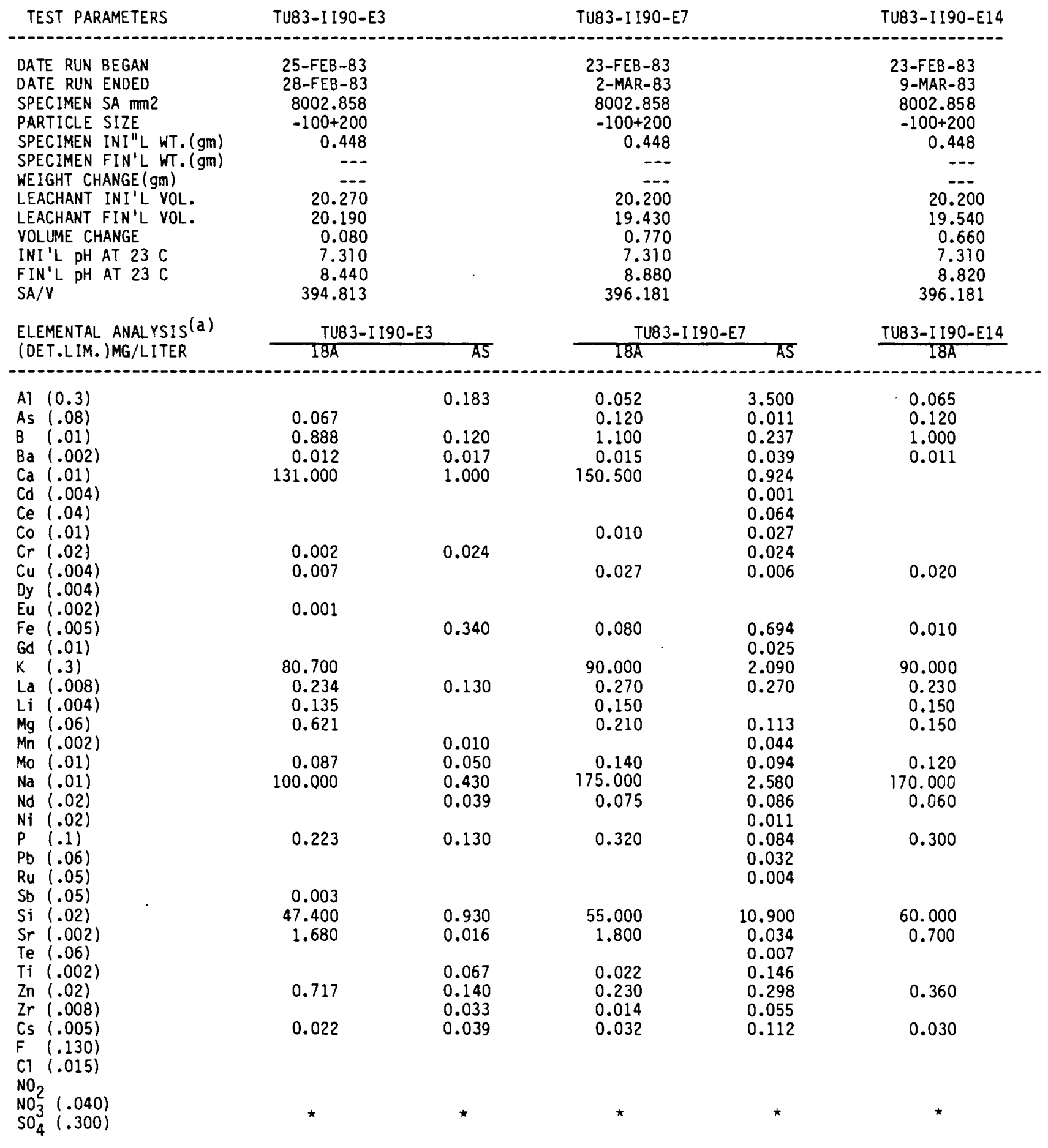

\footnotetext{
18A - 18 Angstrom Filtered Solution

AS - Acid Strip

(a) - Blanks Indicate Elements Below Detection Limits
} 
LLNL WASTE PACKAGE TESTS LEACH TEST II DATA (GL.AS + ROCK), TUFF WATER

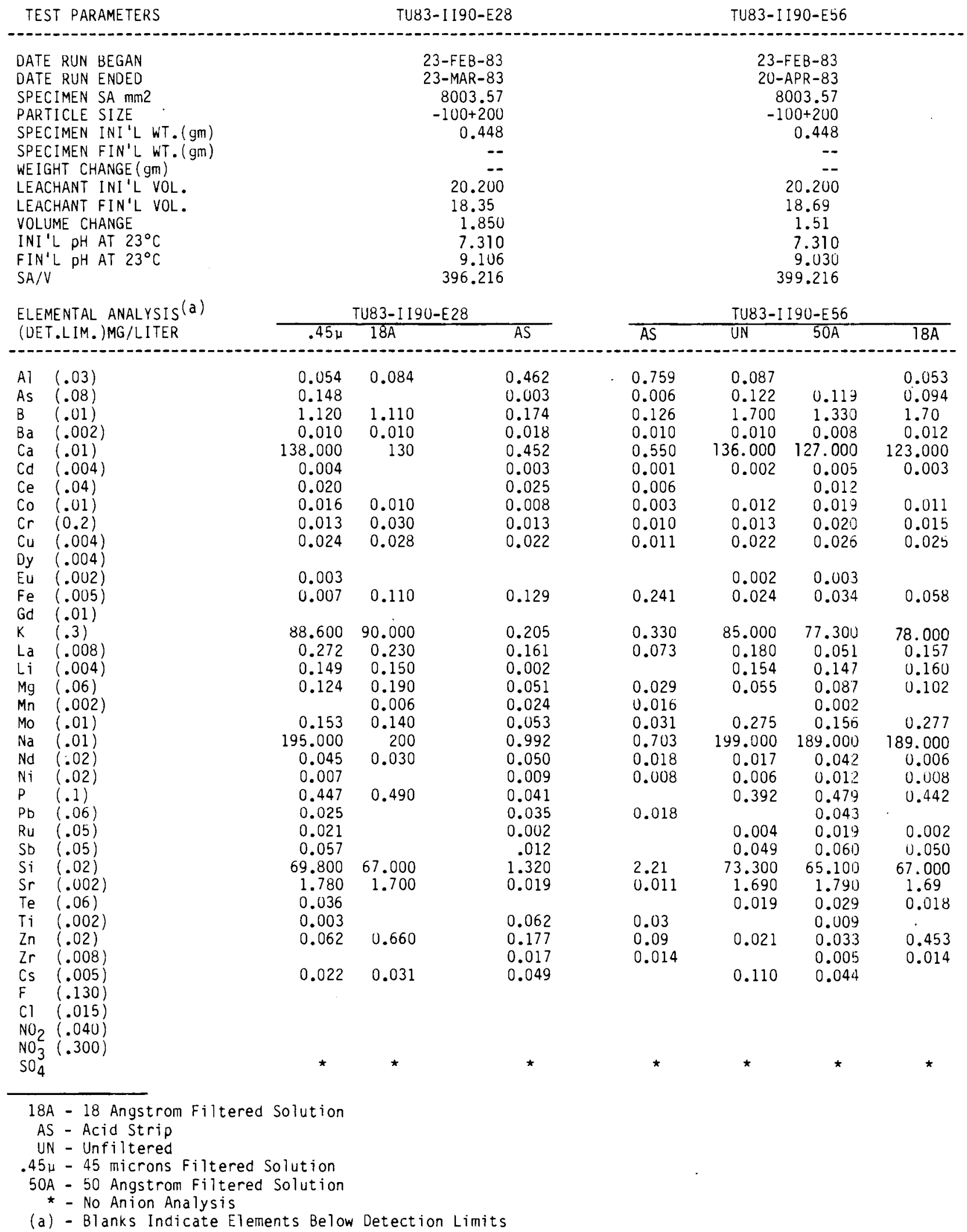


LLNL WASTE PACKAGE TESTS LEACH TEST II DATA (GLASS AND ROCK), TUFF WATER

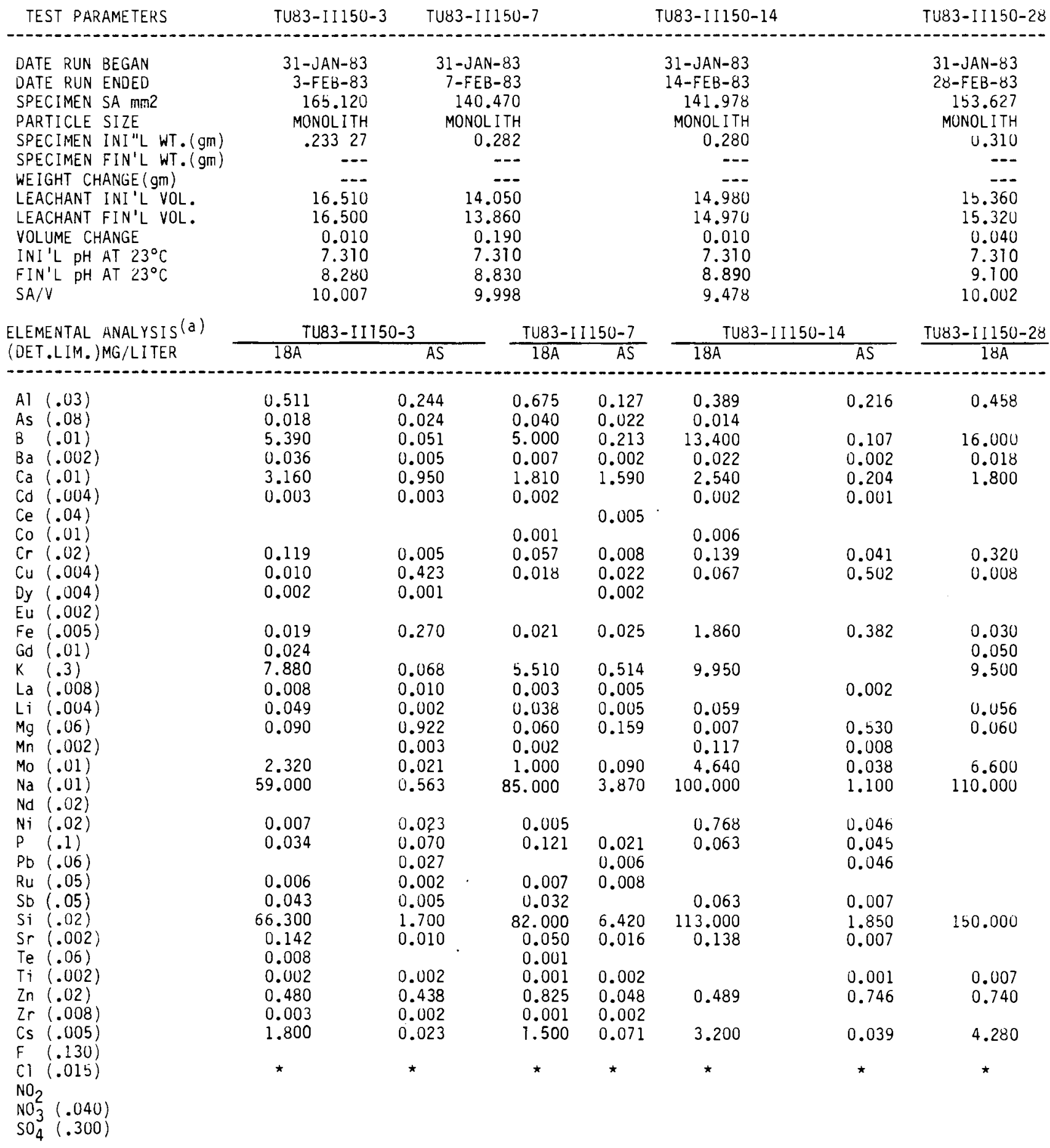

18A - 18 Angstrom Filtered Solution

AS - Acid Strip

UN - Unfiltered

(a) - Blanks Indicate Elements Below Detection Limits 
LLNL WASTE PACKAGE TESTS LEACH TEST II DATA (GLAS.S AND ROCK), TUFF WATER

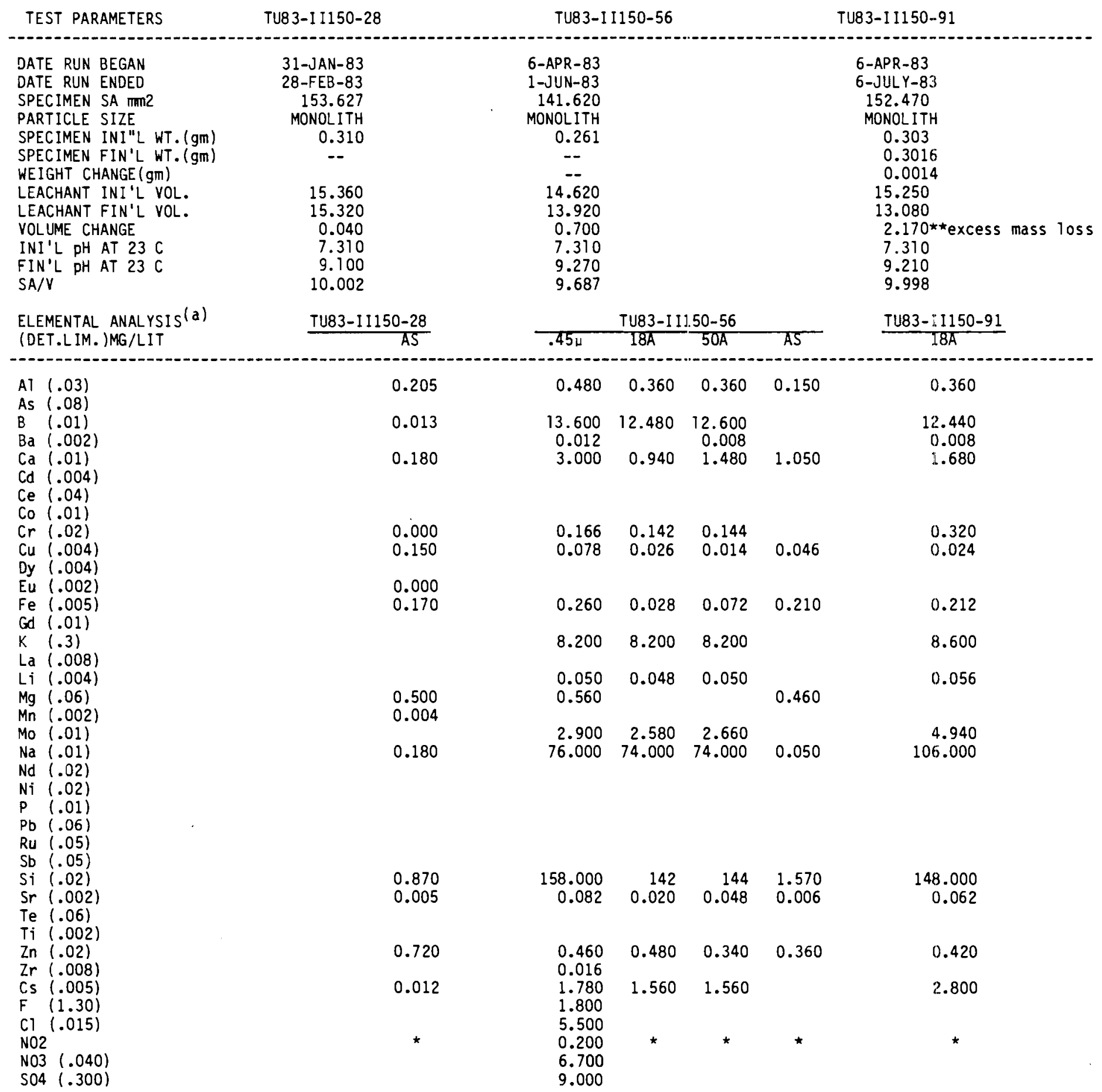

\footnotetext{
18A - 18 Angstrom Fittered Solution

AS - Acid Strip

UN - Unfiltered

$0.45 \mu-45$ microns Filtered Solution

$50 \mathrm{~A}$ - 50 Angstrom Filtered Solution

* - No Anion Analysis
}

(a) - Blanks Indicate Elements Below Detection Limits 
LLNL WASTE PACKAGE TEST

LEACH TEST DATA FOR TEST III (GLASS, ROCK AND METAL)

$40,70,90,150^{\circ} \mathrm{C}$, STATIC

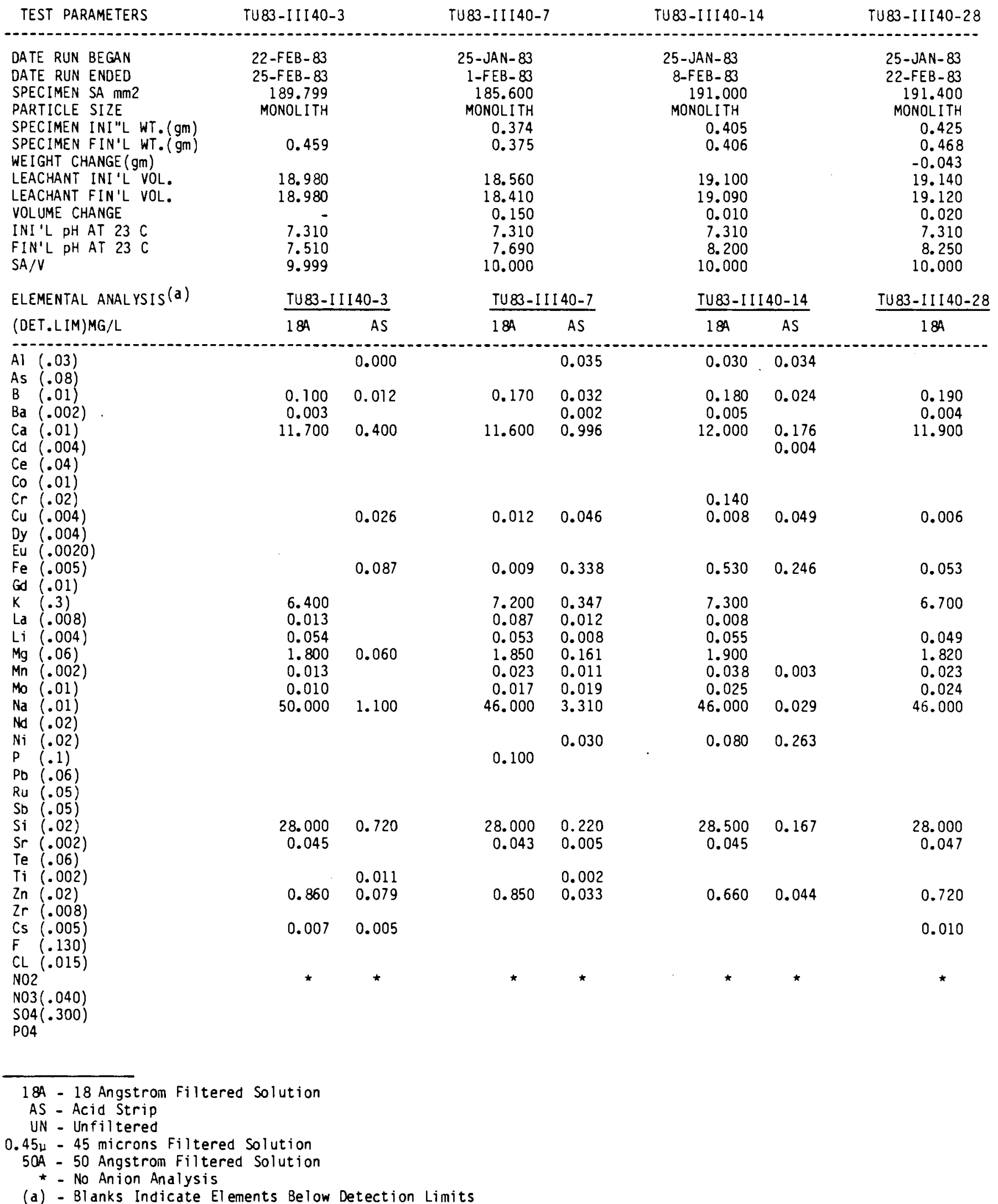


LLNL WASTE PACKAGE TESTS LEACH TEST II DATA 'GLASS, ROCK AND METAL), TUFF WATER $40,70,90,150^{\circ} \mathrm{C}$, STATIC

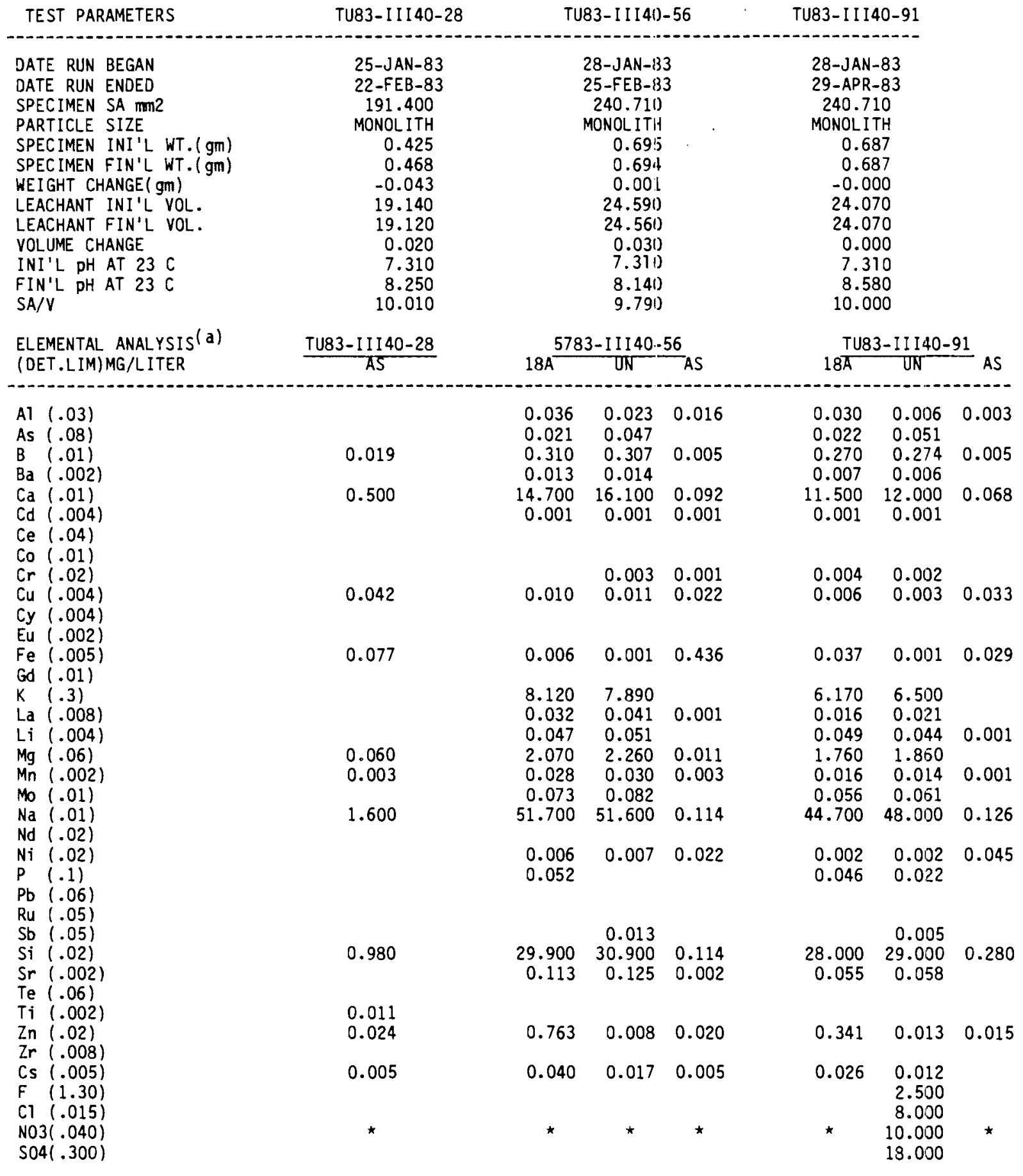

\footnotetext{
18A - 18 Angstrom Filtered Solution

AS - Acid Strip

UN - Unfiltered

$0.45 \mu-45$ microns filtered Solution

$50 A$ - 50 Angstrom Filtered Solution

* - No Anion Analysis
}

(a) - Blanks Indicate Elements Below Detection Limits 
LLNL WASTE PACKAGE TESTS LEACH TEST II I DATA (GLASS, ROCK AND METAL), TUFF WATER $40,70,90,150^{\circ} \mathrm{C}$, STATIC

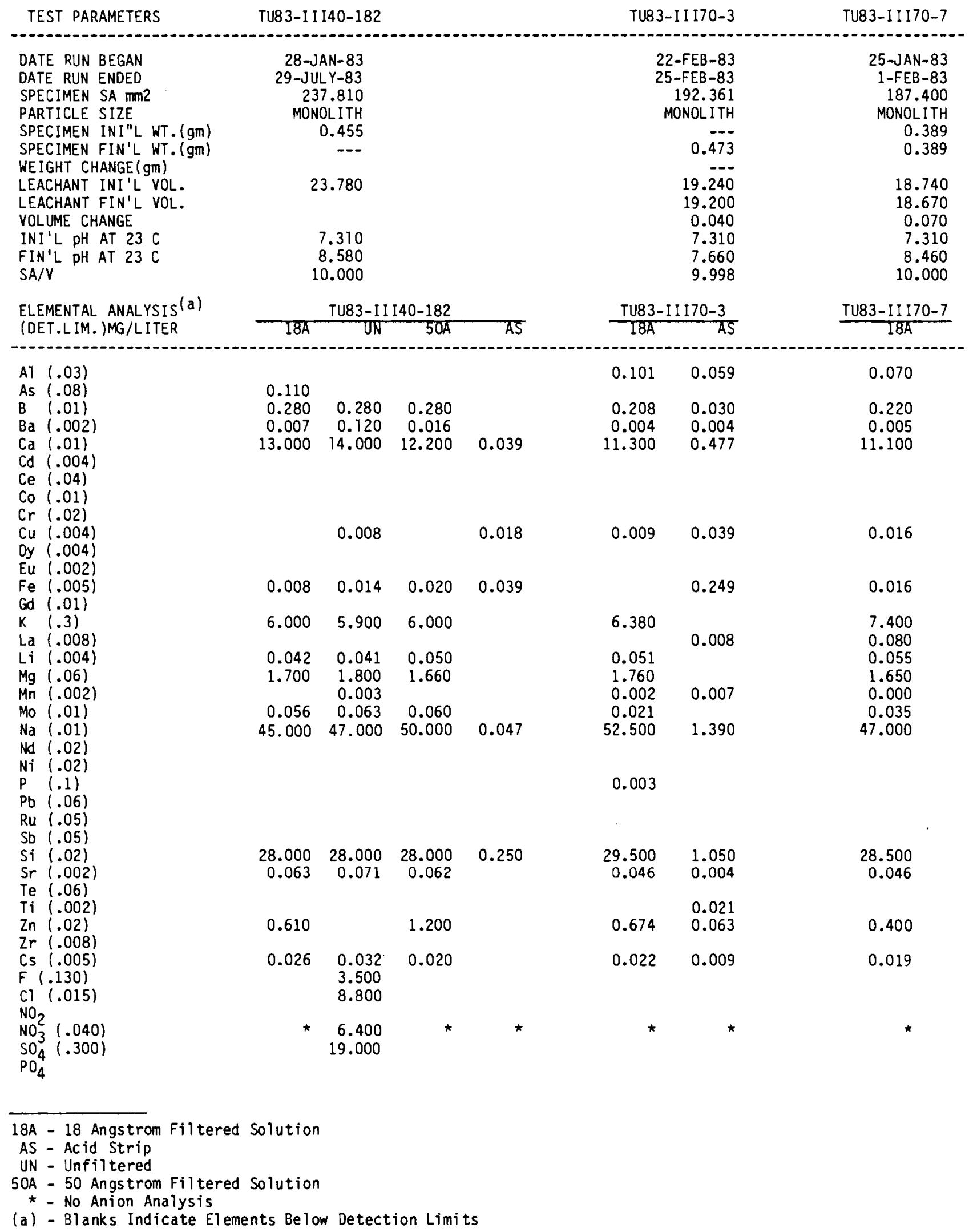


LLNL WASTE PACKAGE TESTS LEACH TEST I I I DATA (GLASS, ROCK AND METAL), TUFF WATER $40,70,90,150^{\circ} \mathrm{C}$, STATIC

\begin{tabular}{|c|c|c|c|c|c|c|c|}
\hline TEST PARAMETERS & TU83-I II70-7 & \multicolumn{2}{|c|}{ TU83-I I I70-14 } & \multicolumn{2}{|c|}{ TU83-I I I70-28 } & \multicolumn{2}{|c|}{ TU83-I I I70-56 } \\
\hline $\begin{array}{l}\text { DATE RUN BEGAN } \\
\text { DATE RUN ENDED } \\
\text { SPECIMEN SA mm2 } \\
\text { PARTICLE SIZE } \\
\text { SPECIMEN INI"L WT. }(\mathrm{gm}) \\
\text { SPECIMEN FIN'L WT. }(\mathrm{gm}) \\
\text { WEIGHT CHANGE (gm) } \\
\text { LEACHANT INI'L VOL. } \\
\text { LEACHANT FIN'L VOL. } \\
\text { VOLUME CHANGE } \\
\text { INI'L PH AT } 23 \mathrm{C} \\
\text { FIN'L PH AT } 23 \mathrm{C} \\
\text { SA } / V\end{array}$ & $\begin{array}{r}25-J A N-83 \\
1-\text { FEB }-83 \\
187.400 \\
\text { MONOLITH } \\
0.389 \\
0.389 \\
--.- \\
18.740 \\
18.670 \\
0.070 \\
7.310 \\
8.460 \\
10.000\end{array}$ & \multicolumn{2}{|c|}{$\begin{array}{l}\text { 25-JAN-83 } \\
\text { 8-FEB-83 } \\
189.100 \\
\text { MONOLITH } \\
0.403 \\
0.403\end{array}$} & \multicolumn{2}{|c|}{$\begin{array}{c}26-J A N-83 \\
23-F E B-83 \\
192.630 \\
\text { MONOL I TH } \\
0.468 \\
0.469\end{array}$} & \multicolumn{2}{|c|}{$\begin{array}{r}28-J \text { AN-83 } \\
\text { 25-MAR-83 } \\
238.800 \\
\text { MONOL ITH } \\
0.688 \\
0.688 \\
-0.000 \\
23.880 \\
23.730 \\
0.150 \\
7.310 \\
8.840 \\
10.000\end{array}$} \\
\hline $\begin{array}{l}\text { ELEMENTAL ANALYSIS }(a) \\
\text { (DET.LIM)MG/LITER }\end{array}$ & $\frac{\text { TU83-I I I-70-7 }}{A S}$ & $\frac{\text { TU83-II }}{18 \mathrm{~A}}$ & $\frac{70-14}{A S}$ & $\frac{\text { IU83-I }}{18 \mathrm{~A}}$ & $\frac{170-28}{A S}$ & $\frac{\text { TU83-I }}{18 A}$ & $\frac{I I 70-56}{U N}$ \\
\hline $\begin{array}{ll}\mathrm{A} 1 & (.03) \\
\mathrm{As} & (.08) \\
\mathrm{B} & (.01) \\
\mathrm{Bd} & (.002) \\
\mathrm{Ca} & (.01) \\
\mathrm{Cd} & (.004) \\
\mathrm{Ce} & (.04) \\
\mathrm{Co} & (.01) \\
\mathrm{Cr} & (.02) \\
\mathrm{Cu} & (.004) \\
\mathrm{Dy} & (.004) \\
\mathrm{Eu} & (.002) \\
\mathrm{Fe} & (.005) \\
\mathrm{Gd} & (.01) \\
\mathrm{K} & (.3) \\
\mathrm{La} & (.008) \\
\mathrm{Li} & (.004) \\
\mathrm{Mg} & (.06) \\
\mathrm{Mn} & (.002) \\
\mathrm{Mb} & (.01) \\
\mathrm{Na} & (.01) \\
\mathrm{Nd} & (.02) \\
\mathrm{Ni} & (.02) \\
\mathrm{P} & (.1) \\
\mathrm{Pb} & (.06) \\
\mathrm{Ru} & (.05) \\
\mathrm{Sb} & (.05) \\
\mathrm{Si} & (.02) \\
\mathrm{Sr} & (.002) \\
\mathrm{Te} & (.06) \\
\mathrm{Ti} & (.002) \\
\mathrm{Zn} & (.02) \\
\mathrm{Zr} & (.008) \\
\mathrm{Cs} & (.005) \\
\mathrm{F} & (.130) \\
\mathrm{Cl} & (.015) \\
\mathrm{NO} & \\
\mathrm{NO} & (.040) \\
\mathrm{SO} & (.300) \\
\mathrm{PO} & \end{array}$ & $\begin{array}{l}0.009 \\
0.007 \\
0.096 \\
0.007 \\
1.620\end{array}$ & $\begin{array}{r}0.024 \\
7.400 \\
0.014 \\
0.050 \\
1.400 \\
0.096 \\
46.000\end{array}$ & $\begin{array}{l}0.012 \\
0.002 \\
0.027\end{array}$ & $\begin{array}{r}6.480 \\
\\
0.051 \\
0.342 \\
0.093 \\
0.229 \\
50.000 \\
C .105\end{array}$ & $\begin{array}{l}0.210 \\
0.013 \\
0.844 \\
0.023\end{array}$ & $\begin{array}{r}8.500 \\
0.017 \\
0.047 \\
0.505 \\
\\
0.439 \\
50.500\end{array}$ & $\begin{array}{r}0.018 \\
8.400 \\
0.029 \\
0.052 \\
0.586 \\
0.479 \\
53.100 \\
\\
0.101 \\
0.004 \\
37.200 \\
0.116\end{array}$ \\
\hline $\begin{array}{l}\text { 18A - } 18 \text { Angstrom Filtered } \\
\text { AS - Acid Strip } \\
\text { UN - Unfiltered } \\
\star \text { - No Anion Analysis } \\
\text { (a) - Blanks Indicate Eleme }\end{array}$ & ents Below De & & & & & & \\
\hline
\end{tabular}


LLNL WASTE PACKAGE TESTS LEACH TEST II I DATA (GLASS, ROCK AND METAL), TUFF WATER $40,70,90,150^{\circ} \mathrm{C}$, STATIC

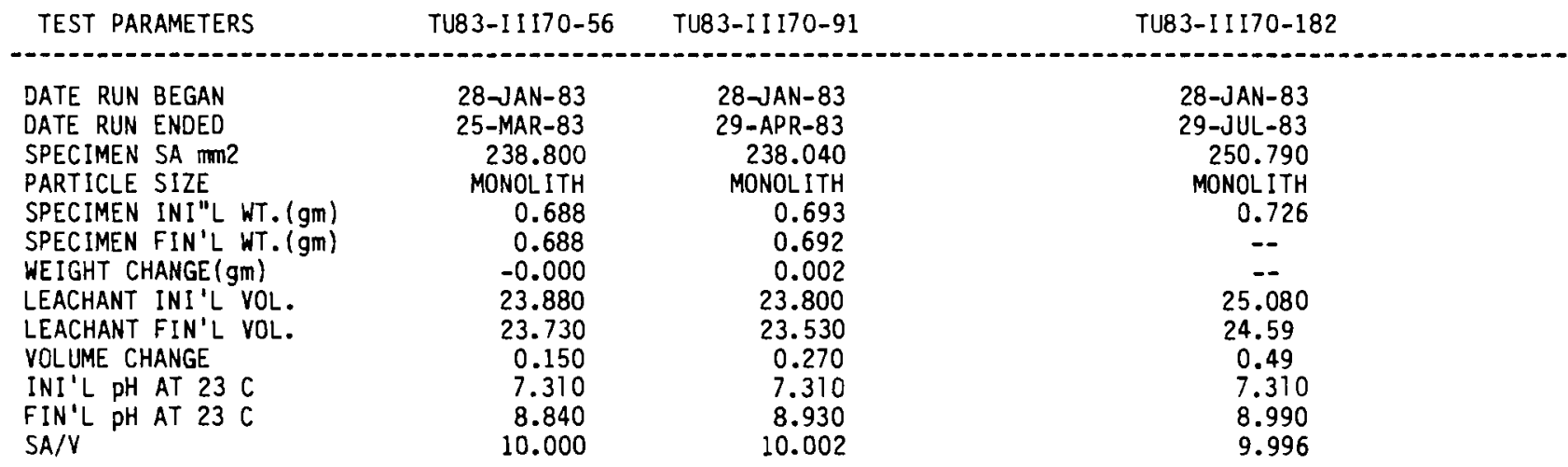

(A)

ELEMENTAL ANALYSIS

(DET. LIM) MG/LITER
TU83-III70-56

$\frac{\text { TU83-III 70-91 }}{18 \mathrm{~A}} \mathrm{UN}$

$\mathrm{Ca}(.01)$

$\mathrm{Cd}(.004)$

$\mathrm{Ce}(.04)$

Co $(.01)$

$\mathrm{Cr}(.02)$

$\mathrm{Cu}(.004)$

Dy $(.004)$

Eu $(.002)$

$\mathrm{Fe}(.005)$

$\mathrm{Gd}(.01)$

$\mathrm{K} \quad(.3)$

La $(.008)$

Li $(.004)$

$\mathrm{Mg}(.06)$

$\mathrm{Nn}(.002)$

Mo $(.01)$

$\mathrm{Na}(.01)$

Nd $(.02)$

$\mathrm{Ni}(.02)$

$P \quad(.1)$

$\mathrm{Pb}(.06)$

$\mathrm{Ru}(.05)$

$\mathrm{Sb}(.05)$

$\mathrm{Si}(.02)$

Sr $(.002)$

$\mathrm{Te}(.06)$

Ti $(.002)$

$\mathrm{Zn}(.02)$

$\mathrm{Zr}(.008)$

Cs $(.005)$

$\mathrm{F} \quad(.130)$

C1 (.015)

$\mathrm{NO} 3(.040)$

$504(.300)$
0.037

$$
0.011
$$

$$
\text { 2. } 230
$$

0.002

0.064

0.039

2.160

0.024

6.420

5.960

0.001

0.008

0.039

0.004

0.041

0.005

0.019

0.062

0.019

0.001

0.010

6.900

0.002

0.050
0.169

0.060

0.001

0.009

7.670

0.013

0.044

0.188

0.903

0.957

56.000

0.008

49.700

0.002

0.022

0.003

0.206

0.019

0.002

0.282

0.002

0.018

1.190

0.025

0.200
0.002

0.020

34.000

34.800

0.132

0.145

1.430

0.005

0.121

0.001

0.223

0.300

0.012

0.400

4.300

11.500

8.800

18.000

\subsection{0}

$\frac{\text { TU83-III70-182 }}{18 \mathrm{~A}} \mathrm{UN}$

$\frac{1083-11170-182}{18 \mathrm{~A} \quad \text { UN } 50 \mathrm{~A}}$

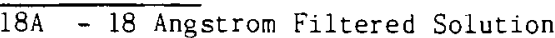

AS - Acid Strip

UN - Unfiltered

50A - 50 Angstrom Filcered Solution

* - No Anion Analysis

(a) - Blanks Indicate Elements Below Detection Limits 
LLNL WASTE PACKAGE TESTS LEACH TEST II I DATA (GLASS, ROCK AND METAL), TUFF WATER $40,70,90,150^{\circ} \mathrm{C}$, STATIC

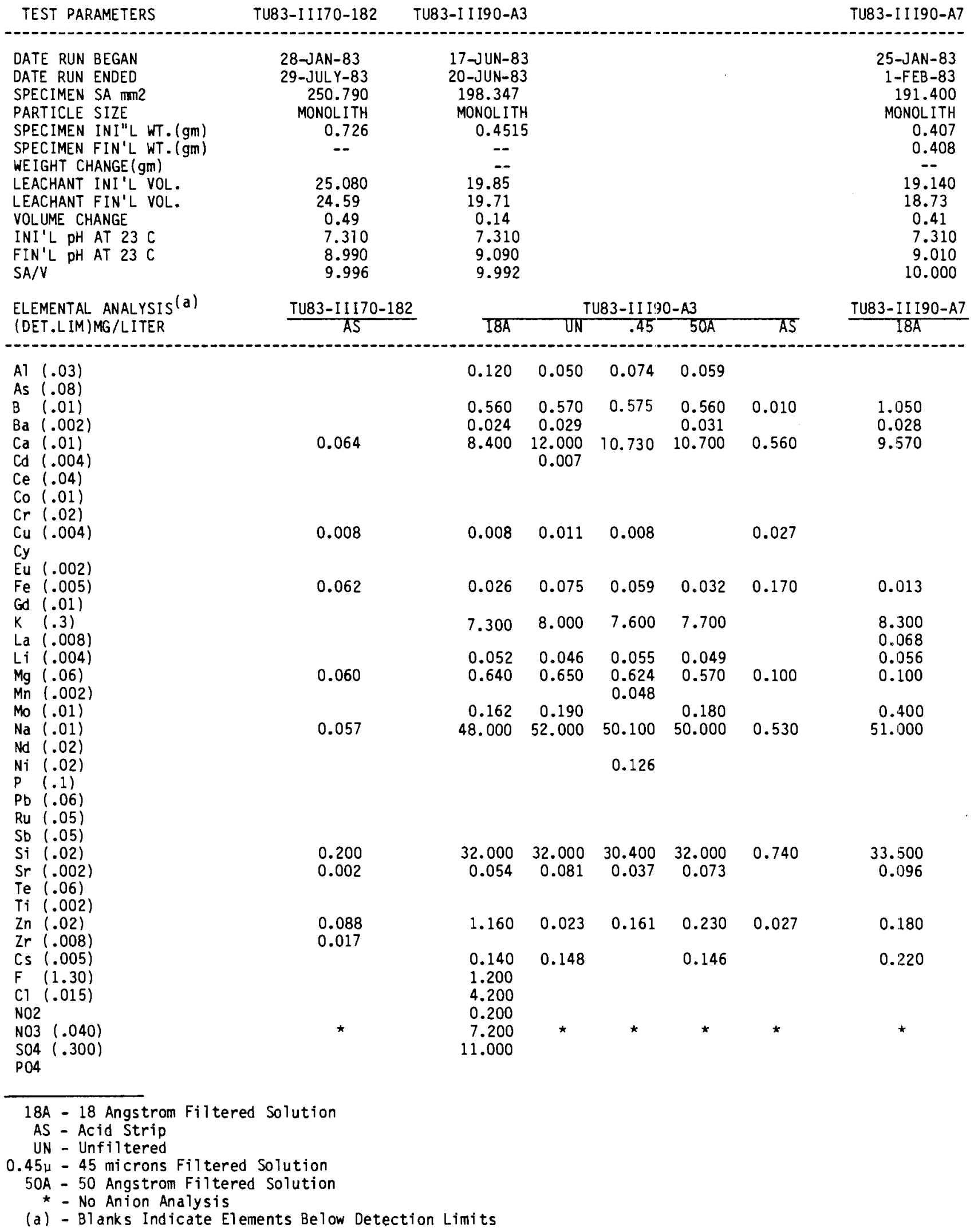


LLNL WASTE PACKAGE TESTS LEACH TEST I I DATA (GLASS, ROCK AND METAL), TUFF WATER $40,70,90,150^{\circ} \mathrm{C}$, STATIC

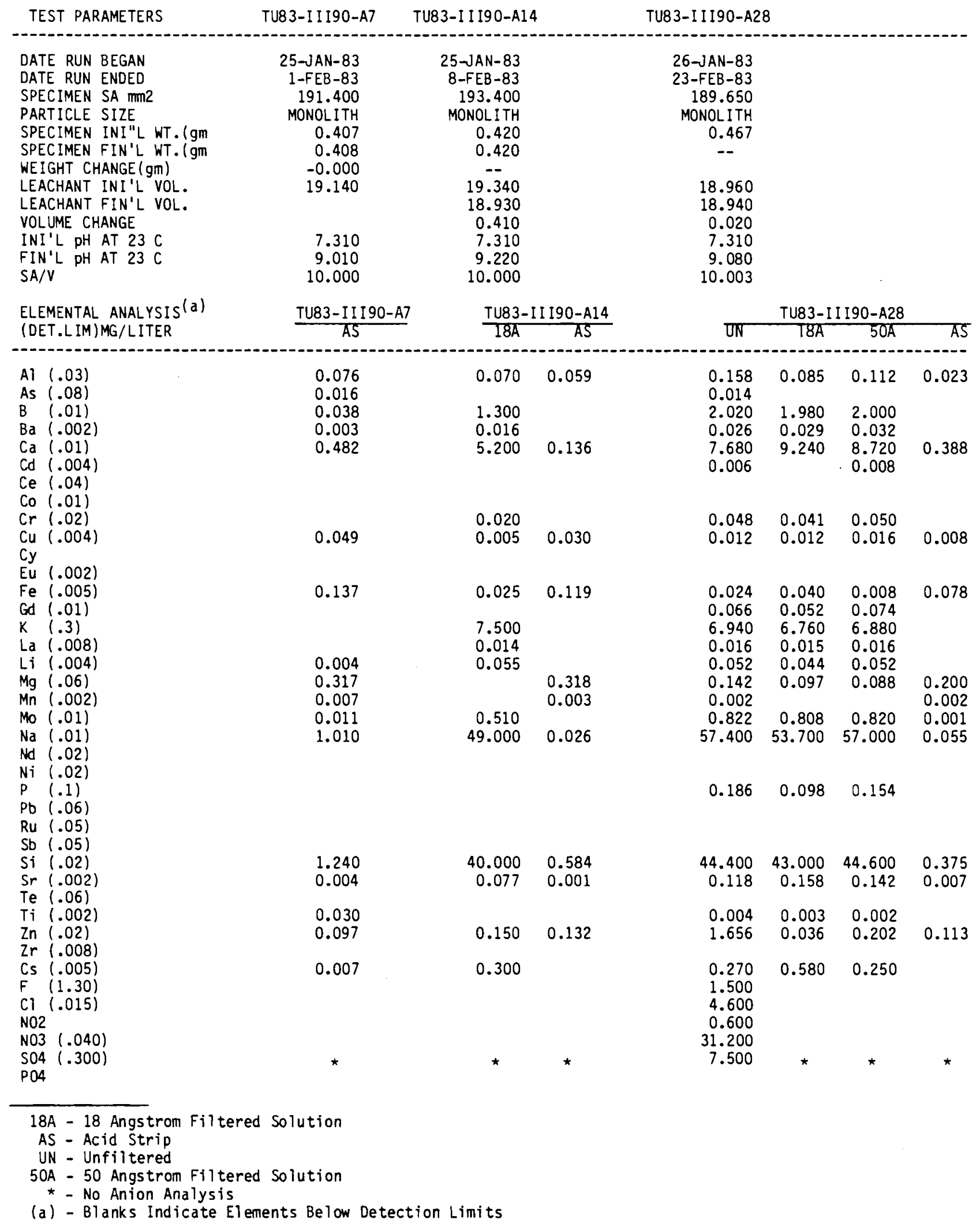


LLNL WASTE PACKAGE TEST

LEACH TEST DATA FOR TEST III (GLASS, ROCK, AND METAL)

$40,70,90,150^{\circ} \mathrm{C}, \subseteq$ TATIC

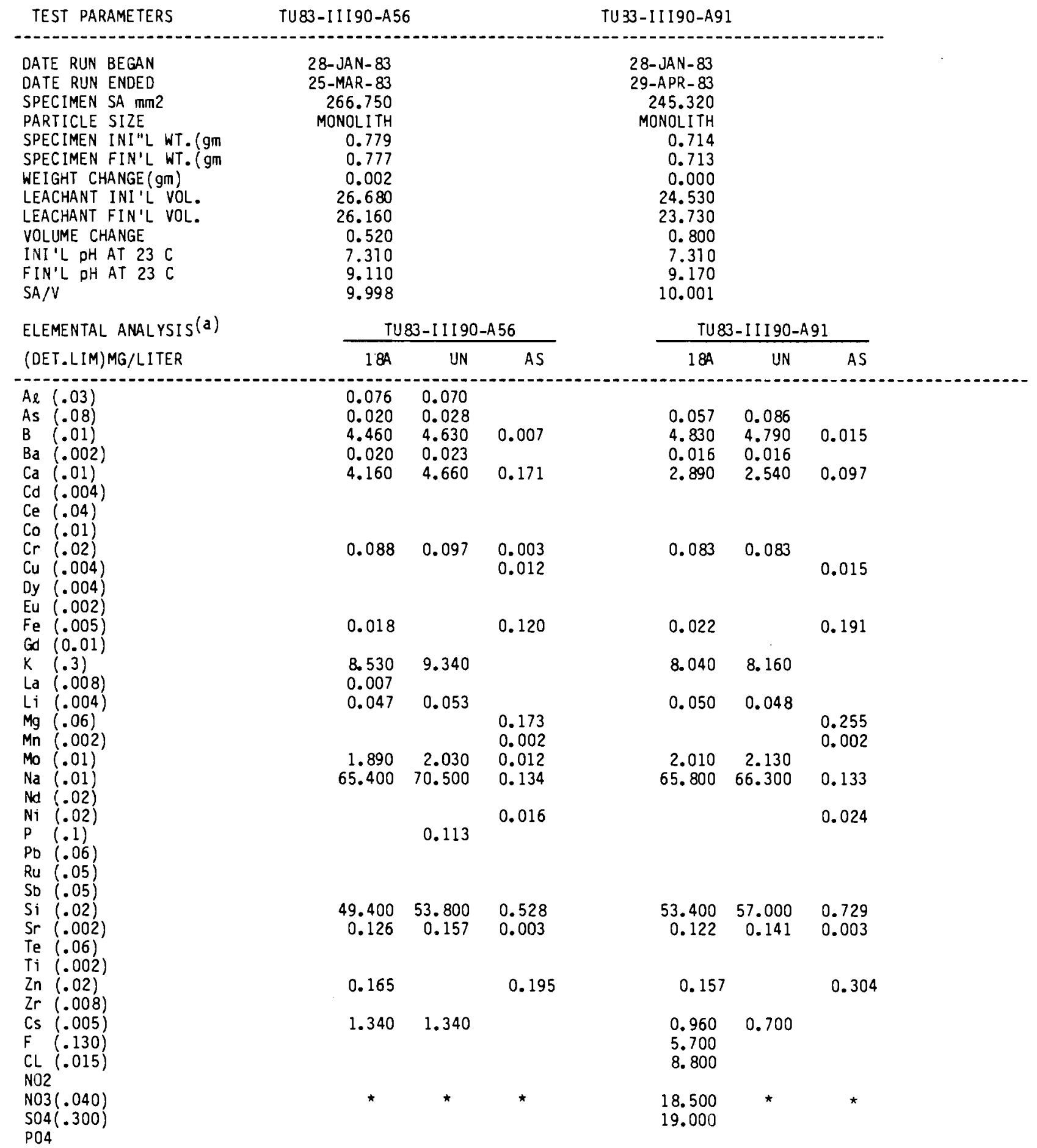

\footnotetext{
184 - 18 Angstrom Filtered Solution

AS - Acid Strip

UN - Unfiltered

$0.45 \mu-45$ microns filtered Solution

50A - 50 Angstrom Filtered Solution
}

* - No Anion Analysis

(a) - Blanks Indicate Elements Below Detection Limits 
LLNL WASTE PACKAGE TESTS LEACH TEST III DATA

(GLASS , ROCK AND METAL), TUFF WATER

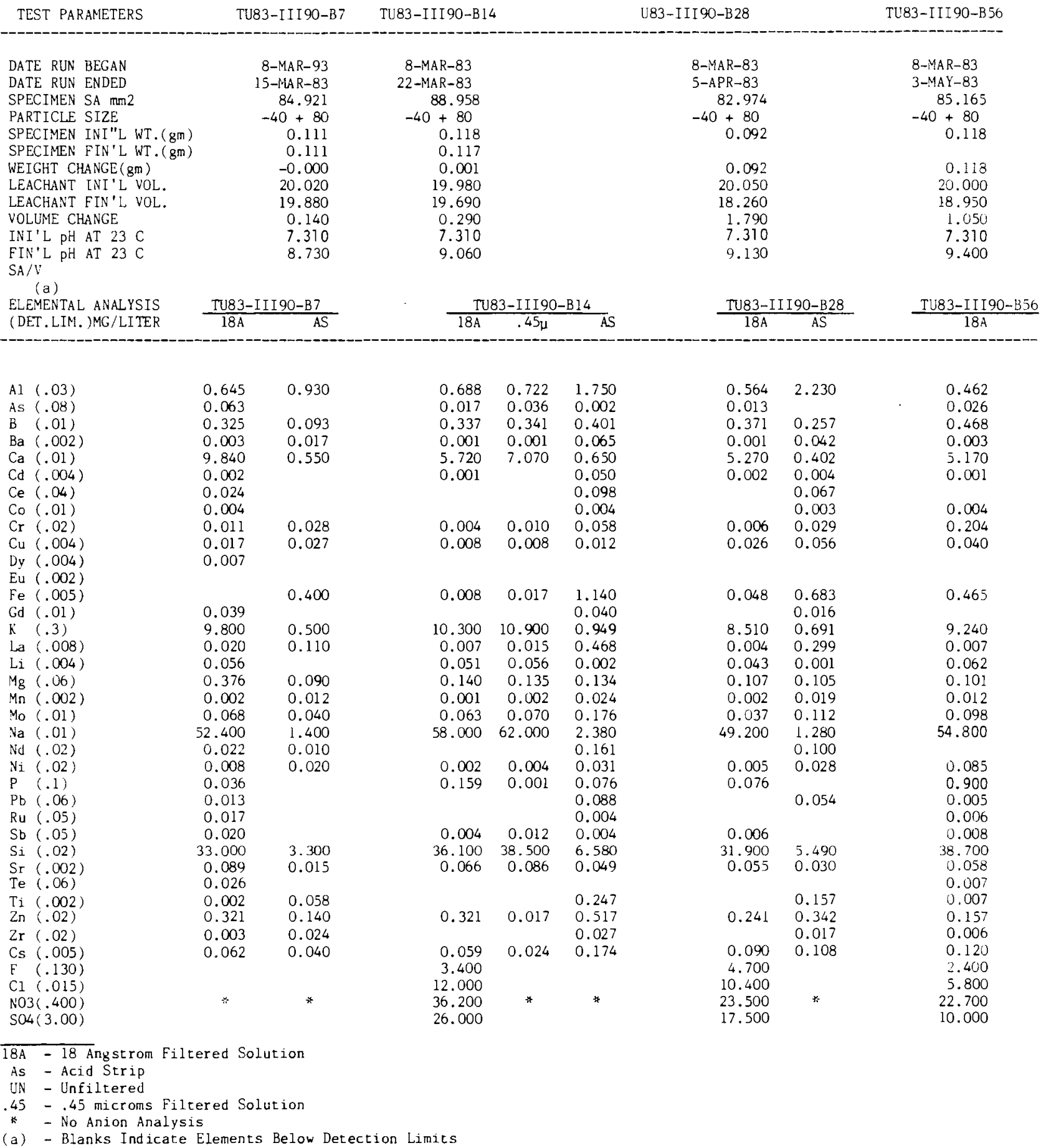




\begin{tabular}{|c|c|c|}
\hline TEST PARAMETERS & \multicolumn{2}{|c|}{ TU83-I I I 90-B3 } \\
\hline $\begin{array}{l}\text { OATE RUN BEGAN } \\
\text { DATE RUN ENDED } \\
\text { SPECIMEN SA mm2 } \\
\text { PARTICLE SIZE } \\
\text { SPECIMEN INI'L WT. }(g m) \\
\text { SPECIMEN FIN'L WT. }(g m) \\
\text { WEIGHT CHANGE (gm) } \\
\text { LEACHANT INI'L VOL. } \\
\text { LEACHANT FIN'L VOL. } \\
\text { VOLUME CHANGE } \\
\text { INI'L PH AT } 23 \mathrm{C} \\
\text { FIN'L PH AT } 23 \mathrm{C} \\
\text { SA/V }\end{array}$ & \multicolumn{2}{|c|}{$\begin{array}{r}08-M A R-83 \\
17-M A R-83 \\
1998.4 \\
-40+80 \\
0.110 \\
0.117 \\
0.007 \\
19.960 \\
19.870 \\
0.090 \\
7.46 \\
8.64 \\
100.12\end{array}$} \\
\hline $\begin{array}{l}\text { ELEMENTAL ANALYSIS(a) } \\
\text { (DET.LIM.)MG/LITER }\end{array}$ & \multicolumn{2}{|c|}{$\frac{\text { TU83-I I190-B3 }}{18 A}$} \\
\hline 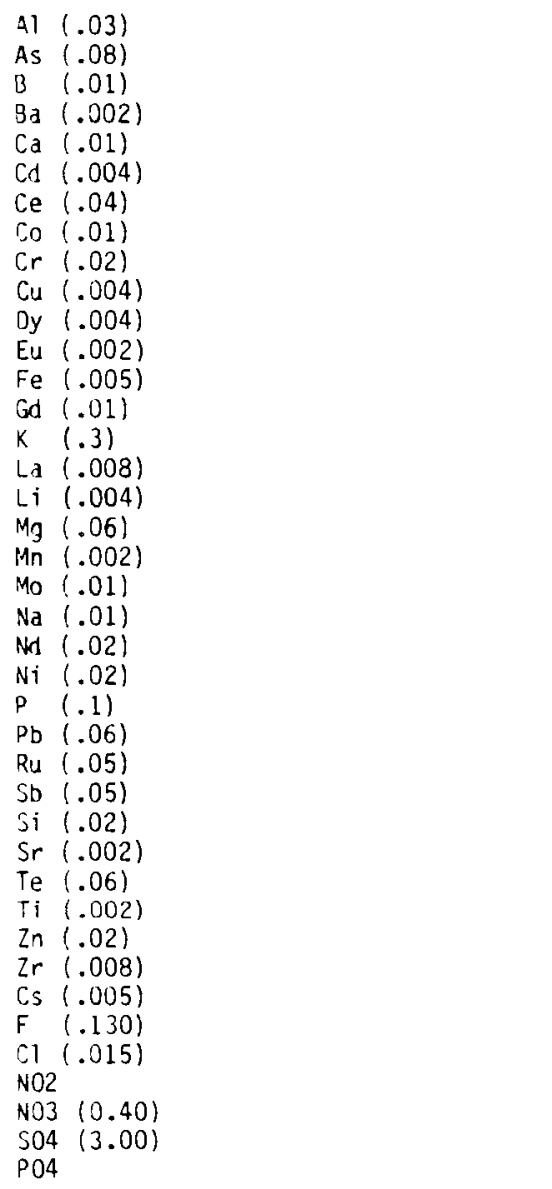 & $\begin{array}{r}0.008 \\
9.200 \\
0.030 \\
0.053 \\
0.630 \\
0.070 \\
52.000 \\
0.140\end{array}$ & $\begin{array}{l}0.940 \\
0.040 \\
0.700 \\
0.430 \\
0.100 \\
0.015 \\
0.140 \\
2.200 \\
0.140 \\
0.030\end{array}$ \\
\hline $\begin{aligned} 18 A & -18 \text { Angstrom Filtered Solution } \\
\text { AS } & \text { - Acid Strip } \\
\text { UN } & \text { Unfiltered } \\
0.45 & -45 \text { microns Filtered Solution } \\
50 A & -50 \text { Angstrom Filtered Solution } \\
& - \text { No Anion Analysis }\end{aligned}$ & & \\
\hline
\end{tabular}


LLNL WASTE PACKAGE TESTS LEACH TEST III DATA (GLASS, ROCK AND METAL), TUFF WATER $40,70,90,150^{\circ} \mathrm{C}$, STATIC

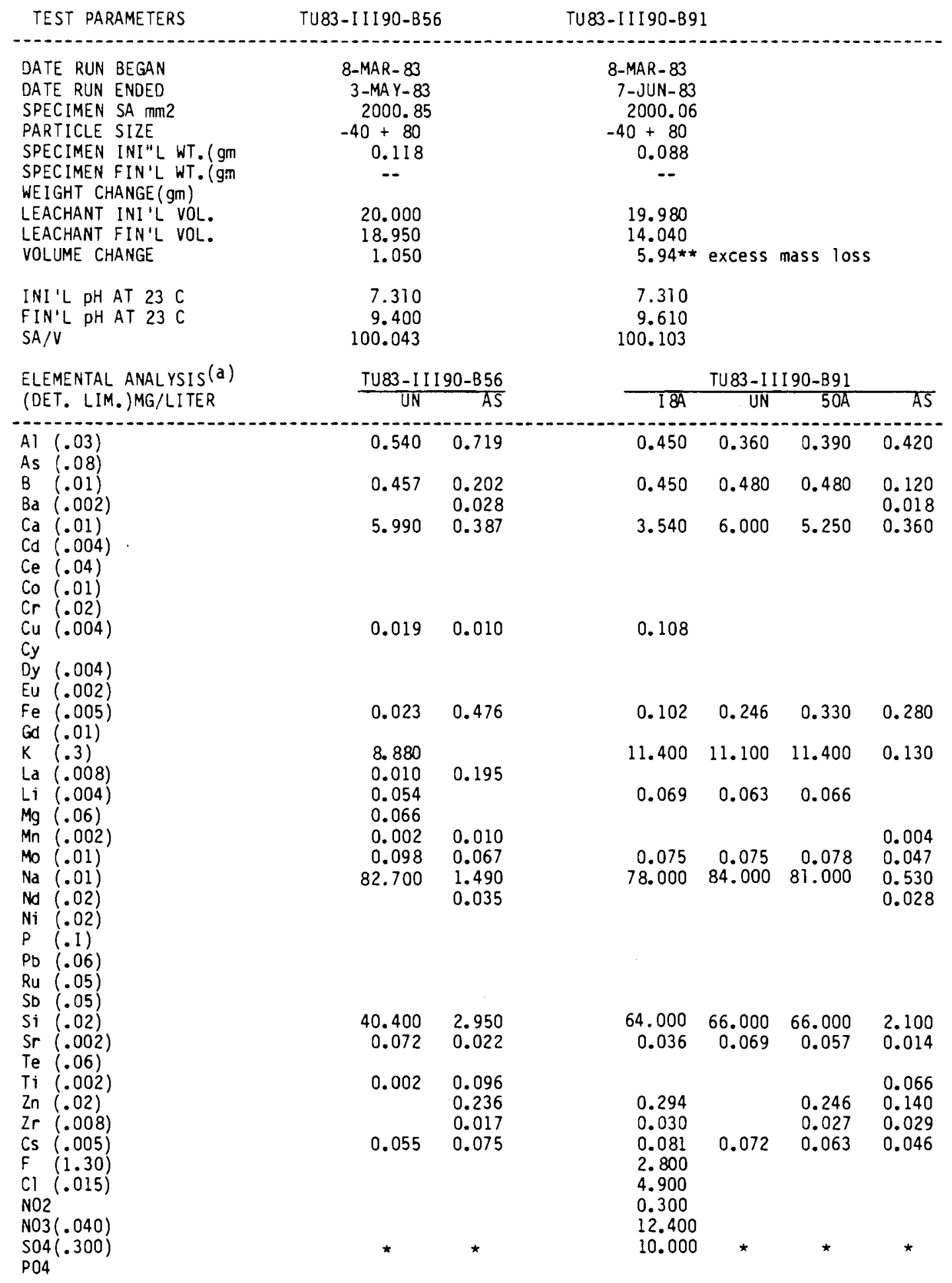

184 - 18 Angstrom Filtered Solution

AS - Acid Strip

UN - Unfiltered

$0.45 \mu-45$ microns Filtered Solution

$50 A$ - 50 Angstrom Filtered Solution

* - No Anion Analysis

(a) - Blanks Indicate Elements Below Detection Limits 
LLNL WASTE PACKAGE TESTS LEACH TEST II I DA“A (GLASS, ROCK AND METAL), TUFF WATER $40,70,90,150^{\circ} \mathrm{C}$, STATIC

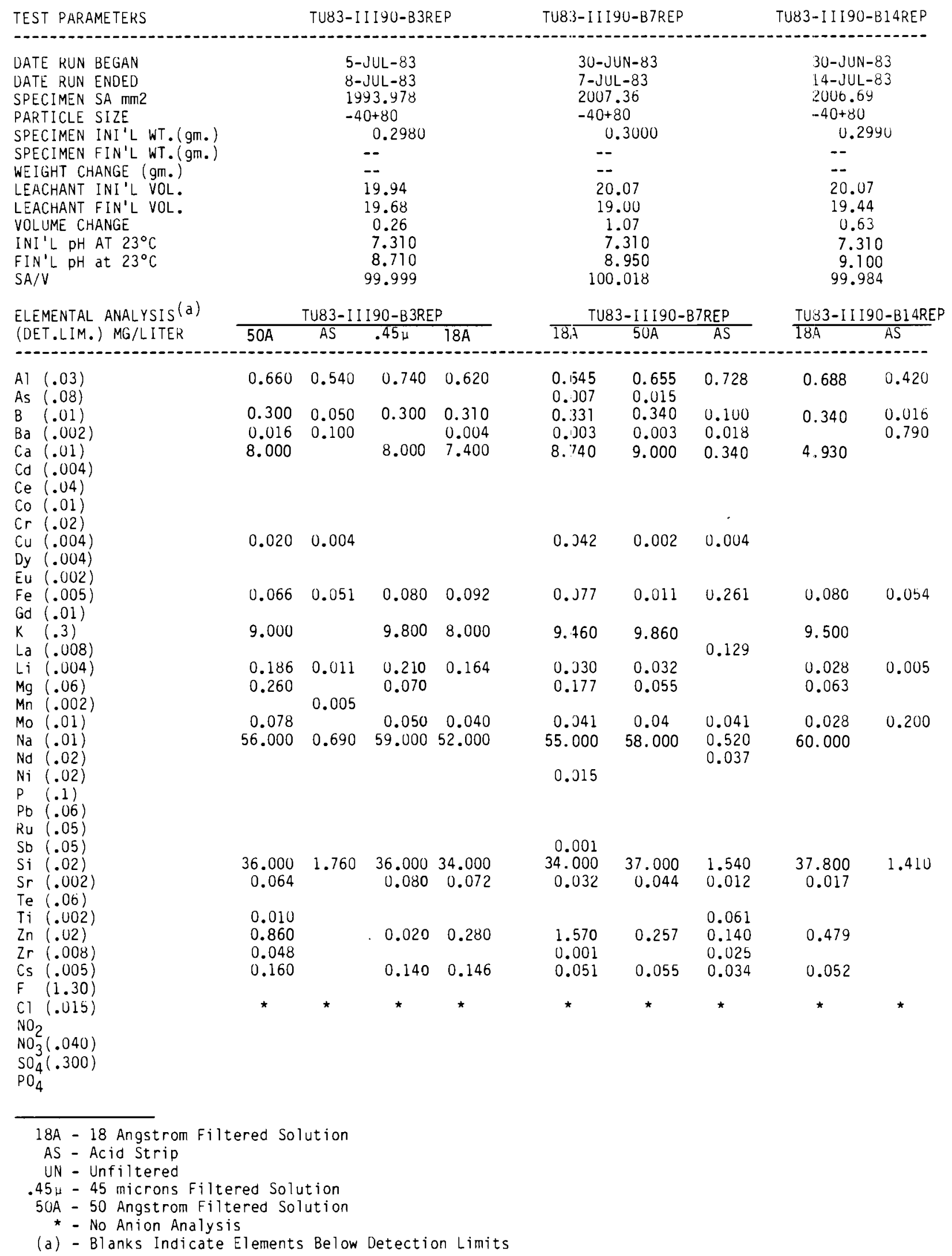


LLNL WASTE PACKAGE TESTS LEACH TEST II I DATA (GLASS, ROCK AND METAL), TUFF WATER $40,70,90,150^{\circ} \mathrm{C}$, STATIC

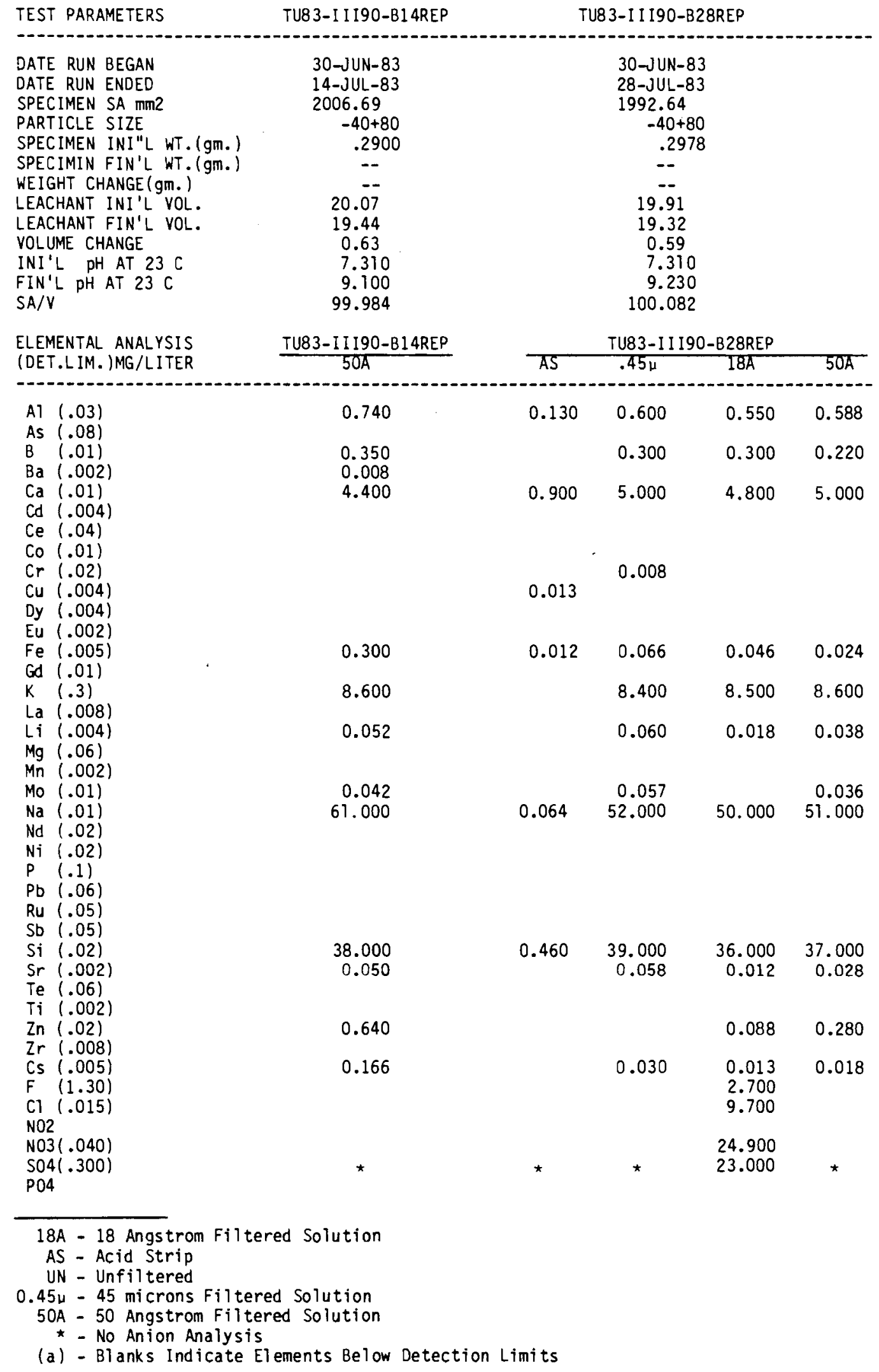


LLNL WASTE PACKAGE TESTS LEACH TEST III DATA (GLASS, R(ICK AND METAL), TUFF WATER $40,70,90,150^{\circ} \mathrm{C}$, STATIC

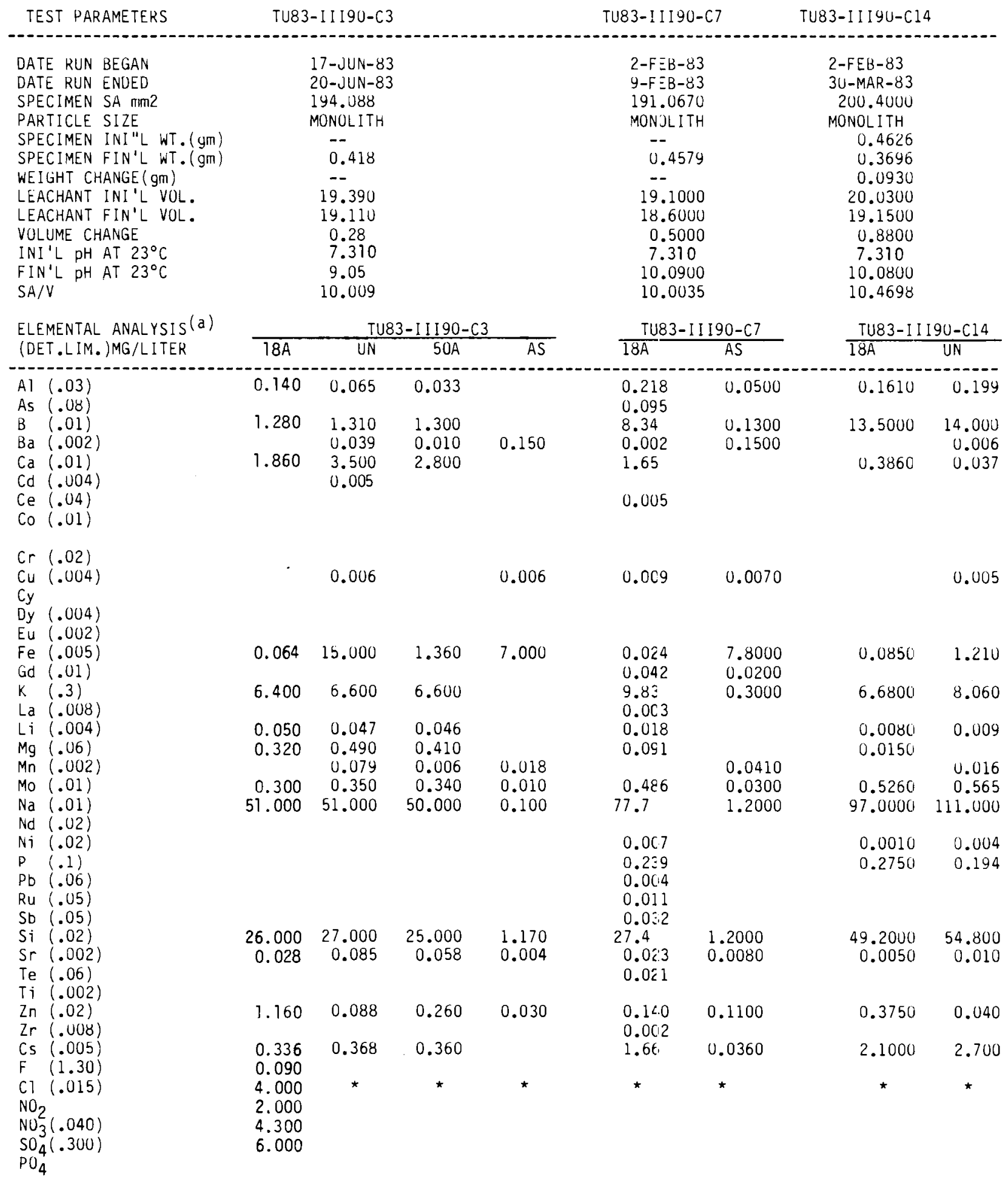

18A - 18 Angstrom Filtered Solution

AS - Acid Strip

UN - Unfiltered

$.45 \mu-45$ microns Filtered Solution

$50 A$ - 50 Angstrom Filtered Solution

* - No Anion Analysis

(a) - Blanks Indicate Elements Below Detection Limits 
LLNL WASTE PACKAGE TESTS LEACH TEST III DATA (GLASS, ROCK AND METAL), TUFF WATER $40,70,90,150^{\circ} \mathrm{C}$, STATIC

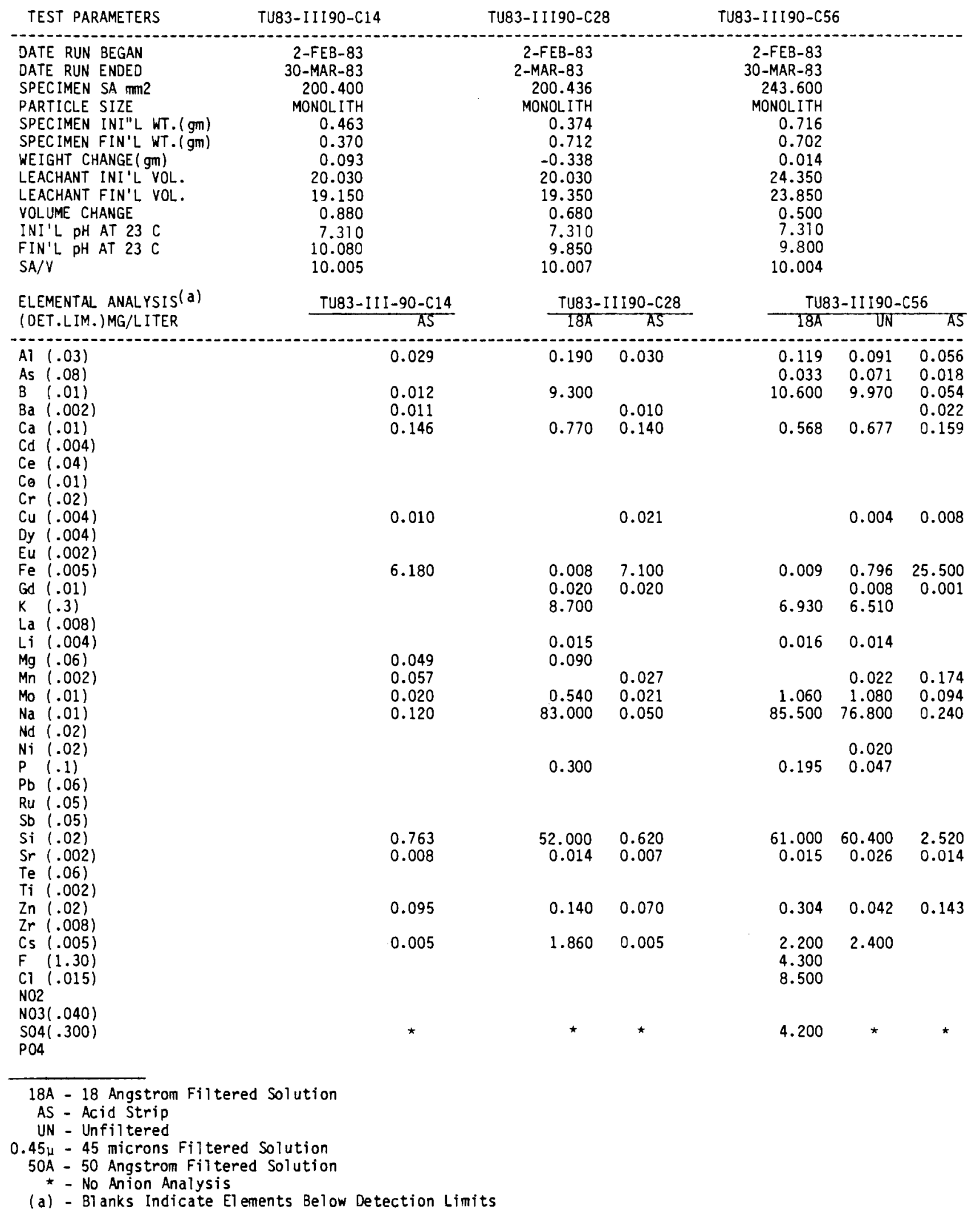


LLNL WASTE PACKAGE TESTS LEACH TEST II I DATA (GLASS, ROCK AND NETAL), TUFF WATER $40,70,90,150^{\circ} \mathrm{C}$, STATIC

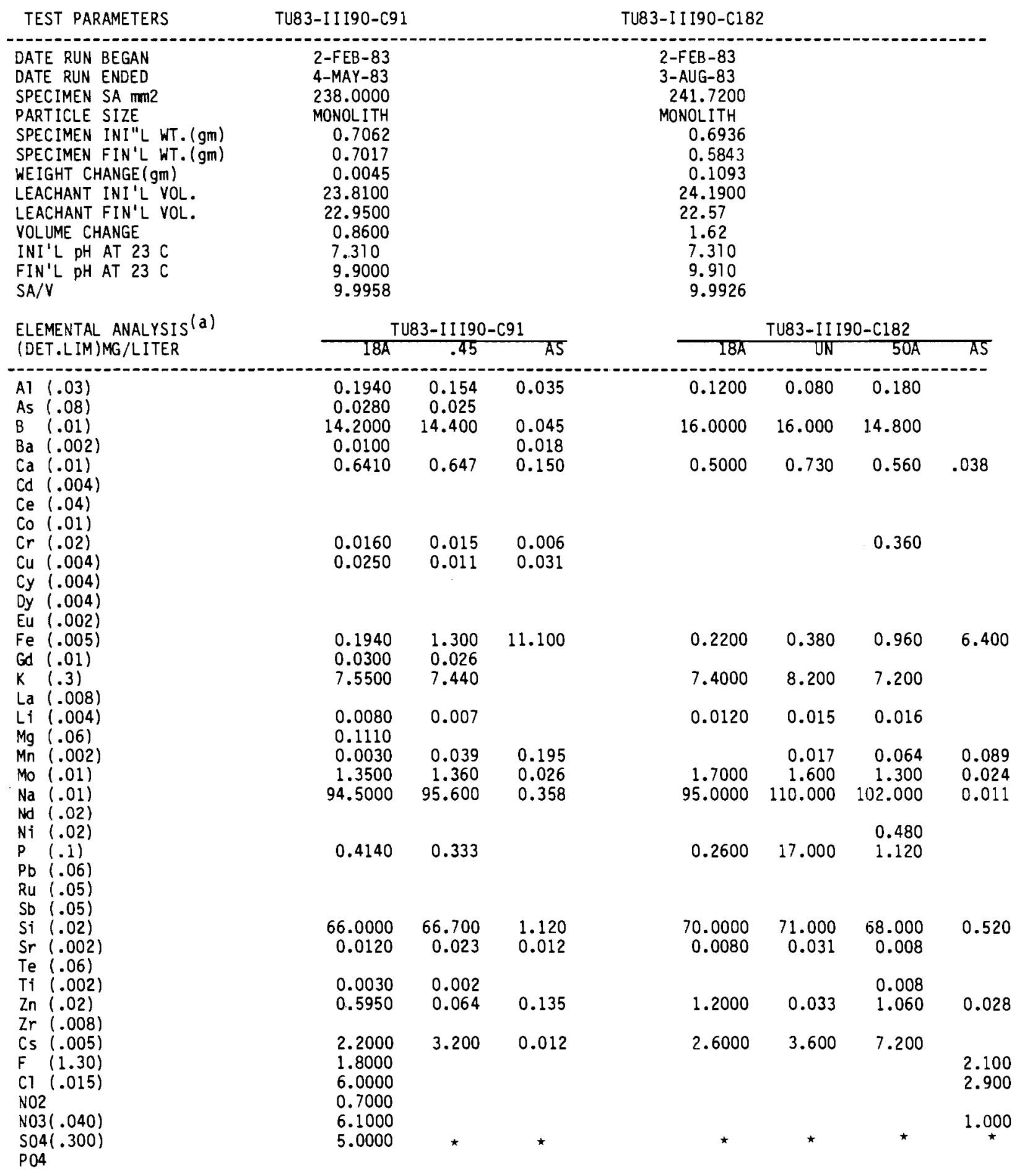

\footnotetext{
18A - 18 Angstrom Filtered Solution

AS - Acid Strip

UN - Unfiltered

0.45 - 45 microns Filtered Solution

$50 \mathrm{~A}$ - 50 Angstrom Filtered Solution

* - No Anion Analysis

(a) - Blanks Indicate Elements Below Detection Limits
} 
LLNL WASTE PACKAGE TESTS LEACH TEST I I D DATA (GLASS, ROCK AND METAL), TUFF WATER $40,70,90,150^{\circ} \mathrm{C}$, STATIC

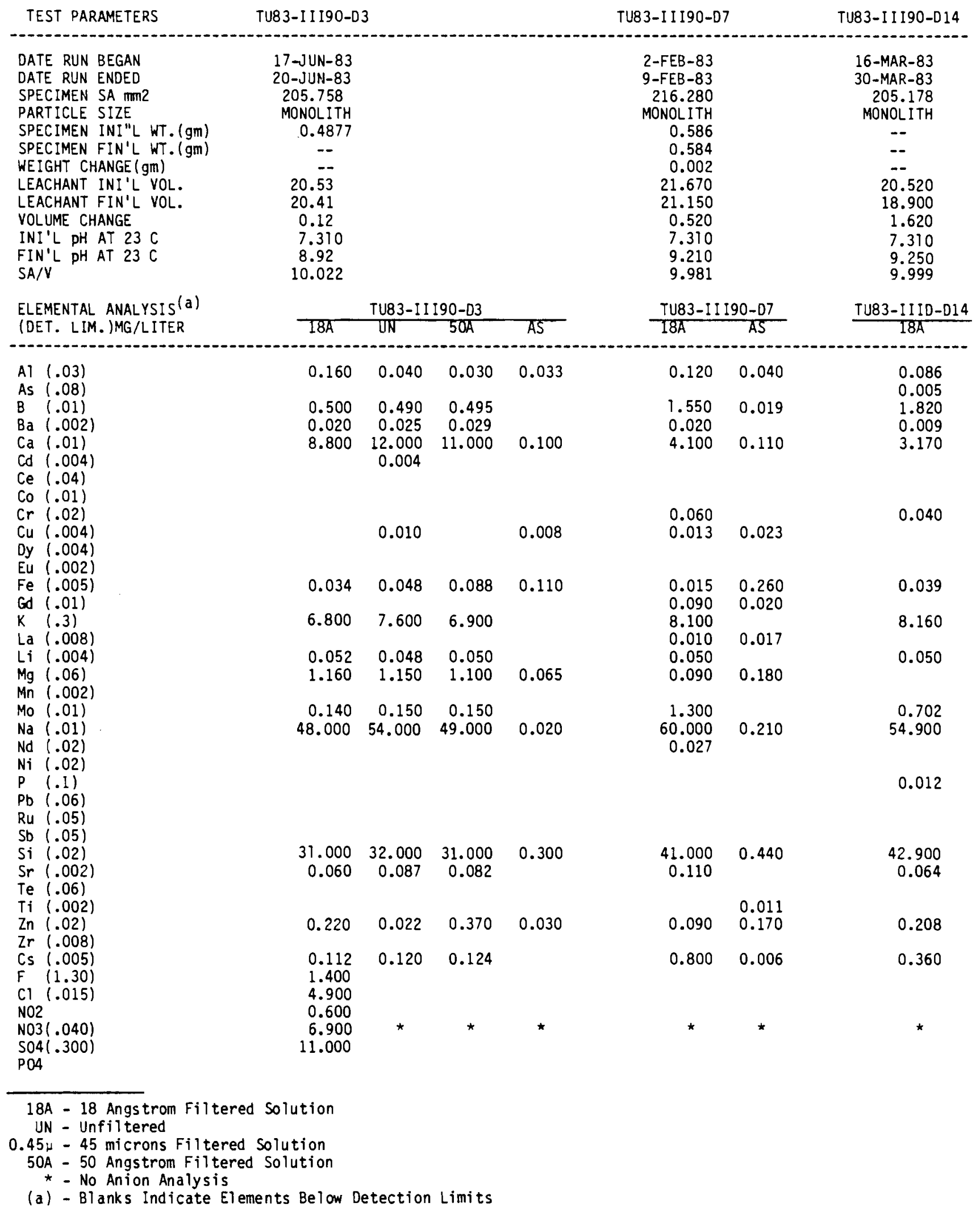


LLNL WASTE PACKAGE TESTS LEACH TEST III DATA (GLASS, ROCK AND METAL), TUFF WATER $40,70,90,150^{\circ} \mathrm{C}$, STATIC

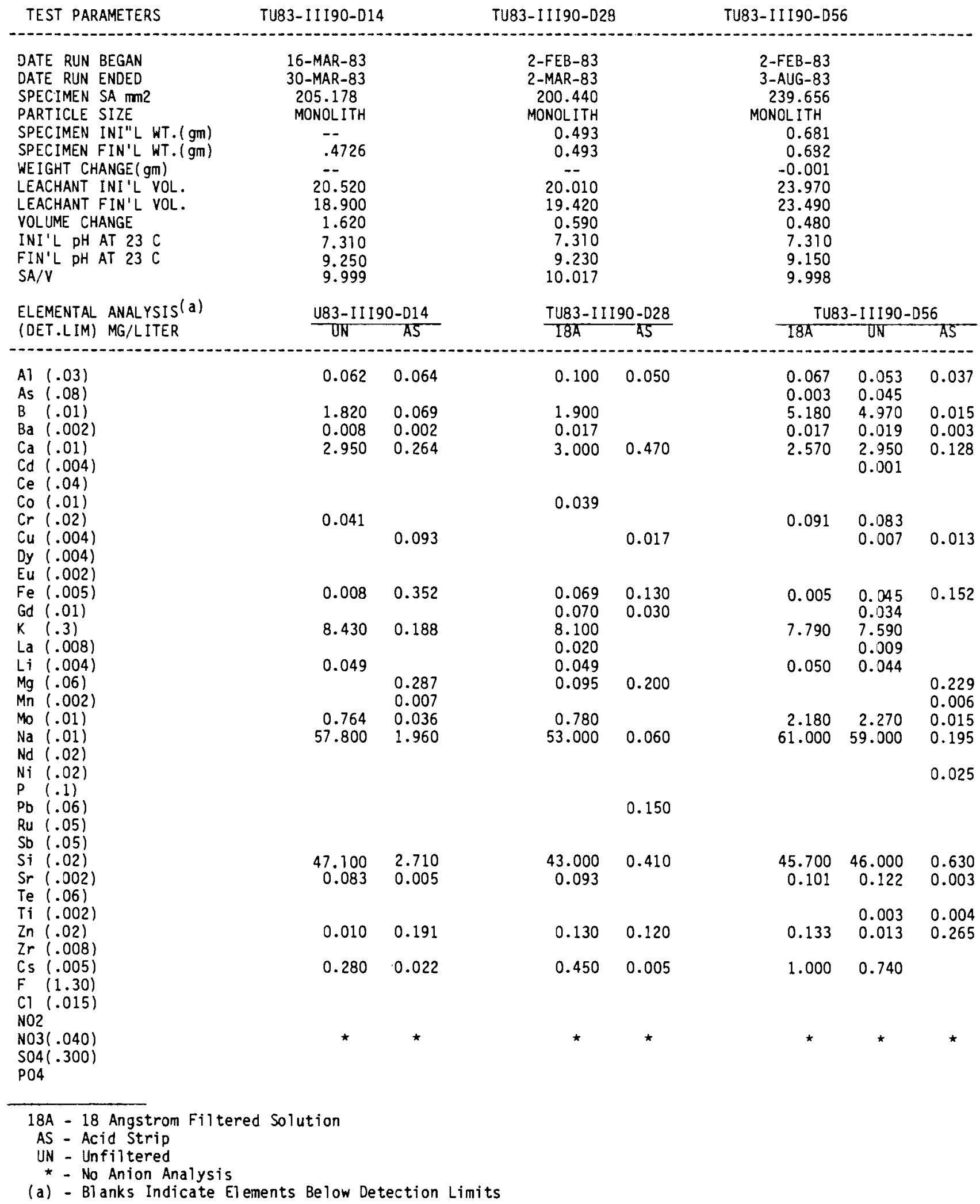


LLNL WASTE PACKAGE TESTS LEACH TEST II I DATA (GLASS, ROCK AND METAL), TUFF WATER $40,70,90,150^{\circ} \mathrm{C}$, STATIC

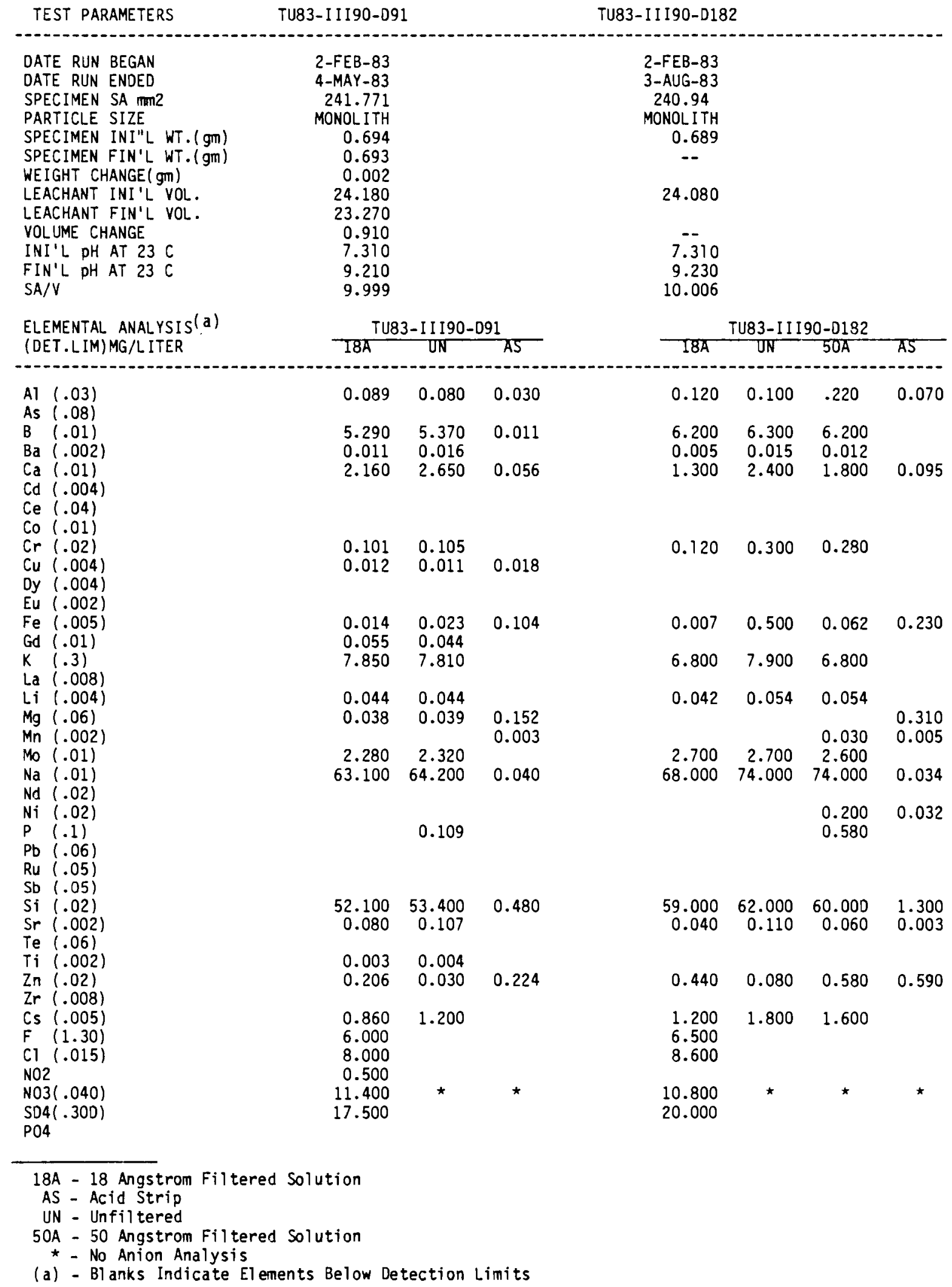


LLNL WASTE PACKAGE TESTS LEACH TEST II I DATA (GLASS, ROCK AND METAL), TUFF WATER $40,70,90,150^{\circ} \mathrm{C}$, STATIC:

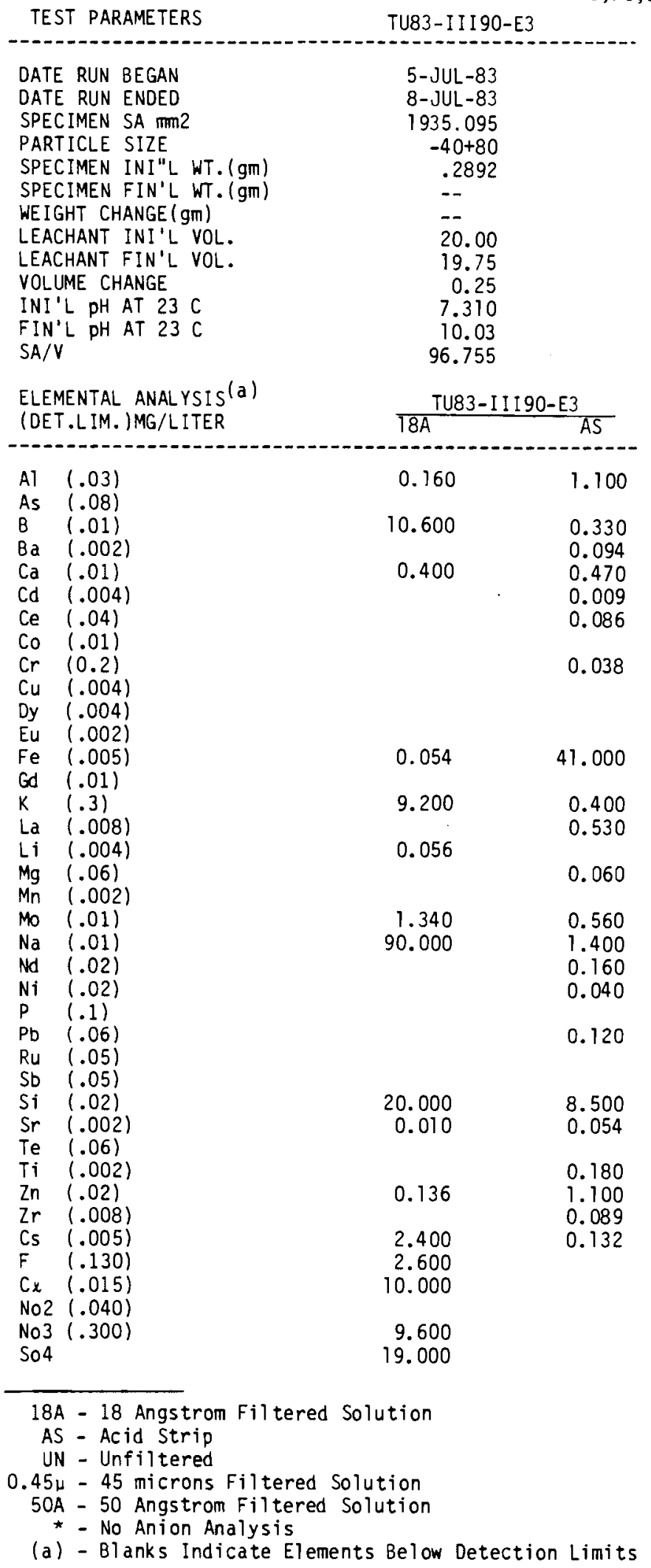


LLNL WASTE PACKAGE TESTS LEACH TEST III DATA (GLASS, ROCK AND METAL), TUFF WATER $40,70,90,150^{\circ} \mathrm{C}$, STATIC

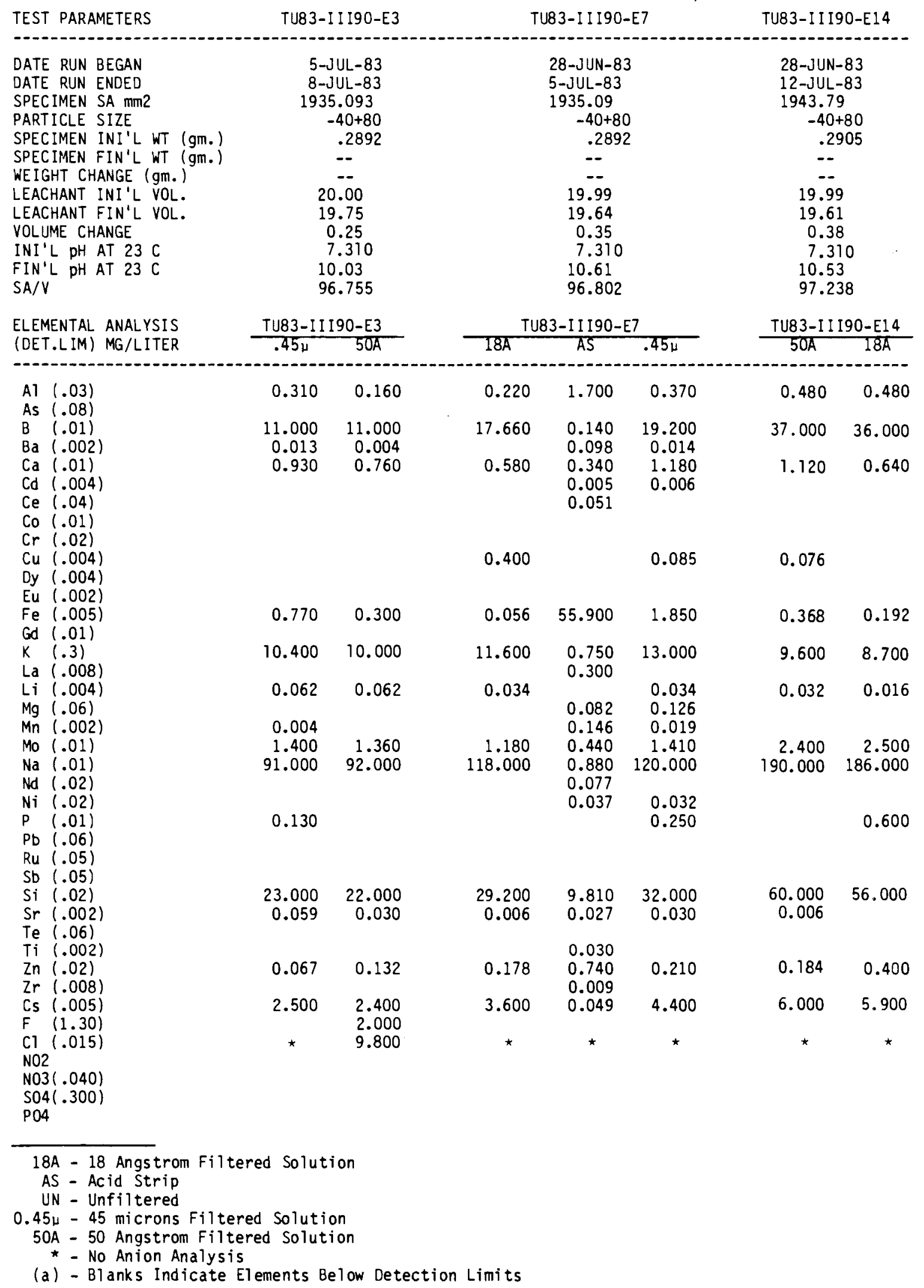




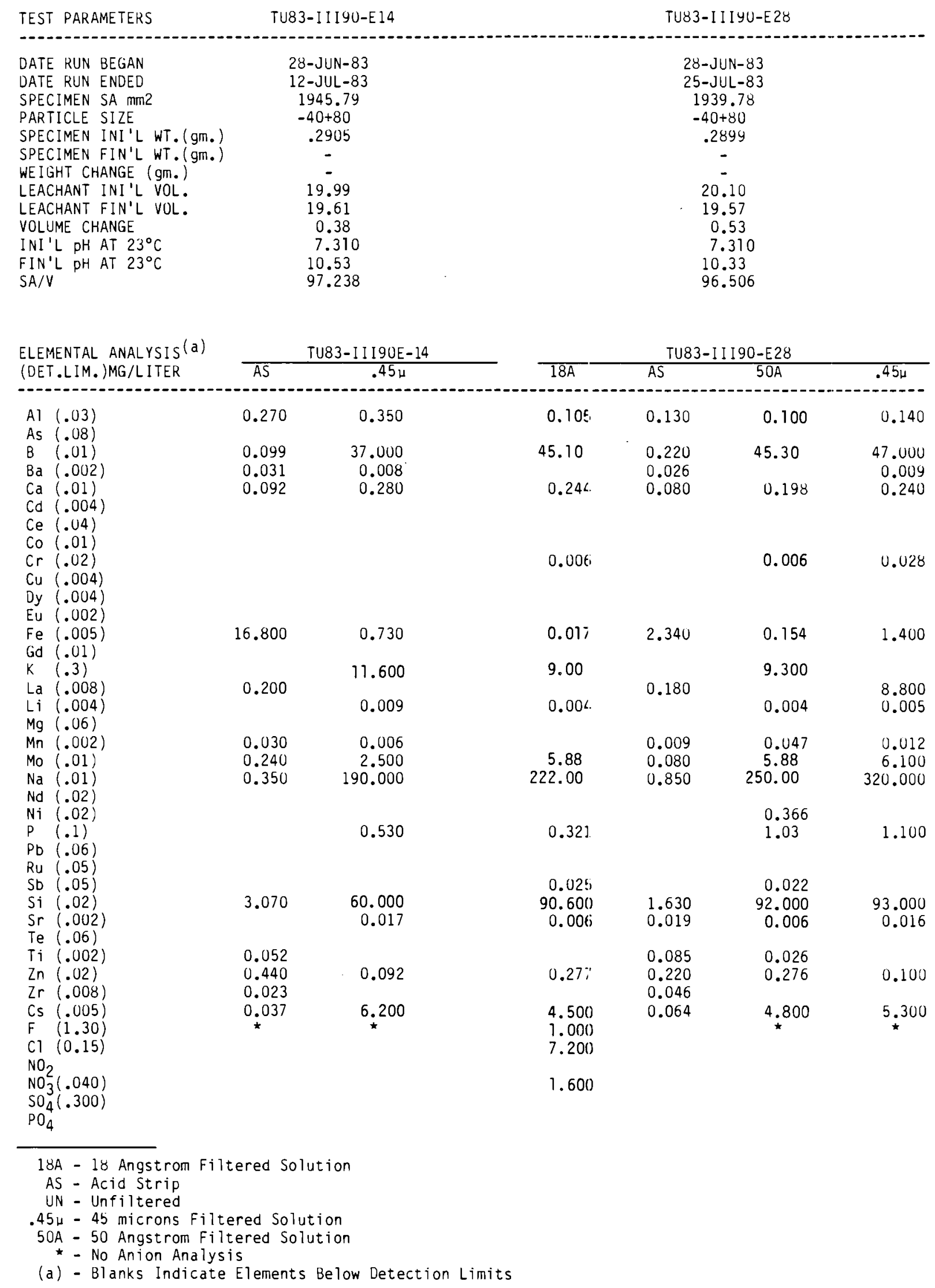


LLNL WASTE PACKAGE TEST

LEACH TEST DATA FOR TEST II I (GLASS, ROCK, AND METAL)

$40,70,90,150^{\circ} \mathrm{C}$, STATIC

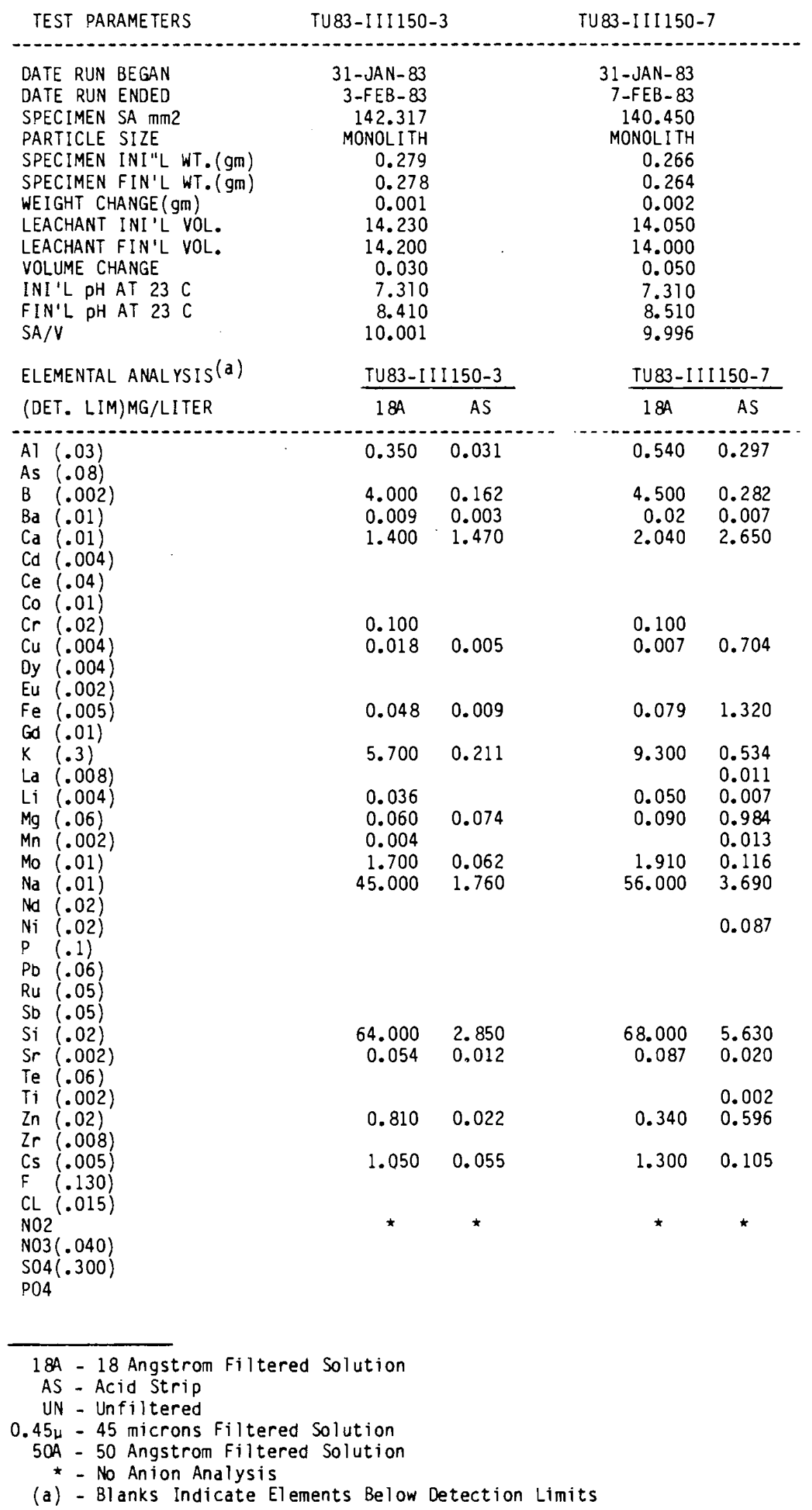


LLNL WASTE PACKAGE TESTS LEACH TEST II I DATA (GLASS, ROCK AND METAL), TUFF WATER $40,70,90,150^{\circ} \mathrm{C}$, STATIC

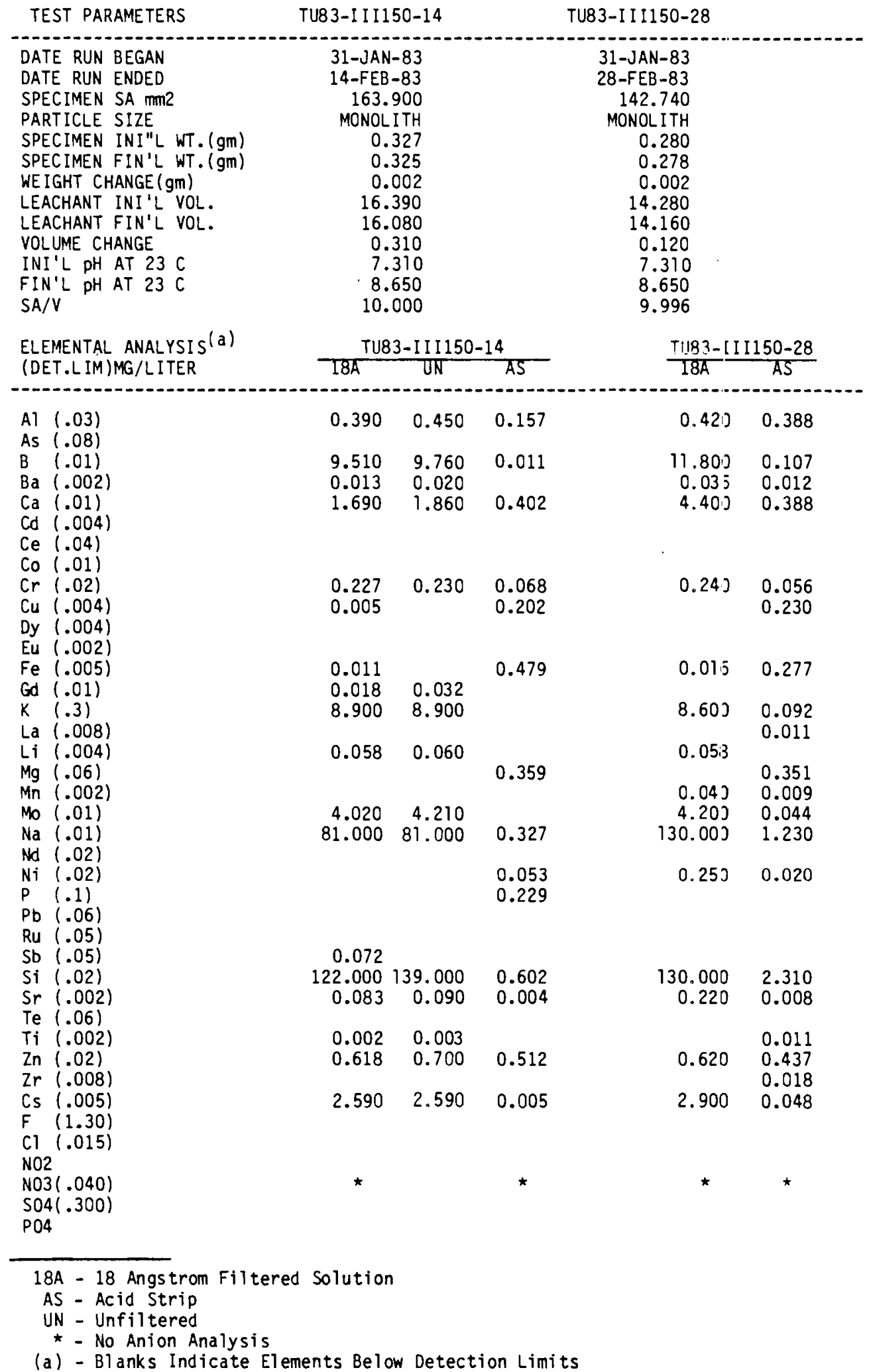


LLNL WASTE PACKAGE TESTS LEACH TEST II I DATA (GLASS, ROCK AND METAL), TUFF WATER $40,70,90,150^{\circ} \mathrm{C}$, STATIC

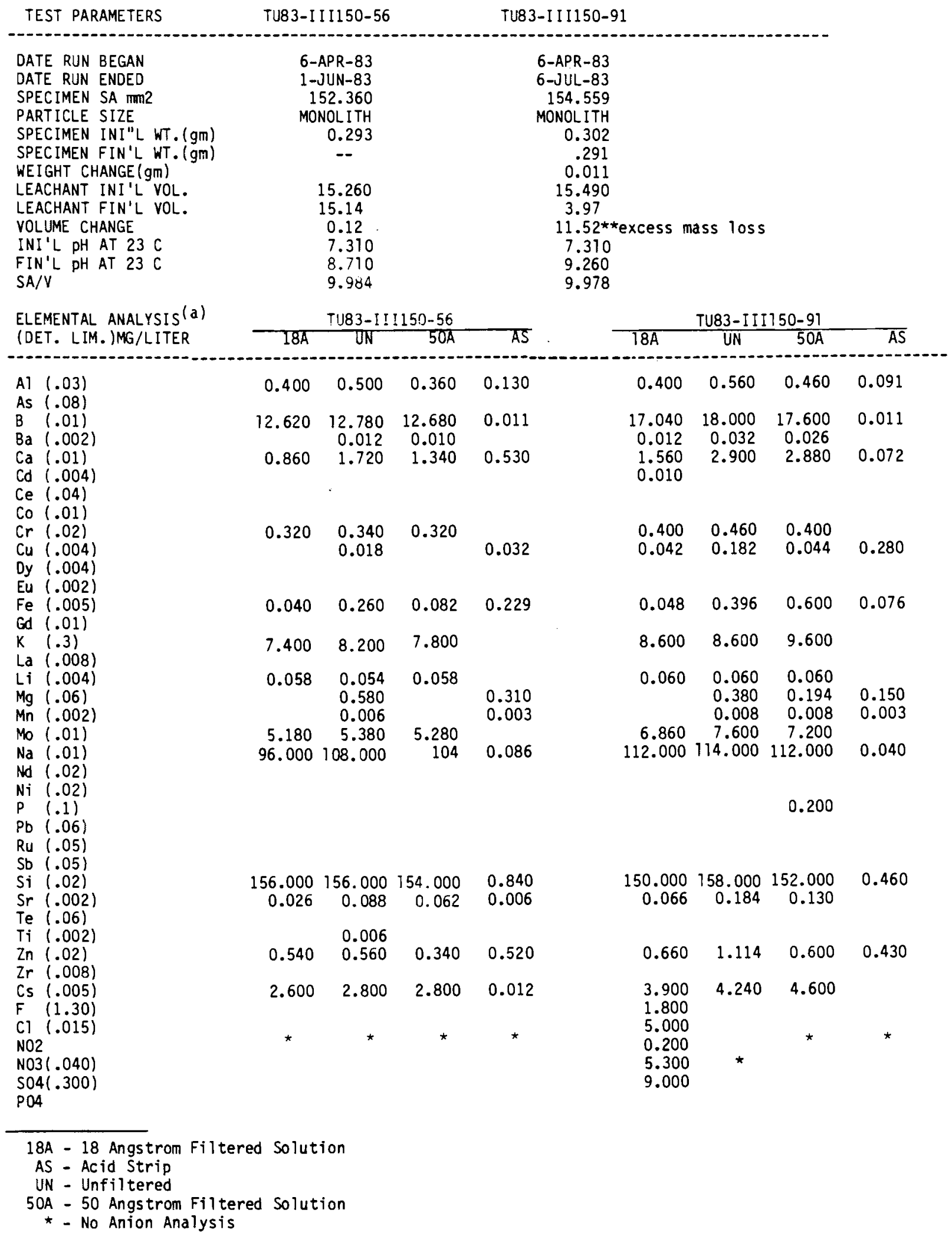


LLNL WASTE PACKAGE LEACH TEST IV DATA (TUFF ROCK MONOLITH) TJFF WATER, $90^{\circ} \mathrm{C}$. STATIC

\begin{tabular}{|c|c|c|c|c|c|}
\hline TEST PARAMETERS & TUIV-90-A7 & TUIV-90-A14 & TUIV-90-A28 & TUIV-90-A56 & TUIV-90-A91 \\
\hline $\begin{array}{l}\text { OATE RUN BEGAN } \\
\text { DATE RUN ENDED } \\
\text { LEACHANT VOL. } \\
\text { INI'L PH AT } 23^{\circ} \mathrm{C} \\
\text { FIN'L PH AT } 23^{\circ} \mathrm{C}\end{array}$ & $\begin{array}{c}11-A P R-83 \\
18-A P R-83 \\
14.98 \\
7.310 \\
9.005\end{array}$ & $\begin{array}{r}11-A P R-83 \\
25-A P R-83 \\
22.40 \\
7.310 \\
9.275\end{array}$ & $\begin{array}{c}11-A P R-83 \\
9-M A Y-83 \\
23.61 \\
7.310 \\
9.389\end{array}$ & $\begin{array}{c}11-A P R-83 \\
6-J U N-83 \\
13.47 \\
7.310 \\
9.457\end{array}$ & $\begin{array}{r}11-A P R-83 \\
11-J L Y-83 \\
22.01 \\
7.310 \\
9.562\end{array}$ \\
\hline $\begin{array}{l}\text { ELEMENTS } \\
\text { (DET.LIM)MG/LITER }\end{array}$ & TUIV-90-A7 & TUIV-90-A14 & TUIV-90-A28 & TUIV-90-A56 & TUIV-90-A91 \\
\hline $\begin{array}{ll}\mathrm{A} 1 & (.03) \\
\mathrm{B} & (.01) \\
\mathrm{Ba} & (.002) \\
\mathrm{Ca} & (.01) \\
\mathrm{Ce} & (.04)\end{array}$ & $\begin{array}{l}0.056 \\
0.164 \\
4.795\end{array}$ & $\begin{array}{l}0.058 \\
0.162 \\
0.002 \\
4.080\end{array}$ & $\begin{array}{l}0.084 \\
0.178 \\
4.381\end{array}$ & $\begin{array}{r}0.062 \\
0.148 \\
0.004 \\
13.199\end{array}$ & $\begin{array}{l}0.073 \\
0.294 \\
3.607\end{array}$ \\
\hline $\begin{array}{ll}\mathrm{Fe} & (.005) \\
\mathrm{K} & (.3) \\
\mathrm{Li} & (.004) \\
\mathrm{Mg} & (.06) \\
\mathrm{Mn} & (.002)\end{array}$ & $\begin{array}{l}0.009 \\
7.752 \\
0.044 \\
0.281\end{array}$ & $\begin{array}{l}0.008 \\
7.944 \\
0.047 \\
0.139\end{array}$ & $\begin{array}{l}0.011 \\
6.660 \\
0.044 \\
0.090\end{array}$ & $\begin{array}{l}0.006 \\
4.981 \\
0.050\end{array}$ & $\begin{array}{l}0.070 \\
8.720 \\
0.049 \\
0.147\end{array}$ \\
\hline $\begin{array}{ll}\mathrm{Mo} & (.01) \\
\mathrm{Na} & (.01) \\
\mathrm{P} & (.1) \\
\mathrm{PD} & (.06)\end{array}$ & $\begin{array}{r}0.014 \\
48.520\end{array}$ & $\begin{array}{r}0.017 \\
49.116\end{array}$ & $\begin{array}{r}0.013 \\
54.430\end{array}$ & $\begin{array}{r}0.015 \\
49.693\end{array}$ & $\begin{array}{r}0.016 \\
56.102\end{array}$ \\
\hline $\operatorname{Si}_{\mathrm{Sm}}\{.02\}$ & 37.350 & 39.328 & 43.888 & 52.190 & 66.424 \\
\hline $\begin{array}{l}\mathrm{Sr}(.002) \\
\mathrm{Ti}(.002) \\
\mathrm{Zr}(.008) \\
\mathrm{Cs}(.005) \\
\mathrm{F},(.130) \\
\mathrm{Cl}(.015) \\
\mathrm{N} 03(.040) \\
\mathrm{SO4}(.300) \\
\mathrm{NO2} \\
\mathrm{PO4}\end{array}$ & $\begin{array}{l}\star \\
\star \\
\star \\
\star\end{array}$ & $\begin{array}{r}2.700 \\
8.500 \\
11.500 \\
22.000\end{array}$ & $\begin{array}{r}2.600 \\
16.700 \\
11.000 \\
19.000\end{array}$ & $\begin{array}{r}1.900 \\
15.500 \\
8.000 \\
11.500\end{array}$ & 0.029 \\
\hline
\end{tabular}

LLNL WASTE PACKAGE LEACH TEST IV DATA (TUFF ROCK POWDER) TUFF WATER, $90^{\circ} \mathrm{C}$, STATIC

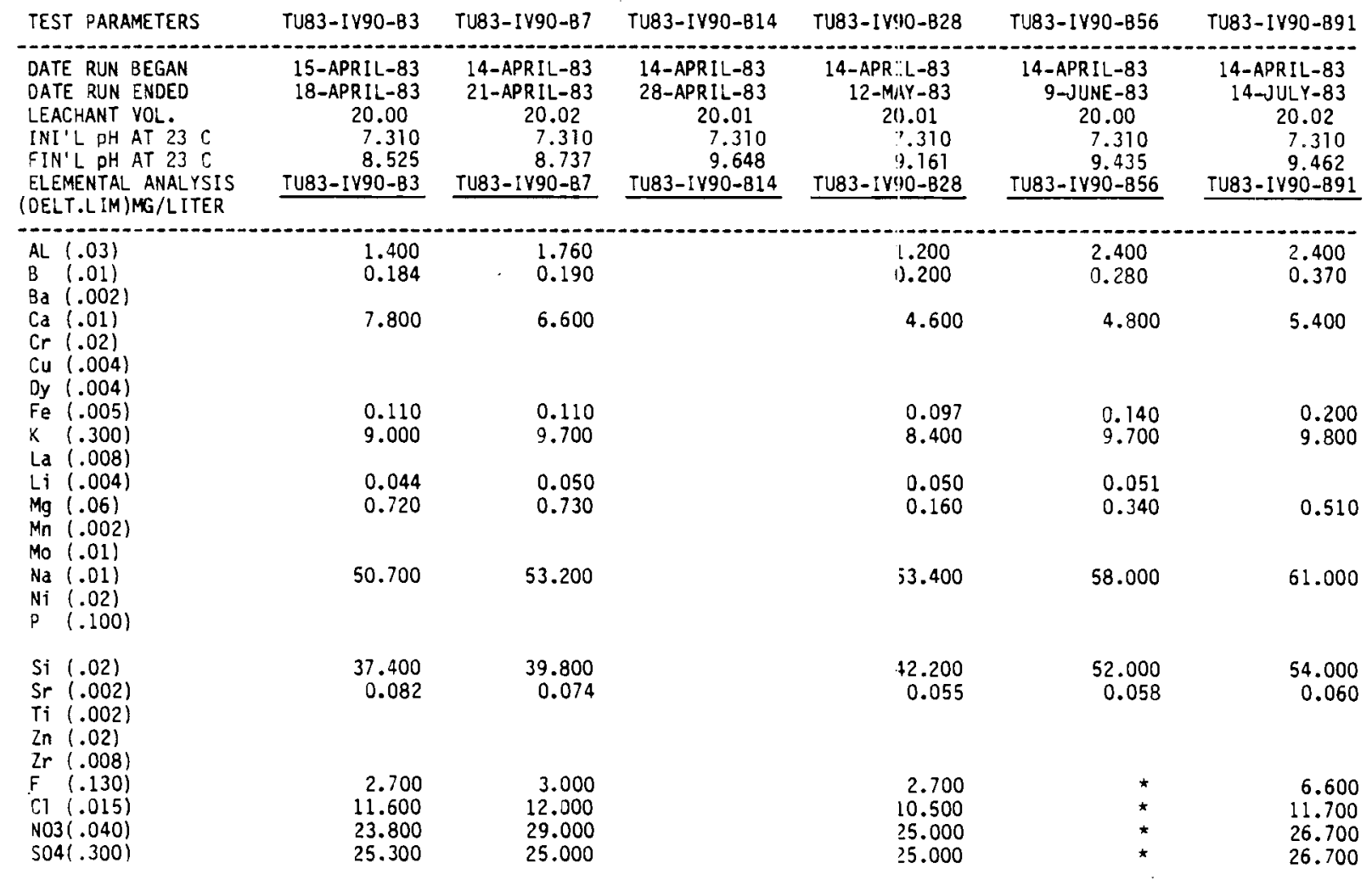

* - No Anion Analysis

(a) - Blanks Indicate Elements Below Detection Limits 


\begin{tabular}{|c|c|c|c|c|c|}
\hline TEST PARAMETERS & TU83-IV40-CP I & TU83-IV70-CP 1 & TU83-IV90-CPI & TU83-IV150-CP1 & TU83-IV23-PO \\
\hline $\begin{array}{l}\text { DATE RUN BEGAN } \\
\text { DATE RUN ENDED } \\
\text { LEACHANT VOL. } \\
\text { INI'L DH AT } 23 \text { C } \\
\text { FIN'L PH AT } 23 \text { C }\end{array}$ & $\begin{array}{r}18-A P R I L-83 \\
19-A P R I L-83 \\
20.05 \\
7.310 \\
8.148\end{array}$ & $\begin{array}{r}18-A P R I L-83 \\
19-A P R I L-83 \\
20.02 \\
7.210 \\
8.315\end{array}$ & $\begin{array}{r}18-A P R I L-83 \\
19-A P R I L-83 \\
20.05 \\
7.310 \\
9.247\end{array}$ & $\begin{aligned} 19-A P R I L-8 \\
\text { 20-APRIL }-83 \\
15.00 \\
7.310 \\
7.841\end{aligned}$ & $\begin{array}{r}\text { ELAPSED TIME }= \\
5.0 \mathrm{MIN} . \\
20.00 \\
7.310 \\
8.12 y\end{array}$ \\
\hline FLEMENTAL ANALYSIS & TU83-:V40-CP1 & T:J83-IV70-CP1 & TU83-iV90-CP1 & TU83-IV150-CP! & $T \cup B 3-I \vee 23-P()$ \\
\hline n- & $m------$ & $-n-\infty-n-\infty$ & $-------n$ & & - \\
\hline $\begin{array}{ll}\mathrm{Al} & (.03) \\
\mathrm{B} & (.08) \\
\mathrm{Ca} & (.01) \\
\mathrm{Fe} & (.005) \\
\mathrm{K} & (.3) \\
\mathrm{Li} & (.004) \\
\mathrm{Mg} & (.06) \\
\mathrm{Na} & (.01)\end{array}$ & $\begin{array}{r}0.020 \\
0.210 \\
12.800 \\
0.010 \\
66.400 \\
0.048 \\
80.000 \\
136.700\end{array}$ & $\begin{array}{r}0.200 \\
0.200 \\
13.000 \\
0.164 \\
15.900 \\
0.054 \\
14.300 \\
63.400\end{array}$ & $\begin{array}{r}0.220 \\
0.200 \\
9.400 \\
0.240 \\
19.400 \\
0.052 \\
16.000 \\
69.400\end{array}$ & $\begin{array}{r}1.240 \\
0.200 \\
7.400 \\
0.096 \\
9.600 \\
0.050 \\
2.140 \\
53.000\end{array}$ & $\begin{array}{r}0.224 \\
0.170 \\
19.534 \\
0.207 \\
7.861 \\
0.044 \\
3.128 \\
53.630\end{array}$ \\
\hline $\begin{array}{l}\mathrm{Si}(.02) \\
\mathrm{Sr} \\
\mathrm{F} \quad(.002) \\
\mathrm{Cl} \quad(.0130) \\
\mathrm{NO}(.040) \\
\mathrm{SO}(.300)\end{array}$ & $\begin{array}{r}29.900 \\
0.062 \\
2.200\end{array}$ & $\begin{array}{r}31.800 \\
0.060 \\
3.600 \\
81.000 \\
13.100 \\
17.700\end{array}$ & $\begin{array}{r}32.500 \\
0.052 \\
2.500 \\
105.000 \\
13.100 \\
17.700\end{array}$ & $\begin{array}{r}53.900 \\
0.048 \\
4.800 \\
24.000 \\
14.300 \\
17.700\end{array}$ & $\begin{array}{r}31.286 \\
0.128 \\
2.200 \\
11.900 \\
33.300 \\
27.900\end{array}$ \\
\hline
\end{tabular}

LLNL WASTE PACKAGE TESTS LEACH TEST IV DATA (TUFF ROCK MOMOLITH) TUFF WATER

\begin{tabular}{|c|c|c|c|c|c|}
\hline TEST PARAMETERS & TU83-IV40-CM1 & TU83-IV70-CMI & TU83-IV90-CM1 & TU83-IV150-CM1 & TU83-IV23-M0 \\
\hline $\begin{array}{l}\text { UATE RUN BEGAN } \\
\text { DATE RUN ENDED } \\
\text { LEACHANT VOL. } \\
\text { INI'L PH AT } 23 \mathrm{C} \\
\text { FIN'L PH AT } 23 \mathrm{C}\end{array}$ & $\begin{array}{r}19-A P R I L-83 \\
19-A P R I L-83 \\
15.20 \\
7.310 \\
8.281\end{array}$ & $\begin{array}{r}18-A P R I L-83 \\
19-A P R I L-83 \\
15.40 \\
7.310 \\
8.476\end{array}$ & $\begin{array}{r}18-A P R I L-83 \\
19-A P R I L-83 \\
16.23 \\
7.310 \\
9.038\end{array}$ & $\begin{array}{r}19-A P R I L-83 \\
20-A P R I L-83 \\
15.23 \\
7.310 \\
7.677\end{array}$ & $\begin{array}{r}\text { ELAPSED TIME = } \\
5.0 \text { MIN. } \\
20.57 \\
7.310 \\
7.899\end{array}$ \\
\hline ELEMENTAL ANALYSIS & TU83-IV40-CM1 & TU83-IV70-CMI & TU83-IV90-CMI & TU83-IV150-CM1 & TU83-IV23-M0 \\
\hline $\begin{array}{ll}\mathrm{A} 1 & (.03) \\
\mathrm{B} & (.08) \\
\mathrm{Ca} & (.01) \\
\mathrm{Fe} & (.005) \\
\mathrm{K} & (.3) \\
\mathrm{Li} & (.004) \\
\mathrm{Mg} & (.06) \\
\mathrm{Na} & (.01)\end{array}$ & $\begin{array}{r}0.160 \\
12.200 \\
0.370 \\
5.500 \\
0.044 \\
2.000 \\
47.200\end{array}$ & $\begin{array}{r}0.100 \\
0.160 \\
12.900 \\
0.020 \\
5.800 \\
0.047 \\
2.000 \\
47.300\end{array}$ & $\begin{array}{r}0.250 \\
0.180 \\
12.000 \\
0.010 \\
7.400 \\
0.055 \\
1.650 \\
49.600\end{array}$ & $\begin{array}{l}0.660 \\
0.160 \\
5.800 \\
0.100 \\
7.200 \\
0.051 \\
0.500 \\
48.200\end{array}$ & $\begin{array}{r}0.112 \\
0.159 \\
12.728 \\
0.037 \\
5.113 \\
0.046 \\
2.064 \\
46.219\end{array}$ \\
\hline $\begin{array}{l}\mathrm{Si}(.02) \\
\mathrm{Sr}(.002) \\
\mathrm{F} \quad(.130) \\
\mathrm{Cl}(.015) \\
\mathrm{NO}(.040) \\
\mathrm{SO}(.300)\end{array}$ & $\begin{array}{r}29.400 \\
0.044 \\
1.900 \\
8.100 \\
9.500 \\
16.200\end{array}$ & $\begin{array}{r}30.500 \\
0.049 \\
1.900 \\
7.400 \\
10.700 \\
17.700\end{array}$ & $\begin{array}{r}32.300 \\
0.046 \\
2.700 \\
9.200 \\
10.700 \\
17.700\end{array}$ & $\begin{array}{r}39.500 \\
0.036 \\
3.900 \\
7.800 \\
11.900 \\
16.200\end{array}$ & $\begin{array}{r}29.386 \\
0.043 \\
1.900 \\
7.700 \\
9.500 \\
16.200\end{array}$ \\
\hline
\end{tabular}


LLNL WASTE PACKAGE LEACH TEST IV DATA (TUFF ROCK MONOLITH) TUFF WATER, 90 $0^{\circ}$, STATIC

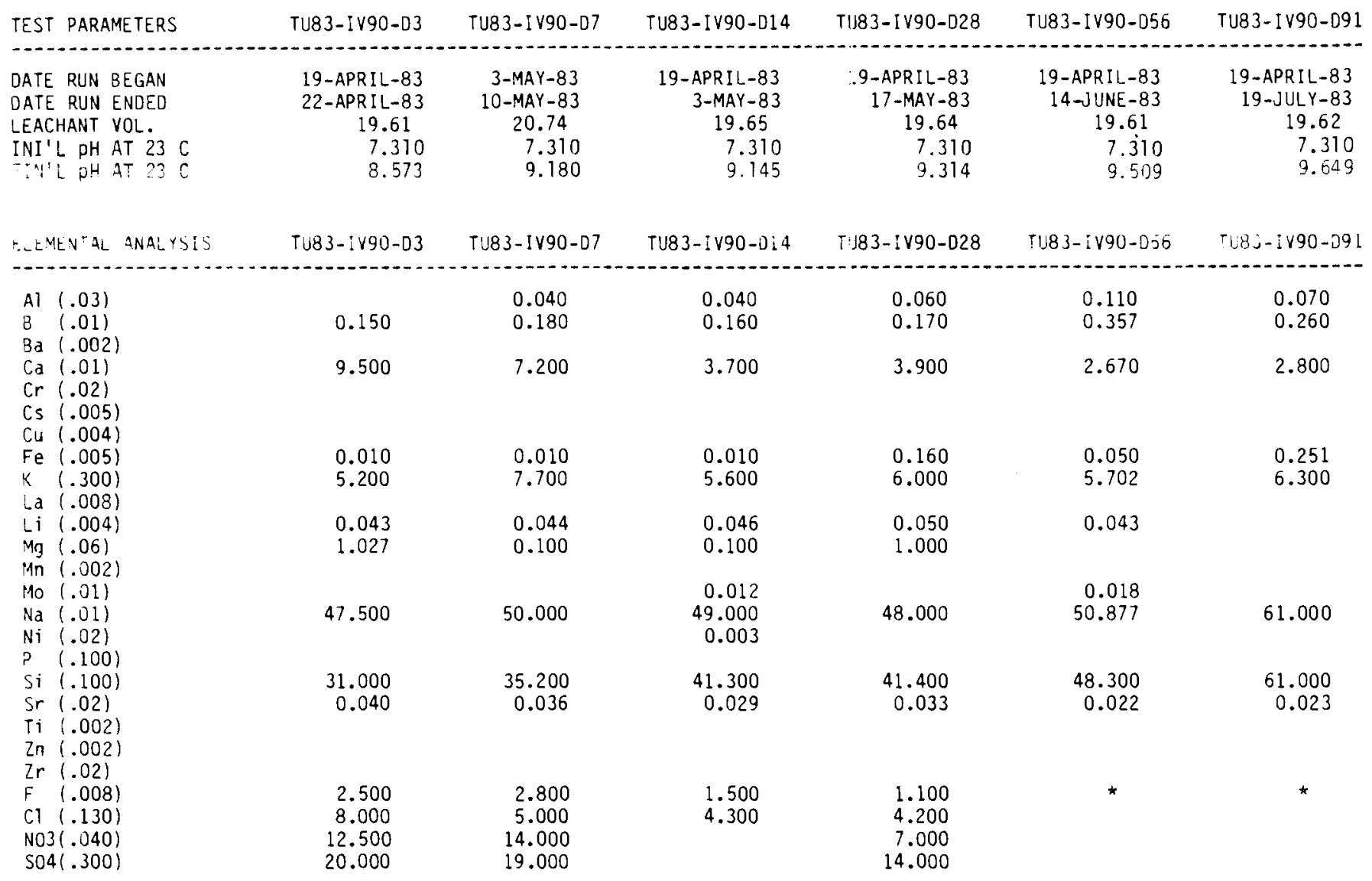

* - No Anion Analysis

LLNL WASTE PACKAGE LEACH TEST IV DATA (TUFF ROCK POWDER) TUFF WATER, $90^{\circ} \mathrm{C}$, STATIC

\begin{tabular}{|c|c|c|c|c|c|c|}
\hline TEST PARAMETERS & TU83-IV90-E3 & TU83-IV90-E7 & TU83-IV90-E14 & TU83-IV90-E28 & TU83-IV90-E56 & TU83- IV90-E91 \\
\hline & & & & & & \\
\hline $\begin{array}{l}\text { DATE RUN BEGAN } \\
\text { DATE RUN ENOED } \\
\text { LEACHANT VOL. } \\
\text { INI'L PH AT } 23 \mathrm{C} \\
\end{array}$ & $\begin{array}{r}\text { 22-APRI L-83 } \\
\text { 25-APRIL-83 } \\
20.04 \\
7.310 \\
9.628\end{array}$ & $\begin{array}{r}21-A P R I L-83 \\
28-A P R I L-83 \\
20.00 \\
7.310 \\
8.728\end{array}$ & $\begin{array}{r}\text { 21-APRIL-83 } \\
4-M A Y-83 \\
20.02 \\
7.310 \\
9.232\end{array}$ & $\begin{array}{c}21-\text { APRIL-83 } \\
19-\text { MAY }-83 \\
20.01 \\
7.310 \\
9.250\end{array}$ & $\begin{array}{c}\text { 21-APRIL-83 } \\
\text { 16-JUNE-83 } \\
20.01 \\
7.310 \\
9.465\end{array}$ & $\begin{array}{r}21-A P R I L-83 \\
21-J U L Y-83 \\
20.00 \\
7.310 \\
9.382\end{array}$ \\
\hline
\end{tabular}

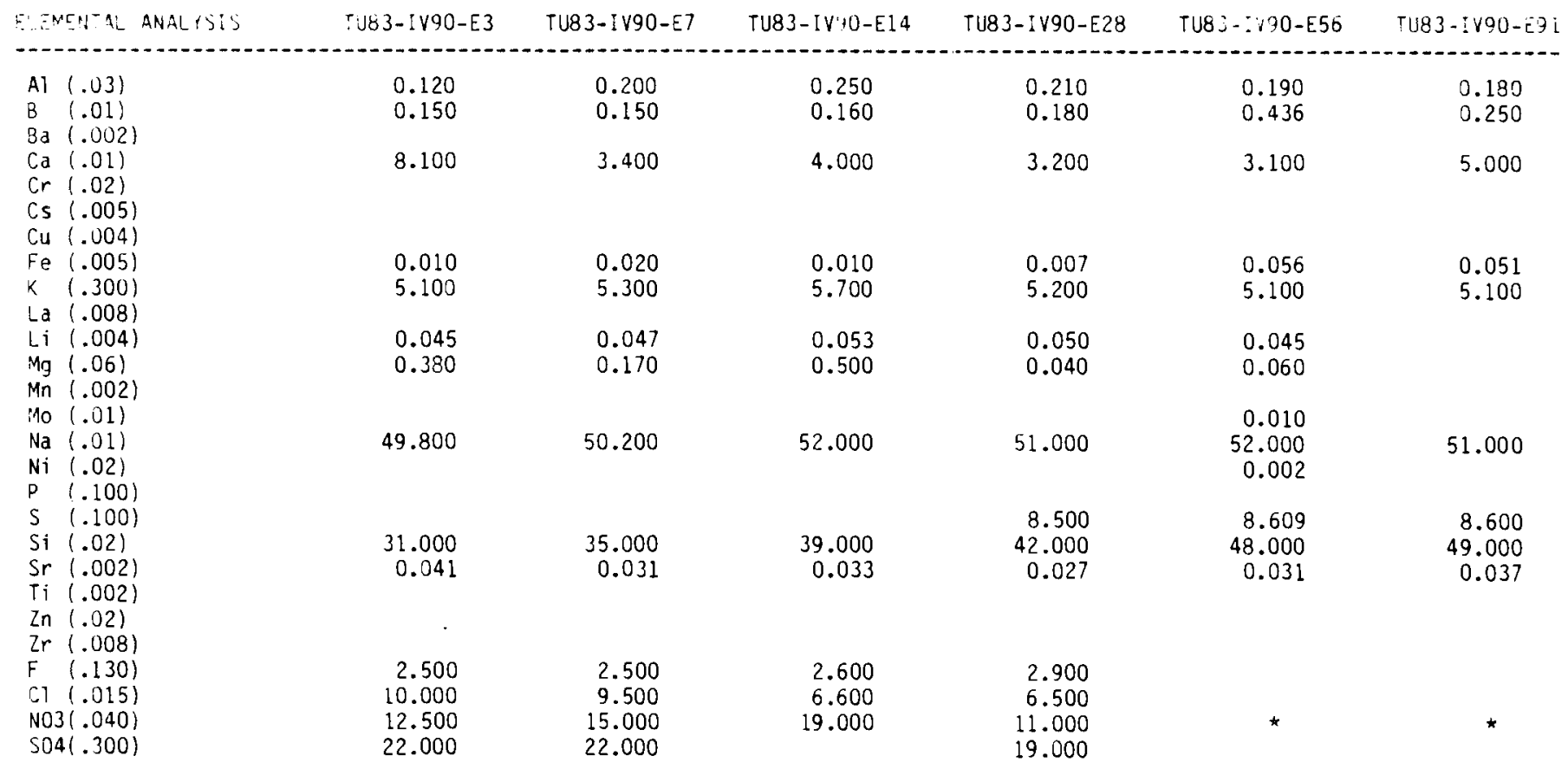


LLNL WASTE PACKAGE LEACH TEST IV DATA (GLASS AND ROCK), TUFF WATER, 90 C, STATIC

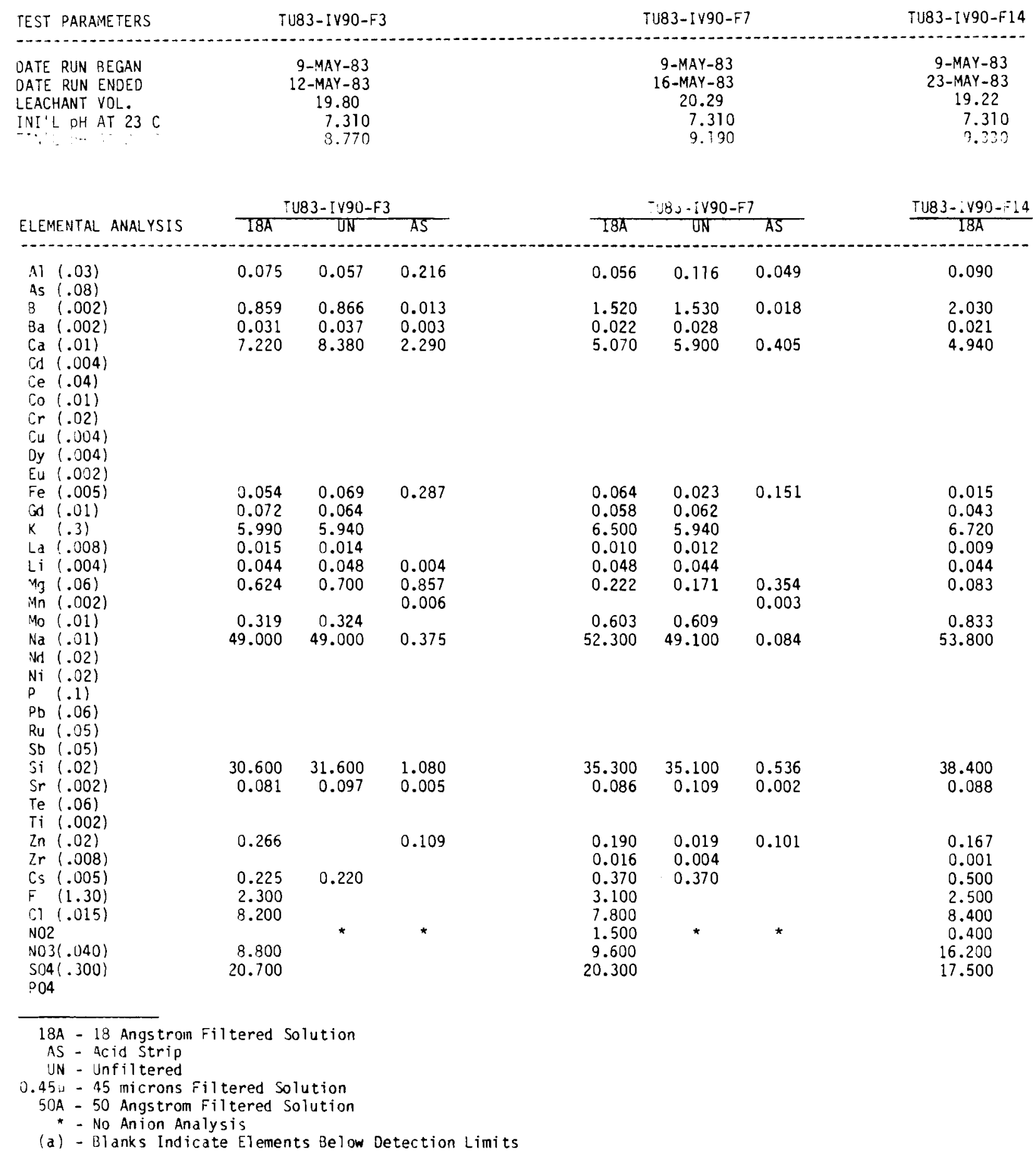


LLNL WASTE PACKAGE LEACH TEST IV DATA (GLASS AND ROCK), TUFF WATER, $90^{\circ} \mathrm{C}$, STATIC

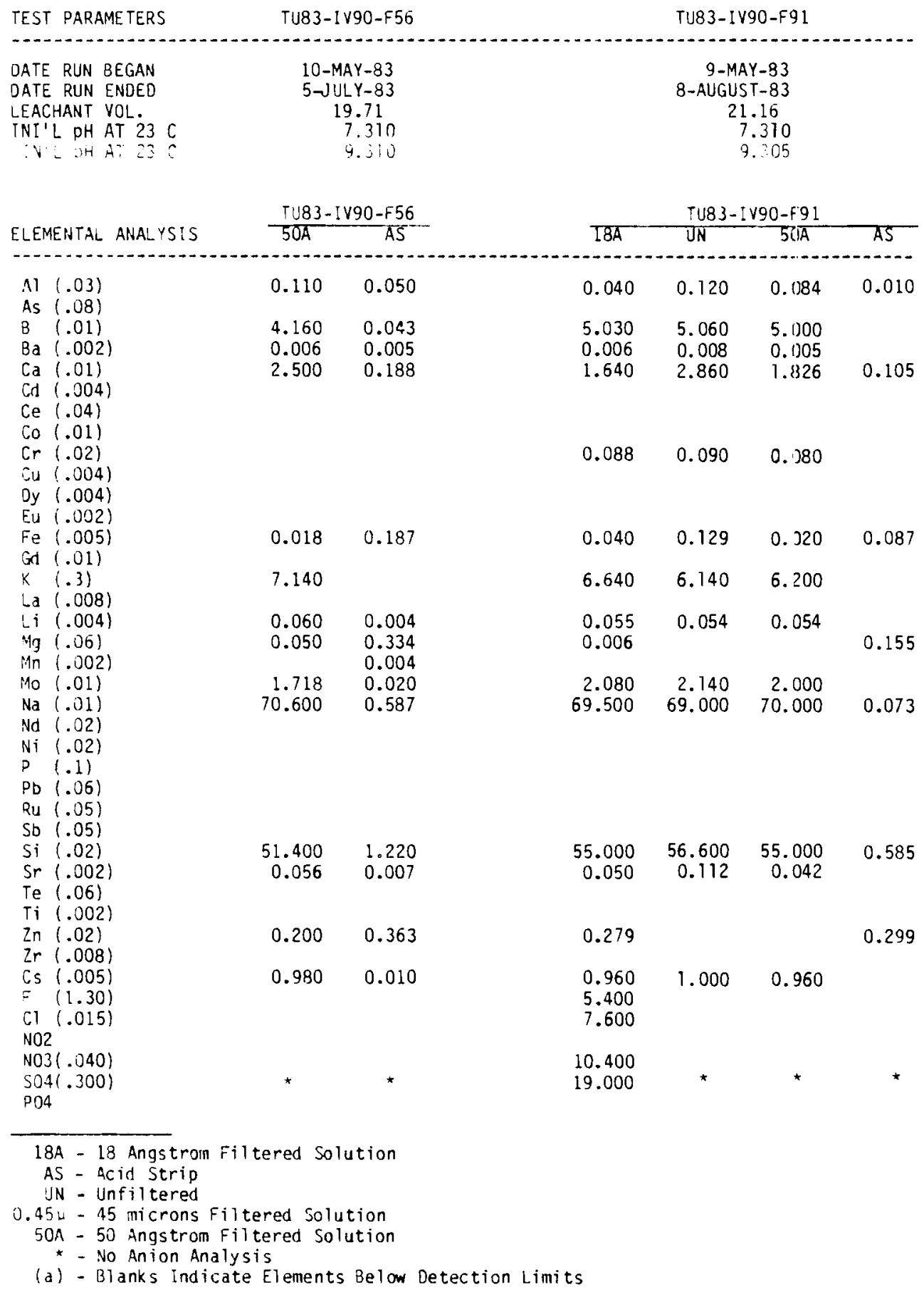


LLNL WASTE PACKAGE LEACH TEST IV DATA (GLASS AND ROCK), TUFF WATER, $90^{\circ} \mathrm{C}$, STATIC

$\begin{array}{lrrr}\text { TEST PARAMETERS } & \text { TU83-IV90-G3 } & \text { TU83-IV90-G7 } & \text { TU83-IV90-G14 } \\ \text { DATE RUN BEGAN } & 14 \text {-JUNE-83 } & 18 \text {-MAY-83 } & 18-\text { MAY-83 } \\ \text { DATE RUN ENDED } & 17 \text { JUNE-83 } & 25 \text {-MAY-83 } & 1-\text { JUNE-83 } \\ \text { LEACHANT VOL. } & 20.15 & 18.61 & 20.62 \\ \text { INI'L DH AT 23 C } & 7.310 & 7.310 & 7.310 \\ \text { FTN'L DH AT 23 C } & 9.830 & 9.520 & ; 870\end{array}$

\begin{tabular}{|c|c|c|c|c|c|c|c|}
\hline \multirow[b]{2}{*}{ ELEMENTAL ANA. $: 3: \vdots$} & \multicolumn{3}{|c|}{ ru83-iv90-G3 } & \multicolumn{3}{|c|}{ TU83-IV90-G7 } & \multirow{2}{*}{$\frac{T(8 ;-\therefore)(10-G 14}{18 A}$} \\
\hline & T8A & UN & $\overline{A S}$ & T8A & UN & AS & \\
\hline $\begin{array}{l}\text { Al }(.03) \\
\text { As }(.08)\end{array}$ & 0.270 & 0.260 & 7.300 & 0.146 & 0.149 & 6.620 & 0.176 \\
\hline $\begin{array}{l}3 \quad(.01) \\
B d(.002)\end{array}$ & 0.380 & 0.386 & 0.023 & 0.882 & 0.881 & 0.010 & 1.120 \\
\hline $\begin{array}{ll}\text { Cd } & (.01) \\
\text { Cd } & (.004) \\
\text { Ce } & (.04) \\
\text { Co } & (.01) \\
\text { Cr } & (.02) \\
\text { Cu } & (.004) \\
\text { Dy } & (.004) \\
\text { Eu } & (.002)\end{array}$ & 2.640 & 3.400 & 2.330 & 17.640 & 18.700 & 2.350 & 2.180 \\
\hline $\begin{array}{l}\mathrm{Fe}(.005) \\
\mathrm{Gd}(.01)\end{array}$ & 0.045 & 0.020 & 0.459 & $\begin{array}{l}0.026 \\
0.010\end{array}$ & $\begin{array}{l}0.012 \\
0.018\end{array}$ & 0.383 & \\
\hline $\begin{array}{ll}\mathrm{K} & (.3) \\
\mathrm{Ld} & (.008)\end{array}$ & 6.600 & 6.520 & 4.580 & 15.140 & 14.900 & 3.700 & 6.600 \\
\hline $\begin{array}{ll}\mathrm{Li} & (.004) \\
\mathrm{Mg} & (.06)\end{array}$ & 0.058 & 0.056 & 0.003 & 0.064 & 0.065 & 0.003 & 0.060 \\
\hline $\operatorname{Mn}(.002)$ & & & 0.033 & 0.002 & 0.002 & 0.036 & \\
\hline Mo $(.01)$ & 0.094 & 0.097 & 0.005 & 0.298 & 0.289 & & 0.392 \\
\hline $\mathrm{Na}(.01)$ & 54.000 & 57.600 & 4.870 & 69.800 & 65.300 & 3.330 & 60.000 \\
\hline
\end{tabular}

Nd (.02)

$\mathrm{Ni}(.02)$

D (.1)

$\mathrm{Pb}(.06)$

Ru (.05)

So $(.05)$

Si $(.02)$

$\mathrm{Sr}(.002)$

Te $(.06)$

$\mathrm{Ti}(.002)$

Zn $(.02)$

$\operatorname{lr}(.008)$

Cs $(.005)$

F $(1.30)$

Cl (.015)

$\mathrm{N} 02$

N03(.040)

$504(.300)$

P04

$\begin{array}{rrr}37.000 & 37.600 & 22.900 \\ 0.030 & 0.042 & 0.007 \\ & & \\ 0.140 & 0.021 & 0.038 \\ & & \\ 0.082 & 0.072 & \\ 0.300 & & \\ 0.900 & & \\ 0.200 & & \\ 10.800 & \star & \\ 20.000 & & \end{array}$

38.600
0.224
0.004
0.316
0.040
0.200
1.500
8.000
0.700
37.700
14.500

38.000

17.200

51.000

$0.241 \quad 0.006$

0.038

$0.026 \quad 0.020$

0.184

0.200

0.288

1.600

5.800

0.100

8.200

18 A - 18 Angstrom Filtered Solution
AS - Acid Strip
UN - Unfiltered
0.45 - 45 microns Filtered Solution
50 - 50 Angstrom Filtered Solution
$\star$ - No Anion Andlysis
(a) - Blanks Indicate Elements Below Detection Limits 
LLNL WASTE PACKAGE LEACH TEST IV DATA (GLASS ANO ROCK), TUFF NATER, 90 C, STATIC

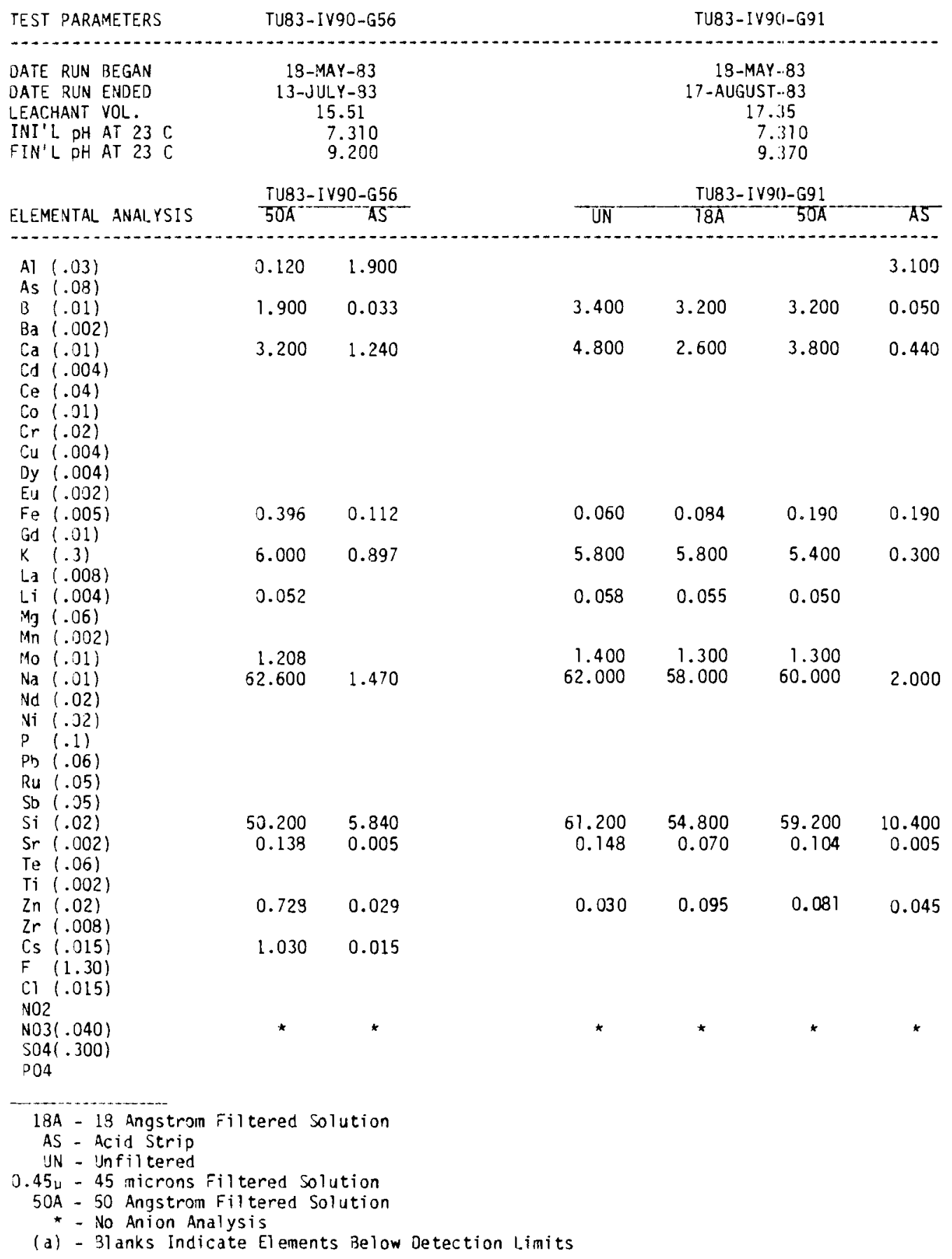


LLNL WASTE PACKAGE LEACH TEST IV DATA (TUFF WATER ONLY), $90^{\circ} \mathrm{C}$, STATIC

\begin{tabular}{|c|c|c|c|c|c|c|}
\hline TEST PARAMETERS & TU83-IV90-3 & TU83-IV90-7 & TU83-I V90-14 & TU83-I V90-28 & TU83-I V90-56 & TU83-I V90-91 \\
\hline DATE RUN BEGAN & $20-M A Y-83$ & 19-MAY-83 & 19-MAY-83 & 19-MAY -83 & 19-MAY-83 & 19-MAY-83 \\
\hline DATE RUN ENDED & $23-M A Y-83$ & 26-MAY-83 & 2-JUNE-83 & 16-JUNE-83 & $7-J U L Y-83$ & 8-AUGUST-83 \\
\hline LEACHANT VOL. & 40.00 & 40.02 & 40.01 & 40.01 & 40.00 & 40.00 \\
\hline FANUL गH तT 230 & 9.015 & 9.084 & 9.267 & 9.065 & 9.185 & 3.380 \\
\hline
\end{tabular}

ELEMENTAL ANALYSIS(a) TUFF WATER TU83-IV90-3 TU83-IV90-7 TU83-[V90-14 TU83-IV90-28 TU83-IV90-56 TU83-IV90-91

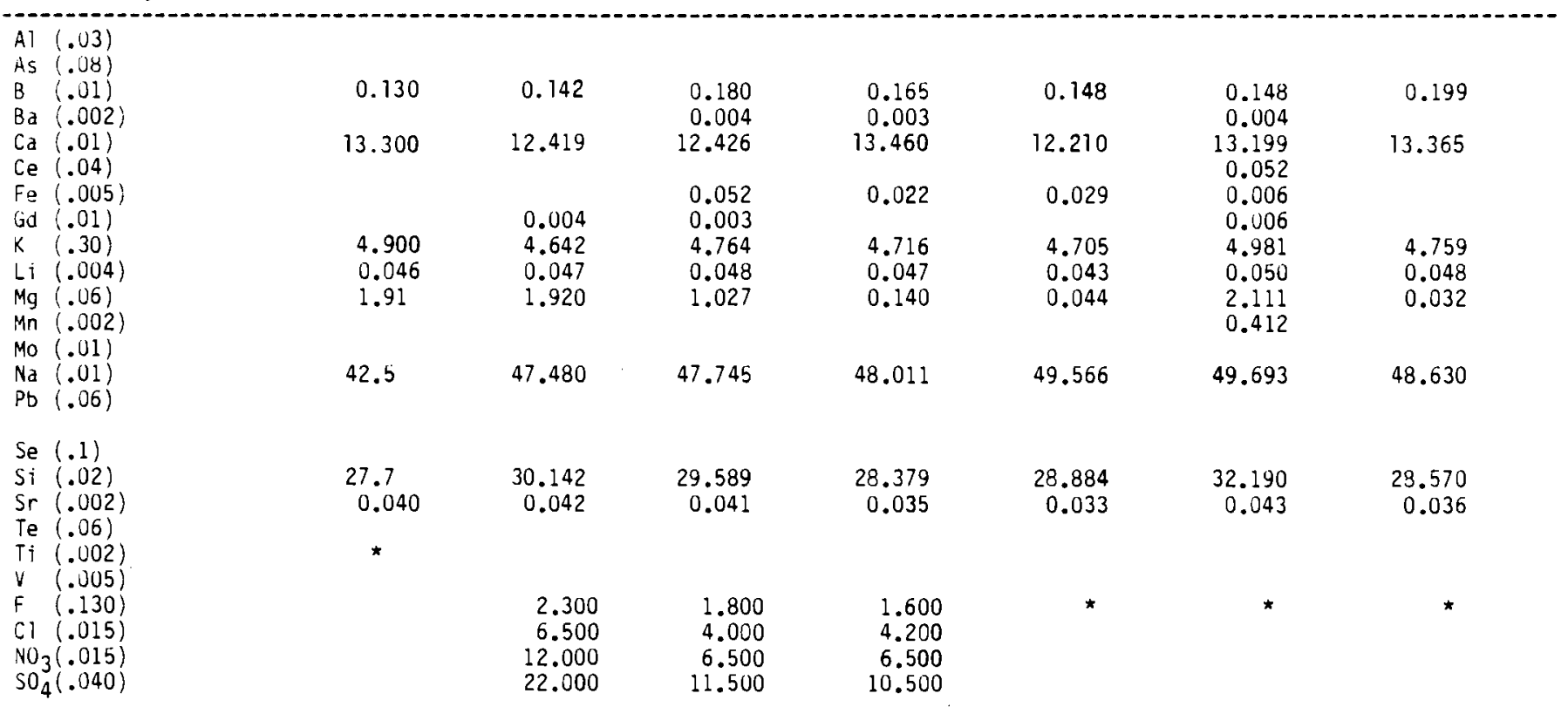

\footnotetext{
* - No Anion Analys is

(a) - Blanks Indicate Elements Below Detection Limits
} 
LLNL WASTE PACKAGE TESTS LEACH TEST I DATA GLASS ONLY), TUFF WATER

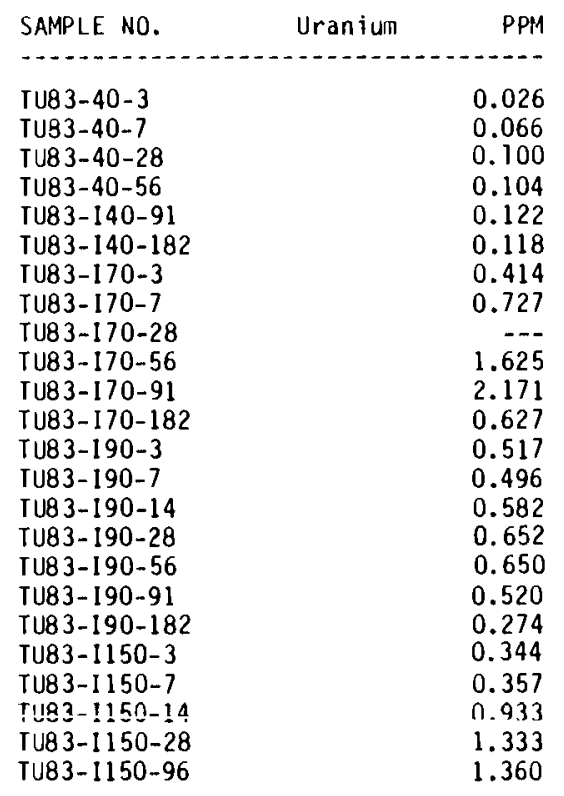

LLNL WASTE PACKAGE TESTS LEACH TEST II UATA (GLASS AND ROCK), TUFF WATER

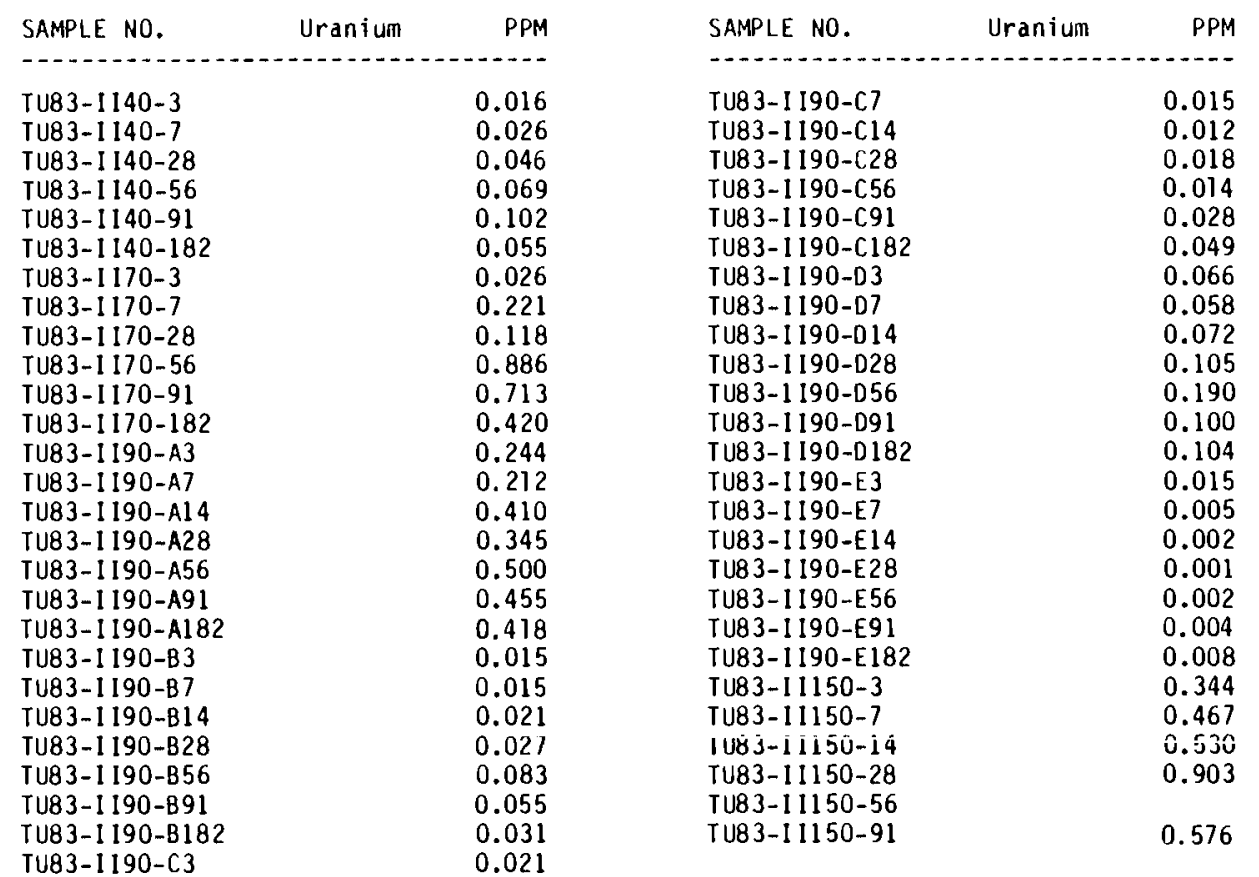


LLNL WASTE PACKAGE TEST LEACH TEST DATA FOR TEST III (GLASS + TUFF ROCK + METAL) $40,70,90, \& 150$ C, STATIC, URANIUM

\begin{tabular}{|c|c|}
\hline SAMPLES & PPM \\
\hline $\begin{array}{l}\text { TU83-I I [40-3 } \\
\text { TU83-I I [40-7 } \\
\text { TU8 3-I I I40-14 } \\
\text { TU83-I I [40-28 }\end{array}$ & $\begin{array}{l}0.017 \\
0.020 \\
0.026 \\
0.027\end{array}$ \\
\hline 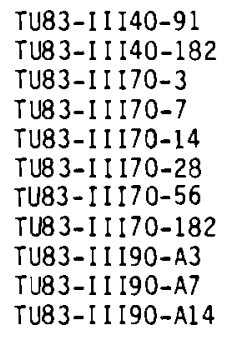 & $\begin{array}{l}0.066 \\
0.053 \\
0.040 \\
0.070 \\
0.168 \\
0.525 \\
1.350 \\
0.600 \\
0.291 \\
0.138 \\
0.312\end{array}$ \\
\hline 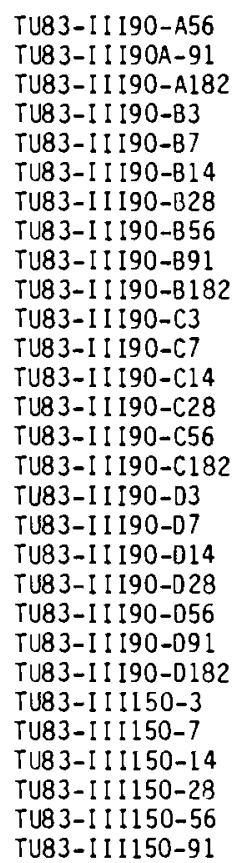 & $\begin{array}{l}0.535 \\
0.477 \\
0.175 \\
0.085 \\
0.097 \\
0.094 \\
0.089 \\
0.079 \\
0.040 \\
0.066 \\
0.167 \\
0.307 \\
0.457 \\
0.710 \\
0.469 \\
0.372 \\
0.144 \\
0.383 \\
0.360 \\
0.542 \\
0.500 \\
0.429 \\
0.246 \\
0.400 \\
0.263 \\
0.240 \\
0.639 \\
0.354 \\
0.533\end{array}$ \\
\hline
\end{tabular}




\section{DISTR IBUT ION}

No. of

Copies

OFFSITE

3 Dr. V. M. Oversby

Lawrence Livermore National Laboratory

P. 0. Box 808

Livermore, California 94550

2 DOE Technical Information Center

ONSITE

DOE Richland Operations Office

H. E. Ransom

8

Pacific Northwest Laboratory

G. L. McVay (2)

G. R. Robinson

R. P. Turcotte

M. R. Kreiter

Technical Information (2)

Publishing Coordination 
